EDS. URŠKA ŠTREMFEL AND MAŠA VIDMAR

early school leaving: training perspectives 
digitalna knjižnica - digital library

uredniški odbor - editorial board igor ž. žagar jonatan vinkler janja žmavc alenka gril 



\section{early school leaving: training perspectives}

eds. Urška Štremfel in Maša Vidmar 



\section{Contents}

9 Figures and Tables

11 Abbreviations and Acronyms

Urška Štremfel and Maša Vidmar

13 Preface

15 1.o Introduction

Urška Štremfel and Maša Vidmar

171.1 Team Cooperation to Fight Early School Leaving:

Training, Innovative Tools and Actions

252.1 Training for Cooperation in Multi-professional Teams

Maša Vidmar

27 2.1.1 The Importance of the Social and Emotional Competencies of Educational Staff

Tina Rutar Leban, Maša Vidmar and Tina Vršnik Perše

45 2.1.2 Team Members' and Teachers' Understanding of their own Unpleasant Emotions in the Process of Teamwork or Teaching

Tina Vršnik Perše, Maša Vidmar and Tina Rutar Leban

63 2.1.3 Teachers' Professional Development 
Tina Vršnik Perše, Maša Vidmar and Ana Kozina

$77 \quad$ 2.1.4 Educators' Self-reflection

95 2.2 Training for Cooperation with Students

Ana Kozina

97 2.2.1 Social and Emotional Learning as a Tool for Preventing ESL

Tina Rutar Leban and Maša Vidmar

111 2.2.2 Developing Students' Emotional Intelligence (EI)

to Help Prevent ESL

Tina Rutar Leban

129 2.2.3 The Student's Academic Self-concept and its Link with ESL

Ana Kozina

143 2.2.4 Preventing ESL by Enhancing Resiliency

Tina Rutar Leban and Maša Vidmar

157 2.2.5 Neuroscientific Findings Concerning Education

and what they Imply for Teaching and Learning

Klaudija Šterman Ivančič

171 2.2.6 Non-formal Motivational Focuses for Potential Early School

Leavers

Klaudija Šterman Ivančič

185 2.2.7 Andragogical Knowledge and Skills for Teachers in Mainstream Education as Prevention for ESL ${ }^{1}$

199 2.3 Innovative Trainings for Teachers and Other Educational Staff

Tina Vršnik Perše and Maša Vidmar

201 2.3.1 Overview of Innovative Online Trainings for Educators

Klaudija Šterman Ivančič

219 2.3.2 What can we Learn from Second-chance Education

Programmes for Adults to Prevent ESL in Younger Generations?

235 Index

239 List of Authorities 


\section{Figures and Tables}

29 Figure 1. The relationship between teacher social and emotional competencies and classroom and student outcomes

52 Figure 2. The circular emotional reaction (CER) model

83 Figure 3. Kolb's model of learning and reflection

85 Figure 4. Korthagen's ALACT cycle of reflection

87 Figure 5. Korthagen's Onion model - the model levels of reflection

118 Figure 6. The CER method for children and adolescents based on the CER model

134 Figure 7. The relationship between self-concept and students' cognitive, social and emotional behaviour

146 Figure 8. The compensatory and protective models of resilience

177 Figure 9. Contextual model of the principles of non-formal and informal learning

188 Figure 10. ESL prevention in mainstream education and role of andragogical knowledge

190 Figure 11. Assumptions of andragogy

229 Figure 12. Implications for mainstream education in order to prevent ESL in early stages 
68 Table 1. Comparative presentation of the stages of professional development

121 Table 2. EI dimensions developed with the CER method for children and adolescents

207 Table 3. Similarities and differences among online platforms for educators' professional development 


\section{Abbreviations and Acronyms}

CDP continuing professional development

CEDEFOP European Centre for the Development of Vocational Training

CER circular emotional reaction

EC European Commission

EI emotional intelligence

ESL early school leaving

ESLer(s) early school leaver(s)

EU European Union

EURYDICE Education Information Network in Europe

ICT information and communications technology

ISCED International Standard Classification of Education

OECD Organisation for Economic Cooperation and Development

PISA Programme for International Student Assessment

SEC social and emotional competencies

SEL social and emotional learning

SES socio-economic status

TALIS Teaching and Learning International Study 1 
TITA Project Team cooperation to fight early school leaving: Training Innovative Tools and Actions

UK United Kingdom

USA United States of America 


\section{Preface}

\section{Urška Štremfel and Maša Vidmar}

\section{M}

ing is regarded as being one of the most pressing. In the last two decades, it has been placed high on the European Union policy agenda and various promising solutions to the problem have been identified and policy, research and practical approaches to address it developed and implemented.

This scientific monograph, as part of the three interconnected monographs: Early school leaving: Contemporary European Perspectives, Early school leaving: Cooperation Perspectives, Early school leaving: Training Perspectives, may be seen as one of them.

Three monographs have been prepared as the scientific base within the TITA project (Team cooperation to fight early school leaving: Training, Innovative Tools and Actions). Each monograph covers in detail one of the three main pillars of the TITA approach - early school leaving, team cooperation and educators training. The three-year project forms part of the programme Erasmus+, Key Action 3 in whose framework the European Commission conducts policy experiments in order to test and improve policy implementation systems, structures and processes that have a potentially significant impact on the future EU policy agenda. The monograph offers valuable scientific insights into the topic of training perspectives of early school leaving also to the wider interested research, policy and practice community in the EU and beyond. 
We would like to express our gratitude to the many people who institutionally and personally supported us in preparing this monograph: to all those who talked things over, read, wrote, offered comments and assisted in the editing, proofreading and design. Special thanks go to our children Tija, Zarja and Jan for giving us the inner strength to start and complete this project. 


\section{I.O \\ introduction}





\section{I.I Team Cooperation to Fight Early School Leaving: Training, Innovative Tools and Actions Urška Štremfel and Maša Vidmar}

Early school leaving (ESL) in the European Union (EU) is recognised as an urgent and serious problem for individuals and society as a whole. It represents the waste of both individual life opportunities and social and economic potential (European Parliament, 2011). In this context, reducing ESL is essential for achieving several key objectives of the Europe 2020 strategy. Decreasing it addresses the 'smart growth' aims by improving education and training levels as well as the 'inclusive growth' aims by targeting one of the biggest risk factors in unemployment, poverty and social exclusion. The Europe 2020 strategy therefore includes the headline target to bring the share of early school leavers (ESLers) (persons aged between 18 and 24 who leave education and training with only lower secondary education or less, and who are no longer in education and training) below $10 \%$ by 2020 , from 14.4\% in 2009. That EU 2020 headline target was also acknowledged as one of the five priority areas of the strategic framework for European cooperation on education and training (ET 2020).

Although considerable effort to tackle ESL at the levels of the EU and member states has already been made (not only in the ET 2020 framework, but also of its predecessor ET 2010), the 2012 Joint Report of the Council and the Commission on the implementation of ET 2020 noted that the EU is not on track to meeting the headline ESL target by 2020. The Education Council (2011) confirmed that all of the efforts so far to address ESL have not been effective and efficient enough and that further and new 
approaches are needed. Further, the European Commission (2011) recognised that, while the factors leading to ESL vary from country to country, the causes of ineffective policies can be boiled down to three typical issues: a) the lack of a comprehensive strategy; b) the lack of evidence-based policy-making; and c) insufficient prevention and early intervention measures. On that basis, the Education Council (2011) recommended the development of a framework for coherent, comprehensive cross-sectoral strategies and evidence-based policies against ESL so as to provide a range of school-wide and systemic policies that target different factors leading to ESL.

The Education Council invited the European Commission to support member states' strategies through the exchange of experience and good practices, and to facilitate effective peer learning, networking and experimentation with innovative approaches to measures aimed at reducing ESL and improving the educational outcomes of children and students from groups at risk of ESL (Education Council, 2011). Member states are thus supported in exploiting all opportunities of the common EU cooperation in the field, taking advantage of the existing and developing new tool kits, which will enable the EU as a whole to achieve the agreed target.

Taking the above EU initiatives into consideration, the TITA (Team cooperation to fight early school leaving: Training, Innovative Tools and Actions) project contributes to accomplishing the EU headline ESL target by addressing one of the key policy messages identifying the critical conditions for successful policies countering ESL (Thematic Working Group, 2013): to promote and support multi-professional teams in schools to address ESL by building on evidence-based policies and practices.

\section{TITA's evidence-based approach to ESL}

The TITA scientific base consists of three sections (European perspectives of ESL, Cooperation perspectives of ESL, Training perspectives of ESL) presented in three interconnected monographs. It was prepared in line with the European Commission's (2007) understanding of evidence-based education. The European Commission (ibid.) believes that such education enables the member states and EU institutions to identify the most effective education policies and practices, and allows for their effective implementation. Evidence-based education provides the foundations for modernising education systems. The improved use of knowledge that occurs as education policies and practices are developed in turn improves the quality of both the content of education policy and governance in the education field. 
This means decision-making in the area of education must be strategically oriented towards improving education based on research and evidence. In the process, policy decision-makers, experts and stakeholders should join forces in the search for ways to develop new knowledge that will, based on high-quality education, contribute to the EU's economic competitiveness and social cohesion (ibid.: 12, 13).

The TITA project consortium brings together educational experts and researchers, policymakers and practitioners from European countries in a collaborative research and implementation process that enables the evidence-based approach to ESL to be fully realised. By identifying the main factors that trigger ESL and reviewing the phenomenon's characteristics at the national, regional and local level of the consortium countries, it provides an accurate understanding of the scope and reasons behind ESL; namely, the preconditions for establishing targeted and effective evidence-based policies and practices regarding ESL. ${ }^{1}$

TITA also considers the European Commission's (2011) recommendation that policy experiments be based on precise information in order to better target measures, monitor their development, while constantly adapting them and drawing policy lessons from their results. By providing indepth information on the contextual factors of ESL in the member states making up the consortium, the TITA scientific base also takes into consideration Edwards and Downes' (2013: 47) thinking that "one implication of recognising the local sensitivity of interventions is the need for practitioners to work with data in order to make evidence-informed decisions about adjusting practices". Although Dale (2010) states that establishing the relative importance of factors, and the nature of the causal links and mechanisms, is a crucial step in enabling policymakers to formulate evidence-based, and possibly targeted, pre-emptive ESL measures, the TITA scientific base focuses more on describing and conceptualising new ways of

1 For example: a) the collection of evidence allows for the analysis of the biggest reasons underlying ESL for different groups of students, schools, and local, regional and national systems; b) the combination of data on ESL and contextual data (e.g. socio-economic information) can help in targeting measures and policies at different groups of students, as well as specific local, regional and national communities; c) gathering and analysing information on the motivation and non-cognitive skills of ESLers and their employment and career perspectives can also assist in the targeting of measures and policies; d) evaluation of the effectiveness and efficiency of the existing policy measures aimed at curtailing ESL is an important basis for improving strategies and programmes for increasing pupils' chances of school success (Council, 2011). 
working with ESLers than on assessing measurable outcomes of policy experiments (Edwards \& Downes, 2013: 48).

\section{Fields of TITA (scientific) backgrounds}

The overriding goal of the TITA project is to support the implementation of innovative policy solutions at the institutional level to reduce ESL, in line with the priorities set out in Europe 2020 and ET 2020. By promoting and supporting multi-professional teams in schools, it provides scientific support, tools for actions and training to address ESL. Therefore, the project presents innovative responses to the generally identified problem of common EU cooperation in the field of education, and thereby addresses the European goals.

Promoting and supporting the development of multi-professional teams in schools at the EU level is identified as a key to successful strategies to cut ESL. To work on ESL with other professionals and to establish student-centred measures, education staff needs to understand ESL, the basic principles of multi-professional cooperation and develop or strengthen special skills. Accordingly, the TITA comprehensive scientific base provides a detailed evidence-based understanding of: a) early school leaving (as the core policy problem the TITA project addresses), presented in the monograph Early school leaving: Contemporary European Perspectives; b) cooperation (as a promising solution to reducing ESL), presented in the monograph ESL: Cooperation Perspectives and training (as a tool for arriving at solutions), presented in this monograph.

This monograph focused on training perspectives of ESL considers the training of the teachers as well as other members of multi-professional teams. First, some relevant domains of the teacher's professional and personal development are presented with a special focus on training to facilitate cooperation in multi-professional teams. The second subsection looks at training to establish cooperation with students. Here, the focus is on non-cognitive approaches which, in addition to traditional 'academic support' measures, are recognised as providing crucial support when addressing ESLers' difficulties, which may be social, personal or emotional in nature. These resilience-building approaches are acknowledged for not only building feelings of confidence, but they also have a (direct and indirect) effect on the academic performance of students. In the third subsection, some innovative forms of training for teachers and other educational staff 
are presented, which may serve as a basis for developing new forms of training to prevent ESL.

\section{Methodological aspects of the TITA scientific base}

Reflecting the TITA project's underlying rationale, its scientific base is based on an interdisciplinary approach (policy analysis, theory of organisations, pedagogy, andragogy, psychology, philosophy). By considering a wide range of research evidence, it provides a holistic approach to ESL, its understanding and targeting policies. The TITA scientific base was prepared using the following sources and methods:

\section{Theory and literature review}

A thorough review of existing theoretical and empirical research on ESL, multi-professional cooperation and training in order to provide comprehensive theoretical bases and a multidisciplinary background to develop policy experiments and elaborate on its results. In that framework, scientific monographs and articles high in academic quality and based on sound evidence are the main source of the reviews.

\section{Review of primary sources (official documents)}

A review of official sources that form the policy framework for addressing ESL at the levels of both the EU and the consortium countries (France, Spain, Luxembourg, Switzerland). The chief source of the investigation in this framework entails EU strategies, Council recommendations and Commission communications, as well as national laws, strategies and other legislative documents.

\section{Review of existing (good) practices}

An analysis of existing (good) policies and practices and measures in order to expose 'what works' when tackling ESL in different environments and which approaches are worthwhile learning from when developing new (school, local, national) approaches to ESL. Data for the analysis are gathered by different sources (mainly the DG EAC and EACEA websites, ESL project websites, national reports etc.). While the focus of the TITA scientific base is ESL in the EU, we also refer to practices outside Europe, which strengthens the evidence base, and suggest alternative solutions. 


\section{Synthesis of the quantitative information available on ESL}

Data were gathered and analysed from different points of view (longitudinal analyses, comparison between member states, different regions and local environments in the EU). Strong disparities in ESL levels might indicate specific structural problems in certain geographical areas or educational tracks and help identify national, regional and local specificities of the phenomenon. The primary sources are EU qualitative reports, country reports, inspection reports, as well as EU and OECD (Organisation for Economic Cooperation and Development) indicators.

\section{Secondary analyses of data from international comparative assessment studies}

Secondary analyses of data emerging from international comparative assessment studies are made in areas where existing studies do not provide sufficient information on ESL that is of special importance to the TITA project. These data can provide an additional strong and robust evidence base for tackling ESL at the level of the consortium countries. These data can provide an important insight into factors that cause ESL (identification and prevention) and effective school and policy practices that contribute to reducing it (intervention). In addition, such data are not only able to explain the big differences between EU member states in attaining the EU benchmark, but can also identify the factors that help cut ESL in the member states which are making the best progress in that regard.

In order to provide a comprehensive review of the ESL phenomenon, the TITA scientific base consists of scientific review articles that are organised in the sections and subsections already described above. Each scientific review article consists of the title, a key message in which the article's main idea is highlighted, an abstract in which the substance of the article is summarised, and the core of the article which elaborates on specific TITArelated content.

Based on the wide and deep pool of knowledge contained in the TITA scientific base, the authors have summarised its main findings in Practice Briefs (Scientific Abstracts on Early School Leaving). These Briefs summarise key (policy) messages of each scientific review article and make recommendations for practice deriving from the scientific findings. The TITA consortium believes it is important for strong and robust evidence to be presented to practitioners, policymakers and other interested members of the public in an easy-to-read format to attract their attention to the topic 
and enhance the opportunities to translate TITA's innovative measures into ESL policies and practices at the school, local, regional, national and international (EU) levels.

\section{Possible uses of the TITA scientific base}

The TITA consortium contends that ESL policies and practices should be evidence-based and adaptable to local, regional and national conditions. Developing such policies requires a strong political commitment but also solid knowledge of ESL processes among the wide range of actors involved. The TITA scientific base has therefore been prepared as:

- Scientific input for the TITA consortium when preparing and implementing evidence-based and targeted policy experiments for addressing ESL by promoting and supporting multi-professional teams in schools and for successfully conducting other project tasks.

- Scientific input for practitioners, implementing policy experiments in three consortium countries (France, Luxemburg, Switzerland). To work on ESL with other professionals and establish student-centred measures, education staff need to understand ESL and develop or strengthen special related skills. The scientific and comprehensive database on ESL, as summarised in the Briefs for Practitioners, has been prepared in order to support these ends.

- Scientific input for policymakers at the national and EU levels (European Commission) to understand the policy relevance of the project results. From the policy point of view, the TITA scientific base establishes the foundations for the effectiveness, efficiency and conditions for the scalability of the policy experimentation results and enables the transnational transfer of good practices. Ultimately, the TITA consortium believes that use of proposed and tested measures has the potential to act as a major catalyst for integrating effective and efficient ESL measures into education systems across the EU.

- Scientific review of ESL for other interested actors. The comprehensive TITA scientific base is freely available to other interested actors so they can exploit it in support of their particular requirements and interests. Although an enormous amount of research 
has already been done on ESL, NESSE (2010) identified the need for a more comprehensive review of what is known about ESL. The TITA scientific base is an attempt to respond to that need.

Scientific review articles, published as chapters of this monograph, are published also at the website of the TITA project (http:// titaproject.eu). Design of the website enables searching and reading the articles interactively.

\section{References}

Council of the European Union (2011). Council Recommendation on policies to reduce early school leaving. Brussels: Council of the European Union.

Dale, Roger (2010). Early school leaving. Lessons from research for policy makers. An independent expert report submitted to the European Commission. Brussels: Network of Experts on Social Aspects of Education and Training.

Edwards, Anne and Downes, Paul (2013). Alliances for Inclusion: Cross-sector policy synergies and interprofessional collaboration in and around schools. An independent report authored for the European Commission. Brussels: Network of Experts on Social Aspects of Education and Training.

European Commission (2007). Commission staff working document. Towards more knowledge-based policy and practice in education and training. Brussels: European Commission.

European Commission (2011). Communication from the Commission to the European Parliament, the Council, the European Economic and Social Committee and the Committee of the Regions: Tackling early school leaving: A key contribution to the Europe 2020 Agenda. Brussels: European Commission.

European Parliament (2011). Study on reducing early school leaving in the EU. Brussels: European Parliament.

Thematic Working Group on Early School Leaving (2013). Reducing early school leaving: Key messages and policy support. Brussels: European Commission. 
2.0

training 2.I training for cooperation in multi-professional teams 



\section{I.I}

\section{The Importance of the Social and Emotional Competencies of Educational Staff}

Maša Vidmar

\section{Synopsis}

The teacher's social and emotional competencies are linked to healthy student-teacher relationships which, in turn, create better student social, emotional and academic outcomes, including lower levels of ESL. Such competencies of the teacher can be acquired in pre-service or in-service teacher education.

\section{Summary}

Social and emotional competencies (SEC) are characterised by a high level of self-awareness (e.g. recognising one's own emotions), social awareness (e.g. understanding that others may have different perspectives), good regulation of one's own emotion and behaviour, relationship skills and responsible decision-making (C ASEL, 2013). Teachers' SEC are vital for students' (social, emotional, academic) outcomes and teachers' own well-being. However, the teacher's SEC are often overlooked in educational research and teacher trainings.

A review of scientific findings in this article shows that teachers' SEC are crucial for developing healthy student-teacher relationships and a positive classroom climate, both of which are factors protecting against ESL. Students who perceived the relationship with teachers negatively were found to be at greater risk of ESL (Lessard et al., 2004; Wahlgren et al., 2015). Further, teachers with interpersonal skills 
facilitate fewer disciplinary problems in the classroom (Crosnoe et al., 2004) which decreases the risk for ESL. We highlight the role of teachers' relational competence, which can be viewed within the general framework of teachers' SEC. Relational competence is defined as the teacher's knowledge, attitudes and skills that enable them to establish and develop relationships with their students that are characterised by trust, respect, empathy and tolerance (Longva \& Klokkehaug, 2013). Relational competence entails the following: respect for the other's individuality, own authenticity in contact with the student and responsibility for the relationship with the student (Juul \& Jensen, 2010). It allows teachers to understand students' motivations and respond to their needs. As such, relationally competent teachers are more proactive and authoritative; they notice changes in students' engagement and use emotional expressions and verbal support to promote enthusiasm for learning. It also supports effective ways of dealing with stress and encourages self-awareness and self-management.

Over the past decade, relational competence has become part of professional development interventions (Sabol \& Pianta, 2012) and initial teacher education training (Nielsen, 2017). Thus, the topic of teachers' relational competence is emerging as relevant for quality education, including ESL. It is therefore extremely important to be aware that teachers' relational competencies can be systematically supported and developed as part of the struggle against ESL.

Key words: teachers, social and emotional competence, relational competence, early school leaving

\section{Introduction}

In the last decade, there has been growing theoretical, empirical and public attention to the promotion of students' social and emotional competencies (Greenberg et al., 2003; Durlak, Weissberg, Dymnicki, Taylor, \& Schellinger, 2011; OECD, 2015; Schonert-Reichl, Hanson Peterson, \& Hymel, 2015; Sklad, Diekstra, De Ritter, \& Ben, 2012; Weare \& Nind, 2011; Zins, Weissberg, Wang, \& Walberg, 2004), including mindfulness and other contemplative practices (Greenberg \& Harris, 2012; MLERN, 2012; Roeser \& Eccles, 2015). Studies show that giving attention to these aspects reduces ESL (e.g. Cornelius-White, 2007) and bolsters students' academic performance, life success as well as active citizenship, health-related behaviours, 
subjective well-being and other domains (e.g. see the review in Durlak et al., 2011; Jennings \& Greenberg, 2009). Nevertheless, not many education systems provide guidance to teachers on how to develop the students' social and emotional competencies (OECD, 2015).

It is suggested that teachers' own social and emotional competencies (SEC) are vital for developing the social and emotional competencies of students (Schonert-Reichl, Hanson-Peterson et al., 2015) as well as for students' learning and development in general (Jennings \& Greenberg, 2009; Jensen, Bengaard Skibsted, \& Vedsgaard Christensen, 2015; Jones, Bouffard, \& Weissbourd, 2013). To better understand the role of teachers' SEC and well-being in education, almost a decade ago Jennings and Greenberg (2009) proposed a theoretical model supported by an extensive literature review. Teacher's SEC influence students' classroom outcomes via three mediators: (1) the quality of the student-teacher relationship; (2) modelling SEC for students; and (3) classroom management (ibid.). Taken together, this helps create a healthy classroom climate which in turn fosters students' social, emotional and academic outcomes, including staying at school (see Figure 1). Various contextual school or community factors (not depicted in the figure; e.g. principal leaderships) may also impact teachers' SEC.

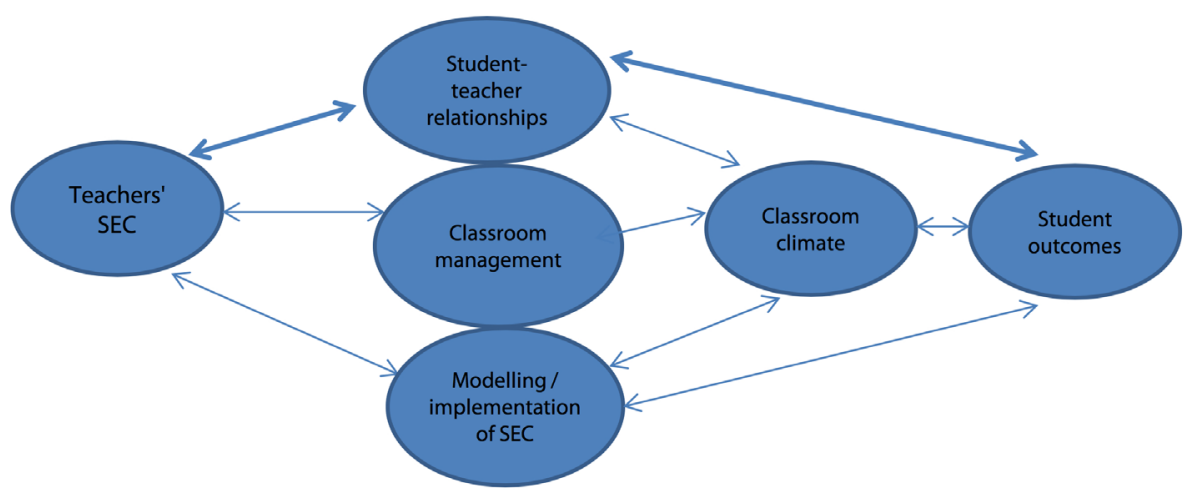

Figure I. The relationship between teacher social and emotional competencies and classroom and student outcomes (Adapted from Jennings \& Greenberg, 2009). The relations shown in bold represent the focus of this article

In this article, we review the literature on the role of the teacher's SEC for the student-teacher relationship and ESL. We start by conceptualising social and emotional competencies, then we review the scientific findings linking the teacher's SECs to the quality of student-teacher relationships 
and examine the links to student outcomes with a focus on ESL. We highlight one specific SEC - relational competence - and its potential for tackling ESL. Finally, we conclude by outlining some implications for teacher education.

\section{Methodology}

This scientific review article is based on computerised literature searches conducted in the Arizona State University library's search engine using the key words: teacher's social and emotional competence, relational competence, student-teacher relationship, early school leaving, drop out etc. In the next step, we examined references cited in the articles (i.e., "backward search" procedures).

\section{Social and emotional competencies (SEC)}

SEC are a broad construct denoting a wide array of competencies, ranging from specific (e.g. managing emotions, managing stress) to more general ones, for example emotional intelligence (emotion knowledge and expression/regulation, empathy, perspective taking), interpersonal skills (understanding social cues, interpreting others' behaviour, interacting positively with others) to cognitive regulation (focusing and shifting attention, inhibiting dominant/inappropriate impulses and activating appropriate, cognitive flexibility) (Jones et al., 2013). In research and practice, CASEL's (2013) five competency clusters for students and teachers (Schonert-Reichl, Hanson-Peterson et al., 2015) are most often used: self-awareness, self-regulation, social awareness, relationship skills and responsible decision-making. Socially and emotionally competent teachers have a high level of self-awareness (e.g. they recognise their emotions, emotional strengths and weaknesses), have social awareness (e.g. they understand others may hold different perspectives, are aware of the effect of their own emotional expressions on others), take responsible decisions in which they consider how their decisions will impact everyone and exhibit prosocial values, they are good at managing (regulating) emotions and behaviour as well as establishing and maintaining relationships (e.g. regulate their behaviour in emotionally challenging situations in a way that supports a positive classroom climate and their own health, set limits firmly and respectfully).

According to the model presented in Figure 23, the teacher's SEC establish a cyclical process; when positive, this results in positive outcomes 
for all, but when the teacher's SEC are low this makes all phases of the cycle become more negative, leading to teacher burnout (Jennings \& Greenberg, 2009).

\section{Why are teachers' SEC important:}

\section{The student-teacher relationship and teacher well-being}

The idea of the teacher's SEC being important reflects the fact that learning in schools is relational (Schonert-Reichl, Hansons-Peterson, et al. 2015) and teaching is an emotional practice (Hargreaves, 1998). Thus, the teacher's SEC influence teacher-student relationships and the centrality of relationships in human development is revealed in many theories and studies (e.g. Bowlby, 1969; Vygotsky, 1978; Ainsworth, Blehar, Waters, \& Wall, 1978). SEC allow teachers to understand students' motivations and respond to their needs. Teachers are more proactive and authoritative, they notice changes in children's engagement and use emotional expressions and verbal support to promote enthusiasm for learning (Jennings, 2015). Teachers who are calm, positive and content are more likely to respond warmly and sensitively, even when students behave in a challenging way (Jones et al., 2013). The wealth of correlational and longitudinal studies conducted in different countries with students of different ages suggests that teacher-student relationship patterns are linked to students' social, emotional and school-related adjustment and functioning; moreover, improving and strengthening the child-teacher relationship can have a dramatic impact on children's outcomes as well as the teachers' own mental health, job satisfaction, sense of efficacy (for a review, see Pianta, Hamre, \& Stuhlman, 2003).

Several longitudinal studies show that a teacher's report of a supportive relationship with a student has positive effects on students' behavioural and academic adjustment (e.g. Birch \& Ladd, 1996; Curby, Rimm-Kaufman, \& Ponitz, 2009; Hamre \& Pianta, 2001; Hughes, Cavell, \& Jackson, 1999; Ladd, Birch, \& Buhs, 1999; Meehan, Hughes, \& Cavell, 2003; O'Connor \& McCartney, 2007; Pianta \& Stuhlman, 2004; Valiente, Lemery-Chalfant, Swanson, \& Reiser, 2008). Results of international studies (e.g. PISA in OECD, 2013 \& OECD, 2017) also support these findings. Namely, in all countries and economies students from a similar socio-economic background and with an equal performance who reported better student-teacher relations (greater teacher support, fairness of the teacher) also reported a stronger sense of belonging to their school. And, on the contrary, different studies show that student-teacher conflict or other types 
of poor relationships negatively affect students' academic adjustment (e.g. Heatly \& Votruba-Drzal, 2017; Portilla et al., 2014; Troop-Gordon \& Kuntz, 2013) and achievement (Anderman, 2003; Pittman \& Richmond, 2007). Similarly, Bryk and Schneider (2004) found in their 7-year study of 400 elementary schools that the quality of social relationships among the school community - principals, teachers, students and parents - is central to their functioning, and strongly predicts positive student outcomes. Hattie (2009) in his review listed student-teacher relationships as being highly influential for student achievement and the effect of high quality relationships between the teacher and students seems to have lasting positive effects on students' learning and motivation (Hattie \& Yeates, 2014). Teacher-rated teacher-student closeness, conflict and dependency predicted student engagement (Doumen, Koomen, Buyse, Wouters, \& Verschueren, 2012). A student-teacher-relationship-based intervention conducted in a high-risk school environment impacted the student's academic achievement (but not their social and emotional adjustment, although some promising trends were observed; Murray \& Malmgren, 2005). Along the same lines, in the literature review commissioned by the Norwegian Ministry of Education it is concluded that the ability to form and maintain quality relations between the teacher and students and an overall view of students as having potential teaching skills (along with solid didactical competencies and classroom management skills) seem to make a difference in the classroom (Nordenbo, Larsen, Tiftikci, Wendt, \& Østergaard, 2008). It is important to note that there is minimal agreement between the student and teacher ratings of their student-teacher relationships (Murray, Murray, \& Waas, 2008).

Student-teacher relations have an exceptionally powerful influence over teachers' job satisfaction (OECD, 2014) and are also related to teachers' sense of efficacy (Yoon, 2002). Many teachers and student teachers find relations and interaction with the pupils to be the most difficult aspect of teaching (Jensen et al., 2015). Thus, in addition to the promotion of social, emotional and academic outcomes in students, another line of scientific interest in the teacher's SEC and student-teacher relationship stems from the increasing concern for teachers' well-being (e.g. Spilt, Helma, Koomen, \& Thijs, 2011; Vesely, Saklofske, \& Leschied, 2013), especially in the context of the growing demands placed on teachers. Teachers and schools are now expected to have much broader areas of responsibility than in the past, e.g. taking individual aspects of students' development into account (including different languages and student backgrounds, disadvantaged students 
and students with learning or behavioural problems - the inclusion paradigm), leading the learning process in the classroom (including the use of new technologies and advances in student assessment), contributing to the school's development and maintaining connections with the local community and wider world (OECD, 2005). This can lead to stress and burnout (Jennings \& Greenberg, 2009). A meta-analysis of effects and causes in teacher stress revealed the strongest association between external stressors (e.g. student behaviour, school structure, colleagues, personal life) and the teacher's (negative) emotional response, confirming the central role of the teacher's SEC (Montgomery \& Rupp, 2005).

\section{The link with ESL}

Theoretical models of ESL (e.g. Battin-Pearson et al., 2000; Fall \& Roberts, 2012) and longitudinal studies (e.g. Jimerson, Egeland, Sroufe, \& Carlson, 200o) establish that personal, family-related and school-related factors contribute to ESL. Although the former influence the probability of ESL, school-related risk factors have received a lot of scientific attention as they represent the best targets for intervention (Lessard, Poirier, \& Fortin, 2010). The student-teacher relationship is one such school-level variable found in many (but not all) studies as a determining factor relating to the student's choice to stay at school or drop out.

In a study by Battin-Pearson et al. (2000), low school bonding at the age of 14 (i.e. low commitment to school, low attachment to teachers, low attachment to school) predicted ESL at age 16 indirectly via poor academic achievement. Students who perceived their relationship with teachers negatively were found to be at greater risk of ESL, an effect even more pronounced for boys (Lessard, Fortin, Joly, Royer, \& Blaya, 2004). Along the same lines, Crosnoe, Johnson and Elder (2004) found that the affective dimension of student-teacher relationships (students' positive views of their teachers) contributed significantly to higher academic achievement and fewer disciplinary problems. Some studies did not find the importance of student-teacher relationships to be an ESL factor as perceptions and attitudes of students to their teachers were generally similar whether or not they were at risk of dropping out of school (Lessard et al., 2010). Low perceived teacher support significantly contributed to school maladjustment (Demaray \& Malecki, 2002).

The integral role of the student-teacher relationship for ESL was also found in qualitative studies of individual stories of potential early school 
leavers (ESLers) and those who already dropped out. Finding a teacher who cared and was supportive made students feel acknowledged, which helped in prolonging their stay at school. On the other hand, a sense of being alienated from their teacher and escalated conflicts with teachers directly resulted in pivotal moments in leaving school (Lessard et al., 2008). Similar findings were reported by Tidwell (1988) and Murray and Mitchel (2013). Clandinin et al. (2010) conducted interviews with 19 young people who had already dropped out of high school. Some participants felt as if their teachers did not care about or support them, resulting in negative relationships while, on the other hand, support and understanding underpinned positive relationships. Similarly, the perceived care and support from teachers in complex models of indirect effects (i.e. via identification with school, behavioural engagement, academic engagement, academic achievement) contributed to lower ESL levels (Fall \& Roberts, 2012). On the contrary, in another study ESL boys reported no particularly negative experiences with their schools, teachers or the way they were treated (Beekhoven \& Dekkers, 2005).

We may conclude that in the case of ESL the teacher-student relationship is an area worthwhile strengthening. Research by Wahlgren, MariagerAndersson and Hovmand Sørensen (2015) suggests that the development of teachers' socio-pedagogical competence has a positive effect on dropout rates and is therefore a good starting point. In a 3-year development project, teachers improved their ability to create networks among students, to talk to students, to read the social interaction of a group and to give academically relevant feedback, which led to more positive relationships and lower dropout rates.

\section{What is the next step?}

Given the fundamental role of educators' SEC demonstrated above, it is clear that these competencies need to (and can) be built, developed and trained. This is not to undermine the importance of substantive knowledge and knowledge about teaching methods, class management and child development, but to put it on an equal footing. However, there is a false assumption that all educators naturally possess SEC; an assumption that needs to be overcome (Jones et al., 2013). For example, in the USA analyses of state-level teacher certification requirements reveal that the promotion

1 It is important to note that a supportive school culture is also very important for enhancing teachers' SEC (Jones et al., 2013). 
of teachers' SEC is given very little emphasis in teacher education standards (Schonert-Reichl, Hanson-Peterson et al., 2015). Practices and policies to support and promote teachers' SEC are vital, including teacher pre-service and in-service training or programmes.

A limited but growing number of interventions/programmes is designed to support teachers' SEC (e.g. RULER, MTP, CARE, SMART, see Jones et al., 2013 for details). For example, a recent study (Schonert-Reichl, Roeser et al., 2015) showed the 'value-added' of a combined programme for cultivating students' socio-emotional competencies - one in which educators receive support for their SEC and then implement a socio-emotional learning programme for students. In another study, the mindfulness-based programme CARE for Teachers improved teachers' SEC (e.g. emotion regulation) as well as the quality of their classroom interactions (Jennings et al., 2017).

However, while these interventions are promising, what really needs to happen is that SEC become embedded in day-to-day interactions at school for everyone - students, teachers, staff and administrators (Jones et al., 2013). This means that SEC must develop in the context of daily life in the classroom/school as emotional and social challenges and other teaching opportunities arise.

\section{Focusing on a specific SEC of the teacher:}

\section{Relational competence}

An attempt to achieve the 'all-present-social-and-emotional-competence' is seen in the Danish Relational Competence project (2012-2016; Nielsen, 2017) that drew together multiple stakeholders, levels and perspectives (i.e. teacher students, faculty professors, in-service teachers, pupils, experts from non-government organisations).

Relational competence is a concept proposed by Juul and Jensen (2010) and can be viewed within the general framework of the teacher's SEC (see CASEL, 2013; Jones et al., 2013). Relational competence is defined as the teacher's ability to see an individual student as a unique being and to thus attune their own actions (behaviour) without abandoning their leadership role and authenticity in their contact with the student. As stated by Juul and Jensen (2011), the basis for high-quality relationships is that students/ children are understood and treated as individuals - as autonomous persons who play an active role in building and maintaining relationships. 
This process is not only about a communication technique, but about the dialogue which is based on the sincere wish and competence of the adults to react openly and with sensitivity; it is "an ability to meet students with openness and respect, to show empathy and be able to take responsibility for one's own part of the relation" (Jensen et al., 2015). The adult has to consider both: his inner reality and their understanding of the child. The quality of the relationship depends on how authentic adults (teachers) are in such communication and how included the children (students) feel. Moreover, it is the professional's ability and will to take full responsibility for the quality of the relationship (Juul \& Jensen, 2010; for a more detailed description, see Vidmar \& Kerman, 2016).

The concept of teachers' responsibility for the student-teacher relationship refers to the fact that student-teacher relationships are asymmetrical (Pianta, Hamre, \& Stuhlam, 2003) and that teachers are responsible for creating contact and for the quality (reciprocity, dynamics) of the relationship. Thus, when a positive, supportive and accepting relationship with a student or a group of students does not develop, the teacher asks himself what is he doing that hinders this positive relationship from being built (and adapts his/her behaviour accordingly). Teachers are role models for how to communicate. Thus, teachers need to know how to form, maintain, improve and strengthen quality relationships; how to work consciously and systematically by viewing the relationship as a space for development and learning. The teacher is responsible for creating contact with the child, as well as the reciprocity and dynamics of the conversations. The teacher holds the biggest responsibility for a creating good interaction and good learning environment, and for engaging in development-supporting relations (Jensen et al., 2015; Juul \& Jensen, 2010, 2011).

Teachers' relational competence was systematically developed within the longitudinal cooperative Relational Competence project (Nielsen, 2017). The project aimed to develop educators' relational competence (including attentive presence of mind (mindfulness) and empathy); educators from different levels were involved: (1) the teacher-educator level (professors at the faculty of education); (2) the teacher-education level (pre-service teachers, i.e. students); and (3) the school level (in-service teachers and other professional staff in schools) (Nielsen, 2017). The fact the relational competence training took place over the course of 4 years and was aimed at the participants' personal development ensured that the training's effects would be better integrated and internalised. Moreover, the fact that 
not only student teachers but also their professors at the faculty and teachers working in schools participated in the training increased the chances of sustainability. The results show that the training actually increases future teachers' relational competence, but that learning and development takes time - after the first two years of the project, the researchers deduced that it had increased relational competence (Jensen et al., 2015). Participants were aware of the possibility to distance themselves from the teacher's role and became both more aware of and actually involved the pupils, their reactions and experiences in the teaching as well as put greater attention on their own reactions and approaches and recognised them as key factors in teaching (Jensen et al., 2015). The participants learned how to effectively manage students via different exercises (Laursen and Nielsen, 2016). The study's final results show that participants acknowledged the importance of the relationships and the concrete tools and approaches for developing these relationships with students as well as the role of continuous reflection, although so-called inner exercises created challenges for some participants (Nielsen, 2017).

\section{Conclusion}

Social and emotional competencies are characterised by a high level of self-awareness (e.g. recognising one's own emotions), social awareness (e.g. understanding that others may hold different perspectives), good regulation of one's own emotion and behaviour, relationship skills and responsible decision-making. Students develop their SEC in everyday interactions with their teachers and other educational and non-educational staff at school. Thus, teachers' SEC are crucial for developing healthy student-teacher relationships and a positive classroom climate, both of which are factors protecting against ESL; the teacher's SEC are also vital for the teacher's own well-being.

Relational competence can be viewed within the general framework of SEC. It includes the knowledge, attitudes and skills that enable someone to establish and develop learning relationships characterised by trust, respect, empathy and tolerance (Longva \& Klokkehaug, 2013). As such, on one hand relational competence allows teachers to function effectively in class as they can adjust their behaviour to the situation (Juul \& Jensen, 2010) and, on the other, they are more able to engage, inspire and motivate students. Further, they know how to become more available when students need help with learning and understanding the material being taught. Relationally 
competent teachers are able to identify and promote young people's special interests and skills to acknowledge that schools value the diversity they bring. Relationally competent teachers are present in their relationship with students and do not escape into the omniscient position of the subject they teach. Relationally competent teachers go beyond autocratic and rigid behaviour management in response to misbehaviour - they take responsibility for the misbehaviour. Within this framework, what is happening is not used as a diagnostic tool (what is wrong with a child, how to fix it), but as a reflective tool (what is the happening telling me). In this way, the education experience is personalised and can also help identify any academic and personal problems (Bridgeland, DiIulio, \& Burke Morison, 2006). We may therefore conclude that in the case of ESL teachers' relational competence is extremely important. And not only does the teacher's relational competence support the development of more positive and close relationships with the students, which in turn motivates them to remain in school, but it also increases the teacher's own quality of life and will to more effectively face the different problems that emerge during the educational process. Over the past decade, relational competence has become part of professional development interventions (Sabol \& Pianta, 2012) and initial teacher education training (Nielsen, 2017).

By using the above conclusions as a starting point, researching and acknowledging behaviour and thinking patterns which affect teaching efficacy and potential realisation are becoming essential for enhancing relational competence. It is important is to realise that teachers' and students' empathy, awareness and self-accord can be strengthened and systematically developed by adopting specific approaches (Jensen, Juul, Høeg, Bertelsen, Stubberup, \& Hildebrandt, 2016) in and outside the learning process.

\section{References}

Ainsworth, M., Blehar, M., Waters, E., \& Wall, S. (1978). Patterns of attachment. Hillsdale, NJ: Erlbaum.

Anderman, L. H. (2003). Academic and social perception as predictors of change in middle school students' sense of school belonging. Journal of Experimental Education, 72(1), 5-22.

Battin-Pearson, S., Newcomb, M., Abbott, R., Hill, K., Catalano, R., Hawkins, J., \& Pressley, G. Michael. (200o). Predictors of early high school dropout: A test of five theories. Journal of Educational Psychology, 92(3), 568-582. 
Beekhoven, S., \& Dekkers, H. P. J. M. (2005). Early school leaving in the lower vocational track. Triangulation of qualitative and quantitative data. Adolescence, 4o(157), 197-214.

Birch, S. H., \& Ladd, G. W. (1996). Interpersonal relations in the school environment and children's early school adjustment: The role of teacher and peers. In J. Juvonen \& K. R. Wentzel (Eds.), Social motivation: Understanding children's school adjustment (pp. 199-225). New York: Cambridge University Press. Retreived from: https://books.google.si/ books?id=C_k_bl5-twMC\&pg=PA197\&source=gbs_toc_r\&cad=4\#v=onepage\&q\&f=false

Bowlby, J. (1969) Attachment and loss: Vol 1. Attachment. New York: Basic Books.

Bridgeland, J., DiIulio, J., \& Morison (2006). The silent epidemic: Perspectives of high school dropouts. Civic Enterprises, LLC, Washington.

Bryk, A. S., \& Schneider, B. (2004). Trust in schools: A core resource for improvement. Contemporary Sociology, 33(3), 368-369.

CASEL (2013). 2013 CASEL Guide: Effective Social and Emotional Learning Programs. Preschool and Elementary School Edition. Chicago, IL: CASEL.

Clandinin, D. J., Steeves, P., Li, Y., Mickelson, J. R. Buck, G. Pearce, M., ... Huber, M. (2010). Composing lives: A narrative account into the experiences of youth who left school early. Retrieved from https://www.researchgate. net/publication/265306620_Composing_Lives_A_Narrative_Account_ into_the_Experiences_of_Youth_Who_Left_School_Early_1

Cornelius-White, J. (2007). Learner-centered teacher-student relationships are effective: A meta-analysis. Review of Educational Research, 77(1), 113-143.

Crosnoe, R., Johnson, M. K., \& Elder, G. H. (2004). Intergenerational bonding in school: The behavioral and contextual correlates of student-teacher relationships. Sociology of Education, 77(1), 60-81.

Curby, T. W., Rimm-Kaufman, S. E., \& Ponitz, C. C. (2009). Teacher-child interactions and children's achievement trajectories across kindergarten and first grade. Journal of Educational Psychology, 101, 912-925.

Demaray, M. K., \& Malecki, C. K. (2002). The relationship between perceived social support and maladjustment for students at risk. Psychology in the Schools, 39(3), 305-316.

Doumen, S., Koomen, H. M. Y., Buyse, E., Wouters, S., \& Verschueren, K. (2012). Teacher and observer views on student-teacher relationships: 
Convergence across kindergarten and relations with student engagement. Journal of School Psychology, 5o(1), 61-76.

Durlak, J. A., Weissberg, R. P., Dymnicki, A. B., Taylor, R. D., \& Schellinger, K. B. (2011). Enhancing students' social and emotional development promotes success in school: Results of a meta-analysis. Child Development, $82,474-501$.

Fall, A., \& Roberts, G. (2012). High school dropouts: Interactions between social context, self-perceptions, school engagement, and student dropout. Journal of Adolescence, 35(4), 787-798.

Greenberg, M. T., \& Harris, A. R. (2012). Nurturing mindfulness in children and youth: Current state of research. Child Development Perspectives, 6, 161-166.

Greenberg, M., Weissberg, R., O’Brien, M. U., Zins, J., Fredericks, L., Resnik, H., \& Elias, M. J. (2003). Enhancing school-based prevention and youth development through coordinated social, emotional, and academic learning. American Psychologist, 58, 466-474.

Hamre, B. K., \& Pianta, R. C. (2001). Early teacher-child relationships and the trajectory of children's school outcomes through eighth grade. Child Development, 72(2), 625-638.

Hargreaves, A. (1998). The emotional practice of teaching. Teaching and Teacher Education, 14(8), 835-854.

Hattie, J. A. C. \& Yates, G. (2014). Visible learning and the science of how we learn. Routledge, UK.

Hattie, J. A. C. (2009). Visible learning: A synthesis of 8oo+ meta-analyses on achievement. Oxford, UK: Routledge.

Heatly, M. C., \& Votruba-Drzal, E. (2017). Parent- and teacher-child relationships and engagement at school entry: Mediating, interactive, and transactional associations across contexts. Developmental Psychology, 53(6), 1042-1062.

Hughes, J. N., Cavell, T. A., \& Jackson, T. (1999). Influence of teacher-student relationships on aggressive children's development: A prospective study. Journal of Clinical Child Psychology, 28, 173-184.

Jennings, P. A. (2015). Early childhood teachers' well-being, mindfulness, and self-compassion in relation to classroom quality and attitudes towards challenging students. Mindfulness, 6, 732-743. 
Jennings, P. A., \& Greenberg, M. T. (2009). The prosocial classroom: Teacher social and emotional competence in relation to student and classroom outcomes. Review of Educational Research, 79, 491-525.

Jennings, P. A., Brown, J. L., Frank, J. L., Doyle, S., Oh, Y., Davis, R., . . . Greenberg, M. T. (2017). Impacts of the CARE for teachers program on teachers' social and emotional competence and classroom interactions. Journal of Educational Psychology.

Jensen, E., Bengaard Skibsted, E., \& Vedsgaard Christensen, M. (2015). Educating teachers focusing on the development of reflective and relational competences. Educational Research for Policy and Practice, 14(3), 201-212.

Jensen, H., Juul, J., Høeg, P., Bertelsen, J., Stubberup, M., \& Hilbebrandt, S. (2016). Empathy: It's what holds the world together. Vienna, Austria: myMorrawa.

Jimerson, S., Egeland, B., Sroufe, L. A. \& Carlson, B. (2000). A prospective longitudinal study of high school dropouts examining multiple predictors across development. Journal of School Psychology, 38(6), 525-549.

Jones, S. M., Bouffard, S. M., \& Weissbourd, R. (2013). Educators' social and emotional skills vital to learning. Phi Delta Kappan, 94, 62-65.

Juul, J., \& Jensen, H. (2010). Od poslušnosti do odgovornosti. [From obedience to responsibility] Radovljica: Didakta.

Juul, J., \& Jensen, H. (2011). Vzgojno delovanje v vrtcu in šoli [Upbringing activity in kindergarten and school]. Šolsko svetovalno delo, 3-4, 61-74.

Ladd, G. W., Birch, S. H., \& Buhs, E. S. (1999). Children's social and scholastic lives in kindergarten: Related spheres of influence? Child Development, 70, 1373-1400.

Laursen, P. F., \& Nielsen, A. M. (2016). Teachers' relational competencies: The contribution from teacher education. Šolsko polje, 27(1-2), 139-161.

Lessard, A., Butler-Kisber, L., Fortin, L., Marcotte, D., Potvin, P., \& Royer, É. (2008). Shades of disengagement: High school dropouts speak out. Social Psychology of Education, 11(1), 25-42.

Lessard, A., Fortin, L., Joly, J., Royer, É., \& Blaya, C. (2004). Students at-risk for dropping out of school: Are there gender differences among personal, family and school factors? Journal of At-risk Issues, 10(2), 91-107.

Lessard, A., Poirier, M., \& Fortin, L. (2010). Student-teacher relationship: A protective factor against school dropout? Procedia Social and Behavioral Sciences, 2(2), 1636-1643. 
Longva, K. P., \& Klokkehaug, A. G. (2008, September). Developing relational competence in guidance- and mentor education. Paper presented at the ECER 2013, Creativity and Innovation in Educational Research. Retrieved from http://www.eera-ecer.de/ecer-programmes/pdf/print/conference/8/ contribution/22275/

Meehan, B. T., Hughes, J. N., \& Cavell, T. A. (2003). Teacher-student relationships as compensatory resources for aggressive children. Child Development, 74, 1145-1157.

MLERN, Mind and Life Education Research Network: J. Davidson, R., Dunne, J., Eccles, J. S., Engle, A., Greenberg, M., Jennings, P., Jha, A., Jinpa, T., Lantieri, L., Meyer, D., Roeser, R. W., \& Vago, D. (2012). Contemplative practices and mental training: Prospects for American education. Child Development Perspectives, 6, 146-153.

Montgomery, C., \& Rupp, A. A. (2005). A meta-analysis for exploring the diverse causes and effects of stress in teachers. Canadian Journal of Education / Revue Canadienne De l'Éducation, 28(3), 458-486.

Murray, C., \& Malmgren, K. (2005). Implementing a teacher-student relationship program in a high-poverty urban school: Effects on social, emotional, and academic adjustment and lessons learned. Journal of School Psychology, 43(2), 137-152.

Murray, K. M., Murray, C., \& Waas, G. A. (2008). Child and teacher reports of teacher-student relationships: Concordance of perspectives and associations with school adjustment in urban kindergarten classrooms. Journal of Applied Developmental Psychology, 29(1), 49-61.

Murray, S., \& Mitchell, J. (2013). 'I want to be here': Early school leavers re-engage in study at TAFE. Youth Studies Australia, 32(2), 13-20.

Nielsen, B. L. (2017). Evaluation of the Relational Competence Project 2012-16. Danish University Colleges. Retrieved from https://www.ucviden.dk/portal/files/40724092/En_Evaluation_RelationalCompetenceProject.pdf

Nordenbo, S. E., Larsen, M. S., Tiftikci, N., Wendt, R.E., \& Østergaard, S. (2008) Larerkompetanser og elevers laring i førskole og skole - Et systematisk review utført for Kunnskapsdepartementet, Oslo. I: Evidensbasen [Teacher competencies and pupils' learning in preschool and school - A systematic review carried out for the Ministry of Education, Oslo. I: Evidence Base]. Copenhagen, Denmark: Dansk Clearinghouse for Uddannelsesforskning, DPU, Aarhus Universitet. Retrieved from http://hihm.no/content/download/27943/313958/file/SRII-Teknisk\%2orapport-sen\%2onorsk.pdf 
O’Connor, E., \& McCartney, K. (2007). Examining teacher-child relationships and achievement as part of an ecological model of development. American Educational Research Journal, 44, 240-269.

OECD (2005). Teachers matter: Attracting, developing and retaining effective teachers. Retrieved from https://www.oecd.org/edu/school/34990905.pdf

OECD (2017). PISA 2015 Results (Volume III): Students' Well-Being, OECD Publishing, Paris.

OECD. (2015). Skills for social progress: The power of social and emotional skills. Paris: OECD Publishing.

OECD. (2014). A teachers'guide to TALIS 2013: Teaching and Learning International Survey. TALIS, OECD Publishing, Paris.

Pianta, R. C., \& Stuhlman, M. W. (2004). Teacher-child relationships and children's success in the first years of school. School Psychology Review, 33(3), 444 .

Pianta, R. C., Hamre, B. K., \& Stuhlman, M. (2003). Relationships between teachers and children. In W. Reynolds and G. Miller (Eds.), Comprehensive Handbook of Psychology (vol. 7) Educational Psychology (pp. 199-234). New York: John Wiley \& Sons.

Pittman, L. D., \& Richmond, A. (2007). Academic and psychological functioning in late adolescence: The importance of school belonging. Journal of Experimental Education, 75(4), 270-290.

Portilla, X. A., Ballard, P. J., Adler, N. E., Boyce, W. T., \& Obradović, J. (2014). An integrative view of school functioning: Transactions between self-regulation, school engagement, and teacher-child relationship quality. Child Development, 85(5), 1915-1931.

Roeser, R. W., \& Eccles, J. S. (2015). Mindfulness and compassion in human development: Introduction to the special section. Developmental Psychology, 51(1), 1.

Sabol, T. J., \& Pianta, R. (2012). Recent trends in research on teacher-child relationships. Attachment \& Human Development, 14(3), 213-231.

Schonert-Reichl, K. A., Hanson-Peterson, J. L., \& Hymel, S. (2015). Social and emotional learning and pre-service teacher education. In J. A. Durlak, R. P. Weissberg, C. E. Domitrovich, and T. P. Gullotta (Eds.), Handbook of Social and Emotional Learning: Research and Practice (pp. 406-421). NY: Guilford.

Schonert-Reichl, K. A., Roeser, R. W., Oberle, E., Whitehead, J., Kitil, M. J., \& Lawlor, M. S. (2015, April). Singular and combined effects of 
mindfulness-based education programs on teacher and student well-being and classroom context. In R. W. Roeser (Chair), Systematic approaches to mindfulness-based interventions for teachers and students: Early childhood and elementary school settings. Symposium presented at the annual meeting of the American Educational Research Association, Chicago, IL.

Sklad, M., Diekstra, R., De Ritter, M., \& Ben, J. (2012). Effectiveness of schoolbased universal social, emotional, and behavioural programs: Do they enhance students' development in the area of skill, behaviour, and adjustment? Psychology in the Schools, 49, 892-909.

Spilt, J. L., Helma M. Y. Koomen, \& Thijs, J. T. (2011). Teacher wellbeing: The importance of teacher-student relationships. Educational Psychology Review, 23(4), 457-477.

Tidwell, R. (1988). Dropouts speak out: Qualitative data on early school departures. Adolescence, 23(92), 939-954.

Troop-Gordon, W., \& Kuntz, K. J. (2013). The unique and interactive contributions of peer victimization and teacher-child relationships to children's school adjustment. Journal of Abnormal Child Psychology, 41(8), 1191.

Valiente C., Lemery-Chalfant K., Swanson J., \& Reiser M. (2008). Prediction of children's academic competence from their effortful control, relationships, and classroom participation. Journal of Educational Psychology, 10o, $67-77$.

Vesely, A. K., Saklofske, D. H., \& Leschied, A. D. W. (2013). Teachers - the vital resource: The contribution of emotional intelligence to teacher efficacy and well-being. Canadian Journal of School Psychology, 28(1), 71-89.

Vidmar, M. \& Kerman, K. (2016). The development of teacher's relational competence scale: Structural validity and reliability. Šolsko polje, 27(1-2), 41-62.

Vygotski, L. S. (1978). Mind and society: The development of higher psychological processes. Cambridge: Harvard University Press.

Wahlgren, B., Mariager-Andersson, K., \& Hovmand Sørensen, S. (2015). Sociopedagogical competence - better relationships. Voksenuddanelse, 112, 1-8.

Weare, K., \& Nind, M. (2011). Mental health promotion and problem prevention in schools: What does the evidence say? Health Promotion International, 26, i29-i69.

Yoon, J. S.(2002). Teacher characteristics as predictors of teacher-student relationships: Stress, negative affect, and self-efficacy. Social Behavior and Personality, 30(5), 485-493.

Zins, J. E., Weissberg, R. P., Wang, M. C., \& Walberg, H. J. (Eds.). (2004), Building academic success on social and emotional learning: What does the research say? New York: Teachers College Press. 


\section{I.2}

\section{Team Members' and Teachers' Understanding of their own Unpleasant Emotions in the Process of Teamwork or Teaching}

Tina Rutar Leban, Maša Vidmar and Tina Vršnik Perše

\section{Synopsis}

The Circular Emotional Reaction (CER) model helps teachers and other professionals working in schools understand their own unpleasant emotions they experience during teaching and teamwork. The knowledge about emotions helps them regulate their emotional reactions and establish better relationships with other professionals or students so as to prevent ESL.

\section{Summary}

Teachers' close work with students and team colleagues sometimes also generates stressful situations that may trigger unpleasant emotions. It is thus important for teachers to be able to understand and regulate their own emotions efficiently. Emotional intelligence was shown in some studies to be a relevant predictor of teamwork effectiveness (e.g. Jordan, Ashkanasy, Hartel, \& Hooper, 2002). Emotionally intelligent individuals can better sense, understand and respond appropriately to emotional reactions shown by other team members. Moreover, different studies and theories show empirical and theoretical evidence that teachers' emotions play an important role in teaching and teacher-student relationships (e.g. CorneliusWhite, 2007; Roorda et al., 2011). Teachers who are socially and emotionally competent develop supportive relationships with students, create activities that build on students' strengths and help students 
develop the basic social and emotional skills necessary to participate in classrooms (Jennings \& Greenberg, 2009). Teachers' focusing on building students' emotional and social competencies was shown to increase school attendance and reduced the likelihood of ESL (Wilson, Gottfredson, \& Najaka, 2001).

Different theorists conceptualise emotions as multicomponential processes (e.g. Frijda, 1986, 2001; Lazarus, 1991; Planalp, 1999). The model of Circular Emotional Reaction - the CER model (Milivojević, 2008) describes seven steps which explain different phases in the processes of the emotion arising and forming the emotional reaction. The model has been found to be well accepted and helpful for teachers and other professionals to better understand their own emotions (MIZŠ, 2010; MIZŠ, 2011; MIZŠ, 2012; MIZŠ, 2013) and thus improve their relationship with one another and with students.

School professionals' familiarity with the CER model can have a positive effect on ESL as it can help improve cooperation between professionals in multi-professional teams, as well teacher-student relationships. Effective multi-professional teams and the establishment of quality relationships between students and teachers are both recognised as important protective factors against ESL.

Key words: model of circular emotional reaction, teachers' unpleasant emotions, student-teacher relationship, self-reflection, emotional competencies, teamwork

\section{Introduction}

Emotions are an integral part of teachers' professional lives. Close work with students and team colleagues every day generates new stressful situations that trigger pleasant or unpleasant emotions. Research into emotions in education encompasses different areas, such as: (a) the role of students' emotions in learning; (b) the development of emotions in children and students; and (c) emotions and the power of relationships in the classroom. Only recently has there been growing interest in researching teachers' emotions and their impact on the quality of instruction (Frenzel, 2014; Pekrun, Frenzel, Goetz, \& Perry, 2007). Meta-analyses of the research on teachers' emotions in the classroom show a considerable degree of correlations between teachers' emotional skills in the teacher-student relationship and some academic (e.g. academic achievements), behavioural (e.g. cooperation with the teacher) and emotional (e.g. emotions students experience in 
school) outcomes of students (Cornelius-White 2007; Roorda et al., 2011). Research results show that teachers themselves need the social and emotional skills required to communicate effectively with students and other professionals and to handle stressful situations that can occur in and outside of classrooms (Brackett et al., 2009).

The aim of the present article is to review literature on the role of emotions for team effectiveness, teachers' emotions and their potential role in tackling ESL and to present the theory of circular emotional reaction (CER) (Milivojević, 2008). This theory helps teachers and other professionals working in schools understand the origins of emotional reactions and thus improve their relationships with other professionals and students (MIZŠ, 2010; MIZŠ, 2011; MIZŠ, 2012; MIZŠ, 2013).

\section{Methodology}

The article is based on a literature review that entailed searching in the PsycINFO, ERIC, Proquest, Science Direct and Google scholar search databases. Key words used in the literature search were teachers' unpleasant emotions, negative emotions, student-teacher relationship, self-reflection, emotional competencies, teamwork, early school leaving etc. For the purposes of this article, we mainly took scientific papers and some online scientific books into consideration.

\section{Emotional competencies and teamwork effectiveness}

The idea that emotional competencies can positively impact workplace outcomes has seen emotional intelligence (EI) increase as an important issue among management practitioners and researchers (Goleman, 1995; Joseph \& Newman, 2010). EI is defined as the 'ability to monitor one's own and others' feelings and emotions, to discriminate among them, and to use this information to guide one's thinking and actions' (Salovey \& Mayer, 1990, p. 189). High-emotional intelligent individuals treat their own and others' emotions as valuable data in navigating workplace situations (Barsade \& Gibson, 2007), thus helping them to maintain good interpersonal relationships at work and enhance their job performance. Different studies have demonstrated a positive relationship between emotional abilities and job performance (e.g., Elfenbein, Der Foo, White, \& Tan, 2007; Matsumoto, LeReoux, Bernhard, \& Gray, 2004; Elfenbein \& Ambady, 2002; Lopes et al., 2006). 
One indicator of a person's effective interpersonal functioning at work is teamwork effectiveness, or the extent to which a person can work well with other team members and effectively attend to their needs (Welbourne, Johnson, \& Erez, 1998). Teamwork effectiveness is greater when team members effectively exchange information and resources. Moreover, the team is more effective when its members actively collaborate with one another and respond to other team members' needs and requests.

EI was shown in some studies to be a relevant predictor of teamwork effectiveness (e.g. Jordan, Ashkanasy, Hartel, \& Hooper, 2002). Emotionally intelligent individuals can better sense, understand and respond appropriately to emotional reactions shown by other team members. To illustrate, a high emotional intelligent individual who sees that conflicting task opinions among team members have caused too much anger and frustration among team members may suggest ways to stop these counterproductive behaviour and unpleasant emotions. Another example would be a high EI member perceiving that team morale is low, and suggesting a break to regain the right and productive work atmosphere. Similarly to these illustrations, Wolff, Pescosolido and Druskat (2002) found that emotional perceptiveness (operationalised as self-reported empathy) was associated with behaviours that facilitated group task coordination. Other studies found that teams of individuals with higher EI reported lower levels of conflict intensity due to the formation of emotionally intelligent team climates and the use of more collaborative and integrative conflict resolution methods, which led to better team functioning (Ayoko, Callan, \& Hartel, 2008; Jordan \& Troth, 2004). These findings suggest that EI relates positively to teamwork effectiveness.

The CER theory presented in this article can be a way to improve the EI of team members. It can help them better understand the emotional reactions that occur in teamwork. For example, when presented to teams of preschool teachers who work together every day they reported gaining a different perspective on their co-worker' emotional reactions. They felt they had become more tolerant and understanding when a co-worker had an angry reaction, they tried to accept the reaction and help the co-worker through understanding and giving time and space to calm down (MIZŠ, 2010; MIZŠ, 2011; MIZŠ, 2012; MIZŠ, 2013). 


\section{The role of teachers' emotions in teaching, the teacher-student} relationship and preventing ESL

Different studies and theories provide empirical and theoretical evidence that teachers' emotions play an important role in teaching and teacher-student relationships (e.g. Cornelius-White, 2007; Roorda et al. 2011). Teachers who are socially and emotionally competent develop supportive relationships with students, create activities that build on the students' strengths and help students develop the basic social and emotional skills necessary to participate in classrooms (Jennings \& Greenberg, 2009). A meta-analysis (Wilson, Gottfredson, \& Najaka, 2001) of 165 studies comparing the effectiveness of different school programmes (focused on teachers building students' emotional and social competencies) pointed to increased school attendance and a reduced likelihood of ESL. Moreover, the quality of the teacher-student relationship has been shown in many studies to be an important predictor of ESL (e.g. Battin-Pearson et al., 2000).

The power of emotions in the teaching process and the difficulties teachers have in regulating their own emotions, especially negative/unpleasant ones, is an important issue to be considered.

Negative emotions focus attention on the particular stimulus that triggered them (Derryberry \& Tucker, 1994). They lead to mobilisation and synchronisation of the brain's activities, intruding and flooding the consciousness (LeDoux, 1996). Students' misbehaviour usually triggers a teacher's negative/unpleasant emotions that distract and divert the teacher's attention from the instructional goals so as to solve their own internal emotional reaction. Teachers' emotions can also influence their categorising, thinking and problem-solving (Isen, 1993). Studies show that high anxiety can reduce the limited resources of working memory (Eysenck \& Calco, 1992) due to intrusive thoughts and worry. The loss of working memory resources obstructs task-relevant processing (Ashcraft \& Kirk, 2001). Accordingly, a teacher at the beginning of their teaching career who is highly anxious about their lesson plans and misbehaving students is less likely to successfully cope with the challenges that occur every day in the classroom. Teachers' emotions impact their approaches to teaching (student-focused vs. content-focused approaches) (Trigwell, 2012) and their students' approaches to learning, which is shown in students' achievements, attitudes to school, school attendance and ESL (Battin-Pearson et al., 200o).

Further, students are often aware of and influenced by teachers' negative emotions. Although teachers may often try to hide their feelings, 
students are mostly aware of their teachers' emotions. There are many ways that emotions can be communicated involuntarily and voluntarily. For example, when kindergarten teachers felt and expressed anger or exasperation, the children in their group showed signs of emotional upset and were less prone to conforming to teachers' demands (Kounin, 1977). There were significant positive correlations between elementary and secondary students' reports of teachers' use of aggressive techniques (e.g. yelling at students who misbehave) and subsequent student disruption and level of misbehaviour (Lewis, 2001).

Although teacher anger can be problematic, it may also have positive consequences in the classroom. Averill, for example (1982), argued that anger serves to communicate and enforce accepted standards of classroom conduct. Teachers express anger over student failures attributed to a lack of effort (Clark, 1997; Clark \& Artiles, 2000; Graham, 1984, 1990) and express sympathy or pity for failures attributed to a lack of ability. These expressions of teachers' emotion then influence students' attributions regarding the causes of their successes and failures (Graham, 1984; Weiner, 2000). This is important because failure attribution influences achievements and engagement in school work (Wagner, Spratt, Gal, \& Paris, 1989; Willig, Harnisch, Hill, \& Maehr, 1983) which may result in other school-related problems such as school attendance and ESL (e.g. Lan \& Lanthier, 2003). Attributing one's failures to a controllable cause such as low effort is more motivationally adaptive than attributing one's failures to an uncontrollable cause such as low ability (e.g. Graham, 1984, 1990). A study revealed that many elementary school students believe their errors made their teachers unhappy. An intervention designed to help teachers understand this phenomenon and promote students' self-regulated learning reduced the share of students believing that errors made their teachers unhappy from $47 \%$ to $33 \%$ and reduced the share reporting that their errors made themselves unhappy from $64 \%$ to $37 \%$. In addition, the share of students choosing easy tasks dropped from $50 \%$ to $26 \%$ (Perry et al., 2002).

It is not only negative/unpleasant emotions but also teachers' expression of positive emotions, especially caring, that affect students of various ages. Middle school students who believed that teachers cared about them were more motivated, less likely to be involved in delinquency and more likely to be helpful, cooperative and to follow classroom rules and norms (Wentzel, 1996). Third-, fourth-, and fifth-grade students' interactions with their teachers were influenced by how much the students thought their 
teachers liked them (Skinner \& Belmont, 1993). As noted above, we may conclude that understanding one's own emotions as well as understanding students' emotions is an important element of the teaching and learning process and an important part of teachers' professional development.

As we can see, emotional competencies, emotional regulation and understanding of how emotions arise can have a considerable important impact on relationships in work teams and in teacher-student relationships. Below we present an emotional theory or a model that helps adults understand the physiological and psychological processes that occur during an emotional reaction.

\section{The Circular Emotional Reaction (CER) Model}

Although social and personality psychologists do not agree on what emotions are, many theorists conceptualise emotions as multicomponential processes (e.g. Frijda, 1986, 2001; Lazarus, 1991; Planalp, 1999). The emotional process consists of a number of changes in a variety of subsystems (or components) of the organism. These components typically include appraisal, subjective experience, physiological change, emotional expression, and action tendencies.

One of the theories/models of emotions that consider all these components is the model of Circular Emotional Reaction (the CER model) (Milivojević, 2008). It explains why different people can react with different emotions in the same situation and helps comprehend that they themselves can regulate their own emotions. Based on many workshops and supervision work conducted over the past decade, the model has proven to have great applied value for teachers and other educational staff (MIZŠ, 2010; MIZŠ, 2011; MIZŠ, 2012; MIZŠ, 2013). When self-reflecting on the teaching process or teamwork on the basis of the CER model, teachers easily realise it is not the students' or their colleagues' (inappropriate) behaviour that triggers their unpleasant emotions. They can better understand that these emotions are triggered on the basis of their own evaluation of the situation and thus they are the only ones who can control this process and their own reactions.

The model is based on the cognitive therapy approach and transactional analyses approach to understanding and regulating emotions. It also shows similarities to the Process Model of Emotion Regulation (Gross, 1998; Quoidbach, Gross, \& Mikolajczak, 2015). The CER model and its application to practice in an educational setting are described below. 
Milivojević (2008) defines emotions as human expressions that arise in situations which people evaluate as significant. Every emotion has its purpose and therefore there are no good or bad (positive or negative) emotions, only pleasant and unpleasant emotions. Emotions tell us that something important (obviously subjective for each one of us) is going on and we should act on it. This is also the source from which this concept of emotions has evolved, since the Latin word emotion can be literally translated as 'beginner', 'the one who moves something' (ei movere, to move). If experiencing and expressing emotions is placed in a social context, in a context of communication with another person or a group of people, then expressing emotions becomes a message which is transferred from the person that experiences and feels to another person. The main message carried by the expressed emotion is that the given content is very important to the person who experiences the emotion.

\section{STIMULUS SITUATION}

\section{ACTION}

(action toward the stimulus situation)

$\uparrow$

7.THINKING

(thinking and choosing the behavioural reaction)

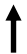

6. ACTION TENDENCY
2. PERCEPTION

(the notice of the stimulus situation)<smiles>[3H][3H]</smiles>

\section{APPERCEPTION}

(linking the stimuli situation to prior similar experiences)

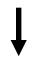

(readiness for action)

(attributing the significance of the stimulus situation; attributing the nature (positive or negative) of the stimulus situation)
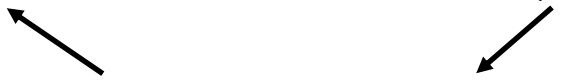

5. PHYSIOLOGICAL

REACTION

(physiological processing of the significant information)

Figure 2. The circular emotional reaction (CER) model (Milivojević, 2008) 
The CER model in Figure 2 explains the cognitive, physiological and behavioural processes that occur in the course of a person's pleasant and unpleasant emotion. Moreover, it explains the processes that lead to the emotion and the processes that happen subsequently and presents them in a circular sequence.

\section{Stimulus situation}

A stimulus situation is defined as a change in a person's environment (e.g. a student raises his/her hand during instruction in the classroom). It can be also defined as a current imbalance in the person's harmony with his/ her environment. A stimulus situation can also be generated by a person's memory of a situation or his/her imagination of a situation in the future.

\section{Perception}

The author defines perception as the creation of a mental representation of a stimulus situation. The mental representation of a stimulus situation is produced through the senses and can be created consciously or subconsciously. This is a very physiological process of merely perceptual processes take place at the level of senses (seeing, hearing, smelling...) (e.g. the teacher sees the image of the student with his/her hand raised).

\section{Apperception}

The mental representation per se does not yet mean anything to the person that creates it, it has a neutral connotation. It needs to be decoded in the context of the person's knowledge, experiences, representations, attitudes, beliefs, values (e.g. the teacher recognises who is the student with the raised hand) etc. to be analysed and obtain a meaning for the designated person. This happens in the process of apperception. The author defines this decoding structure as the person's frame of reference. The decoding of the stimulus situation happens almost instantly, automatically, so it is difficult for a person to distinguish between the mere perception of the stimulus and its decoded meaning (apperception) for them.

\section{Valorisation}

The decoding/interpretation of the stimulus situation (apperception) is followed by valorisation of the situation. If a person estimates the situation as important for his/her life, an emotion will arise (e.g. based on the teacher's 
previous experiences with the student with the raised hand (usually he/she only speaks in the classroom to contradict the teacher and disturb the instruction), the teacher estimates that the situation is important for him/her because the student will disturb the lecture, he/she will have to stop the instruction and deal with the student's comment; he/she starts to feel upset and tensed and oriented towards his/her own feeling). Accordingly, if he/ she estimate the situation as unimportant, there will be no emotional reaction (e.g. the teacher estimates the situation is unimportant for him/her personally because he/she encourages students to express all their opinions and understand that this student's arguing with him/her is a way of expressing some other issues, which the teacher is trying to understand; he/ she remains calm and oriented towards the student).

The significance of the situation is also valorised according to whether the stimulus situation threatens or endorses someone's personal values. If the situation endorses an individual's values, he/she will react with pleasant emotions. However, if the situation threatens his/her values, the individual will react with unpleasant emotions. Hence, the arising of emotions depends on the individual's value system. That is why different people may react in different ways to the same stimulus situation.

Like the process of apperception, valorisation also happens very quickly, automatically. It seems that the emotion arises by itself, that it is automatically triggered by the situation. That is why it is difficult to understand that we create our emotions ourselves, that it is we who decide that the situation is important enough for us to feel a certain emotion.

\section{Physiological emotional reaction}

A physiological emotional reaction is the biological reaction to what we perceive as important for us (e.g. the teacher's heart starts pounding, their breathing becomes deeper, their muscles tense - the physical reactions for anger). It includes different bodily sensations, arousals, stimulations, visceral and motor reactions. The function of these processes is to prepare the body to react quickly to the stimulus situation. In other words, these processes mobilise our bodily energy for possible quick action.

\section{Action tendency}

The physiological emotional reactions in the body activate one or more specific behavioural programmes. The person feeling the emotion is now motivated for a specific type of behaviour (e.g. the teacher feels like he/she needs 
to angrily shout at the student, saying that he/she is only allowed to speak if he/she will talk about a topic related to the lesson). The author defines this motivation as the action tendency or action potential, action disposition. Subjectively, this feels like the inner impulse for action, while objectively it can be seen as a specific body position (emotional habitus) and as a particular facial expression. In specific urgent or dangerous situations, this action tendency is directly followed by the actual action of the person (e.g. the teacher actually shouts at the student). However, in most situations this phase is followed by mental operations including reasoning about which action can lead to a wanted result.

\section{Thinking}

The emotional reaction in the body transmits to the mind the information that there is something very important going on. This results in setting the solving of the situation as the top priority of all mental processes. The author names this function of the emotions as prothymia or the prothymic effect of the emotion (from the Greek pro - before, and thymos - mind, meaning mental alertness, preference, preparedness). The emotion selectively stimulates and activates only those mental perceptions and processes that are strictly relevant for the present stimulus situation that triggered the emotion (e.g. all the teacher can think about in this moment (while experiencing anger) is how to stop this inner tension that the emotional reaction creates; he/she is unable to focus on the lesson in the way he/she had focused before the emotional reaction; his/her brain is only focused on the anger he/she feels). The sole goal is to find the best action to achieve the wanted result, which is to end the emotional reaction.

\section{Action}

Action or adaptive behaviour is the final phase of the CER model. When experiencing an unpleasant emotion, the goal of the action is to stop the emotional reaction. On the other hand, when experiencing pleasant emotions the adaptive behaviour is directed to stabilising, reinforcing or seeking the environmental change that triggered the pleasant emotion.

If the stimulus situation that spurred the unpleasant emotion can be changed, the adaptive behaviour is directed to changing the situation and regaining the equilibrium with the environment (such as in the case of anger; e.g. the teacher sends the student out of the classroom to prevent him/ her from disturbing the lesson) or it may also be directed towards avoiding 
or escaping the situation (e.g. in the case of fear). When the stimulus situation cannot be changed or avoided (e.g. with sadness when losing a loved one), the adaptive behaviour is directed to changing the person's valorisation of the situation or, in other words, towards changing their frame of reference.

Unlike unpleasant emotions which are triggered by an imbalance between a person and their environment, pleasant emotions are a person's reaction to the establishment of a new kind of balance between the two. They reflect better environmental conditions for the person. Pleasant emotions are thus defined as a sign that the environment has changed according to the person's values or wishes and direct the person's actions to seeking the environmental change that triggered the pleasant emotion.

\section{Application of the model to pedagogical practice}

When teachers and other school workers are presented with the model, the most important thing they realise is that they are completely in charge of their emotions. For example, when a student misbehaves during instruction, the teacher now understands that they are the only one who decides whether to be angry at the student or not. The student has no control over the teachers' emotions. This realisation brings great comfort to teachers and motivates them to try to change their perspective about class management and own emotions. The teacher feeling less unpleasant emotions during instruction impacts his/her teaching approaches and relationships with students. Better teacher-student relationships correlate positively with higher achievement, higher school attendance and lower ESL rates (Ragozzino et al., 2003; Roorda et al., 2011).

A similar example can be described for teamwork. When a team member, for instance, impolitely argues with others in the team about an issue, by knowing the CER model the other team members understand they do not need to respond with anger. They can decide to stay calm and also help the angry team member to calm down and discuss the issue peacefully. This kind of EI in teamwork increases teamwork effectiveness (e.g. Jordan, Ashkanasy, Hartel, \& Hooper, 2002) and more collaborative and integrative conflict resolution methods that lead to better team functioning (Ayoko, Callan, \& Hartel, 2008; Jordan \& Troth, 2004). 


\section{Conclusions}

Emotions play an important role in regulating a person's relationship with their environment. Teamwork or the class, school environment present even more challenges and stimulus situations that may trigger emotions. Being able to understand the nature of one's own emotions and trying to adequately regulate them is considered emotionally intelligent and socially desirable. Moreover, different studies show that emotionally more competent team members contribute to team effectiveness (e.g. Jordan, Ashkanasy, Hartel, \& Hooper, 2002), whereas emotionally more competent teachers develop better relationships with their students (Ragozzino et al., 2003; Roorda et al., 2011), which also affects students' general attitude to the school. As we already established, better relationships between teachers and students correlate positively with higher student achievements, higher school attendance and lower ESL rates (Ragozzino et al., 2003; Roorda et al., 2011). All things considered, the issue of developing emotional competencies should be a priority for all school professionals.

The CER model presented in this article represents an option for understanding human emotions. The model has proven to be very effective, especially in the school environment. Teachers and other school professionals reported finding it particularly useful in dealing with anger and frustration in relationship with students or colleagues (MIZŠ, 2010; MIZŠ, 2011; MIZŠ, 2012; MIZŠ, 2013). Teachers understanding that it is their own valorisation of the situation that triggers their anger or frustration in the relationship with a student made them feel in control of their own emotions and less hopeless and dependent on students' behaviour. They also started to analyse their beliefs and values related to teaching and the teacher-student relationship to become aware of potential dysfunctional beliefs that may unnecessarily trigger their anger or frustration. Hence presenting teachers and other school professionals with the CER model could help them better regulate their emotions and establish better relationships with one another and with their students. As the quality of teacher-student relationships has been proven to be an important predictor of ESL (Ragozzino et al., 2003; Roorda et al., 2011), this should also have an impact on preventing ESL.

\section{References}

Ashcraft, M. H. \& Kirk, E. P. (2001). The relationships among working memory, math anxiety, and performance. Journal of Experimental Psychology: General, 130, 224-237. 
Averill, J. A. (1982). Anger and aggression: An essay on emotion. Springer: New York.

Ayoko, O. B., Callan, V. J., \& Hartel, C. E. J. (2008). The influence of team emotional intelligence climate on conflict and team members' reactions to conflict. Small Group Research, 39, 121-149.

Barsade, S. G., \& Gibson, D. E. (2007). Why does affect matter in organizations? Academy of Management Perspectives, 21, 36-59.

Battin-Pearson, S., Newcomb, M., Abbott, R., Hill, K., Catalano, R., \& Hawkings, J. (2000). Predictors of early high school dropout: A test of five theories. Journal of Educational Psychology, 3, 568-582.

Brackett, M. A., Patti, J., Stern, R., Rivers, S. E., Elbertson, N., Chisholm, C. et al. (2009). A sustainable, skill-based model to building emotionally literate schools. In R. Thompson, M. Hughes, \& J. B. Terrell (Eds.), Handbook of developing emotional and social intelligence: Best practices, case studies, and tools (pp. 329-358). New York, NY: Wiley.

Clark, M. D. (1997). Teacher response to learning disability: A test of attributional principles. Journal of Learning Disabilities, 30, 69-79.

Clark, M. D., \& Artiles, A. J. (2000). A cross-national study of teachers' attributional patterns. Journal of Special Education, 34, 77-89.

Cornelius-White, J. (2007). Learner-centered teacher-student relationships are effective: A meta-analysis. Review of Educational Research, 77, 113-143.

Derryberry, D., \& Tucker, D. M. (1994). Motivating the focus of attention. In P. M. Niedenthal \& S. Kitayama (eds.), The heart's eye: Emotional influences in perception and attention (pp. 167-196). San Diego, CA: Academic Press.

Elfenbein, H. A., \& Ambady, N. (2002). Predicting workplace outcomes from the ability to eavesdrop on feelings. Journal of Applied Psychology, 87, 963-971.

Elfenbein, H. A., Der Foo, M. D., White, J., Tan, H. H., \& Aik, V. C. (2007). Reading your counterpart: The benefit of emotion recognition accuracy for effectiveness in negotiation. Journal of Nonverbal Behavior, 31, 205-223.

Eysenck, M. W., \& Calco, M. G. (1992). Anxiety and performance: The processing efficiency theory. Cognition and Emotion, 6, 409-434.

Frenzel, A. C. (2014). Teacher emotions. In: R. Pekrun and A. Linnenbrink (Eds.), International handbook of emotions in education (pp. 494-519). New York: Routledge.

Frijda, N. H. (1986). The emotions: Studies in emotion and social interaction. Paris: Maison de Sciences de l'Homme. 
Frijda, N. H. (2001). The nature of pleasure. In Bargh, John A. \& Apsley, Deborah K. (Eds). Unraveling the complexities of social life: A festschrift in honor of Robert B. Zajonc, (pp. 71-94). Washington, DC, USA: American Psychological Association.

Glasgow, K. L., Dornbusch, S. M., Troyer, L., Steinberg, L., \& Ritter, P. L. (1997). Parenting styles, adolescents' attributions, and educational outcomes in nine heterogeneous high schools. Child Development, 68(3), 507-529.

Goleman, D. (1995). Emotional intelligence: Why it can matter more than IQ. New York, NY: Bantam Books.

Graham, S. (1984). Communicating sympathy and anger to black and white children: The cognitive (attributional) consequences of affective cues. Journal of Personality and Social Psychology, 47, 40-54.

Graham, S. (1990). Communicating low ability in the classroom: Bad things good teachers sometimes do. In Graham, S., \& Folker, V. S. (Eds.), Attribution theory: Applications to achievement, mental health, and interpersonal conflict (pp. 17-52), Erlbaum, Hillsdale, NJ.

Gross, J. J. (1998). The emerging field of emotion regulation: An integrative review. Review of General Psychology, 2, 271-299. http://dx.doi .org/10.1037/1089-2680.2.3.271

Isen, A. M. (1993). Positive affect and decision making. In Lewis, M., \& Haviland, J. M. (Eds.), Handbook of emotions (pp. 261-277). Guilford Press, New York.

Jennings, P. A., \& Greenberg, M. T. (2009). The prosocial classroom: Teacher social and emotional competence in relation to student and classroom outcomes. Review of Educational Research, 79, 491-525.

Jordan, P. J., Ashkanasy, N. M., Hartel, C. E. J., \& Hooper, G. S. (2002). Workgroup emotional intelligence: Scale development and relationship to team process effectiveness and goal focus. Human Resource Management Review, 12, 195-214.

Jordan, P. J., \& Troth, A. C. (2004). Managing emotions during team problem solving: Emotional intelligence and conflict resolution. Human Performance, 17, 195-218.

Joseph, D. L., \& Newman, D. A. (2010). Emotional intelligence: An integrative meta-analysis and cascading model. Journal of Applied Psychology, 95, 54-78.

Kounin, J. S. (1977). Discipline and group management in classrooms. Kreiger Publishing, Huntington, NY. 
Lan, W., \& Lanthier, R. (2003). Changes in students' academic performance and perceptions of school and self before dropping out of schools. Journal of Education for Students Placed at Risk, 8(3), 309-332.

Lazarus, R. S. (1991). Progress on a cognitive-motivational-relational theory of emotion. American Psychologist, 46(8), 819-834.

LeDoux, J. (1996). The emotional brain. Simon \& Schuster, New York.

Lewis, R. (2001). Classroom discipline and student responsibility: The students' view. Teaching and Teacher Education, 17, 307-319.

Lopes, P. N., Cote, S., Grewal, D., Kadis, J., Gall, M., \& Salovey, P. (2006). Emotional intelligence and positive work outcomes. Psichothema, 18, $132-138$.

Matsumoto, D., LeRoux, J. A., Bernhard, R., \& Gary, H. (2004). Unraveling the psychological correlates of intercultural adjustment potential. International Journal of Intercultural Relations, 28, 281-309.

Milivojević, Z. (2008). Emocije - razumevanje čustev v psihoterapiji [Emotions - understanding emotions in psychotherapy.] Belgrade: Psihopolis.

Pekrun, R., Frenzel, A. C., Goetz, T., \& Perry, R. P. (2007). The control-value theory of achievement emotions: An integrative approach to emotion in education. In P. A. Schutz, \& R. Pekrun (Eds.), Emotion in education (pp. 13-36). San Diego: Academic Press.

Perry, N. E., VandeKamp, K. O., Mercer, L. K., \& Norby, C. J. (2002). Investigating teacher-student interactions that foster self-regulated learning. Educational Psychology, 37, 5-15.

Planalp, S. (1999). Communicating emotion: Social, moral, and cultural processes. Cambridge University Press.

Quoidbach, J., Gross, J. J., \& Mikolajczak, M. (2015). Positive interventions: An emotion regulation perspective. Psychological Bulletin, 141(3), 655-693.

Ragozzino, K., Resnik, H., Utne-O Brien, M., \& Weissberg, R. P. (2003). Promoting academic achievement through social and emotional learning. Educational Horizons, 81, 169-171.

Roorda, D. L., Koomen, H. M. Y., Spilt, J. L., \& Oort, F. J. (2011). The influence of affective teacher-student relationships on students' school engagement and achievement: A meta-analytic approach. Review of Educational Research, 81, 493-529.

MIZŠ (2010). Evaluation report of teacher training 'Emotional intelligence: understanding emotions through CER model' by Tina Rutar Leban. Ministry of Education, Republic of Slovenia: Unpublished evaluation report. 
MIZŠ (2011). Evaluation report of teacher training 'Emotional intelligence: understanding emotions through CER model' by Tina Rutar Leban. Ministry of Education, Republic of Slovenia: Unpublished evaluation report.

MIZŠ (2012). Evaluation report of teacher training 'Emotional intelligence: understanding emotions through CER model' by Tina Rutar Leban. Ministry of Education, Republic of Slovenia: Unpublished evaluation report.

MIZŠ (2013). Evaluation report of teacher training 'Emotional intelligence: understanding emotions through CER model' by Tina Rutar Leban. Ministry of Education, Republic of Slovenia: Unpublished evaluation report.

Salovey, P., \& Mayer, J. D. (1990). Emotional intelligence. Imagination, Cognition, and Personality, 9, 185-211.

Skinner, E. A., \& Belmont, M. J. (1993). Motivation in the classroom: Reciprocal effects of teachers' behavior and student engagement across the school year. Journal of Educational Psychology, 85, 571-581.

Trigwell, K. (2012). Relations between teachers' emotions in teaching and their approaches to teaching in higher education. Instructional Science 4o(3), 607-621.

Wagner, D. A., Spratt, J. E., Gal, I., \& Paris, S. G. (1989). Reading and believing: Beliefs, attributions, and reading achievement in Moroccan schoolchildren. Journal of Educational Psychology, 81(3), 283-293.

Weiner, B. (2000). Intrapersonal and interpersonal theories of motivation from an attributional perspective. Educational Psychology Review, 12(1), 1-14.

Welbourne, T. M., Johnson, D. E., \& Erez, A. (1998). The Role-Based Performance Scale: Validity analysis of a theory-based measure. Academy of Management Journal, 41, 540-555.

Wentzel, K. R. (1996). Social goals and social relationships as motivators of school adjustment. In Juvonen, J., \& Wentzel, K. R. (Eds.), Social motivation: Understanding children's school adjustment, (pp. 226-247). Cambridge University Press, New York.

Willig, A. C., Harnisch, D. L., Hill, K. T., \& Maehr, M. L. (1983). Sociocultural and educational correlates of success-failure attributions and evaluation anxiety in the school setting for Black, Hispanic, and Anglo children. American Educational Research Journal, 20(3), 385-410.

Wilson, D. B., Gottfredson, D. C., and Najaka, S. S. (2001). School-based prevention of problem behaviors: A meta-analysis. Journal of Quantitative Criminology 17(3) 247-272.

Wolff, S. B., Pescosolido, A. T., \& Druskat, V. U. (2002). Emotional intelligence as the basis of leadership emergence in self-managing teams. Leadership Quarterly, 13, 505-522. 



\section{I.3}

\section{Teachers' Professional Development}

Tina Vršnik Perše, Maša Vidmar and Tina Rutar Leban

\section{Synopsis}

The continuing professional development (CDP) of teachers is one of the most important approaches for preventing ESL. Improving educators' competencies (e.g. communication, discipline management and cooperation competencies) implies improving students' educational experience and reducing their risk for ESL. CPD should intertwine the different modes (e.g. study groups, self-reflection etc.) taking teachers' motivation, interests and their stage of professional development into account.

\section{Summary}

Regardless of the quality of (future) teachers' and other educators' formal preservice education, it cannot be expected that it can prepare them for all situations that will occur during their education practice. Therefore, education systems are trying to provide opportunities for their continuing professional development so as to establish high education standards and well-qualified staff (OECD, 2009). In order to examine the related issues on the international level, the TALIS (Teaching and Learning International Survey; 2009) has adopted a definition of professional development among teachers as "activities that develop an individual's skills, knowledge, expertise and other characteristics as a teacher". In the last few decades, several professional development models have been developed accordingly 
(such as Day, 2007; Huberman, 1997) that recognise several stages of professional development. The understanding and supporting of teachers and other educators at various stages of their professional development is one of the key factors for improving the educational process and students' experiences with their studies. Professional development can be ensured through different approaches such as seminar courses, supervision, self-reflection etc. and combinations of several approaches seem to be the most effective for gaining competencies for preventing ESL. The research has proven (Bradshaw et al., 2008a, 2008b; Burke, 2008; Koster et al., 2005; Pantic \& Wubbels, 2010; Trent \& Slade, 2001; Zhu, 2013) that mostly professional development in the field of improving the quality of students' school experiences, students' decision-making competencies and prosocial connections are the kinds of professional development programmes that effectively prevent ESL. To make such improvements, the development of teachers' competencies for creating a supportive education environment, such as social and emotional competencies, communication competencies, discipline and cooperation are essential.

Key words: educators, teachers, professional development, early school leaving

\section{Introduction}

The profession of teachers and other educators is nowadays considered one of the most complex professions and its features and requirements are changing and developing year after year. There is thus no straightforward approach to achieving the competencies required for the optimal performance as an educator. The Council of the European Union issued Council conclusion on the professional development of teachers and school leaders (2009) with regard to several previous Council conclusions, objectives, decisions, resolutions and recommendations. This conclusion emphasises that teachers' knowledge, skills and commitment along with the quality of school leadership are the most important factors for achieving high quality educational outcomes. Further, given the increasing demands placed on educators and the growing complexity of their roles, educators need access to effective personal and professional support throughout their careers, particularly when they first enter the profession. Based on a Eurydice report (European Commission, 2015), it was determined that both the European Commission and the Council of the European Union stress the need to 
improve teacher education, continuing professional development in education, and the teaching profession's attractiveness. In relation to continuing professional development (CPD), relatively large proportions of teachers in all age groups, and irrespective of their experience and school subjects, expressed a moderate or high level of training needs in areas that would allow them to develop more appropriate, diversified and innovative teaching practices (European Commission, 2015).

Thus, the role of a continuum of educators' professional development consisting of initial teacher training and CPD should be endorsed so as to keep up with the demands. One of these demands incudes tackling early school leaving (ESL). The Council of the European Union (2015) highlights the CPD of all educators as one of the most important approaches for reducing ESL.

The aim of this paper is therefore to investigate the definitions and models of educators' professional development and to analyse the relationship between educators' professional development and the possibilities for preventing and reducing ESL.

\section{Methodology}

We conducted a review of the literature by searching in the ERIC, SpringerLink, Wiley, Sage, Proquest, and Science Direct search engines for information about educators' professional development, professional development models, characteristics and their relationship to ESL. We included four types of documents: scientific papers, scientific monographs explaining the theoretical background, scientific research reports along with EU documents and reports on the subject matter.

\section{Defining professional development}

Definitions of teachers' and educators' professional development generally vary widely. The Oxford English Dictionary (OED) (2015) defines professional development as the development of competencies or expertise in one's profession; the process of acquiring the skills needed to improve performance in a job. The first mention of the term professional development according to the OED (ibid.) dates back to 1857, although the concept of educators' professional development has only started to develop since the $20^{\text {th }}$ century. The earliest mentions of the need for school staff's professional development came to the forefront in the 1960s in the USA (Murphy-Latta, 
2008). Until the early 1970s, learning opportunities for educators were mainly referred to as "in-service education" and university courses and seminars were largely being referred to (Joyce \& Calhoun, 2010). TALIS (OECD, 2009; 2014) confirms these traditional methods are still predominant. Traditionally, educators have had a fairly narrow view of professional development and regarded (or still do) professional development as special events that are restricted to several isolated days. Contributing to this narrow view are policies that require educators to accumulate a certain number of professional development hours or credits each year (Guskey, 2000). Super (1984) was among the first researchers on professional development to define the term in a slightly broader way as developing a concept of professional self through several stages, albeit he focused on initial training during adolescence and early adulthood.

However, by the end of the 2 oth century the concept of educators' professional development has developed considerably. Day's (1999) definition of CPD encompasses all behaviours intended to bring about changes in the classroom:

Professional development consists of all natural learning experiences and those conscious and planned activities which are intended to be of direct or indirect benefit to the individual, group or school, which contribute, through these, to the quality of education in the classroom. It is the process by which, alone and with others, teachers review, renew and extend their commitment as change agents to the moral purpose of teaching; and by which they acquire and develop critically the knowledge, skills and emotional intelligence essential to good professional thinking, planning and practice with children, young people and colleagues throughout each phase of their teaching lives (Day, 1999, p. 4).

Day and Sachs (2004) unified the definition of CPD as a term used to describe all activities in which teachers/educators engage during the course of a career that are designed to enhance their work. Guskey (2000) also defined professional development as those processes and activities designed to enhance the professional knowledge, skills and attitudes of educators so that they might, in turn, improve the learning and well-being of students. He also defined the characteristics of professional development as an intentional, ongoing and systematic process.

In the international TALIS survey, the OECD $(2009,2010)$ defined professional development as a system of activities for developing an individual's skills, knowledge, expertise and other characteristics as a teacher, 
including initial training, induction courses, in-service training, and continuous professional development within school settings. TALIS (OECD, 2009; 2014) also determined that participation in professional development is a common feature and that, on average, between countries in lower secondary schools teachers have 16 years of teaching experiences and more than $80 \%$ are permanently employed. Since the career of an educator is clearly a stable path and the majority stays on it one way or another throughout their entire working life, it is extremely important to emphasise that being/becoming a (good) educator requires an intentional, systematic ongoing process of development to maintain the motivation throughout the entire career and to develop the competencies needed to meet students' changing needs, although this sometimes also occurs unintentionally. Not only does the process need to be continuous, it must also meet the different needs of educators at various stages of their career and in different education systems.

\section{Models and stages of professional development}

Several professional development models have been designed to support efforts to provide opportunities to maintain a high standard of education practice, with these models being based on different concepts and therefore applying dissimilar approaches. The models typically take the stages of professional development into account. The most noteworthy models will be introduced in this paper in order to indicate the specifics of the different stages of educators' professional development and link them with possibilities for reducing ESL. The model of the professional development of teachers and other educators that is most often cited was developed by Fuller (Fuller et al., 1969; Fuller \& Brown, 1975) who identified the stages as: concern for self (primary survival as a teacher); concern for the task (which focuses on actual performance) and concern for impact (relating to a positive influence on students).

Huberman $(1989,1997)$ produced a more detailed model of teacher career development that describes several interrelated phases linked to the years of teaching, and can also be attributed to other educators. This model has influenced most of the later work on this subject matter. Day (2007) recently established a six-phase professional development model with similar characteristics but with slightly different focuses of the phases. Hargreaves (2005) also produced a model of the professional development of teachers (and other educators), but only three phases were established there. In the 
table below, we present the stages of these three models in a comparative perspective.

Table I. Comparative presentation of the stages of professional development

\begin{tabular}{|c|c|c|c|}
\hline $\begin{array}{l}\text { Years of } \\
\text { teaching } \\
\text { experience }\end{array}$ & Huberman $(1989,1997)$ & Day et al. (2007) & Hargreaves (2005) \\
\hline 1 & \multirow{3}{*}{ Survival and discovery } & \multirow{3}{*}{$\begin{array}{l}\text { Commitment: support and } \\
\text { challenge }\end{array}$} & \multirow{5}{*}{ Early career } \\
\hline 2 & & & \\
\hline 3 & & & \\
\hline 4 & \multirow{3}{*}{ Stabilisation } & \multirow{4}{*}{$\begin{array}{l}\text { Identity and efficacy in the } \\
\text { classroom }\end{array}$} & \\
\hline 5 & & & \\
\hline 6 & & & \multirow{14}{*}{ Mid-career } \\
\hline 7 & \multirow{12}{*}{$\begin{array}{l}\text { Experimentation/ } \\
\text { Activism or Reas- } \\
\text { sessment/ } \\
\text { Self-doubts }\end{array}$} & & \\
\hline 8 & & \multirow{8}{*}{$\begin{array}{l}\text { Managing changes, growing } \\
\text { tensions }\end{array}$} & \\
\hline 9 & & & \\
\hline 10 & & & \\
\hline 11 & & & \\
\hline 12 & & & \\
\hline 13 & & & \\
\hline 14 & & & \\
\hline 15 & & & \\
\hline 16 & & \multirow{8}{*}{$\begin{array}{l}\text { Work-life transitions, challen- } \\
\text { ges to motivation and com- } \\
\text { mitment }\end{array}$} & \\
\hline 17 & & & \\
\hline 18 & & & \\
\hline 19 & \multirow{12}{*}{ Serenity/Conservatism } & & \\
\hline 20 & & & \multirow{12}{*}{ Later career } \\
\hline 21 & & & \\
\hline 22 & & & \\
\hline 23 & & & \\
\hline 24 & & \multirow{7}{*}{$\begin{array}{l}\text { Challenges to sustaining mo- } \\
\text { tivation }\end{array}$} & \\
\hline 25 & & & \\
\hline 26 & & & \\
\hline 27 & & & \\
\hline 28 & & & \\
\hline 29 & & & \\
\hline 30 & & & \\
\hline $31>$ & $\begin{array}{l}\text { Disengagement (serene } \\
\text { or bitter) }\end{array}$ & $\begin{array}{l}\text { Sustaining/declining moti- } \\
\text { vation }\end{array}$ & \\
\hline
\end{tabular}

Huberman's model $(1989,1997)$ introduces five stages. During the initial phase (Survival and discovery), teachers face high demands concerning 
how and what to teach and how to manage the classroom. He also highlighted the sense of survival as a key characteristic of this phase. In the secondary phase (Stabilisation), teachers gain confidence in their competencies. They make a commitment to the profession and shift the focus from themselves to meeting the students' needs and developing their own education style. During the phase he named Experimentation/Activism or Reassessment/Self-doubts, teachers follow separate scenarios but can also transfer from one scenario to another. After stabilisation, teachers either start experimenting with various segments of their work (such as different materials, methods, strategies, institutional changes etc.) or exhibit more negative attitudes to teaching, they experience monotony and selfdoubts about continuing their career as a teacher. During the quaternary stage (Serenity/Conservatism), teachers also follow separate scenarios but can transfer from one to another. When experiencing serenity, teachers are more relaxed, feel self-acceptance and are also less emotionally engaged or have more relational distance. Under the other scenario, teachers express greater conservatism, rigidity, a reluctance to accept innovations and complain about different circumstances regarding the education. Near the end of their teaching career, Huberman $(1989,1997)$ postulates a gradual withdrawal and disengagement from work commitments (Disengagement - serene or bitter).

Day et al. (2007) formulated an even more detailed model with six phases of teachers' professional development. It differs from Huberman's model $(1989,1997)$ by its different emphasis during the first stage of professional development where Day et al. (2007) stressed two sub-groups of teachers are categorised: a) those developing a sense of efficacy; and b) those with a reduced sense of efficacy. Both should be motivated to join in professional development activities to stimulate their active participation. Other stages have similar emphasises as Huberman's $(1989,1997)$ with two groups of teachers developing: those with a positive attitude to change and teaching, and those focusing more on tensions and disappointment although Day et al. (2007) concentrated more on the motivation of teachers and other educators.

Hargreaves provides a denser model (2005). The model focuses more on the characteristics of teachers in different stages of CPD, such as enthusiastic, optimistic and adaptive during the early career, open to changes and confident during mid-career, and tired, resistant and resilient to change during their later career. 
Regardless of the model applied, it is evident that the professional development stages when teachers have already developed their identity as educators are the most important phases for developing the competencies required for preventing and reducing ESL. Further, regardless of the model during the last stages of CPD the approaches with the greatest influence on changing teachers' perspectives and practice should be more emphasised, such as active research and guided self-reflection. These are equally effective in all stages of CPD but during earlier stages other approaches are also welcomed by the teachers and other educators that are not well accepted by educators in later CPD stages.

We also argue that another phase of professional development during the initial teacher training is important and may be referred to as Gaining basic knowledge, developing identity and experience. During this phase, future educators are gradually beginning to identify with their future profession and to transfer their point of view from the students' perspective to that of educators.

It is interesting (but not encouraging) that TALIS $(2009,2013)$ identified that, on average, the amount of professional development attended by teachers decreases with the age of the teachers. Richter (2011) reported that the uptake of in-service training had a curvilinear pattern, with the highest uptake in mid-career (around age 42), confirming the hypothesis that teachers primarily pursue formal learning opportunities during the mid-career phase of experimentation, activism and managing changes. The results also showed (Richter, 2011) that teacher collaboration follows a linear pattern, with older teachers collaborating less frequently than younger teachers although older teachers used professional literature more frequently than younger teachers. Richter (2011) claims that the finding that teachers collaborate more at the start of their career than in the middle or at the end may be attributable to younger teachers still being more eager to learn from and draw on the professional expertise of more experienced teachers. It also holds important implications for professional development concerning ESL since the collaboration of teachers and other educators has been shown to be one of the most important factors for reducing the possibilities of ESL.

Clearly the priorities of teachers change over the years of their career and professional development. Considering these findings, no group of educators should be omitted from efforts to be actively involved in professional development, but the focuses and approaches should also take the 
professional development phase of each educator into account. Besides involvement in professional development activities, it is also crucial how these professional development activities are implemented. It is essential that such activities are carried out that enable educators at different stages of their professional development to improve their knowledge and competencies in order to prevent the ESL of students at risk.

\section{How to implement professional development?}

Educators are committed to focussing on both content knowledge (what to teach) and pedagogical knowledge (how to teach). In recent decades, there has been strong support (e.g. Krauss et al., 2008, Loughran et al., 2012; OECD, 2014) for the belief that teachers should acquire in-depth pedagogical knowledge, including notions about teaching and learning, alongside their knowledge of the subject matter taught. Therefore, educators' professional development needs to incorporate all those aspects and should be put into effect through different strategies. It should include less traditional approaches so as to develop not only the knowledge but also the beliefs, attitudes, values and commitment, thus making the programme more attractive for educators.

Guskey (2000) introduced seven major modes of professional development that are still prominent in today's professional development programmes: training, observation/assessment, involvement in a development/ improvement process, study groups, inquiry/action research, individually guided activities, and mentoring. These could all be implemented in more flexible programmes, e.g. as face-to-face-based activities, ICT-based activities or as a combination of both, while all of the above modes can also be combined with each other. Given the complexity of the possible combinations, seeking the best modes to fit all educators in their different professional development phases and different education systems is not the most productive approach. Professional development should incorporate the intertwining of modes considering the motivation and interests of each educator and their stage of professional development.

Improving individuals' knowledge and competencies must be complemented by the use of different strategies, models, changing the beliefs and, more specifically, with effective collaboration among teaching staff to produce better learning for both staff and students (OECD, 2009). This would enable better education experiences which are also essential for improving the prevention of ESL. 
Since teaching is much more than the task of transmitting knowledge to students, and involves values or assumptions concerning education, learning and society, the concept of teacher competencies is likely to resonate differently in various national contexts (European Commission, 2012). Therefore, implementation of CPD should also be designed so that it can be adapted to local (national) specifics such as understanding, traditions and characteristics related to ESL.

\section{Professional development of educators and ESL}

ESL is not a new phenomenon (Attianese, et al., 2015) and several focuses concerning ESL were applied in the past. Lately, an inclusive paradigm and shift of focus from the individual (who is leaving education) to the signs prior to the leaving have produced a need for educators to be able to react accordingly. The complexity of the phenomenon is illustrated by Burke (2008) who reported the main reasons for students withdrawing from school included uninteresting classes, truancy, too much freedom and not enough rules in their life (i.e. family-related reasons). Other reasons include the relationship with teachers and poor academic achievements. Trent and Slade (2001) emphasised that students' dissatisfaction and lack of motivation in school is partly due to the impact of teachers and their teaching, and argued there were too many unsuitable teachers who either created or exacerbated the problems. Research also indicates that schoolwide models of professional development (Positive Behavioural Interventions and Supports - PBIS) improve schools' organisational environment and reduce students' behavioural problems considerably (Bradshaw et al., 2008b) through improved cooperation between educators and the improved cooperation of teachers with the student and their parents. This is likely to translate into better motivation for education, increased academic performance and a reduction of ESL rates.

The challenge for teachers and other educators is thus to implement strategies and methods that will reduce the influence of those reasons, thereby helping students to meet their potential and stay focused on their education. Since most educators were not qualified to do so during their initial training, the need for CPD that enables an understanding of the ESL phenomena and the development of the competencies to effectively confront these issues has emerged.

Trent and Slade's (2001) research thus highlighted that teachers play an important role in the quality of students' school experiences, academic 
achievement and attitudes to school authority. Therefore, a straightforward relationship is implied whereby improving educators' competencies on a schoolwide level that imply improving students' educational experience would reduce these ESL risk factors. These competencies relate to the individualisation of teaching, working with mixed classes and the efficient use of ICT (Peklaj, 2010).

A review of the literature confirms that teachers' and other educators' social and emotional competencies (such as relational competence, communication competence, cooperation competence and competence of self-reflection) are vital for their performance and were significant predictors of overall innovative teaching performance as reported by the teachers themselves together with their educational and technological competencies (Durlak et al., 2011; Koster et al., 2005; Pantic \& Wubbels, 2010; Zhu, 2013) and in that sense also vital for preventing ESL. As indicated, an innovative teaching performance, social, emotional and communication competencies along with an understanding of ESL phenomena are some of the most important factors that can reduce the proportion of students who consider the classes uninteresting, of those without good relationships with teachers and those with poor academic achievements, which are among the key reasons for ESL according to Burke (2008). The CPD programmes should focus on tackling these.

\section{Conclusions}

Teachers' professional development is a concept that, even though it is today an important issue, only began to develop in the late $20^{\text {th }}$ century. This issue is being addressed by research, policy and practice and is therefore one of the fastest developing concepts regarding teachers and other educators and their work. According to research (Day, 2007; Hargreaves, 2005; Huberman, 1997), educators are shaping their professional identity and work performance during their professional careers and several stages are reported. Whatever model of CPD is taken into consideration, when developing programmes for the professional development of educators different needs reflecting their professional development phase should be considered as a major concern for the developers. The combination of different modes of CPD (such as training courses, action research, self-reflection etc.) seems to be the most appropriate way to address the specifics of each teacher or educator and each education system. 
It has been proven that professional development is a process influenced by different characteristics and that it is also a factor of influence for several types of outcomes (Durlak et al., 2011; Loucks-Horsley et al., 1998). An important implication is that the professional development of educators relates to developing their competencies that are crucial for improving the educational experience for both them and their students. Bradshaw et al. (2008a, 2008b) showed that schoolwide models of educators' professional development concerning the promotion of effective decision-making, self-control skills and prosocial connections are effective approaches that may hold implications for reducing ESL. Therefore, building up such educator competencies through professional development is vital for influencing the high-risk factors for ESL.

\section{References}

Attianese, A., Augenti, A., Casale, M. F., Chiatante, A., Geraci, M. A., Macrì, F. , Tancredi, A. (2015). New methodologies against early school leaving. Publications Universitat Oberta La Salle: Andorra.

Bradshaw, C. P., O’Brennan, L. M., \& McNeely, C. A. (2008a). Core competencies and the prevention of school failure and early school leaving. In $\mathrm{N}$. G. Guerra \& C. P. Bradshaw (Eds.), Core competencies to prevent problem behaviors and promote positive youth development. New Directions for Child and Adolescent Development, 122, 19-32.

Bradshaw, C. P., Koth, C. W., Bevans, B. K., Ialongo, N., Leaf, P. J. (2008b). The impact of school-wide Positive Behavioral Interventions and Supports (PBIS) on the organizational health of elementary schools. School Psychology Quarterly, 23(4), 462-473.

Burke, K. (200o). What to do with the kid who .... Developing cooperation, self-discipline, and responsibility in the classroom (3rd Edition). London: Corwin Press, Sage Ltd.

Council of the European Union. (2009). Council conclusions on the professional development of teachers and school leaders. European Commission, Brussels. Retrieved from www.consilium.europa.eu/uedocs/cms_data/ docs/.../en/.../111471.pdf

Day, C. (1999). Developing teachers: The challenges of lifelong learning. London: Falmer Press.

Day, C., \& Sachs, J. (2004). Professionalism, performativity and empowerment: Discourse in the politics, policies and purposes of continuing professional development. In C. Day \& J. Sachs, J. (Eds.). International handbook on 
the continuing professional development of teachers. Maidenhead, Birks, Open University Press.

Day, C., Sammons, P., Stobart, G., Kington, A., \& Gu, Q. (2007). Teachers matter: Connecting lives, work and effectiveness. New York: McGraw Hill.

Durlak, J. A., Weissberg, R. P., Dymnicki, A. B., Taylor, R. D., \& Schellinger, K. B. (2011). The impact of enhancing students' social and emotional learning: A meta-analysis of school-based universal interventions. Child Development, 82, 405-432.

European Commission. 2012. Supporting teacher competence development for better learning outcomes. Education and Training. Luxembourg: Publications Office of the European Union.

European Commission/EACEA/Eurydice. 2015. The teaching profession in Europe: Practices, perceptions, and policies. Eurydice Report. Luxembourg: Publications Office of the European Union.

Fuller, F. (1969). Concerns of teachers: A developmental conceptualization. American Educational Research Journal, 6, 207-226.

Fuller, F. \& Bown, O. (1975). Becoming a teacher. In K. Ryan (ed.), Teacher education (74th Yearbook of the National Society for the Study of Education. Part 2, pp. 25-52). Chicago: University of Chicago Press.

Guskey, T. R. (200o). Evaluating professional development. Thousand Oaks: Corwin.

Hargreaves, A. (2005). Educational change takes ages: Life, career and generational factors in teachers' emotional responses to educational change. Teaching and Teacher Education, 21, 967-983.

Hargreaves, D. H., \& Fullan, M. (2012). Professional capital: Transforming teaching in every school. New York, London: Teachers College Press.

Huberman, M. A. (1989). The professional life cycle of teachers. Teachers College Record, 91(1), 31-57.

Huberman, M. A. (1997). Qualities of instruction and varieties of qualitative research. Faculty of Education and Psychology, University of Geneva.

Joyce, B. R. \& Calhoun, E. (2010). Models of professional development: A celebration of educators. Thousand Oaks: Corwin.

Koster, B., Brekelmans, M., Korthagen, F. A. J., \& Wubbels, T. (2005). Quality requirements for teacher educators. Teaching and Teacher Education, 21(2), 157-176.

Kraus, S., Brunner, M., Kunter, M, Baumert, J., Planck, M., Blum, W., Neubrand, M., \& Jordan, A. (2008). Pedagogical content knowledge and content 
knowledge of secondary mathematics teachers. Journal of Educational Psychology, 100(3), 716-725.

Loucks-Horsley, S., Hewson, P. W., Love, N., \& Stiles, K. E. (1998). Designing professional development for teachers of science and mathematics. Thousand Oaks, CA: Corwin Press.

Loughran, J., Mulhall, P., Berry, A. (2012). Understanding and developing science teachers' pedagogical content knowledge. Series Professional Learning, v.12. Sense Publishers: Rotterdam, Boston, Taipei.

Murphy-Latta, Terry (2008). A comparative study of professional development utilizing the Missouri Commissioner's Award of Excellence and indicators of student achievement. Dissertation. Retrieved from http:/gradworks.umi.com/32/97/3297825.html

OECD. (2009). Creating effective teaching and learning environments: First results from TALIS. Paris: OECD.

OECD. (2014). New insights from TALIS 2013. Teaching and learning in primary and upper secondary education. Paris: OECD.

Pantic, N., \& Wubbels, T. (2010). Teacher competencies as a basis for teacher education - views of Serbian teachers and teacher educators. Teaching and Teacher Education, 26, 694-703.

Peklaj, C. (ed.). (2010). Teacher competencies and educational goals. Aachen: Shaker Verlag.

Richter, D., Kunter, M., Klusmann, U., Lüdtke, O., \& Baumert, J. (2011). Professional development across the teaching career: Teachers' uptake of formal and informal learning opportunities. Teaching and Teacher Education, 27(1), 116-126.

Super, D. E. (1984). Career and life development. In D. Brown and L. Brooks (eds.). Career choice and development: Applying contemporary theories and practice, 192-234. San Francisco: Jossey-Bass.

The Oxford English Dictionary (2015). Retrieved from http://www.oed.com/

Trent, F., \& Slade, M. (2001). Declining rates of achievement and retention. The perception of adolescent males. Evaluations and Investigations Programme, Higher Education Division. Department of Education, Training and Youth Affairs. The Flinders University of South Australia.

Zhu C., Wang D, Cai Y. H., \& Engels, N. (2013). What core competencies are related to teachers' innovative teaching? Asia-Pacific Journal of Teacher Education, 41(1), 9-27. 


\section{I.4 \\ Educators' Self-reflection}

Tina Vršnik Perše, Maša Vidmar and Ana Kozina

\section{Synopsis}

Self-reflection of educators is a key factor of their professional development. It can also influence educators' perspectives, notions and practice regarding the education of students at risk of early school leaving (ESL). Therefore, self-reflection should be implemented as an important element of ESL prevention but with a consideration of its possible downsides.

\section{Summary}

This paper focuses on educators' self-reflection as a professional development tool. The individual's ability to reflect and assess their behaviours and abilities affects their choices, aspirations, motivations and coping mechanisms (Frydenberg, 2011) and this ability should therefore be promoted and developed, especially among educators. An overview of the development of the concept of self-reflection in education (from Dewey, 1933 to Korthagen, 2004) highlights the most important models of self-reflection. The definitions regarding self-reflection and related approaches in education (such as core reflection and critical reflection) reveal the process' attributes and the relationship to early school leaving (ESL). In the article, the importance of self-reflection as an element of educators' professional development is addressed while some contemporary approaches of self-reflection are also discussed since it has been determined that 
self-reflection can help educators analyse their own competencies, their own teaching practices and their own evaluation strategies. This analysis is a good foundation for changing their perspectives, notions and practice regarding their education experiences and consequently for preventing ESL.

Video-based self-reflection is introduced here as one of the latest methods of self-reflection linked to improving competencies regarding the prevention of ESL. As with other professional development approaches, such as lessons, courses, supervision, coaching or others also when using (video) self-reflection, some considerations and possible negative effects need to be taken into account. The paper analyses and discusses the possibilities of self-reflection and the related approaches and methods and establishes that it can have a great influence on educators' practice involving interactions with students at risk of ESL and on preventing ESL if used with evidence-based considerations.

Key words: educators, self-reflection, professional development, preventing ESL

\section{Introduction}

In more recent EU documents on education, the reduction of ESL is often tackled as a comprehensive task that must address the entire education spectrum, including educators' awareness of the scope and challenges of ESL (European Commission, 2013). Awareness of the scope and challenges, what triggers ESL and the practices to prevent it are mostly left up to educators and their skills and competencies (although individual and systemic factors also importantly contribute to ESL). These aspects are typically not achieved through formal education process of future educators but evolve during the process of their professional development.

Developments in teacher education and professional development require a rethinking of how best to build linkages between theory and practice and, in this context, reflection has become a keyword in the education of teachers (Korthagen, 2014). The individual educator's ability to reflect and assess their behaviours and abilities affects their choices, aspirations, motivations and coping mechanisms (Frydenberg, 2011). In order to become aware and improve educators' behaviours, coaching and self-reflection have been shown to have positive and promising results with significant effect sizes and nowadays especially video self-reflection is recognised 
as a powerful tool (Osipova et al., 2015). Self-reflection is thus recognised as an important method of professional development with the possibility to tackle contemporary educational issues, including reducing ESL. Currently, the approach to implementing self-reflection in every educators' practice is not systematic and is left more up to each individual.

Despite the numerous scientifically recognised advantages of engaging in self-reflection as a systematic approach to professional development, there are also downsides that need to be considered. Košir and colleagues (2015) demonstrated that, in the interaction with perceived workload, reflection can actually be a maladaptive personal characteristic. It seems that in the circumstances of a high workload, reflection works as an additional stressor and contributes to intensified stress levels. Therefore, it is important that self-reflection is applied with a consideration of all characteristics of each educational experience (students, educators, content...).

The research into self-reflection tends to focus on two of its core aspects, one that centres on rumination (that is a negative, chronic and persistent self-focus motivated by perceived threats, losses or injustices to the self and contributing to neuroticism and depression) and a more healthy form of self-reflection (motivated by curiosity or epistemic interest in the self and associated with openness to experiences and the promotion of self-knowledge and positive mental health) (e.g. Trapnell and Campbell, 1999). The latter aspect is referred to in this paper.

The purpose of the paper was to analyse the characteristics of educators' self-reflection and to discuss its possibilities in terms of changing educators' practice in general and in the context of ESL prevention. Conceptual issues and several models and methods of educators' self-reflection were therefore introduced.

\section{Methodology}

We conducted a review of the literature by searching in the ERIC, SpringerLink, Wiley, Sage, Proquest, and Science Direct search engines for information about teachers' self-reflection, video self-reflection, the development of the concept and its relationship to ESL. We included four types of documents: scientific papers, webpages presenting educators' self-reflection, scientific monographs explaining the theoretical background for engaging in educators' self-reflection along with EU documents and reports on the subject matter. 


\section{Self-reflection: conceptual issues}

The definition of self-reflection has been developing since about the 17th century when the first known use of the term self-reflection was documented in the Merriam-Webster Dictionary (n.d.) as a careful thought about one's own behaviour and beliefs and as related to self-examination, defined as a careful reflective examination of one's own behaviour and beliefs to see whether they are good or bad (also introspection). This definition can easily be related to educators and their professional development with regard to improving competencies for reducing ESL. Educators' careful thinking about their teaching and the related beliefs offers an opportunity to reconsider and improve their performance as educators. Sellars (2014) also provides a broad definition that reflection or self-reflection can be defined as deliberate, purposeful, metacognitive thinking and/or action in which educators engage in order to improve their professional practice and to establish such a practice that would enable all students to be successful. The Encyclopaedia of Child Behaviour and Development defines self-reflection as related to self-evaluation and describes self-evaluation as a key regulatory process through which an individual compares self-generated or externally provided performance information against personal standards or goals (Cleary, 2011). If such goals are set in order to establish a supportive environment for all students to succeed, the comparison of one's own performance should emphasise such actions of the educator that in the future would establish a more supportive environment for more students. In the Encyclopedia of Adolescence, self-reflection refers to the capacity to exercise introspection and the willingness to learn more about one's purpose, essence and true self (Levesque, 2011). These can also help greatly in learning about one's performance, emotions and notions, followed by altering them so as to improve their own education practice according to the goal of reducing ESL.

However, the definitions are not straightforward since interpretations vary by scientific discipline and also by the purpose of using this terminology. The concept of self-reflection regarding its use in education also has some specifics. The question remains if self-reflection is (or should be) a systematic or spontaneous process, which characteristics are (should be) included in this process, and which methods and approaches are (should be) used.

When self-reflection is used as a method for improving educators' work performance it can be addressed as one of the three cyclical phases 
of self-regulatory processes: forethought, performance and self-reflection. Therefore, self-reflection can also be perceived as a process that occurs after learning (or other) efforts and is designed to optimise a person's reactions to their outcomes (Zimmerman, 2008). The methods of self-reflection can have different intentions, but they can generally all be used to improve self-regulated learning on one hand and as a principle of assessment on the other. As regards educators' self-reflection, these principles can also be used for both purposes depending on the paradigm whether educators' work is being assessed or they are trying to improve their work. Since this is a cyclic model, self-reflection again influences forethought and also the work performance, so both purposes are eventually tackled. In terms of reducing ESL, forethought may be interpreted as preparing for education interactions (i.e. teaching, mentoring...) and classroom management in terms of supporting all students. The second phase is the actual educational experience, followed by self-reflection (critical evaluation) on the success of the prepared plan and its implementation. Afterwards, based on these observations there come planning and preparing for further education experiences that would engage all students.

Changing pedagogies to include more relevant (life-related, practical, vocational) experiences for students and develop more individualised approaches as well respectful inclusive relations is crucial to keep students engaged in school (Rogers, 2016). Thus, reflection and self-reflection can be understood as a key element of educators' professional development (but it is not the only element or better than others) in order to acquire better approaches and competencies for meeting students' needs and creating a supportive education environment for all students in order to reduce ESL. Ever since Schön (1983) presented self-reflection as a powerful tool for professional development, research has proven that teachers who reflect on their practice are more likely to change their practice to better meet the needs of their students (Osipova et al., 2011). When educators observe some critical indicators that could lead to a student's ESL, a subsequent self-reflection could lead to more supportive actions of the educator that would prevent the student dropping out.

\section{Different models of educators' self-reflection}

Dewey (1933) was one of the first to research reflection in relation to the professional work of educators. His research was about linear models of thinking and the interaction of thinking, experience and reflection. His work 
has influenced several researchers regarding the concepts of reflection and self-reflection, such as Schön (1983) and Kolb (1984).

Dewey (1933, p. 9) defines reflective thinking as "active, persistent, and careful consideration of any belief or supposed form of knowledge in the light of the grounds that support it, and the further conclusions to which it tends". He recognised five steps of thinking or reflection: (i) a felt difficulty; (ii) its location and definition; (iii) suggestion of possible solution; (iv) development by reasoning of the bearings of the suggestion; and (v) further observation and experiment leading to its acceptance or rejection, that is, the conclusion of belief or disbelief.

One can recognise Dewey's influence on the characteristics Schön (1983) established regarding educators' reflection, where it was concluded that skilled practitioners are reflective practitioners and apply their experience as a basis for assessing and revising their existing theories to develop more effective strategies. Schön (1983) identified a framework for thinking and becoming aware of one's own implicit knowledge and learning from experience, but he aimed to determine the development of educators' reflective practice rather than explicitly explain reflection as a step-by-step process. Nevertheless, he recognised three levels of reflection (setting a problem, framing the experiment, deciding on a course of action). Another important contribution he made was the recognition of three types of reflection: reflection-in-action (reflecting during the action or interaction, i.e. while teaching), reflection-on-action (reflection on a previous event, i.e. reflection about previous educational experience) and reflection-for-action (planning and reflecting before an action, i.e. reflection before an educational experience for the purpose of planning) (Schön, 1987).

Based on previous models, Kolb (1984) developed a model of reflection that comprises four stages: (i) reflective observation; (ii) abstract conceptualisation; (iii) active experimentation; and (iv) concrete experience. Kolb (1984) believes that this is a cyclic process that can be entered at any stage, but it can only have a learning effect when all four stages are carried out. Because Kolb's model incorporates the characteristics developed in previous models and also represents an upgrade of them, it is introduced here in greater detail. 


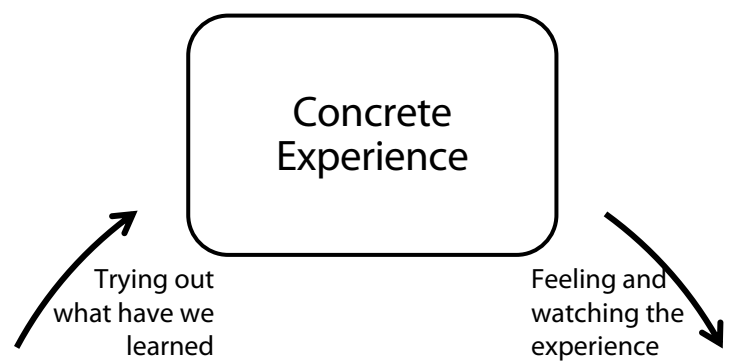

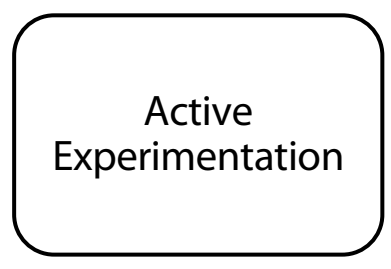

Thinking, concluding and learning from the experience

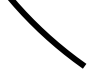

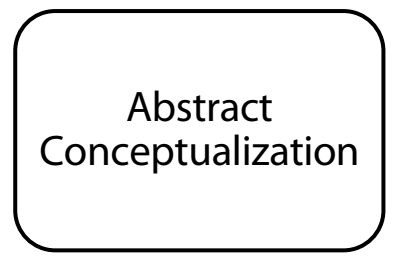

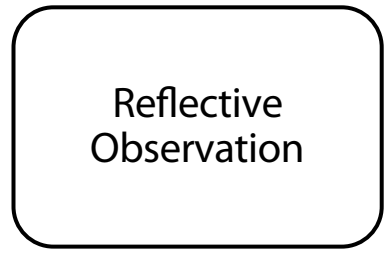

Observing, and reviewing the experience

\section{Figure 3. Kolb's model of learning and reflection}

(Adapted from: Kolb, D. A., Boyatizis, R. E. and Mainemelis, C. 200I, p.229)

Attributing the effects of reduction of ESL to Kolb's model for the professional development of educators would mean the educator is involved in reflective observation (of their own performance, of the performance of others, of how supportive the learning experience is...), then they should engage the abstract conceptualisation (which could be induced by a mentor or tutor). After that, educators should be allowed to autonomously experiment with new approaches to produce a more supportive learning environment for all students and, based on that, to analyse the experience and their feelings about it. Again, a reflective observation on the educational experience follows.

Tripp (1993) also added to the contemporary understanding of reflection, self-reflection, reflective teaching and using reflection for educators' professional development. He describes reflection as a component 
of professional judgement that is developed through a diagnosis of their practice and critical incidents. Tripp (1993) claims that being aware of what something means to us is of little practical value unless we do something about it by creating a critical incident. This critical incident acts as both an agenda for further action and a way of evaluating and interpreting it. This cycle can be used instantly during teaching in an informal or more formal way. It can also be used in professional development in terms of reducing ESL since creating (or observing) and analysing critical incidents would enable educators to establish understanding and usage of good (and weaker) practices.

Ziecher and Liston (1996) developed an understanding of reflective teaching which emphasises five key features and where a reflective teacher:

1. examines, frames and attempts to solve dilemmas of classroom practice;

2. is aware of and questions the assumptions and values they bring to education;

3. is attentive to the institutional and cultural context;

4. takes part in curriculum development and is involved in school change efforts; and

5. takes responsibility for their own professional development.

These authors (Ziecher \& Liston, 1996) believe that viewing educators as reflective practitioners assumes that educators can both pose and solve problems related to their educational practice, including ESL.

Of course, the reflection and self-reflection of educators may have different perspectives and comprise several characteristics. Accordingly, continuing changes in understanding and interpreting the meaning and content of educators' reflection and self-reflection is expected. Thus, a model of critical reflection was developed (Brookfield, 1995) that views it as a process where those who are performing the self-evaluation actively engage with a (most often first-hand and meaningful) situation with the intention to "integrate the understanding gained into experience in order to enable better choices or actions in the future as well to enhance overall effectiveness" (Rogers, 2001, p. 41). 


\section{Self-reflection of educators today: The ALACT model of core self-reflection and its implications for ESL}

Recently, Korthagen (2004) developed a model of so-called core self-reflection through which an individual can become aware and improve their options for transforming their already acquired knowledge, experience, cognitive structures, feelings, emotions, motivation to learn and an engaged attitude to work etc. The model is based on several already presented models of reflection developed in the 2oth century but it highlights new aspects of educators' professional development such as their professional identity, mission and core qualities. It has been developing for almost two decades and today it is one of the most referenced contemporary models on educators' self-reflection, especially with the link to educators' professional development and the possible implications for preventing ESL.

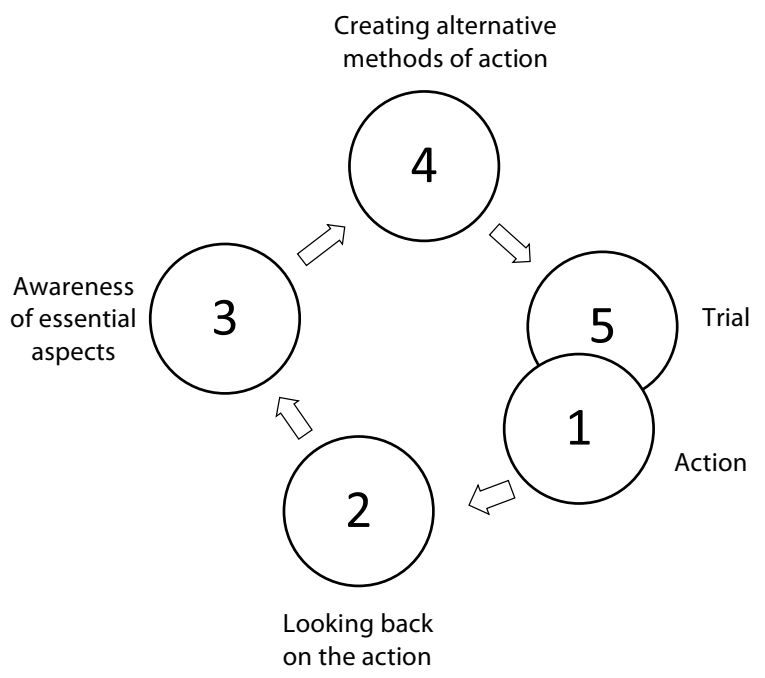

Figure 4. Korthagen's ALACT cycle of reflection (Adapted from Korthagen, 2014, p. 75)

Korthagen and Kessels (1999) describe four phases of self-reflection (the ALACT model) which are suitable for facilitating and developing an (active) reflective attitude to one's professional activities and professional development, based on an analysis of one's own practice and cognition that guide an individual's thinking, actions, evaluation and comprehensive activities: 1. Action; 2. Looking back on the action; 3. Awareness of essential aspects; 4. Creating alternative methods for action (also see Figure 4). The 
fourth phase is followed by a fifth labelled Trial, which at the same time functions as phase 1 - Action. During phase 2 of the model, teachers reflect on their thinking, feeling, wanting and doing, as well as on the same aspects in their pupils. The aim is to become more aware of how they are reacting during their teaching, what their feelings and needs are along with the feelings and needs of their pupils (Korthagen, 2005).

Korthagen's ALACT model is also relevant to improving educators' competencies and reflecting on already established practices in order to reduce ESL. The first phase (Action) can be considered as teaching or counselling a student with high-risk factors for ESL by using a certain approach. During the second phase (Looking back on the action), educators reflect on their thinking, feeling, wanting and doing during the first phase, and on the same aspects in their students. During the third phase (Awareness of essential aspects) educators focus on becoming aware of the aspects that are important for improving their further education practice. The fourth phase (Creating alternative methods of action) is when educators can plan for the future education experience with the same student or other students based on their observation during the second phase. The fifth phase (Trial) represents the period when an educator tries to implement what was created and planned during the third phase, i.e. tries to use another approach with the same student or with other students. This is simultaneously also the first phase (Action) since the educator then looks back on this trial, reflects and the cycle begins from the start.

Korthagen and colleagues (Korthagen \& Kessels, 1999; Korthagen, 2004; Korthagen, 2005; Korthagen \& Vasalos, 2010; Korthagen, 2013; Korthagen, 2014) established that the ALACT model of self-reflection is a helpful process model, but it does not support the practitioner in knowing what to reflect on, and that this can easily make the reflection somewhat superficial. Especially in complex and recurring problematic situations, such as preventing ESL, a reflection which only focuses on one's previous and future behaviour is counterproductive. In order for more transformational changes to take place, deeper layers of educators' understanding need to be touched on. For this reason, Korthagen et al. supplemented the ALACT model with a model describing possible contents of reflection at six different levels - the Onion model (Korthagen \& Vasalos, 2010).

The "onion model" or "a model of levels of change" presents various levels that can be influenced by self-reflection (individuals' behaviour, competencies, beliefs, identity and mission) (see Figure 5; Korthagen, 2004). 


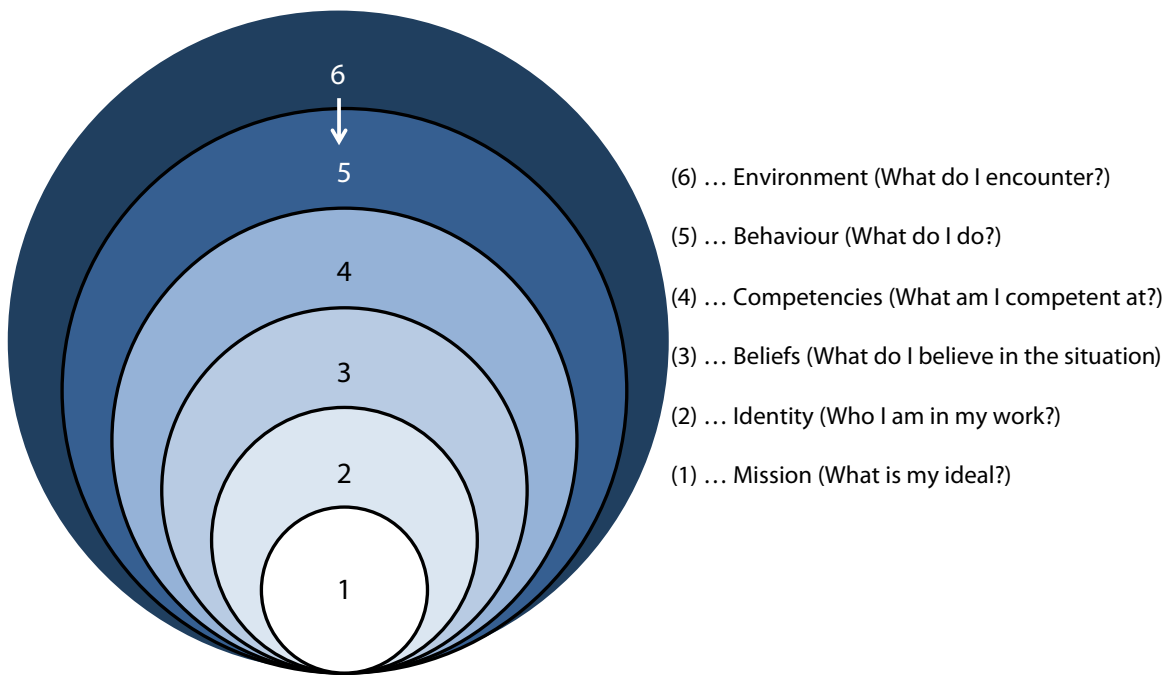

Figure 5. Korthagen's Onion model - the model levels of reflection (Adapted from Korthagen, 2014, p. 76)

The link with ESL can be explained on each level. The environment for each educator means reflecting on the way students react (e.g. students at risk of dropping out) as well as the whole classroom and school climate and culture (whether it is accepting and motivating for students at risk of dropping out). The reflection on behaviour may focus on behaviours that are more and less effective (e.g. showing empathy for students at risk of dropping out). The reflection on competencies may focus on one's own competency to respond empathetically or motivatingly. The reflection on beliefs about ESL can also put many actions into a different perspective. It is also important for educators to reflect on what kind of educators they are and what kind of educators they want to be. Finally, the reflection at the level of mission would deal with questions about why somebody decided to become an educator (e.g. only to educate the best students or to support all of them).

Core reflection as a concept is an important ingredient of effective learning at all levels of schooling and teachers' professional development and is also crucial as a method for growth in collegial coaching (Korthagen, 2013) although it needs to exceed the superficial levels of the reflection. When teachers are able to progress through the various model phases 
independently, they will have developed a growth competence (Korthagen, 2014).

A very interesting conclusion was drawn by teacher educators after including core self-reflection in their curriculum that core reflection is a profoundly reciprocal process and that the further we integrate the approach within our work with students, the more we ourselves are changed as a result (King \& Lau-Smith, 2013). Williams and Power (2009) concluded that acknowledging and examining personal characteristics (core qualities) and emotions in teaching practice, and in the core reflection process itself, is an important way in which educators can construct their professional identities, and examine and improve their practice. Further, Attema-Noordewier, Korthagen and Zwart (2013) described how, after professional development through core self-reflection, teachers reported an increased feeling of autonomy, stronger coaching skills together with enhanced core qualities of students, colleagues and themselves. The teachers also reported an increase in the students' working and communication skills and in the students' attitudes, which are among the most important factors in preventing ESL.

(Self)-reflection as a core reflection in such a cyclic form based on the ALACT model is an activity that directs teachers towards examining the existing and creating new approaches and methods for further actions (educational experiences), new views and notions and new competencies while analysing their own activities or activities of another. Teachers' own views of knowledge, learning and teaching can also be key to what teachers report about students (are students successful, how successful they are) and how students perceive the school environment (as supportive and engaging or not). When educators reflect on a certain educational experience they can better understand not only their own but also their students' perspective which enables them to create a more supportive environment and therefore reduce the risk factors for ESL.

\section{Methods of self-reflection}

Self-reflections may be conducted in various forms. Effective teachers may reflect on their work formally or informally; for instance, they may review a day's work mentally, keep a journal, meet regularly with a mentor or with colleagues, or assess a videotaped recording of their teaching (Good \& Brophy, 1997). Yet the self-reflection of teachers should not be limited to reflecting on their day's work (such as teaching approach or assessment strategies) but also on their social and emotional competencies (such as 
relational competence) and responses. A connection between professional and the personal elements is important (Korthagen \& Vasalos, 2010) since many authors emphasise that a strong divide between the personal and the professional may lead to an ineffective friction in an educators' identity (Beijaard et al., 2004). Therefore, inadequate conceptions about students, defragmentation of relational competence and inability to engage students are associated with an inability to prevent ESL since students at risk for ESL are generally less motivated for school work and do not perceive the school and teachers to be very a positive environment and good motivators (Traag \& Van der Velden, 2008; Harrington, 2008) and thus they need educators who possess the best possible combination of the above characteristics.

Several different methods can be used to engage in self-reflection in order to induce professional development, such as the "thinking-aloud" interview or stimulated recall, in which a subject engaged in a task speaks their thoughts aloud (Gläser-Zikuda, 2012). This allows the study of thoughts without influencing the subject to think too long about what they are asked, for example, in questionnaires. Further, written forms of self-reflection are a learning diary, learning protocol, and portfolio (Gläser-Zikuda, 2012). As indicated, the choice of self-reflection strategy is extremely important for attaining the expected outcomes and reducing the adverse effects.

One approach for reflecting on one's own education experiences or reflecting on the educational experiences of other educators is based on video. Video has become quite a widely used tool in teacher professional development (Brophy, 2004) and also in educators' self-reflection (Osipova et al., 2011). However, as Seidel and colleagues (2011) point out, the available research only provides limited insight into teachers' experiences of watching videos of their own teaching versus others' teaching. It also offers limited information on how teaching practice changes following video-based (self) reflection during in-service professional development courses. They (Seidel et al., 2011) discovered that teachers who analysed their own teaching experienced higher activation, indicated by higher immersion (deep-level engagement), resonance (a link to own teaching) and motivation than before the self-reflection, and higher than when reflecting on others' teaching. Osipova (2015) then demonstrated with the results of a study that lessons undertaken when applying a certain intervention: coaching, video self-reflection, and the combined intervention of coaching and video self-reflection, produced much higher quality ratings than lessons without such intervention. Research (Tripp \& Rich, 2012) has also proven that participating 
in video reflections increased teachers' desires to change their teaching. The implication was that, where teachers see no need to change their practice, participation in video reflection may alter that view and create an intrinsic desire to change. Teachers also reported that, based on the video self-reflection, they were also changing their teaching when returning to the classroom (Tripp \& Rich, 2012). Since one of the main principles for reducing the impact of the risk factors for ESL is to create a supportive educational environment for all students which includes educational experiences that engage all the students, video self-reflection combined with coaching and the implications for changing one's teaching could contribute greatly to preventing ESL since it leads to a better understanding of the educational process, educators' own behaviour, students' behaviour and better education outcomes.

\section{Conclusion}

We have demonstrated several benefits of educators' self-reflection and thus believe that self-reflection should be a major element of every educator's professional development since it enables a wide range of understanding and analysing of one's own practice, competencies, beliefs, identity and mission and in such a way contributes to students' higher engagement and therefore lower ESL rates.

Several models of self-reflection were presented, with all indicating the importance of educators' active participation in the self-reflection process and all determining that self-reflection is a process that can help educators with their professional development.

According to Korthagen and Kessels (1999), being aware of the main aspects connected with our actions is the key phase of reflection. Self-reflection based on the ALACT model (Korthagen \& Kessels, 1999; Korthagen, 2004; Korthagen, 2005; Korthagen \& Vasalos, 2010; Korthagen, 2013; Korthagen, 2014) has been shown to have effects regarding both educators as well as students. Educators must therefore first become aware of their perceptions of learning and teaching and regarding ESL and only afterwards can they alter their subjective conceptions and (re)actions as an educator if the deeper levels of self-reflection are applied. The incorporation of video self-reflection within professional development should focus on helping teachers move beyond a superficial level of self-reflection and to use the dissonance experience to reflect on how their practice could enhance student learning (Osipova et al., 2011) and reduce ESL. Self-reflection 
as an approach to educators' professional development was recognised as highly valued and engaging but it can also have some disadvantages, such as facilitating stress or rumination or as a process that on a superficial level can lead to complaining instead of searching for ways to improve. In order to reduce these side-effects, several approaches should be combined and as many aspects as possible should be addressed during the professional development process so as to enable educators to develop their own ability to rethink the education process they are providing for students at risk for ESL.

\section{References}

Attema-Noordewier, S., Korthagen, F. A. J., \& Zwart, R. C. (2013). Core reflection in primary schools: A new approach to educational innovation. In F. A. J. Korthagen, Y. M. Kim, \& W. L. Greene (Eds.), Teaching and learning from within: A core reflection approach to quality and inspiration in education (pp. 111-130). New York/London: Routledge.

Beijaard, D., Meijer P. C., \& Verloop, N. (2004). Reconsidering research on teachers' professional identity. Teaching and Teacher Education, 2o(2), 107-128.

Brookfield, S. (1995). Becoming a critically reflective practitioner: Thousand Oaks, CA: Sage.

Cleary, T. J. (2011). Self-evaluation in academic settings. In Goldstein, S. \& Naglieri, J. A. (Eds.), Encyclopedia of Child Behavior and Development (pp. 1320-1321). New York: Springer.

Dewey, J. (1933). How we think: A restatement of the relation of reflective thinking to the educative process. Boston: DC Heath and Company.

European Commission - EC. (2013). Reducing early school leaving: Key messages and policy support. Final Report of the Thematic Working Group on Early School Leaving. Retrieved from: http://ec.europa.eu/education/policy/ strategic-framework/doc/eslgroup-report_en.pdf

Frydenberg, E. (2011). Self-efficacy. In Levesque, R. J. R. (Ed.). Encyclopedia of Adolescence (pp. 2554-2559). New York: Springer.

Gläser-Zikuda, M. (2012). Self-reflecting methods of learning research. In Seel, N. M. (Ed.), Encyclopedia of the Science of Learning (pp. 3011-3015). New York/ Dordrecht/Heidelberg/London: Springer.

Good, T. L., \& Brophy, J. E. (1997). Looking in classrooms (7th ed.). New York: Addison-Wesley. 
Harrington, I. (2008). The motivation of boys who leave school early: Impact of teachers. Educational Research for Policy and Practice, 7, 47-55.

King, J. T. \& Lau-Smith, J. A. (2013). Teaching from the inside out. In Korthagen, F. A. J., Younghee, M. K., \& Greene, W. L. (Eds.). Teaching and learning from within (pp. 45-6o). New York and London: Routledge.

Korthagen, F. A. J., \& Kessels J. P. A. M (1999). Linking theory and practice: Changing the pedagogy of teacher education. Educational Researcher, 28(4), 4-17.

Korthagen, F. A. J. (2004). In search of the essence of a good teacher: Towards a more holistic approach in teacher education. Teaching and Teacher Education, 20(1), 77-97.

Kolb, D. A. Boyatizis, R. E. and Mainemelis, C. (2001). Experiential learning theory: Previous research and new directions. In R. J. Sternberg and L. F. Zhang (Eds.), Perspectives on thinking, learning, and cognitive styles, pp. 227-247. Mahwah, NJ: Lawrence Erlbaum.

Korthagen, F. A. J. (2005). Practice, theory, and person in life-long professional learning. In Beijaard, D., Meijer, P. C., Morine-Dershimer, G., \& Tillema, H. (Eds.), Teacher professional development in changing conditions. Dordrecht: Springer.

Korthagen, F. A. J. (2014). Promoting core reflection in teacher education: Deepening --professional growth. In L. Orland-Barak, \& C. J. Craig (Eds.), International teacher education: Promising pedagogies (Part A), (pp. 73-89). Bingley, UK: Emerald.

Korhagen, F. A. J., \& Vasalos, A. (2010). Going to the core: Deepening reflection by connecting the person to the profession. In Lyons, N. (Ed.), Handbook of reflection and reflective inquiry. New York: Springer.

Korthagen, F. A. J. (2013). The core reflection approach. In Korthagen, F. A. J., Younghee, M. K., \& Greene, W. L. (Eds.). Teaching and learning from within (pp. 24-42). New York and London: Routledge.

Košir, K., Tement, S., Licardo, M., Habe, K. (2015). Two sides of the same coin? The role of rumination and reflection in elementary school teachers' classroom stress and burnout. Teaching and Teacher Education: An International Journal of Research and Studies, 47, 131-141.

Levesque, R. J. R. (2011). Self-reflection. In Levesque, R. J. R. (Ed.), Encyclopedia of Adolescence (pp. 2585-2586). New York: Springer.

Merriam-Webster Dictionary. (n.d.). Retrieved from www.merriam-webster. com/dictionary 
Osipova, A., Prichard, B., Gould Boardman, A., Kiely, M. T., \& Carroll, P. E. (2011). Refocusing the lens: Enhancing elementary special education reading instruction through video self-reflection. Learning Disabilities Research \& Practice, 26(3), 158-171.

Osipova, A. V. (2015). Academic language self-reflection and coaching training of pre-service special education teachers in the context of content area writing instruction. Doctoral dissertation: UCLA. Retrieved from http:// www.escholarship.org/uc/item/7p79g50g

Rogers, R. R. (2001). Reflection in higher education: A concept analysis. Innovative Higher Education, 26(1), 37-57.

Rogers, L. (2016). Disengagement from education. London: Institute of Education Press.

Schön, D. A. (1983). The reflective practitioner: How professionals think in action. London: Temple Smith.

Schön, D. A. (1987). Educating the reflective practitioner: Toward a new design for teaching and learning in the professions. San Francisco: Jossey-Bass.

Seidel, T., Sturmer, K., Blomberg, G., Kobarg, M., \& Schwindt, K. (2011). Teacher learning from analysis of videotaped classroom situations: Does it make a difference whether teachers observe their own teaching or that of others? Teaching and Teacher Education: An International Journal of Research and Studies, 27(2), 259-267.

Sellars, M. (2014). Reflective practice for teachers. London: Sage Publications.

Traag, T., \& van der Velden, R. K. W. (2008). Early school-leaving in the Netherlands. The role of student-, family- and school factors for early school-leavinginlowersecondaryeducation. Retrievedfromhttp://citeseerx. ist.psu.edu/viewdoc/download?doi=10.1.1.667.1466\&rep=rep1\&type $=$ pdf

Tripp, D. (1993). Critical incidents in teaching: Developing professional judgement. London/New York: Routledge.

Tripp, T. R., \& Rich, P. J. (2012). The influence of video analysis on the process of teacher change. Teaching and Teacher Education, 28(5), 728-739.

Williams, J., \& Power, K. (2009). Using core reflection in teacher education. Refereed paper presented at "Teacher education crossing borders: Cultures, contexts, communities and curriculum", annual conference of the Australian Teacher Education Association (ATEA), Albury, 28 June-1 July. Retrieved from http://atea.edu.au/ConfPapers/2009/Refereed/ Williams\&Power.pdf 
Zeichner, K. M. \& Liston, D. P. (1996). Reflective teaching: An introduction. New York: Lawrence Erlbaum Associates.

Zimmerman, B. J. (2008). Goal setting: A key proactive source of academic self-regulation. In D. H. Schunk, \& B. J. Zimmerman (Eds.), Motivation and self-regulated learning. Theory, research and applications (pp. 267295). New York: Lawrence Erlbaum Associates. 
2.2 training for cooperation with students 

2.2.I

\section{Social and Emotional Learning as a Tool for Preventing ESL}

Ana Kozina

Synopsis

Social and emotional learning plays an important role in preventing ESL through several mechanisms. When implemented in schools, social and emotional learning prevents ESL directly by promoting school connectedness, commitment and positive attitudes to school, teachers and peers and, indirectly, by enhancing educational success.

\section{Summary}

The paper presents the role of social and emotional learning (SEL) in ESL with a theoretical review and the development of policy guidelines. SEL is a process through which students learn to recognise and manage emotions, care about others, make good decisions, behave ethically and responsibly, develop a positive relationship and avoid negative behaviours (Collaborative for Academic, Social and Emotional Learning, 2003). The literature review showed the positive impact of SEL on preventing ESL directly by promoting school connectedness, commitment.... Hawkins, Smith, \& Catalano (2004) revealed that by enhancing school bonding schools can decrease ESL, and positive attitudes to school, teachers and peers and, indirectly, by enhancing educational success. Wilson and colleagues (Wilson, Gottfredson, \& Najaka, 2001) conducted a meta-analysis of 165 published studies of the outcomes of school-based SEL prevention programmes that ranged from individually focused counselling 
through to broad school-wide efforts in changing the way schools are managed. One of their findings is that programmes which focus on SEL resulted in improving outcomes related to ESL and truancy. Unfortunately, many students lack social-emotional skills and become less connected to school as they progress from basic to upper secondary school, and this lack of connection negatively affects their academic outcome, behaviour and health (Blum \& Libbey, 2004). Based on the literature review and the topic's established importance for preventing ESL, the possibilities of enhancing social and emotional skills on the national and European levels are discussed. The paper demonstrates that social and emotional skills and SEL are an innovative strategic solution in addressing the EU's strategic goal of preventing ESL.

Key words: social and emotional learning, emotional competencies, social competencies, academic achivement, prevention programs

\section{Introduction}

SEL is the process of acquiring fundamental emotional and social skills: self-awareess, self-regulation, social awareness, successful management of relationships and responsible decision-making (Ragozzino, Resnik, UtneO’Brien, \& Weissberg, 2003). Self-awareness encompasses familiarity with one's own emotions and feelings, a realistic assessment of one's own competencies, skills and self-concept. Self-regulation relates to the regulation of one's own emotions in such a way that these emotions foster activity, the ability to forgo a reward for the sake of following one's own goals, and perseverance in spite of failure, standstill or regression. Social awareness includes the perception of other people's emotions and feelings, the ability to view things from other people's perspective, a positive attitude towards and active participation in different groups. Successful management of relationships includes the efficient regulation of emotions and relationships, establishing and maintaining good relationships based on cooperation, opposition when it comes to unsuitable social pressure, use of negotiation as a means of resolving conflicts and enlisting help whenever necessary. Responsible decision-making encompasses correct risk assessment, taking decisions based on a consideration of all important factors and the most probable consequences of various actions, respect for others and assuming personal responsibility for one's own decisions (Ragozzino et al., 2003). Among these, in relation to the school environment, Ellias et al. (1997, in 
Durlak et al., 2011) highlight emotional recognition and regulation, setting and achieving positive goals, taking other people's perspectives into consideration, establishing and maintaining positive relationships, dealing with interpersonal conflicts in a constructive way and taking responsible decisions.

Learning and teaching are two processes that include both the cognitive as well as the emotional and social aspects of individuals' functioning (Zins, Bloodworth, Weisseberg, \& Walberg, 2004). In this article we focus on fostering the emotional and social aspects. Research (Humphrey, 2013) has shown that, without developed emotional and social competencies, students establish a lower level of connection with school, which negatively impacts their academic achievement, behaviour and health (Blum \& Libbey, 2004; Humphrey, 2013) and can lead to ESL. Students at risk of ESL experience alienation from school, with low bonding, low engagement and frequently low academic achievement (Ellias \& Haynes, 2008; MottiStefanidi \& Masten, 2013). Social and emotional competencies are the ones that differentiate students at risk who succeed in school and students at risk who do not (Blum \& Libbey, 2004).

\section{Methodology}

The literature review entailed use of a scientific literature search (database PychArticles (EBSCO-HOST)) with the key words social and emotional learning (in the title) and early school leaving (anywhere in the text): o results; social and emotional learning (anywhere in the text) and early school leaving (anywhere in the text): o results. Social and emotional learning (in the title) and drop-out (anywhere in the text): 1 article; social and emotional learning (in the title) school (anywhere in the text): the result was 7 articles. We used articles combining social and emotional learning and academic achievement and relevant scientific monographs and handbooks on the topic of social and emotional learning (also through a backward search).

\section{SEL in school and its role in ESL}

The literature on the relationship between SEL and academic achievement in recent years cannot go without the meta-analysis conducted by Durlak et al. (2011). This meta-analysis included 213 selective and school-based universal SEL programmes and (among other things) its impact on pupils' and 
students' academic achievement. The researchers established the significant positive impacts of these types of programmes on targeted emotional-social competencies, attitude towards self, others and school. Also relevant to ESL prevention are positive attitudes to school (related to school connectedness and school engagement) and an increase in academic achievement. In the meta-analysis, only $16 \%$ of all studies considered academic achievement data. They reported an 11-percentile-point gain (on average) in academic achievement. This meta-analysis is therefore considered a starting point for many others (e.g. Schonfeld et al., 2015; Rimm-Kaufmann et al., 2014) following this direction and focusing more specifically on the relationship between SEL and academic achievement. The studies that followed (Schonfeld et al., 2015; Rimm-Kaufmann et al., 2014) confirmed that SEL enhances students' connection to school, classroom behaviour and academic achievement also when controlling for cognitive abilities (Teo, Carlson, Mathieu, Regeland, \& Sroufe, 1996, in Malecki \& Elliot, 2002) which is all related to ESL prevention.

Wilson, Gottfredson and Najaka (2001) similarly compared the efficacy of various school SEL prevention programmes in a meta-analysis of 165 studies (ranging from individual counselling to behaviour modification programmes). The main finding of their study was that school-based prevention programmes (including programmes based on SEL, especially social competency promotion) are effective in reducing ESL (among other positive outcomes). They also established that prevention programmes (SEL programmes included) are even more effective in high-at-risk groups compared to low-at-risk groups of students (Bierman, Coie, Dodge, Lochman, McManon, \& Pinderhughes, 2010; Ellias \& Haynes, 2008). This is common finding of school-level intervention programmes (Humphrey, 2013). And since ESL is present to a larger extent in low SES students (also minorities and migrants) (Reys, Ellias, Parker, \& Rosenblatt, 2014), this is an important starting point for prevention and intervention. Even though the decrease in school connectedness is normative $(40 \%-60 \%$ of students in upper secondary education have a low level of connection with school (Klem \& Connell, 2004)), it is present to a greater extent in high-risk groups SES and migrants (Castro-Olivo, 2014). A study by Rosenblatt and Maurice (2008) revealed a possible solution for ESL in the form of SEL. They monitored the effects of various SEL programmes on academic achievement in the transition from lower secondary to upper secondary education and established that, even though students are generally characterised by lower 
achievement in the transition stage, the decline is less noticeable in students who were exposed to more intense SEL programmes (the initial level of social and emotional skills was controlled) in comparison with the decline of learning achievement in students who were either exposed to less intense SEL programmes or not exposed to them at all.

Schools are especially suitable for SEL as they encompass the majority of students, without further exposing individuals at risk (Masten \& MottiStefanidi, 2009).

\section{Mechanisms linking SEL and ESL}

There are several explanations of the connections between SEL and ESL. The first set of explanations considers changes within an individual due to participation in SEL programmes. Changes within individual are related to higher academic achievement, increased social competence (students successful in school have greater social competencies) (Cook, Gresham, Kern, Barreras, \& Crews, 2008), increased emotional competence, enhanced self-efficacy and also decreased mental health problems (which can undermine the pursuit of academic activities).

In SEL, social competencies are related to: social awareness, relationship management skills, responsible decision-making and emotional competencies through to self-awareness and self-regulation (Caprara, Barbaranelli, Pastorelli, Bandura, \& Zimbardo, 20oo; Gresham, Bao Van, \& Cook 2006; Mallecki \& Elliot, 2002). Even though there is strong support for bi-directional effects (social competencies influencing academic achievement and academic achievement influencing social competencies), there is evidence that this influence is somewhat stronger in the direction social competencies influencing academic achievement (Malecki \& Elliot, 2002; Vidmar, 2011). In school, students with better social competencies are more active in the classroom, express their opinions and points of view more clearly, integrate, evaluate and accept other people's opinions, have better relationships with their peers and teachers (Cook et al., 2008; Ragozzino et al., 2003; Elliot, Frey, \& Davies, 2015; Mallecki \& Elliot, 2002) and ask for help when necessary. The latter is especially important since academic development is socially situated and relies strongly on interpersonal support (Caprara et al., 200o). The knowledge of solving interpersonal problems (identifying a problem, setting goals to address the problem, generating an appropriate response and evaluating the outcome) can also be easily transferred to solving academic problems. Teaching social skills in 
class usually includes: (i) modelling correct behaviour; (ii) eliciting an imitative response; (iii) providing corrective feedback and reinforcement; and (iv) arranging opportunities to practise the new skill (Elliot et al., 2015).

Even though social competencies and emotional competencies cannot be separated (Saarni, 2007, in: Ellias \& Haynes, 2008), emotional competencies have their own independent role in the learning process (Ellias et al. 1997, in Durlak et al., 2011) in the form of stress regulation (Duckworth \& Seligman, 2005). Emotions are a response to life events that are seen as important and as such form part of everyday school life. In the school environment, learning achievement is, in particular, related to a number of emotions that can be positive activating, positive deactivating, negative activating and negative deactivating (Pekrun, 2009). Positive emotions aid in setting learning objectives and are a basis for self-regulation mechanisms that lead to higher academic achievement (Ashby, Isen, \& Turken, 1999). On the other hand, negative emotions are linked to a decrease in achievement in school and may lead to ESL (Zeidner, 1998). In the absence of adequate coping skills, a student's attention will be directed to responding to emotional stressors at the expense of academic learning. The link between emotional stressors and academic performance is especially evident in periods of transitions. Periods of transitions are characterised by navigating a new social structure, forming new friendships, managing increased academic demands with new expectations for independence and personal responsibility (Rosenblatt \& Ellias, 2008).

Besides targeting social and emotional competencies, SEL influences students' metacognition and self-efficacy. Self-efficacy is particularly important since it is directly related to behaviour in academic tasks (e.g. effort, persistence in tasks despite obstacles and challenges) (Maddux, 2014; Ragozzino et al., 2003; Mottin-Stefanidi \& Masten, 2013). High perceived self-efficacy for self-regulated learning (related to high metacognitive abilities) contributes to better learning outcomes and increases the likelihood of remaining in school (Caprara, Fida, Vecchione, Del Bove, Veccio, \& Barbaranelli, 2008). Students with a high sense of efficacy to regulate their learning activities are likely to do better in school and are less prone to ESL (Caprara et al., 2008). Self-efficacy and self-regulation help prevent ESL independently of academic achievement (Caprara et al., 2008) and are therefore an important tool to be considered for stopping ESL. Ellias and colleagues (1997, in Durlak et al., 2011) additionally highlighted setting and 
achieving positive goals and taking responsible decisions as relevant skills for enhancing academic achievement.

SEL also fosters academic achievement by changing the characteristics of the environment (Blum \& Libbey, 2004; Hawkins et al., 2004). When teachers either implement an SEL programme or integrate SEL into their curriculum this also affects the classroom climate. The characteristics of the classroom climate linked to SEL and academic achievements are: (i) peer and adult norms that encourage high expectations and support academic achievement; (ii) good interpersonal relationships between the students and teacher, which encourage the feeling of belonging to a certain class and school; (iii) cooperative learning; and (iv) providing a safe and organised learning environment. The most commonly mentioned example of fostering SEL within the classroom is cooperative learning (Malecki \& Elliot, 2002), also supported by the theories of Vygotsky (zone of proximal development) and Bandura (social cognition theory) (Malecky \& Elliot, 2002).

The best possible combination entails changes at both the individual and school level, which lead to instant (for instance, a decrease in aggressive behaviour, emotional difficulties) and long-term positive consequences (Catalano, Berglund, Ryan, Lonczak, \& Hawkins, 2002), including for the prevention of ESL.

\section{Putting SEL into practice}

At the school level we can implement SEL by either creating a safe and encouraging learning environment or by administering already developed SEL programmes. The creation of a safe and encouraging classroom environment includes the integration of peers and parents into the building of a positive classroom and social climate (Hawkins et al., 2004). At this level, the importance of informing the school leader about the means of creating and maintaining a stimulating school climate needs to be highlighted (Rimm-Kaufman, 2014; Kozina, Rožman, Vršnik Perše, \& Rutar Leban, 2012). The second way includes structured SEL programmes. Through systematic teaching in SEL programmes students are able to learn social and emotional competencies in such a way that they can easily apply them to different situations and use them in everyday life (Zins \& Ellias, 2006).

The finding by Durlak et al. (2011) that the school staff (and not only professional help from outside the school) is also efficient in delivering SEL programmes is important for school implementation. For instance, 
teachers could implement them during their regular class activities or integrate them into the curriculum. This means that such programmes are easy to integrate into regular school work. When administered by the teacher this also improves their relationships with students. In more detail, SEL intervention can improve low academic performance (and ESL) in two ways: (i) through the professional development of educators; and (ii) by encouraging students to change their behaviour in such a way that they are able to persist in difficult academic tasks and elicit greater support from educators. When receiving support to teach social and emotional skills to their students, teachers are given the same lessons and frequently apply them to themselves, thereby preventing burn out and helping them self-regulate more efficiently (Kres \& Ellias, 2012).

When implementing a programme, the first and most important condition is that it is high in quality. Zins and colleagues (2004) defined the qualities of good SEL programmes that foster academic achievement: (i) a theoretical basis and empirically proven efficacy; (ii) learning emotional and social skills that are useful in everyday life; (iii) an orientation to the emotional and social components of learning; (iv) control, integration, unity of the programme in relation to academic achievement; (v) added instructions for efficient learning of emotional and social skills; (vi) participation of parents and the wider environment; and (vii) the presence of sustainable development, evaluations and result dissemination. The programmes also need to be evaluated and tested in different cultural settings. Europe-based research is (compared to research based in the USA) in need of a randomised controlled trial in a longitudinal setting and multi-year programmes integrated into the school curriculum (Bierman et al., 2010). A bottom-up approach (similar to the Collaborative for Academic, Social and Emotional Learning (CASEL) initiative in the USA) is advised in order to obtain an evidence-based platform of programmes that works in the EU. Based on this platform, good practice (high quality SEL programmes) could be disseminated across EU member states.

The implementation of SEL is nevertheless not a straightforward process of teachers simply administering unit after unit of an SEL programme, but needs cooperation on multiple levels (students, teachers, principals, parents). The implementation process and its quality assurance is stressed across all the research literature with the focus of research shifting from the pure effect of an SEL programme on academic achievement to how we can successfully implement the programme and sustain the effects (Kres 
\& Ellias, 2012). In the school setting, it is advised to focus on the link between programme developers and the ones actually implementing it by stressing the importance of monitoring and supporting teachers during the implementation process (Kres \& Ellias, 2012). Successful implementation should: (i) create systems that allow integration of the intervention at multiple levels of the school and across risks (e.g. being successful for high-, medium- and low-risk students); (ii) develop infrastructure for monitoring progress; and (iii) ongoing support systems or professional development that often includes coaches external to the school systems. Moreover, the interventions need to be culturally adapted to be most efficient (Castro-Olivo, 2014).

For the purpose of fostering students' comprehensive development, it is advisable to integrate efficient SEL programmes in all schools within primary, lower secondary and upper secondary education (and preschools). Since upper secondary schools have been pointed out as the most problematic (a general decline in academic achievement and school bonding has been perceived in the transition from lower secondary to upper secondary education), when it comes to ESL (Motti-Stefanidi \& Masten, 2013), the implementation of SEL programmes is most advised there. But, in the long run and taking the theoretical discussions and empirical research results into consideration, the earlier we start the more beneficial it will be.

\section{Conclusion}

There is a common fear that focussing on social and emotional skills will take time away from pure academic learning. Here it is necessary to point out that SEL does not deter schools from the fundamental teaching and learning processes and the acquisition of basic knowledge, but enables better quality and more efficient teaching and learning within schools. As far as ESL is concerned, an SEL intervention is a strong tool with effects on school connectedness, commitment and positive attitudes to school, teachers and peers and, nevertheless, also educational success. The school setting is perfect for implementing these programmes since they are less time-consuming for schools and students, while their efficiency is supported by several empirical studies regarding both the functioning of students and the functioning of the school as a whole. Most importantly, the effects (also on ESL) are largest and long term when the whole school approach is adopted, namely, when the students, their teachers and other school staff actively participate in SEL. 


\section{References}

Ashby, F. G., Isen, A. M., \& Turken, A. U. (1999). A neuropsychological theory of positive affect and its influence on cognition. Psychological Review, 106, 529-550.

Bierman, K. L., Coie, J. D., Dodge, K. A., Greenberg, M. T., Lochman, J. E., McManon, R.J., \& Pinderhughes, E. (2010). The effects of multiyear universal social emotional learning program: The role of student and school characteristics. Journal of Consulting Clinical Psychology, 78(2), 156-168.

Blum, R. W., \& Libbey, H. P. (2004). School connectedness - strengthening health and education outcomes for teenagers. Journal of School Health, 74, 229-299.

Boxer, P., Edwards-Leeper, L., Goldstein, S. E., Musher-Eizenman, D., \& Dubow, E. F. (2003). Exposure to "low-level" aggression in school: Associations with aggressive behaviour, future expectations, and perceived safety. Violence and Victims, 18(6), 691-704.

Brown, K. M., Anfara, V. A., \& Roney, K. (2004). Student achievement in high performing, suburban middle schools and low performing urban middle schools - plausible explanations for the differences. Education and Urban Society, 36(4), 428-456.

Caprara, G. V., Barbaranelli, C., Pastorelli, C., Bandura, A., \& Zimbardo, P. G. (2000). Prosocial foundations of childrens' academic achievement. Psychological Science, 11(4), 302-306.

Caprara G. V., Fida, R., Vecchione, M., Del Bove, G., Veccio, G. M., \& Barbaranelli, C. (2008). Longitudinal analyses of the role of perceived self-efficacy for self-regulated learning in academic continuance and achievement. Journal of Educational Psychology, 10o(3), 525-534.

Castro-Olivo, S. M. (2014). Promoting social-emotional learning in adolescent Latino ELLs: A study of the culturally adapted Strong Teens program. School Psychology Quarterly, 29(4), 567-577.

Catalano, R. F., Berglund, M. L., Ryan, J. A. M., Lonczak, H. S., \& Hawkins, J. D. (2002). Positive youth development in the United States: Research findings on evaluations of positive youth development programs. Prevention \& Treatment, 5, Article 15.

Cook, C. R., Gresham, F. M., Kern, L., Barreras, R. B., \& Crews, S. D. (2008). Social skills training for secondary students with emotional and/or behavioural disorders. Journal of Emotional and Behavioural Disorders, 6(3), 131-144. 
Duckworth, A. S., \& Seligman, M. E. P. (2005). Self-discipline outdoes IQ in predicting academic performance of adolescents. Psychological Science, 16, 939-944.

Durlak, J. A., Weissberg, R. P., Dymnicki, A. B., Schellinger, K. B., \& Taylor, R. D. (2011). The impact of enhancing students' social and emotional learning: A meta-analysis of school-based universal interventions. Child Development, 1, 405-432.

Ellias, M. J., \& Haynes, N. M. (2008). Social competence, social support, and academic achievement in minority, low income, urban, elementary school children. School Psychology Quarterly, 23(4), 474-495.

Elliot, S. N., Frey, J. R., \& Davies, M. (2015). Systems for assessing and improving students' social skills to achieve academic competencies. In J. A. Durlak, C. E. Domitrovich, R. P. Weissberg \& T. P. Gullotta (Eds.), Handbook of social and emotional learning - research and practice (301320). New York: The Guilford Press.

Gresham, F. M., Bao Van, M., \& Cook, C. R. (2006). Social skills training for teaching replacement behaviors: Remediating acquisition deficits in at risk students. Behavioral Disorders, 31(4), 363-377.

Hawkins, J. D., Smith, B. H., \& Catalano, R. F. (2004). Social development and social and emotional learning. In J. E. Zins, R. P. Weissberg, M. C. Wang \& H. J. Walberg (Eds.), Building academic success on social and emotional learning: What does the research say? (pp. 135-150). New York: Teachers College Press.

Humphrey, N. (2013). Social and emotional learning. London: Sage.

Jones, S. M., Brown, J. L., Hoglund, W. L. G., \& Aber, J. L. (2010). A school-randomized clinical trial of an integrated social-emotional learning and literacy intervention: impact after 1 school year. Journal of Consulting and Clinical Psychology, 78(6), 829-842.

Klem, A. M., \& Connell, J. P. (2004). Relationships matter: Linking teacher support to student engagement and achievement. Journal of School Health, 74, 262-273.

Kozina, A., Rožman, M., Vršnik Perše, T, \& Rutar Leban, T. (2012). Napovedba vrednost različnih ocen šolske klime za dosežke v raziskavah TIMSS. Pedagoška obzorja, 27(1/2), 127-144.

Kozina, A. (2015). Anksioznost in agresivnost $v$ šolah: dejavniki, trendi in smernice za zmanjševanje. Ljubljana: Pedagoški inštitut. 
Kres, J. S. \& Ellias, M. J. (2002). Consultation to support sustainability of social and emotional learning initiatives in schools. Consulting Psychology Journal: Practice and Research, 65(2), 149-163.

Maddux, J. E. (2009). Self-efficacy: The power of believing you can. In S. J. Lopez \& C. R. Snyder (Eds.), The Oxford handbook of positive psychology ( $2^{\text {nd }}$ ed.) (pp. 335-345). New York: Oxford University Press.

Malecki, C. K., \& Elliot, S. N. (2002). Children's social behaviors as predictors of academic achievement: A longitudinal analysis. School Psychology Quarterly, 17(1), 1-23.

Masten, A. S., \& Motti-Stefanidi, F. (2009). Understanding and promoting resilience in children: Promotive and protective processes in schools. In T. B. Gutkin \& C. R. Reynolds (Eds.), The handbook of school psychology (pp. 721-739). Hoboken: Wiley.

Motti-Stefanidi, F., \& Masten, A. S. (2013). School success and school engagement of immigrant children and adolescents. European Psychologist, 18(2), 126-135.

Pekrun, R. (2009). Emotions at school. In K. R. Wentzel \& A. Wigfield (Eds.), Handbook of motivation at school (575-604). New York: Routledge.

Ragozzino, K., Resnik, H., Utne-O’Brien, M., \& Weissberg, R. P. (2003). Promoting academic achievement through social and emotional learning. Educational Horizons, 81, 169-171.

Reyns, J. A., Elias, M. J., Parker, S. J., \& Rosenblatt, J. L. (2014). Promoting educational equity in disadvantaged youth: The role of resilience and social-emotional learning. In S. Goldstein \& R. B. Brooks (Eds.), Handbook of resilience in children (pp. 349-370). New York: Springer.

Rimm-Kaufman, S. E., Baroody, A. E., Curby, T., Ko, M., Thomas, J.B., Merritt, E.G., Abry, T., \& DeCoster, J. (2014). Efficacy of the responsive classroom approach - results from a 3-year longitudinal randomized controlled trial. American Educational Research Journal, 51(3), 567-603.

Rosenblatt, J., \& Maurice, J. E. (2008). Dosage effects of a preventive social-emotional learning intervention on achievement loss associated with middle school transition. Journal of Primary Prevention, 29(6), 535-555.

Schonfeld, D. J., Adams, R. E., Fredstorm, B. K., Weissberg, R. P., Gilman, R., Voyce, C., Tomlin, R., \& Speece-Lineham, D. (2015). Cluster-ramdomized trial demonstrating impact on academic achievement of elementary social emotional learning. School Psychology Quarterly, 3o(3), 406-420. 
Wilson, D. B., Gottfredson, D. C., \& Najaka, S. S. (2001). School-based prevention of problem behaviour: A meta-analysis. Journal of Quantitative Criminology, 17, 247-272.

Zins, J. E., \& Elias, M. J. (2006). Social and emotional learning. In G. G. Bear \& K. M. Minke (Eds.), Children's needs III: Development, prevention, and intervention (1-13). Bethesda, MD: National Association of School Psychologists.

Zeidner, M. (2007). Test anxiety in educational contexts: What I have learned so far. In P. A. Schutz and R. Pekrun (Eds.), Emotion in Education (165184). San Diego, CA: Academic Press.

Zins, J. E., Weissberg, R. P., Wang, M. C., \& Walberg, H. J. (Eds.). (2004). Building academic success on social and emotional learning: What does the research say? New York: Teachers College Press.

Zins, J. E., Bloodworth, M. R., Weissberg, R. P., \& Walberg, H. J. (2004). The scientific base linking social and emotional learning to school success. In J. E. Zins, R. P. Weissberg, M. C. Wang \& H. J. Walberg (Eds.), Building academic success on social and emotional learning: What does the research say? (pp. 3-22). New York: Teachers College Press. 



\section{2 .2}

\section{Developing Students' Emotional Intelligence (EI) to Help Prevent ESL}

Tina Rutar Leban and Maša Vidmar

Synopsis

Children and adolescents with better emotional skills have higher academic achievements and are less prone to ESL. Teachers can help students develop understanding, awareness and regulation of emotions from an early age. The theory and model of circular emotion reaction and the 5-step CER method can be used by teachers in this regard.

\section{Summary}

As different studies reveal, students with higher emotional competencies have better grades at school and show higher school engagement (e.g. Marquez, Martin, \& Brackett, 2006). All of these factors negatively correlate with early school leaving (ESL) and developing emotional intelligence can thus be an important prevention measure against ESL.

Programmes for developing EI in schools have been developed and implemented in schools showing important improvements in students' emotional competencies. Moreover, the results also show an improvement in academic achievements (e.g. Catalano, Berglund, Ryan, Lonczak, \& Hawkins, 2002; Greenberg et al., 2003; Clouder et al., 2008). 
In the paper, we present the Circular Emotional Reaction (CER) method for children and adolescents (Rutar Leban, 2011) as a method for guiding students through their experience of an (unpleasant) emotion. It is based on the theory of circular emotional reaction (Milivojević, 2008). The method consists of five steps: (1) helping the child to calm down; (2) asking what happened; (3) summarising and naming the emotion the child is experiencing; (4) helping the child to evaluate the situation; and (5) helping the child to think about the strategy for his/her action. The method can be used with children aged from 2 years up. At approximately the age of 15, the average teenager can understand the CER model and is able to relate it to his/her emotional experiences and thus it can be explained to them in a lecture or workshop (Rutar Leban, 2011). The method helps children and teenagers develop emotional awareness and regulation. It supports students in their understanding of perceiving, using, understanding and regulating their emotions, including (unpleasant) emotions related to school, which in consequence can lead to ESL.

Key words: emotional intelligence, emotional development, early school leaving, CER model, CER method for children and adolescents, emotional competencies, students

\section{Introduction}

Teaching and learning in schools have strong social, emotional and academic components (Zins, Weissberg, Wang, \& Walberg, 2004). Students usually learn in collaboration with their teachers, in the company of their schoolmates, and with the encouragement and support of their family environment. Emotions can facilitate or block a student's academic engagement, their attitude to school work, commitment, and ultimate academic success (Qualter, Gardner, Pope, Hutchinson, \& Whiteley, 2012). Relationships and emotional processes strongly affect how and what we learn. Schools should therefore effectively address these aspects of the educational process for the benefit of all students (Elias, 1997). Emotional skills support both the cognitive and social development of young children (Denham, 2007). Emotional knowledge predicts academic competence and task orientation in middle childhood, even when controlling for verbal ability (Izard, 2002; Izard et al., 2001). Further, poor emotional competence amongst adolescents results in school difficulties associated with academic underachievement, such as school drop-out and persistent antisocial behaviour (Gagnon et al., 
1995; Haapasalo \& Tremblay, 1994; Kochenderfer \& Ladd, 1996). Studies reveal that students with higher emotional intelligence (EI) show higher social competencies, have better grades at school and display higher school engagement (e.g. Marquez, Martin, \& Brackett, 2006). In different studies these factors negatively correlate with early school leaving (ESL) and seem to work as preventive factors for ESL (Qualter, Gardner, Pope, Hutchinson, \& Whiteley, 2012).

In this article, we present different findings in support of the importance of the relationship between students' EI and their academic results, which likely prevents ESL. Moreover, we describe a method for helping a child/student develop their EI which can be used by teachers, parents and other school professionals working with children in everyday communication.

\section{Methodology}

The article is based on a review of the literature by searching in the PsycARTICLES, PsycINFO, ERIC, Proquest, Science Direct and Google scholar search databases. Key words used in the literature search were child's emotional intelligence, emotional development, students' unpleasant emotions, emotional support in schools, student-teacher relationship, child's emotional competencies, early school leaving, school drop-out etc. For the purposes of the article, we mainly considered scientific papers and online scientific books.

\section{Models of emotional intelligence}

Recently, different models of EI have been developed. Some focus on detecting and grouping socio-emotional traits, others focus on emotional abilities, while the third group of models conceptualises emotions as multi-componential processes and concentrate on presenting and explaining these processes.

Some researchers define EI as an emotion-related cognitive ability involving the ability to perceive, use, understand and regulate emotion (Mayer \& Salovey, 1997; Mayer, Salovey, \& Caruso, 2004). These EI models are addressed as ability EI models. Others define EI as a constellation of emotion-related self-perceptions at the lower levels of personality hierarchies (Petrides, Furnham, \& Mavroveli, 2007; Petrides, Pita, \& Kokkinaki, 2007). These EI models are named trait EI models. For example, the theoretical 
model of emotional competencies developed by Bisquerra and Perez (2007) can be considered a trait EI model because it incorporates both cognitive and personality dimensions. It groups emotional competencies into five big dimensions: emotional awareness, emotional regulation, personal autonomy, social competence, and life competencies and well-being. Emotional awareness includes the capacity to be aware of one's own emotions, and the ability to detect the emotional climate in a specific context. Emotional regulation describes the capacity to use and express emotions appropriately. It requires being aware of the relationship between emotion, cognition and behaviour, and to have efficient coping strategies and capacity to self-generate positive emotions. Personal autonomy refers to a group of characteristics such as self-esteem, positive life attitude, responsibility, capacity to critically analyse social rules, capacity to look for help and resources when needed, and self-efficacy beliefs. Social competence addresses the capacity to establish positive relationships with other people. Life competencies and well-being refers to the capacity to display responsible and appropriate behaviors to solve personal, family, professional and social problems to achieve better individual and society well-being.

In comparison to trait models, the ability EI models explain EI as the capacity to process emotional information in order to enhance cognitive activities and facilitate social functioning. The ability model by Mayer and Salovey (1997) identifies four abilities linking cognitive processes with emotions and emotions with thinking. These four abilities are perceiving, using, understanding and managing emotions.

On the other hand, the model of Circular Emotional Reaction (CER model) (Milivojević, 2008) focuses on multi-componential processes that occur in the organism while experiencing emotions. It explains the sequence of processes that lead from the perception of the stimulus to the individual's reaction to it. This model's advantage is that it is easily comprehensible and can be directly used in programmes for developing the EI of teenagers and adults.

\section{EI, academic performance, learning and early school leaving}

Different studies have focused directly on the relationship between EI and academic performance. For example, correlations between EI and school grades ranged from $r=.20$ to .25 for college students (Barchard, 2003; Brackett \& Mayer, 2003; Lam \& Kirby, 2002; Parker, Creque, Barnhart, Harris Irons, Majeski, Wood, Bond, \& Hogan, 2004) and $r=.28$ to .32 for 
high school students (Parker, Summerfeldt, Hogan, \& Majeski, 2004). However, in some studies, once general intelligence and personality were controlled, the correlation between EI and school grades did not remain statistically significant (Barchard, 2003; Brackett \& Mayer, 2003; Lam \& Kirby, 2002). In their research, Marquez, Martin and Brackett (2006) concluded that in a sample of high school students EI was related to six out of nine variables of social competence and final school grades. The most robust connections were between EI and self-confidence, prosocial behaviour, and academic grades. All of these associations remained significant when general intelligence and personality were controlled.

Some authors (e.g. Berrocal \& Aranda, 2008) stress that nowadays it is necessary to educate the emotional intelligence of children. This idea of emotional education is also theoretically supported and undergoing constant revision and updates (e.g. Goleman, 1995; Mayer, Caruso, Perkins, \& Salovey, 2001; Gardner, 1993; Cherniss, 2000; Hedlund \& Sternberg, 2000, among many others). Experts in this field agree certain emotional competencies can be learnt, and that there is a need to integrate them within the early and continuous learning of students in schools (e.g. Caruso, Mayer, \& Salovey, 2002; Petrides, Frederickson, \& Furnham, 2004; Saarni, 2000).

By promoting social and emotional learning programmes in schools, educators try to minimise emotional and behavioural problems that interfere with the learning process and the development of positive peer relationships (Aber, Brown, \& Henrich, 1999). Research shows that, without intervention, students who experience difficulties in regulating their emotional experiences early in their schooling continue to experience academic, emotional and behavioural difficulties later on in life (Huffman, Mehlinger, \& Kerivan, 2000). Moreover, researchers have found that early emotional and behavioural problems lead to school failure, dropout, depression, low self-esteem, involvement in a delinquent lifestyle during adolescence, peer and teacher rejection, and vocational problems (Kamps \& Tankersley, 1996). EI has an important impact on academic success, even after personality and academic intelligence are statistically controlled (Marquez, Martin, \& Brackett, 2006; Lyons \& Schneider, 2005). Trait EI is also an important factor in the academic achievement of university and high school students (e.g., Austin, Evans, Goldwater, \& Potter, 2005; Downey, Mountstephen, Lloyd, Hansen, \& Stough, 20o8; Parker, Summerfeldt, Hogan, \& Majeski, 2004). In addition, it is an important predictor when academic success is 
conceptualised as dropout versus completion of Year 1 at university (Parker et al., 2004; Qualter et al., 2012), and exclusions versus non-exclusions in secondary school (Petrides et al., 2004; Qualter et al., 2012).

\section{Different programmes and methods for developing students' emotional competencies at school}

The findings about how social and emotional competencies influence students' academic performance led to the development of different programmes to support the development of these competencies in school. Socio-emotional programmes for elementary school students, such as Promoting Alternative Thinking Strategies (Greenberg, Kusché, \& Mihalic, 1998) and Second Step (Grossman et al., 1997), as well as compressive multi-componential programmes like Fast Track (Bierman et al., 1999) have been shown to affect several of the core socio-emotional competencies, including self-control, a moral belief system, and decision-making skills, as well as co-occurring behavioural problems. These effects were also shown to improve academic achievement and reduce early school leaving.

Several studies have investigated the impact of different programmes for developing EI (e.g. Catalano et al., 2002; Greenberg et al., 2003; Clouder et al., 2008). Their findings show an important effect of such programmes in all institutional settings from kindergarten to high school. The results of a meta-analysis (Greenberg et al., 2003) that analysed 300 social and emotional learning programmes show that such programmes produce significant improvements in students' school performance. A study by Nelis and colleagues (2009) found that young adults who participated in an intensive emotional training course significantly improved their emotional intelligence levels. This improvement was also sustained six months later. In the same study (Nelis et al., 2009), the authors detected three kinds of design problems limiting the majority of EI training programmes they examined: 1) most are not based on a solid theoretical model; 2) they only target certain dimensions of emotional intelligence; and 3) they do not use control groups. In light of these findings, the focus when developing future EI programmes and methods should be on overcoming these shortcomings. The CER method for children and adolescents presented below tries to surmount these problems. It is based on a theoretical model - the CER model (Milivojević, 2008). Moreover, it is a multi-component model that focuses and explains different dimensions 
of EI, including emotional awareness, emotional regulation, personal autonomy, social competence etc.

\section{Developing students' EI with the CER method for children and adolescents}

The CER model explains the cognitive, physiological and behavioural processes that occur in the course of a person's pleasant and unpleasant emotion. Further, it explains the processes that lead to the emotion and the processes that happen subsequently and presents them in a circular sequence. It helps someone develop emotional awareness and emotional regulation by helping them perceive, understand and manage their emotions.

The CER model (Milivojević, 2008) describes seven steps which explain different phases in the process of the emotion arising and the emotional reaction being formed: stimulus situation, perception, apperception, valorisation, physiological reaction, action tendency, thinking, action (see the figure).

The CER method for children and adolescents (Rutar Leban, 2011) was developed based on the theory and model of the CER (Milivojević, 2008). The reasoning behind the method's development was the idea that by talking to the child through the whole process of the emotional reaction while he/she is experiencing it an adult helps them raise awareness and regulation about the inner cognitive processes they experience. If the child is frequently exposed to this method, they can eventually internalise it and achieve greater emotional awareness (Rutar Leban, 2011). The method consists of five steps (having adapted the 8 steps of the original CER model): (1) helping the child to calm down; (2) asking what happened; (3) summarising and naming the emotion the child is experiencing; (4) helping the child to evaluate and valorise the situation; and (5) helping the child to think about the strategy for his/her action.

In Figure 6, the five steps of the CER method for children and adolescents are presented (in orange) relative to the CER model (in blue). 


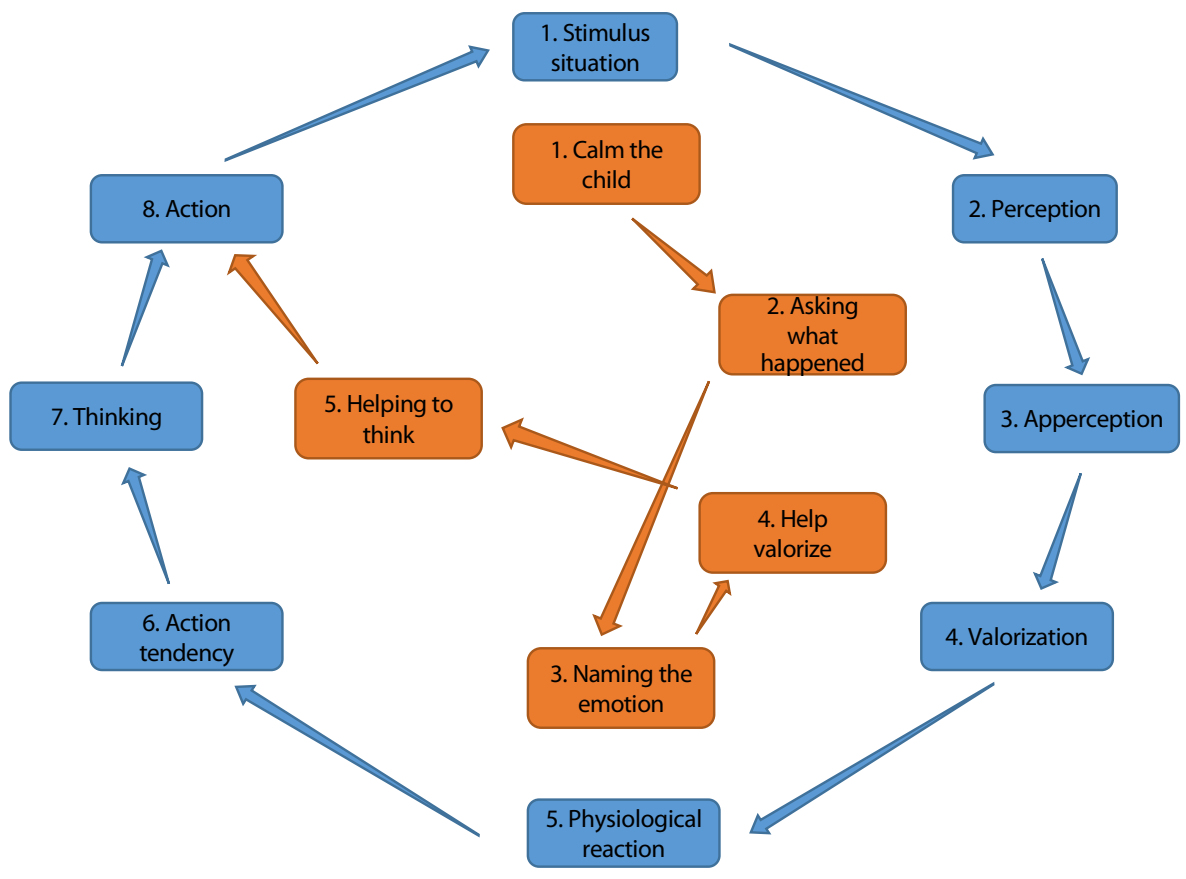

Figure 6. The CER method for children and adolescents

(Rutar Leban, 20II) based on the CER model (Milivojević, 2008)

\section{Helping the child to calm down}

If the child is experiencing a very strong emotion (this usually happens when experiencing unpleasant emotions), we must first calm them down so they are able to follow the conversation.

Example: a 13-year-old boy gets a $\mathrm{D}$ in a maths test and starts crying during the lesson. His usual/average grade in maths is C.

The teacher approaches the boy, leans closer, hugs him or caresses him if appropriate. Speaks if necessary (e.g. I see you don't feel well. I am here to help, we can talk about it. and waits for the boy to stop crying. Maybe gives him a tissue and brings him a glass of water or asks other students in the classroom to do so. Speaks if necessary (e.g. Here, use a tissue and drink some water). Focusing on drinking and cleaning the face helps the child calm down. The teacher can also suggest the boy goes to the toilet and washes his face. The movement and cold water also help in calming down. 
If the child is still too overwhelmed by the emotion and unable to participate in the conversation, the adult needs to give them the right space to be able to calm down. Sometimes, the only thing that helps a child overwhelmed by emotion to calm down is to be alone in a quiet and safe space.

\section{Asking what happened}

In this step, the adult investigates the situation (stimulus situation) in which the emotion has arisen. It is important that the adult does not assume which emotion the child is experiencing before they hear what happened. The emotion arises according to the child's perception and apperception of the situation which is unique for each individual and includes their previous experiences and beliefs about the situation. Hearing the child's understanding of the stimulus situation enables the adult to detect the emotion the child is experiencing and the reasons for this emotion to have arisen (the child's valorisation process).

Question adults ask in this step: What happened? What is bothering you? Why does this bother you?

Example:

When the boy stops crying, the teacher can start the conversation.

Teacher (T): What is bothering you? (Even though the teacher suspects the boy is crying because of the grade, they need to ensure this is really the reason and find out why this grade is so important.)

Child (C): this grade.

T: Why is this grade bothering you?

C: I don't think the grade is fair.

T: I see. Why do you think the grade is not fair?

C: Because you did not tell us that the circle circumference will also be in the test and I did not study it.

\section{Summarising and naming the emotion the child is experiencing}

When the adult has enough information and has detected the emotion the child is experiencing, they name it and thus label all the physical sensations and mental processes they are experiencing.

Example:

T: I see you are angry at me, because you think I was unfair.

C: yes. 
It is important that the adult identifies and names the right emotion. For example, we feel anger when someone unjustifiably interferes with our plans (e.g. sister A takes sister B's favourite dress without asking and sister B planned to wear it, but now she can't). We are sad when we forever lose someone (or something) very dear and close to us (e.g. a relative or a pet dies; a dear and close friend moves far away) (Milivojević, 2008). Adults tend to confuse the feeling of anger and sadness in children. Children tend to cry when they are angry because crying is their first tool for expressing an unpleasant emotion and they are still learning the right way to express it. On the other hand, adults usually cry only when they are sad. That is why adults link crying with sadness and tend to ask crying children why they are sad. In this way, they communicate the wrong message to children. That is why it is important to investigate the child's perception and apperception before making assumptions about their emotions. Moreover, it is important to be able to define different emotions.

\section{Helping the child to evaluate and valorise the situation}

In this step, the adult summarises the child's valorisation of the stimulus situation. The adult describes the importance and significance of the situation for the child.

Example:

T: I see you really value fairness in a relationship. I understand that this is why you decided to be angry at me.

Hearing the valorisation of the stimulus situation in this way helps children understand that it is their decision which starts the emotional reaction. It gives them control over their emotions and thus shows them they can regulate them successfully.

\section{Helping the child to think about the strategy for his/her action}

The last step includes helping the child think about the actions they can take to stop the emotional reaction they are feeling. The a dult's role in this step is to encourage the child to elaborate different strategies that can lead to calming the emotional reaction down and establishing the previous equilibrium and the natural, calm inner feeling. According to the CER model, when experiencing an unpleasant emotion we have three possible strategies for stopping the emotion: 
- $\quad$ changing our own valorisation of the situation, e.g. changing our own view and understanding of the stimulus situation;

- changing the other person's behaviour, e.g. changing the view and understanding of the other person involved and make them behave according to our own ideas; and

- changing or avoiding the environment in which the stimulus situation is constantly occurring.

The role of the adult in this step is to help the child understand they have all these possibilities for acting. The adult also guides the child through the process of understanding which strategy is the most effective in this specific situation. It depends on the maturity of the child how much the adult will direct and guide this process. When the child is still very young ( 2 to 5 years old), the adult talks them through the whole process. Children older than 10 years and familiar with this method can do the thinking almost by themselves; they just need the initial direction.

Example:

T: What do you think you can do that will change how you feel?

Table 2. EI dimensions developed with the CER method for children and adolescents

Steps of the CER method for children and adolescents

Step 1: Helping the child calm down

Step 2: Asking what happened

Step 3: Summarising and naming the emotion the child is experiencing

Step 4: Helping the child to evaluate and valorise the situation

Step 5: Helping the child to think about the strategy for his/her action
EI dimensions developed

Emotional regulation: learning new strategies to calm emotional reactions

Emotional awareness: understanding the situation in which the emotion arises

Emotional awareness: recognition of emotion, naming emotions

Emotional awareness: understanding why emotion arises

Personal autonomy: learning about yourself, own values

Social competence: learning why others can feel a different emotion in the same situation

Emotional regulation: learning strategies to stop the emotional reaction

Social competence: learning the strategies to communicate emotions to others

Personal autonomy: learning to plan and evaluate different possibilities

Teacher can help the boy understand that he has three different possibilities. He can ask other students if they knew about the circle circumference 
being part of the test and try to understand why he did not know (changing his own view and understanding of the stimulus situation). He can also try to convince the teacher to change his grade (changing the other person's behaviour). Or he can find a way to avoid the teacher he thinks is unfair by changing class, or even the school, maybe skipping school or even dropping out of school (changing or avoiding the environment in which the stimulus situation is constantly occurring).

As already emphasised, the CER method for children and adolescents helps students develop different dimensions of EI, including emotional awareness, emotional regulation, personal autonomy, social competence etc. In the table below, we define the EI dimensions children and adolescents develop in each of the method's five steps.

\section{Application of the CER method for children and adolescents in pedagogical practice and ESL prevention}

The method can be used with children aged from 2 years up. Teachers and other adults who work with students can use this method in their everyday communication with children and adolescents whenever they experience an unpleasant emotion. With younger children, the method can also be applied while reading stories where a literary character is experiencing unpleasant emotions. The teacher can use the method to guide students through the understanding of the emotional experience of the character in the book. In the same way, the method can be used with teenagers, for example by analysing an emotional experience that really happened to a teenager or using a book appropriate for teenagers. The method helps children and teenagers develop their emotional awareness and regulation. It supports students in their understanding of perceiving, using, understanding and regulating emotions. Further, using this method especially helps teenagers who have less social and emotional support in their families and usually have less motivation to participate in ESL programmes that are not part of the obligatory school lessons. These teenagers are also more at risk for behavioural problems, lower achievements and ESL (Gagnon et al., 1995; Haapasalo \& Tremblay, 1994; Kochenderfer \& Ladd, 1996). Supporting the development of children's and adolescents' social and emotional skills and competencies is an important part of ESL prevention in schools.

At approximately the age of 15 , the average teenager can understand the CER model if we explain it to them by showing them the model. They 
are able to relate the model to their emotional experiences and it can thus be used in a workshop or other activities on EI in the school environment (Rutar Leban, 2011).

\section{Conclusions}

Studies show that the relationships and emotional processes students experience in school strongly affect how and what they learn (Elias et al., 1997). Emotional competencies support the cognitive and social development of young children (Denham, 2007) and predict academic achievement (Izard, 2002; Izard et al., 2001). Thus, the development of social and emotional competencies has become an important goal of the education system.

Different ESL programmes have been developed and implemented in schools to help students improve in this area. The impact of these programmes has been proven to be positive (e.g. Catalano et al., 2002; Greenberg et al., 2003; Clouder et al., 2008), showing significant improvements in students' school performance (Greenberg et al., 2003).

Besides SL programmes that are usually implemented in schools outside the basic compulsory curriculum, there are methods that can be used during everyday interaction with students and can support students' emotional and social development. One of these methods is the CER method for children and adolescents (Rutar Leban, 2011) that was developed based on the Circular Emotional Reaction theory (Milivojević, 2008). While using this method adults guide children and adolescents through their experience of an unpleasant emotion and help them raise emotional awareness and regulation through the following steps: 1 . Helping the child calm down; 2. Asking what happened; 3. Summarising and naming the emotion the child is experiencing; 4. Helping the child to evaluate and valorise the situation; and 5. Helping the child to think about the strategy for his/her action. Especially with teenagers who already have behavioural and academic problems in school and thus experience many unpleasant emotions in the school environment, this method can help them understand why they feel this way and how they can react to stop the emotional reaction. Better emotional competencies and skills can help adolescents have better academic achievements (Izard, 2002) and represent an important preventive factor for ESL and persistent antisocial behaviour (Gagnon et al., 1995; Haapasalo \& Tremblay, 1994; Kochenderfer \& Ladd, 1996). 


\section{References}

Aber, J. L., Brown, J. L., \& Henrich, C. C. (1999). Teaching conflict resolution: An effective school-based approach to violence prevention. Research Brief.

Austin, E. J., Evans, P., Goldwater, R., \& Potter, V. (2005). A preliminary study of emotional intelligence, empathy and exam performance in first year medical students. Personality and Individual Differences, 39(8), 1395-1405.

Barchard, K. A. (2003). Does emotional intelligence assist in the prediction of academic success? Educational and Psychological Measurement, 63(5), $840-858$.

Bechara, A., Tranel, D., \& Damasio, H. (2000). Characterization of the decision-making deficit of patients with ventromedial prefrontal cortex lesions. Brain, 123(11), 2189-2202.

Berrocal, P. F., \& Aranda, D. R. (2008). La inteligencia emocional en la educación. Electronic Journal of Research in Educational Psychology, 6(15), 421-436.

Bierman, K. L., Coie, J. D., Dodge, K. A., Greenberg, M. T., Lochman, J. E., McMahon, R. J., \& Pinderhughes, E. E. (1999). Initial impact of the Fast Track prevention trial for conduct problems: II. Classroom effects. Journal of Consulting and Clinical Psychology, 67(5), 648-657.

Bisquerra, R., \& Pérez, N. (2007). Las competencias emocionales. Educación $X X I, 10,61-82$.

Brackett, M. A., \& Mayer, J. D. (2003). Convergent, discriminant, and incremental validity of competing measures of emotional intelligence. Personality and Social Psychology Bulletin, 29(9), 1147-1158.

Caruso, D. R., Mayer, J. D., \& Salovey, P. (2002). Relation of an ability measure of emotional intelligence to personality. Journal of Personality Assessment, 79(2), 306-320.

Catalano, R. F., Berglund, M. L., Ryan, J. A., Lonczak, H. S., \& Hawkins, J. D. (2002). Positive youth development in the United States: Research findings on evaluations of positive youth development programs. Prevention \& Treatment, 5(1), 15 a.

Cherniss, C. (200o, April). Emotional intelligence: What it is and why it matters. In Annual Meeting of the Society for Industrial and Organizational Psychology, New Orleans, LA (Vol. 15). 
Clouder, C., Dahlin, B., Diekstra, R., Berrocal, P. F., Heys, B., Lantieri, L., \& Paschen, H. (2008). Social and emotional education: An international analysis. Santander: Fundación Marcelino Botín. Retrieved 7 July 2010.

Denham, S. A. (2007). Dealing with feelings: How children negotiate the worlds of emotions and social relationships. Cognition, Brain, Behavior, 11(1), $1-48$.

Downey, L. A., Mountstephen, J., Lloyd, J., Hansen, K., \& Stough, C. (2008). Emotional intelligence and scholastic achievement in Australian adolescents. Australian Journal of Psychology, 6o(1), 10-17.

Elias, M. J. (1997). Promoting social and emotional learning: Guidelines for educators. Ascd.

Gagnon, C., Craig, W. M., Tremblay, R. E., Zhou, R. M., \& Vitaro, F. (1995). Kindergarten predictors of boys' stable behavior problems at the end of elementary school. Journal of Abnormal Child Psychology, 23(6), 751-766.

Gardner, H. (1993). Frames of mind: The theory of multiple intelligences. New York: Basic Books.

Goleman, D. P. (1995). Emotional intelligence: Why it can matter more than IQ for character, health and lifelong achievement. New York: Bantam Books.

Greenberg, M. T., Kusche, C. A., \& Mihalic, S. F. (1998). Blueprints for violence prevention: Book Ten: Promoting alternative thinking strategies. Boulder, CO: Center for the Prevention of Violence.

Greenberg, M., Weissenberg, R., O’Brien, U., Zins, J., Fredericks, L., Resnik, H., \& Elias, M. (2003). Enhancing school-based prevention and youth development through coordinated social, emotional, and academic learning, American Psychologist, 58(6/7), 466-474.

Grossman, D. C., Neckerman, H. J., Koepsell, T. D., Liu, P. Y., Asher, K. N., Beland, K., ... \& Rivara, F. P. (1997). Effectiveness of a violence prevention curriculum among children in elementary school: A randomized controlled trial. Jama, 277(20), 1605-1611.

Haapasalo, J., \& Tremblay, R. E. (1994). Physically aggressive boys from ages 6 to 12: Family background, parenting behavior, and prediction of delinquency. Journal of Consulting and Clinical Psychology, 62(5), 1044.

Hedlund, J., \& Sternberg, R. J. (200o). Too many intelligences? Integrating social, emotional, and practical intelligence in Bar-On, R. (Ed); Parker, J. D. A. (Ed). (200o). The handbook of emotional intelligence: Theory, development, assessment, and application at home, school, and in the workplace, (pp. 136-167). San Francisco, CA, USA: Jossey-Bass, xv, 528 pp. 
Huffman, L. C., Mehlinger, S. L., Kerivan, A. S., Cavanaugh, D., Lippitt, J., \& Moyo, O. (2000). In Peth. Pierce, R. (ed.). A good beginning: Sending America's children to school with the social and emotional competencies they need to succeed. The Child Mental Health Foundations and Agencies Network.

Izard, C., Fine, S., Schultz, D., Mostow, A., Ackerman, B., \& Youngstrom, E. (2001). Emotion knowledge as a predictor of social behavior and academic competence in children at risk. Psychological Science, 12(1), 18-23.

Izard, C. E. (2002). Translating emotion theory and research into preventive interventions. Psychological Bulletin, 128(5), 796.

Kamps, D. M., \& Tankersley, M. (1996). Prevention of behavioral and conduct disorders: Trends and research issues. Behavioral Disorders, 41-48.

Kochenderfer, B. J., \& Ladd, G. W. (1996). Peer victimization: Cause or consequence of school maladjustment? Child Development, 67(4), 1305-1317.

Lam, L. T., \& Kirby, S. L. (2002). Is emotional intelligence an advantage? An exploration of the impact of emotional and general intelligence on individual performance. The Journal of Social Psychology, 142(1), 133-143.

Lyons, J. B., \& Schneider, T. R. (2005). The influence of emotional intelligence on performance. Personality and Individual Differences, 39(4), 693-703.

Márquez, P. G. O., Martín, R. P., \& Brackett, M. A. (2006). Relating emotional intelligence to social competence and academic achievement in high school students. Psicothema, 18(Suplemento), 118-123.

Mayer, J. D., Perkins, D. M., Caruso, D. R., \& Salovey, P. (2001). Emotional intelligence and giftedness. Roeper Review, 23(3), 131-137.

Mayer, J. S., \& Salovey, Y. P.(1997): What is emotional intelligence. Emotional Development and Emotional Intelligence: Implications for Educators, 3-31.

Mayer, J. D., Salovey, P., \& Caruso, D. R. (2004). Emotional intelligence: Theory, findings, and Implications. Psychological Inquiry, 15(3), 197-215.

Milivojević, Z. (2008). Emocije - razumevanje čustev v psihoterapiji [Emotions - understanding emotions in psychotherapy.] Belgrade: Psihopolis.

Nelis, D., Quoidbach, J., Mikolajczak, M., \& Hansenne, M. (2009). Increasing emotional intelligence: (How) is it possible? Personality and Individual Differences, 47(1), 36-41.

Parker, J. D., Creque, R. E., Barnhart, D. L., Harris, J. I., Majeski, S. A., Wood, L. M., ... \& Hogan, M. J. (2004). Academic achievement in high school: Does emotional intelligence matter? Personality and Individual Differences, 37(7), 1321-1330. 
Parker, J. D., Summerfeldt, L. J., Hogan, M. J., \& Majeski, S. A. (2004). Emotional intelligence and academic success: Examining the transition from high school to university. Personality and Individual Differences, 36(1), 163-172.

Petrides, K. V., Frederickson, N., \& Furnham, A. (2004). The role of trait emotional intelligence in academic performance and deviant behavior at school. Personality and Individual Differences, 36(2), 277-293.

Petrides, K. V., Furnham, A., \& Mavroveli, S. (2007). Trait emotional intelligence: Moving forward in the field of EI. In Matthews, G., Zeidner, M., Roberts, R. D. (eds.), Science of Emotional Intelligence: Knowns and Unknowns (pp. 151-166). New York, Oxford University Press.

Petrides, K. V., Pita, R., \& Kokkinaki, F. (2007). The location of trait emotional intelligence in personality factor space. British Journal of Psychology, 98(2), 273-289.

Qualter, P., Gardner, K. J., Pope, D. J., Hutchinson, J. M., \& Whiteley, H. E. (2012). Ability emotional intelligence, trait emotional intelligence, and academic success in British secondary schools: A 5-year longitudinal study. Learning and Individual Differences, 22(1), 83-91.

Rutar Leban, T. (2011). Čustvena inteligentnost in nenasilna komunikacija. [Emotional intelligence and nonviolent communication.] In Rutar Leban, T. (ur.). Vzgoja za nenasilje: priročnik za starše [Education for nonviolence: handbook for parents.] Nova Gorica: delovni odbod "Nova Gorica otrokom prijazno Unicefovo mesto".

Saarni, C. (200o). The social context of emotional development. Handbook of Emotions, 2, 306-322.

Zins, J. E., Bloodworth, M. R., Weissberg, R. P., \& Walberg, H. J. (2004). The scientific base linking social and emotional learning to school success. Journal of Educational and Psychological Consultation 17(1-2), 191-210. 



\section{2 .3}

\section{The Student's Academic Self-concept and its Link with ESL}

Tina Rutar Leban

\section{Synopsis}

Supporting the development of a positive academic self-concept is an important factor in preventing ESL. In order to support its development, teachers should pay attention to how they provide feedback to their students (i.e. negative feedback should only be directed to the behaviour/achievement/result and never to the person).

\section{Summary}

Self-concept is defined as a person's conception of themselves (Bong \& Skaalvik, 2003), which includes the set of characteristics, abilities, attitudes and values an individual believes defines them. It is multidimensional and contains an individual's perception of a variety of areas (Shavelson, Hubner, \& Stanton, 1976). The academic self-concept forms part of the self-concept that includes one's characteristics, abilities, attitudes and values that refer to the academic context one finds oneself in (Bong \& Skaalvik, 2003).

Empirical and theoretical evidence shows that academic self-concept may be associated with ESL. For example, ESLers and underachievers are identified as having lower self-esteem, a lower academic self-concept and a lower perception of self-efficiency than other students (PPMI, 2014). Other studies reveal the importance of a positive self-concept for achieving good results at school (Schunk, 2003), 
itself recognised as an important preventive factor for ESL (e. g. Battin-Pearson et al., 2000; Lan \& Lanthier, 2003).

Since one's academic self-concept primarily develops in the school environment (or similar environments) relative to teachers' feedback to a student's school achievements (Bean \& Lipka, 1986; Milivojević, 2004) as well as the teacher-student relationship, it is important for teachers to understand the development of (academic) self-concept and their role as students' significant others in it. In terms of communicating negative feedback, it is paramount that teachers recognise the difference between criticism of behaviour and criticism of the person (Milivojević, 2004). Negative feedback should only be directed to the behaviour/achievement/result and never to the individual involved.

Key words: ESL, self-concept, academic self-concept, school achievements, motivation for school work

\section{Introduction}

School achievement and success such as high grades and school completion do not take place in a vacuum. To achieve success at school, students must not only value school but believe they are capable of achieving success. The influence of psychological factors like self-concept, motivation, and readiness to take on challenges are important factors that predict school success or ESL (e.g. Battin-Pearson et al., 2000; Lan \& Lanthier, 2003).

Typically, children enter the middle-childhood years very optimistic about their ability to master a wide array of tasks, including their schoolwork (Eccles, Wigfield, \& Schiefele, 1998; Parsons \& Ruble, 1977; Stipek, 1984). When asked how good they are at reading, maths etc., most first graders rank themselves near the top of the class, and there is essentially no relationship between their ability self-ratings and actual performance levels (Nicholls, 1979; Wigfield, 1997). By age 10, however, students are typically less optimistic, and there is a much stronger correlation between their self-ratings and actual performance. Their academic self-concepts and expectations of success tend to decline during elementary school. This decline in their academic self-concept and motivation for school continues through adolescence, and may lead students to avoid certain school subjects or drop out of school altogether.

This article explores various aspects of the relationship between students' academic self-concept and ESL risk factors. It explains the 
development of academic self-concept and presents the role teachers play in it. Moreover, it offers some practical suggestions for teachers to use in pedagogical practice. It includes some examples and suggestions for teachers to consider while giving students feedback on their school work and achievements so as to support the development of a healthy academic self-concept.

\section{Methodology}

The article is based on a review of the literature entailing searches in the PsycINFO, ERIC, Proquest, Science Direct and Google scholar, Proquest Dissertation \& Theses Global databases. Key words used in the literature search were predictors for ESL, self-concept, academic self-concept, self-efficacy, school achievements, motivation for school work, school dropout etc. For the purposes of the article, we mainly considered scientific papers and some scientific books available online.

\section{Development of self-concept and academic self-concept}

Self-concept is defined as a person's conception of themselves (Bong \& Skaalvik, 2003). It includes the set of characteristics, abilities, attitudes and values a person believes defines them. Although self-concept can be viewed and measured as a general construct, studies show it is multidimensional and that it should be defined and measured in different areas of life, such as academic self-concept or self-concept with respect to reading etc. (Bong \& Skaalvik, 2003).

The development of self is a process of various interrelated and interacting developments or phases occurring in an individual's life. Individuals are not born with a self-concept or an awareness of self-perception. It must be learned and developed implicitly and indirectly throughout one's life (Hattie, 1992). Frey and Carlock (1983) suggested that many modalities of learning influence the development of self-concept, including direct experience, verbal/nonverbal human interaction, social learning through parenting, schooling, and various group memberships. The social context of the child is considered to exert the greatest influence on development of the child's self-concept (Bandura, Barbaranelli, Caprara, \& Pastorelli, 1996; Shavelson et al., 1976). The self-concept builds on the child's experience and learning history and is influenced by important people close to the child (Nalavany \& Carawan, 2012; Shavelson et al., 1976). Some researchers argue that it is the parents who have the primary influence over development of 
the child's self-concept (Emler, 2001), while others contend that friends and teachers have a bigger impact on developing an individual student's self-image (e.g. Burnett \& Demnar, 1996; Burns, 1982; Glazzard, 2010; Humphrey, 2003; Troia, Shankland, \& Wolbers, 2012).

Learning about oneself begins with physical interactions and continues through behavioural and social development. Finally, it is psychologically internalised. During infancy, the initial mother-infant relationship provides the responses to and acceptance of the infant by the mother. This internalisation of the care, love and feelings of significant others during infancy becomes part of the internal structure of the self-concept. It influences both the initial and subsequent levels of self-concept (Bowlby, 2008). Throughout childhood, the child begins to interact more and more with his/her social environment. Their level of social competence is defined by obvious success and failure. More precisely, it is not the failure to achieve per se that builds a negative self-concept; it is the way significant people in the child's life react to such failure and interpret it that defines the outcome as a failure and thus builds the negative self-concept (Pollard \& Pollard, 2014).

Middle childhood is the period when the initial rapid physical growth and physical advancement begins to slow down (Sols \& Mullen, 1982). The child's social experiences expand to the school environment and significant others begin to include teachers and other adults. Self-concept in middle childhood relates especially to performance in school work tasks and in games with friends (Bean \& Lipka, 1986). This is also the period when the academic self-concept starts to develop. The academic self-concept is part of the self-concept that includes one's characteristics, abilities, attitudes and values that refer to one's academic context in comparison to academic standards and peers (Bong \& Skaalvik, 2003). In their academic context, students primarily define themselves according to the feedback they receive from the teacher (and wider school environment) about their academic achievements and other school-related behaviour. Establishing a healthy academic self-concept is especially important at the beginning of schooling, when students first receive the teacher's feedback about their achievements. However, each new teacher the student meets becomes an opportunity to obtain different feedback (perhaps feedback about a new school subject) and thus improve or expand their academic self-concept. At the same time, each relationship with a new teacher also brings the risk 
of negatively influencing the academic self-concept, especially in academic subjects or areas new to the student.

In late childhood and adolescence, the social context and the school environment become even more important factors that influence the development of self-concept. The school structure changes from a self-contained class with a limited number of students and guided instruction to a more open schedule of classes with a bigger number of students and/or teachers and independent instruction. Peer interactions become more important and intense. This all brings pre-adolescents face to face with some important changes that then lead to changes in or threats to their self-concept and academic self-concept (Hattie, 1992). Moreover, when adolescents change schools and move to high school their academic self-concept encounters a fresh challenge: it is being re-evaluated in another context, in their eyes possibly also a more serious and important context than elementary school (Bean \& Lipka, 1986; Hattie, 1992). It is thus even more important for teachers who teach adolescents to understand how they can support the development of a healthy academic self-concept among their students. This explains why it is even more important to pay attention to students' academic self-concept in the periods of pre-adolescence and adolescence.

\section{Academic self-concept and risk factors for ESL}

Students' perceptions of themselves and their abilities are an important component of achievement motivation and a predictor of student engagement in school (National Research Council, 2003). Different studies have examined a number of self-perceptions and their relationship to high school ESL and graduation. All of these perceptions are constructed as composite measures based on student responses to questions about their academic self-concept.

Academic self-concept is often shown to be an important precursor of school engagement, itself shown to be a predictor of ESL. More specifically, a positive academic self-concept results in higher levels of task engagement (Eccles, 1983). This relationship between academic self-concept and school engagement also forms part of the conceptual model of high school performance (Rumberger \& Rotermund, 2012) where self-perception (as an overall term for self-concept and self-esteem) is considered a precursor of engagement and engagement is viewed as a precursor of student achievement, which in turn can influence subsequent attitudes, including self-perception, 
and is also regarded as an important ESL predictor (e.g. Battin-Pearson et al., 2000; Lan \& Lanthier, 2003).

Different studies have also established a correlation between academic self-concept and academic achievement (e.g. Helmke \& van Aken, 1995; Skaalvik \& Hagtvet, 1990), which is also considered an important predictor of ESL (e.g. Battin-Pearson et al., 2000; Lan \& Lanthier, 2003). Moreover, research reveals the importance of a positive self-concept for achieving good results at school (Schunk, 2003). It is also shown that students with various degrees of self-conception exhibit different cognitive, social and emotional behaviour at school (Bong \& Skaalvik, 2003), such as students' academic engagement (e.g. Skaalvik \& Rankin, 1996; Skinner, Wellborn, \& Connell, 1990), goal-setting (Bong, 2001; Skaalvik, 1997), task choice (Bandura \& Schunk, 1981; Pajares \& Miller, 1995), persistence and effort (e.g. Skaalvik \& Rankin, 1995), intrinsic motivation (Gottfried, 1990; Harter, 1982; Mac Iver, Stipek, \& Daniels, 1991; Meece, Blumenfeld, \& Hoyle, 1988; Skaalvik, 1997; Skaalvik, \& Rankin, 1996), strategy use (Pintrich \& De Groot, 1990; Wolters \& Pintrich, 1998), performance and achievement (e.g. Bandura, Barbaranelli, Caprara, \& Pastorelli, 1996, Skaalvik \& Vals, 1999) and even career selection (e.g. Bets \& Hackett, 1981, 1983).

Cognitive, social and emotional behaviour

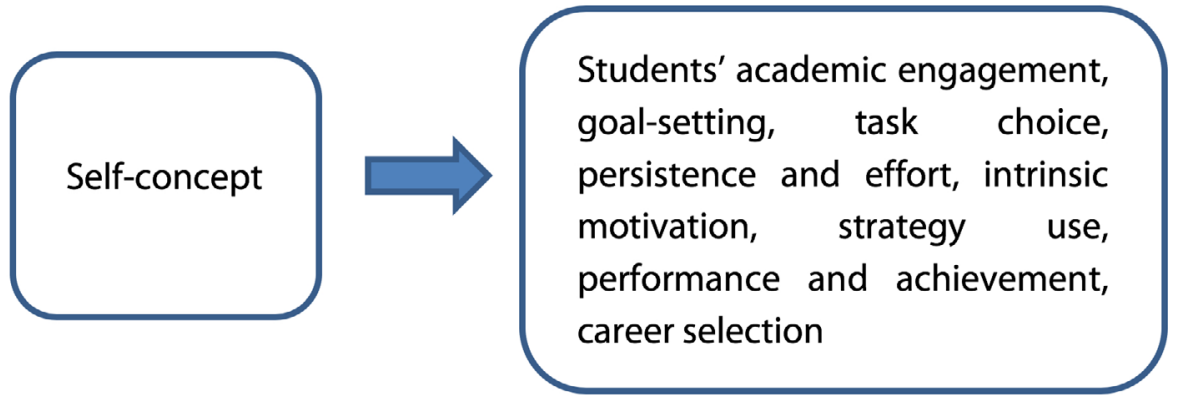

Figure 7. The relationship between self-concept and students' cognitive, social and emotional behaviour

A recent study (PPMI, 2014) identifies the competence profiles of ESLers and underachievers. The study results show that ESLers tend to have low self-esteem, a low academic self-concept and a lower perception of self-efficacy. Other studies reveal that self-concept plays a significant role in enhancing students' intrinsic motivation, positive emotion, and performance 
- all shown in different studies to be important factors for preventing ESL (e.g. Battin-Pearson et al., 2000; Lan \& Lanthier, 2003).

\section{Developing a healthy academic self-concept at school}

At school, the teacher is an important adult for students. Students' academic self-concept is built through the teacher-student relationship, thus the teacher has an important impact on developing the students' healthy academic self-concept that will support their academic development (Bean \& Lipka, 1986; Milivojević, 2004; Rutar Leban, 2011) and act as a factor preventing ESL. It is hence important for teachers to understand their role in developing students' academic self-concept. Moreover, it is important they learn how to efficiently and supportively give their students feedback about their academic achievements in order to help them build a healthy academic self-concept (Milivojević, 2004).

Milivojević (2004) explains that to support the development of an appropriate (academic) self-concept the child (student) must learn to distinguish between himself as a person and his/her behaviour, mistakes/failures, successes etc. The child (student) needs to understand that mistakes and failures are an inevitable part of life, but do not define the person. Students must accept that mistakes are a necessary element of learning and that a person makes mistakes throughout their whole life. He argues that the verbal communication between the significant other and the child is absolutely crucial in this process. He explains that when a child (student) makes a mistake, the adult must target their criticism at the child's (student's) behaviour, not at them as a person. It is not the failure to achieve that produces low self-esteem and a negative (academic) self-concept. As already stated, it is the way significant people in the child's life react to such failure that defines their (academic) self-concept (Pollard \& Pollard, 2014).

According to Milivojević (2004), clearly distinguishing between the child's (student's) behaviour and them as a person supports a positive and productive (academic) self-concept even when the child's (student's) behaviour/achievement is not as expected. This is important for the child's (student's) motivation. It is only if children (students) believe they are capable of producing better behaviour/results/achievements (if they have a healthy, positive and realistic self-concept) that they will be motivated to put greater effort into changing their inappropriate behaviour or achieving improved results (Milivojević, 2004). If they receive negative feedback addressed to them as a person (e.g. "You are slow and inaccurate in multiplying"), they 
start to believe they are incapable and do not see any sense in trying harder since there is no 'capability within' that can be further developed through practising/additional effort. If teachers understand these basic rules in communicating feedback on students' work, they can easily apply them in the classroom and thereby help students develop a healthy academic self-concept and consequently prevent ESL.

Below are some examples that help clarify the difference between criticism addressed to the student's behaviour and criticism addressed to a student as a person. The examples also include an additional explanation to help students distinguish between the person and the behaviour.

Example 1: A student (secondary school/high school) has prepared a science project and is presenting it to the class. His presentation is not at the best of his capabilities. In term of grades, he gets a $C$, although he is mostly used to receiving $A$ and $B$.

Criticism addressed to the behaviour: Your presentation lacked a bit of clarification at times and I missed greater interaction with the audience.

Criticism addressed to the child as a person: You were boring and not clear enough. (unsuitable for academic self-concept)

To state the difference between the student as a person and their mistake/behaviour even more clearly, the teacher should also explain the difference to the student.

Criticism addressed to the behaviour with an explanation: From my point of view, your presentation lacked a bit of clarification at times and I missed greater interaction with the audience. When we present something, we usually think about the audience we will be presenting to and prepare the presentation from their perspective, trying to engage them as much as possible and make it as clear as possible for them. I believe you are capable of doing this and trust that you will be able to improve your presentation next time.

In this way, the adults (teachers) criticise the inappropriate behaviour/ result/lower achievement, but also communicate to the children that they can produce the appropriate behaviour/higher achievement because they are capable of doing that. The message the student receives to help build his/her (academic) self-concept is 'I am capable of making a better presentation, I just made a mistake and this mistake does not define me'. As already explained, it is important that the teacher affirms the difference 
between the student as a person and their achievement/mistake/behaviour by explaining this difference to the student.

Example 2: A student ( $3^{\text {rd }}$ grade of primary school) was very slow in doing the multiplication table and made 10 mistakes in 20 equations.

Criticism addressed to the behaviour: Your results with the multiplication table today show you solved half the equations correctly and the time you needed for solving was slower than yesterday.

Criticism addressed to the child as a person: You are slow and inaccurate in multiplying. (unsuitable for academic self-concept)

To help the student understand the difference between them as a person and their result in multiplying, the teacher should explain even further.

Criticism addressed to the behaviour with an explanation: I noticed that your results with the multiplication table today show you solved half the equations correctly and the time you needed for solving was slower than yesterday. I know you can multiply and I believe if you put more effort into it tomorrow you can solve 15 equations correctly and improve your solving time.

The same rules also apply when communicating to a student criticism of their inappropriate behaviour that does not include their academic performance. In this case, the teacher's feedback does not impact the student's academic self-concept but still has an impact on the student's general self-concept (e.g. the "relational" self-concept - the student's conception of their own relational competencies).

Example 3: A 12-year-old girl responds rudely to a schoolmate

Criticism addressed to the behaviour: Your response was rude.

Criticism addressed to the child as a person: You were rude. (unsuitable for self-concept)

If the teacher wants to pinpoint the difference between the person and the mistake/behaviour, they will explain the difference to the student.

Criticism addressed to the behaviour with an explanation: From my perspective, your response to your schoolmate was a bit rude. Usually, we use more polite ways in communication. I believe you are a polite girl and I trust that next time you will be able to find a more polite answer for your schoolmate. 
In this way, we criticise the inappropriate behaviour but also communicate to the student that they can produce more appropriate behaviour because they are capable of doing that. The message the girl receives for her self-concept is 'I am capable of a polite response, I just made a mistake and this mistake does not define me or my relational competencies'.

Since different studies show that a negative academic self-concept has an important impact on ESL (e.g. PPMI, 2014; Rumberger \& Rotermund, 2012), we believe that understanding these principles of giving negative feedback and applying them in the everyday routine will help teachers better support their students, especially adolescent lower achievers who have been shown to be most at risk for ESL (e.g. Battin-Pearson et al., 200o; Lan \& Lanthier, 2003). Low achievers are students who every day receive the most negative feedback from teachers. When they enter adolescence, they already have a negative academic self-concept. By establishing appropriate communication and a good relationship with teachers, the teachers can help them change their negative academic self-concept into a more realistic and functional one. This change may be crucial to their decision to stay at or leave school.

\section{Conclusions}

Self-concept develops through our life experiences in relationship with the environment, specifically in our relationship with significant others in our environment (Nalavany \& Carawan, 2012). It includes the set of characteristics, abilities, attitudes and values an individual believes defines them. It contains an individual's perception in a variety of areas (Shavelson, Hubner, \& Stanton, 1976). Academic self-concept forms part of one's self-concept that covers the area of academic education. It encompasses one's characteristics, abilities, attitudes and values that refer to the academic context one finds oneself in.

Academic self-concept is developed in the academic/school environment in which the teacher represents a significant other for the students. Therefore, teachers have an important role to play in developing their students' academic self-concept. Their reactions to their students' school-related behaviour and achievements, and their verbal and non-verbal feedback on the students' work provide basic information on which the students can build their academic self-concept (Milivojević, 2004; Rutar Leban, 2011).

This explains why it is important for teachers to understand how they can give appropriate feedback about school work to students so as to support 
the development of a healthy academic self-concept. It is vital for teachers to recognise the difference between criticism of behaviour and criticism of the person (Milivojević, 2004). Negative feedback should only be given visà-vis the behaviour/achievement/result and never the person. Moreover, while communicating feedback, teachers should help the students understand the difference between them as persons and their behaviour/achievements/successes while also providing encouragement for their future progress/improvement. According to Milivojević (2004), this helps students maintain a positive academic self-concept even when their achievements are not as expected. This is important for their motivation. It is only if students believe they are capable of achieving better results that they will be motivated to put more effort into achieving improved results (Milivojević, 2004).

Further, possessing a lower academic self-concept is an important ESL risk factor. Students who left school before completing it had lower self-esteem, a lower academic self-concept and a lower perception of self-efficiency than other students (PPMI, 2014). This is why it is even more important for teachers to support the development of a healthy, positive and realistic academic self-concept among their students' to help them establish a lifelong learning concept of living and assist them in staying at school until they have accomplished their academic goals.

\section{References}

Bandura, A., \& Schunk, D. H. (1981). Cultivating competence, self-efficacy, and intrinsic interest through proximal self-motivation. Journal of Personality and Social Psychology, 41(3), 586.

Bandura, A., Barbaranelli, C., Caprara, G. V., \& Pastorelli, C. (1996). Multifaceted impact of self-efficacy beliefs on academic functioning. Child Development, 1206-1222.

Battin-Pearson, S., Newcomb, M. D., Abbott, R. D., Hill, K. G., Catalano, R. F., \& Hawkins, J. D. (2000). Predictors of early high school dropout: A test of five theories. Journal of Educational Psychology, 92(3), 568.

Bean, J. A., \& Lipka, R. P. (1986). Self-concept, self-esteem, and the curriculum. New York: Columbia University Press.

Betz, N. E., \& Hackett, G. (1983). The relationship of mathematics self-efficacy expectations to the selection of science-based college majors. Journal of Vocational Behavior, 23(3), 329-345. 
Bong, M. (2001). Between- and within-domain relations of academic motivation among middle and high school students: Self-efficacy, task value, and achievement goals. Journal of Educational Psychology, 93(1), 23.

Bong, M. \& Skaalvik, E. M. (2003). Academic self-concept and self-efficacy: How different are they really? Educational Psychology Review, 15(1), 1-40.

Bowlby, J. (2008). A secure base: Parent-child attachment and healthy human development. Basic Books.

Burnett, P. C. \& Demnar, W. J. (1996). The relationship between closeness to significant others and self-esteem. Journal of Family Studies, 2(2), 121-129.

Burns, R. B. (1982). Self-concept development and education. Cassell.

Eccles, J. (1983). Expectancies, values and academic behaviors. In J. T. Spence (Ed.), Achievement and Achievement Motives: Psychological and Sociological Approaches (pp. 75-146). San Francisco, CA: Free man.

Eccles, J. S., Wigfield, A., \& Schiefele, U. (1998). Motivation to succeed. In N. Eisenberg (Vol. Ed.) \& W. Damon (Series Ed.), Handbook of Child Psychology (5th ed., Vol. 3, pp. 1017-1095). New York: Wiley.

Emler, N. (2001). Self esteem: The costs and causes of low self worth. York Publishing Services.

Glazzard, J. (2010). The impact of dyslexia on pupils' self-esteem. Support for Learning, 25(2), 63-69.

Gottfried, A. E. (1990). Academic intrinsic motivation in young elementary school children. Journal of Educational Psychology, 82(3), 525.

Harter, S. (1982). The perceived competence scale for children. Child Development, 87-97.

Hattie, J. (1992). Measuring the effects of schooling. Australian Journal of Education, 36(1), 5-13.

Helmke, A., \& van Aken, M. A. (1995). The causal ordering of academic achievement and self-concept of ability during elementary school: A longitudinal study. Journal of Educational Psychology, 87(4), 624.

Humphrey, N. (2003). Facilitating a positive sense of self in pupils with dyslexia: The role of teachers and peers. Support for Learning, 18(3), 130-136.

Lan, W. \& Lanthier, R. (2003). Changes in students' academic performance and perceptions of school and self before dropping out of schools. Journal of Education for Students Placed at Risk, 8(3), 309-332.

Mac Iver, D. J., Stipek, D. J., \& Daniels, D. H. (1991). Explaining within-semester changes in student effort in junior high school and senior high school courses. Journal of Educational Psychology, 83(2), 201-211. 
Meece, J. L., Blumenfeld, P. C., \& Hoyle, R. H. (1988). Students' goal orientations and cognitive engagement in classroom activities. Journal of Educational Psychology, 8o(4), 514.

Milivojević, Z. (2004). Mala knjiga za velike starše [The little book for big parents.] Belgrade: Psihopolis.

Nalavany, B. A., \& Carawan, L. W. (2012). Perceived family support and self-esteem: The mediational role of emotional experience in adults with dyslexia. Dyslexia, 18(1), 58-74.

National Research Council. (2003). Engaging schools: Fostering high school students' motivation to learn. National Academies Press.

Nicholls, J. G. (1979). Quality and equality in intellectual development: The role of motivation in education. American Psychologist, 34(11), 1071.

Pajares, F., \& Miller, M. D. (1995). Mathematics self-efficacy and mathematics performances: The need for specificity of assessment. Journal of Counseling Psychology, 42(2), 190.

Parsons, J. E. \& Ruble, D. N. (1977). The development of achievement-related expectancies. Child Development, 1075-1079.

Pintrich, P. R. \& De Groot, E. V. (1990). Motivational and self-regulated learning components of classroom academic performance. Journal of Educational Psychology, 82(1), 33.

Pollard, A. \& Pollard, A. (Eds.). (2014). Readings for reflective teaching in schools. London: Bloomsbury Publishing.

PPMI - Public Policy and Management Institute (2014). Study on the effective use of early childhood education and care in preventing early school leaving - Final Report.

Rumberger, R. W. \& Rotermund, S. (2012). The relationship between engagement and high school dropout. In Christenson, S. L., Reschly, A. L., Wylie, C. (Eds.). Handbook of Research on Student Engagement (pp. 491-513). New York: Springer USA.

Rutar Leban, T. (2011). Razvoj ustrezne samopodobe. [Development of a healthy self-concept.] In Rutar Leban, T. (Ed.). Vzgoja za nenasilje: priročnik za starše [Education for nonviolence: Handbook for parents]. Nova Gorica: delovni odbor "Nova Gorica - otrokom prijazno Unicefovo mesto".

Schunk, D. H. (2003). Self-efficacy for reading and writing: Influence of modeling, goal setting, and self-evaluation. Reading \& Writing Quarterly, 19(2), 159-172. 
Skaalvik, E. M. (1997). Self-enhancing and self-defeating ego orientation: Relations with task and avoidance orientation, achievement, self-perceptions, and anxiety. Journal of Educational Psychology, 89(1), 71.

Shavelson, R. J., Hubner, J. J., \& Stanton, G. C. (1976). Self-concept: Validation of construct interpretations. Review of Educational Research, 46(3), 407-441.

Skaalvik, E. M., \& Hagtvet, K. A. (1990). Academic achievement and self-concept: An analysis of causal predominance in a developmental perspective. Journal of Personality and Social Psychology, 58(2), 292.

Skaalvik, E. M., \& Rankin, R. J. (1995). A test of the Internal/External Frame of Reference Model at different levels of math and verbal self-perception. American Educational Research Journal, 32, 161-184.

Skinner, E. A., Wellborn, J. G., \& Connell, J. P. (1990). What it takes to do well in school and whether I've got it: A process model of perceived control and children's engagement and achievement in school. Journal of Educational Psychology, 82(1), 22.

Stipek, D. J. (1984). Sex differences in children's attributions for success and failure on math and spelling tests. Sex Roles, 11(11), 969-981.

Suls, J. \& Mullen, B. (1982). From the cradle to the grave: Comparison and self-evaluation across the life-span. In Suls, J. M. (Ed.), Social Psychological Perspectives on the Self (pp. 97-125). Hillsdale, NJ: Lawrence Erlbaum Associates.

Troia, G. A., Shankland, R. K., \& Wolbers, K. A. (2012). Motivation research in writing: Theoretical and empirical considerations. Reading and Writing Quarterly, 28(1), 5-28.

Wigfield, A. (1997). Reading motivation: A domain-specific approach to motivation. Educational Psychologist, 32(2), 59-68.

Wolters, C. A., \& Pintrich, P. R. (1998). Contextual differences in student motivation and self-regulated learning in mathematics, English, and social studies classrooms. Instructional Science, 26(1), 27-47. 


\subsection{4 \\ Preventing ESL by Enhancing Resiliency}

Ana Kozina

\section{Synopsis}

Educational resilience is related to staying in school despite high risks (e.g. low social economic status, migrant status) present in one's life and, as such, can offer a path for preventing ESL. Enhancing educational resilience is a result of fostering protective factor(s) on either the contextual (family, school, community, e.g. parental education trainings, positive school climate improvements...) or individual level (e.g. mind-set trainings).

\section{Summary}

Resilience entails positive adaptation, e.g. doing well despite high risks or adversities. These adversities are either contextual (e.g. poverty, minority status, immigrant status, parental illness, harsh parenting...) or individual (e.g. illness, self-control impairment, learning difficulties, lack of coping skills...). Two models of resilience can be used for prevention and intervention planning: protective (a protective factor moderates the effect of a risk factor) and compensatory (a protective factor tempers a risk factor). The first one supports indicative prevention and the second universal prevention. Educational resilience is defined in terms of educational success even though there are personal attributes and environmental circumstances which reduce the likelihood of succeeding (Sacker \& Schoon, 2007). Since the mentioned adversities are also related to 
ESL, the resilience concept can contribute significantly to understanding and preventing ESL by providing an answer to why some students stay in school even though high risks for ESL are present in their lives. The difference between individuals who are found to be more resilient than others in the face of adverse circumstances is the number of protective factors: resources (positive contextual factors) and individual assets (positive individual characteristics) found in one's environment (Masten, 2016). The protective factors can be grouped in four categories: child characteristics, family characteristics, community characteristics, and cultural or societal characteristics. Based on a review of possible protective factors, certain practical implications of enhancing resilience are listed on the contextual level (e.g. family, school and community; such as parental education trainings, positive school climate improvement, bettering student-teacher relations) and individual level (e.g. focusing on mindset intervention, boosting social and emotional skills, self-regulation techniques). In the conclusion, the importance of enhancing any of the protective factors is stressed - even a single protective factor can make a great difference to the life of a young person and prevent ESL.

Key words: ESL, resilience, protective factor, context, individual

\section{Introduction}

Resilience entails positive adaptation, e.g. doing well despite high risks or adversities, and the aim of this article was thus to investigate what differentiates students who thrive notwithstanding those risks from those do not in order to identify the way this knowledge can be used to prevent ESL. The research on resiliency was prompted by the fact that some individuals at a high risk due to adversity or disadvantage appear to be functioning or developing normally or even flourishing (Masten, 2014; Masten, Cutulli, Herbers, \& Reed, 2009). Signs of risky circumstances include adverse socio-economic conditions (Felner \& DeVries, 2013; Masten, Cutuli, Herbers, Hinz, Obranović, \& Wenzel, 2014), minority ethnicity (Abubakar \& Dimitrova, 2016; Kuperminc, Wilkins, Roche, \& Alvarez-Jimenez, 2009; Motti-Stefanidi, 2015) and parental ill-health (Jaffe, 2013). Resilience research has focused on competencies despite exposure to at-risk environments (Masten, 1994). Since the mentioned adversities (e.g. low SES, mental illness...) are also related to ESL (Turner, Thurston, Gaye, \& Gentry, 2008), the concept of resilience can contribute significantly to understanding and 
preventing ESL. Thus, this article aims to identify the factors positively related to resilience in order to find a way to plan resilience enhancement to prevent ESL.

\section{Methodology}

In the literature search, we used the database PsychArticles (EBSHOST) with the key words: early school leaving (in title) \& resilience (in title) o articles; drop out (in title) \& resilience (in title) - o articles; early school leaving (anywhere in text) \& resilience (anywhere in text) - 611 (4 selected based on reviewing the abstract). Other than the four articles, we used special issues on resilience (European Journal of Developmental Psychology) and handbooks of resilience as the main source (with extensive backward searching).

\section{Resilience}

From a system perspective, resilience refers to the capacity to successfully adapt to disturbances that threaten the function, viability or development of a system. Observable success in adapting to such challenges is termed manifested resilience (Masten, 2016). Moreover, the building stones of this effective adaptation are those that can be used in ESL prevention. As stated in the resilience research, a common goal of the research has been to establish the characteristics of the processes leading to resilience in order to promote these processes in other youth at risk (Borge, Motti-Srefanidi, \& Masten, 2016; Turner, Thurston, Gaye, \& Gentry, 2008).

The characteristics of individuals found to be more resilient than others in such adverse circumstances are the number of resources or protective factors present in one's environment (Masten, 2016). The more protective factors there are in one's life, the more capable the individual is of adapting to adverse circumstances. The role of protective factors depends on the model of resilience. Two key models of resilience are identified in the literature: the compensatory model and the protection model (Schoon, 2006). In the compensatory model, the existence of protective factors cancels out the effect of adversity or risk. A compensatory resilience model assumes that resources and assets are independent of the risk factor; that they have a direct effect on an outcome; and that they fully or partially compensate or counteract the effects of the risk. The protective model assumes that positive factors buffer or moderate the negative influence of exposure to risk. 

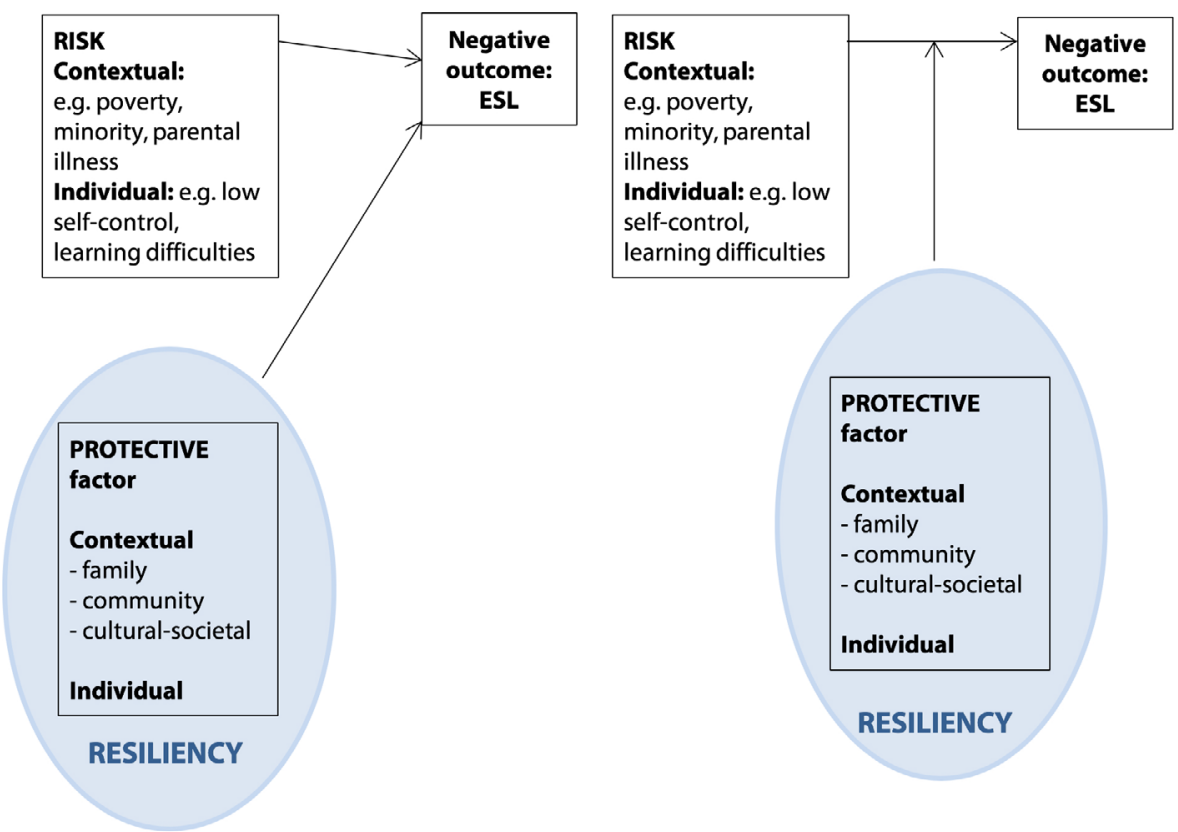

Figure 8. The compensatory and protective models of resilience

The two models hold different implications for potential intervention. With the protection model, the policies that target at-risk populations are indicated (the interventions are directed at at-risk groups in order to accommodate intervention in characteristics of the at-risk group), whereas the universal provision of resources is suggested by the compensatory model (where the protective factor is independent of the risk factors and therefore has a positive effect on its own, for everyone). Sacker and Schoon (2007) propose an additional model (the "reserve capacity" model) in which the protective effect of promotive factors appears with some time delay (Sacker \& Schoon, 2007), indicating that when one is exposed to protective factors this may not result in an immediate positive change, but can accumulate and have a positive effect later in life. Protective factors comprise individual assets (such as confidence, coping skills) and contextual factors (such as parental support). Stressing the importance of both: individual factors and contextual factors result in the definition of resilience as a process and not a fixed trait (Ostaszewski, 2012). This is related to contemporary research and 
theory on resilience, which understands resilience as an outcome of individual-context relations and not as a resilience trait that is inherent to the individual (Kaplan, 2013; Masten, 2016). Some children who face stressful, high-risk situations fare well in life, but their chances of doing so depend on the extent to which the risk factors in their lives are balanced by protective factors, both individual and environmental (Jackson \& Martin, 1998). A key feature of resilience in the face of adversity is that it requires the existence of protective factors that reduce the prospect of a negative outcome or increase the likelihood of a positive one (Sacker \& Schoon, 2007).

\section{Resilience and ESL}

Educational resilience is defined in terms of educational success despite personal attributes and environmental circumstances that reduce the likelihood of succeeding (Sacker \& Schoon, 2007). Due to the complexity of resilience itself, the question of how we can use resilience theory to prevent ESL is multifaceted. Students more prone to ESL are also students who come from an at-risk environment (e.g. low SES, harsh parenting...) or have individual vulnerabilities (e.g. mental health issues, learning difficulties...). ESL may be understood as a non-resilient outcome - the interplay between individual characteristics and the context has not yielded positive outcomes. Therefore, the intervention or change can be directed to enhancing one or possibly several protective factors.

The main findings in relation to remaining in education beyond the mandatory leaving age and preventing ESL follows the hypothesis that promotive factors (either at the individual or contextual level) can act independently and cumulatively to support educational aspirations. Regarding ESL prevention, the compensatory model of resilience (fostering protective factors in order to reduce the effect of risk factors for ESL) is more useful (Sacker \& Schoon, 2007). When looking at the important protective factors, these vary according to the developmental period one is in. For instance, in early life, reserve capacity for education was topped up predominantly from interpersonal (i.e. family) resources whereas in later life it is predominantly from individual assets (i.e. self-regulation, peer acceptance...) (Grolnik, Friendly, \& Bellas, 2009; Sacker \& Schoon, 2007).

Further on, we will examine the promotive factors that assist young people from disadvantaged socio-economic backgrounds to remain in education or increase their chances of gaining further qualifications later in life. As mentioned, promotive factors that help young people avoid the 
negative consequences of socio-economic disadvantage may be described as either assets or resources.

Based on extensive research, Masten (2007) came up with a so-called short list of protective factors supporting overall human development that can also be used in preventing ESL. These are:

(i) Child characteristics (social and adaptable temperament in infancy; good cognitive abilities, problem-solving skills, and executive functions; ability to form and maintain positive peer relationships; effective emotional and behavioural regulation strategies; positive view of self (self-confidence, high self-esteem, self-efficacy); positive outlook on life (hopefulness); faith and a sense of meaning in life; characteristics valued by society and self (talents, sense of humour, attractiveness to others);

(ii) Family characteristics (stable and supportive home environment (e.g. harmonious inter parental relationship, close relationship to a sensitive and responsive caregiver, authoritative parenting style (high on warmth, structure/monitoring, and expectations), positive sibling relationships, supportive connections with extended family members), parents involved in child's education; parents have individual qualities listed above as protective for child; socio-economic advantages; post-secondary education of parent; faith and religious affiliations;

(iii) Community characteristics (high neighbourhood quality (e.g. safe neighbourhood, low level of community violence; affordable housing, access to recreational centres, clean air and water); effective schools (e.g. well-trained and well-compensated teachers; after-school programmes; school recreation resources (e.g. sports, music, art)); employment opportunities for parents and teens; good public health care; access to emergency services (police, fire, medical); connections to caring adult mentors and prosocial peers; and

(iv) Cultural or societal characteristics (protective child policies (child labour, child health, and welfare); value and resources directed at education; prevention of and protection from oppression or political violence; low acceptance of physical violence) (Masten, 2007).

The protective factors identified as being most strongly associated with later educational success were: (i) stability and continuity of relationships 
and contexts; (ii) learning to read early and fluently; (iii) having a parent or carer who valued education and saw it as the route to a good life; (iv) having friends outside care who did well at school; (v) developing out-of-school interests and hobbies (which also helped to increase social skills and bring them into contact with a wider range of non-care people); (vi) meeting a significant adult who offered consistent support and encouragement and acted as a mentor and possibly a role model; and (vii) attending school regularly (Jackson \& Martin, 1998).

As we can see, numerous protective factors are related to overall positive development and also educational success and so an answer on how to use these protective factors in preventing ESL is not straightforward.

\section{Resilience enhancement}

Some examples of possible ways to enhance protective factors are presented on both the contextual and individual level. The idea behind it is that, instead of focusing on the potential weaknesses and identifying potential ESLers, we should instead focus on developing protective factors that can offer protection against adverse situations (Hupfeld, 2007).

\section{Contextual level}

Contexts (such as family, school, community, peers...) play a significant role in resilience enhancement (Motti-Stefanidi, 2015). One of the strongest protective factors is a positive relationship with at least one adult (Walsh, 2016). For instance, when researchers (Jackson \& Martin, 1998) in a school setting compared high achievers and a comparison group at the level of encouragement to go into further education by a parent or a significant adult, they found that the high achievers were given greater encouragement in general than the comparison group. Parents or carers of high achievers were significantly more likely to attend school events and show an interest in the child's educational progress than those in the less successful comparison group. In more detail, parental expectations were found to be more important than parental aspirations, suggesting that aspirations alone are not as effective in changing behaviour as expectations are. The level of educational expectation is related to the support and guidance, e.g. parents who expect their children to stay in school pay more attention to their schooling and provide more support. Alternatively, children and adolescents whose parents expect them to stay in school also have their own 
high expectations and may be more likely to expect to stay too (Sacker \& Schoon, 2007; Turner et al., 2008), also in an immigrant population (MottiStefanidi, 2015). There are several effective parental programmes that can be of use in building a promotive environment and also have an effect on academic outcomes (Sandler, Ingram, Wolhik, Tein, \& Winslow, 2015; Sheridon, Sjutts, \& Coutts, 2013; Walsh, 2016). Since parental support is especially crucial early in childhood (Grolnick et al., 2009), the interventions should start early.

If in the family environment the adversities also relate to the lack of a supportive person in the family setting, the school can be of great value by providing an additional caring and supportive relationship to students (Cadima, Erico, Ferreira, Verschueren, Leal, \& Matos, 2016; Wenzel, 2009). As established by Hupfeld (2007), it is very hard for students to gain and sustain resiliency skills in difficult circumstances without supportive adults to provide guidance, support and recognition. Interestingly, by asking students about the support they received from their teachers, and teachers about the level of guidance they provided to students, the researchers discovered that a positive student-teacher relationship worked as a strong protective factor and reduced ESL rates by half. This impact was even higher for students from socially disadvantaged backgrounds and those who had previously experienced academic underperformance (Cadima et al., 2016; Hupfeld, 2007). On the other hand, when schools do not provide support and develop protective systems this leads to greater school disengagement and potential ESL in students who are at risk (e.g. immigrant students) (Motti-Stefanidi, 2015). In the school setting, we should stress that educators have little or no control over family characteristics (or the innate abilities of students or community demographics); nevertheless, many resiliency skills can be taught to students or provided in the school and classroom environment that move students towards academic achievement (Doll, 2013; Hupfeld, 2007). Of the educational assets, academic achievement is the most important predictor of remaining in education (Sacker \& Schoon, 2007). If students were unsuccessful at school, they were still more likely to reintegrate into education if they had higher general ability and reading and mathematics test scores. This underlines the important role of school in building students' core competencies that can be used as a personal reserve to be drawn on when needed throughout the life span (Sacker \& Schoon, 2007). Success and academic achievement are also related with confidence that has been shown to be especially effective for getting back 
to school even after having already left school early. When addressing the role of resilience in ESL, we have to consider that resilience is both multidimensional and changeable: individuals may achieve resilient adjustment in one domain of functioning but not in another, and at one point in time but not another. An example of this is shown by Luthar et al. (1993) in their examination of adolescents' resilience. They showed that an at-risk individual might demonstrate good educational attainments but simultaneously experience behavioural problems. Within the educational domain, an individual may develop successfully at primary level but fail to succeed in secondary school. This highlights the importance of continuous care for enhancing promotive factors. Importantly, despite the findings that resilience in one domain of functioning does not always promote resilience in another domain, it was established that confidence and competencies in areas such as sport, music and art can have that effect, which is they can promote educational resilience (Sacker \& Schoon, 2007). From a practical point of view, this is particularly important because confidence can be developed not only through academic performance, but through recognition of being able to do well in a variety of settings. Therefore, the school should focus on a wider range of school activities to provide young people with experiences that can assist in shaping their ambitions and supporting their confidence (Sacker \& Schoon, 2007).

When protective factors on the family level and the school level are lacking, the community can step in. For instance, Jackson and Martin (1998) reported on social workers who had made a significant contribution, most often by organising financial help for a young person to continue their education after school, or occasionally by assisting a child in returning to school after a period of exclusion or a change of placement (Jackson \& Martin, 1998). The community also has power to influence more systemic risk factors like poverty and homelessness by introducing prevention and intervention programmes and support (Masten et al., 2014).

\section{Individual level}

On the individual level, enhancing coping skills together with social and emotional skills development lead to better adaptation, higher resilience and prevent ESL (Shure \& Aberson, 2013; Zins, Weissberg, Wang, \& Walberg, 2004). Another possible and effective tool for building resilience is mind-set trainings (Dweck, 2006; Yeager \& Dweck, 2012). Dweck (2006, $2008,2012)$ describes ability mind-sets as people's implicit theories about 
the malleability of abilities: these mind-sets can be placed on a continuum from fixed mind-set or entity self-theories, believing that their abilities are fixed traits, to growth mind-set or incremental theories, believing that abilities can be developed through efforts and education. Recent studies show that a growth mind-set is associated with various benefits and may be enhanced using simple interventions (e.g. O'Rourke et al., 2014; Panesku et al., 2015; Yeager et al., 2014). Research shows that the growth mind-set is related to positive outcomes in different domains: individuals with such a mind-set are more open to learning and confronting new challenges, more persistent when coping with difficult tasks and more resilient - i.e. capable of recovering from failures (Ahmavaara \& Houston, 2007; Dweck, 2000). Consequently, they perform better when facing challenges; for example, Blackwell, Trzesniewski and Dweck (2007) reported that students' implicit theories of intelligence predicted their academic performance over time, particularly when facing challenging work. A growth mind-set is likely to be associated with higher motivation for acquiring new skills, putting greater effort into academic or work tasks, and better recovery after setbacks. The very recent study by Claro, Panesku and Dweck (2016) indicates that students from lower income families are more likely to hold a fixed mind-set. Research also shows that mind-sets can be affected by environmental cues and can be deliberately changed (Blackwell et al., 2007; Good, Aronson, \& Inzlicht, 2003). Thus, the growth mind-set can be systematically enhanced by interventions (Yeager \& Dweck, 2012). The reported interventions (i.e. Dweck, 2012) focused on enhancing students' learning about the malleability of the brain and how to adopt growth mind-sets based on that understanding. Within these studies, authors found that mind-set interventions build a student's perseverance when encountering difficult academic tasks (Paunesku et al., 2015).

\section{Conclusions}

The paper presents the complexity of resilience. Even though resilience is an important concept in ESL, the question of why some students stay in school despite the adversities in their lives and others do not remains without a straightforward answer. The response offered by the research literature lies in fostering the promotive factors on either the individual or contextual level so as to help students thrive educationally and otherwise. Despite the complexity, we would like to finish by again highlighting the fact that any, and in many cases even a single, protective factor counts. For instance, in 
qualitative analyses based on semi-structured interviews with people who finished school despite high adversity, several cases are recorded of students who only reported one significant protective factor that made a difference in their life (Jackson \& Martin, 1998). The only protective factor of one girl mentioned in the research literature (Jackson \& Martin, 1998) was early reading skills and an English teacher who supported her reading. Therefore, we should foster the promotive factors existing on any level: either contextual or individual. For example, offering parent programmes that will empower parents in their role in their child's educational path, fostering positive models of school-home cooperation; developing teachers' social and emotional competence (SEC) so they are able to become the supportive caring person the student is lacking, bringing in music, sport and art to support a sense of competencies and confidence for a wider range of students, involving the community with positive role models and adult support for students at risk and building students' resilience using mindset training, SEC training or self-regulation techniques.

\section{References}

Abubakar, A., \& Dimitrova, R. (2016). Social connectedness, life satisfaction and school engagement: Moderating role of ethnic minority status on resilience processes of Roma youth. European Journal of Developmental Psychology, 13 (3), 361-371.

Ahmavaara, A., \& Houston, D. M. (2007). The effects of selective schooling and self-concept on adolescents' academic aspiration: An examination of Dweck's self-theory. British Journal of Educational Psychology, 77, 613-632.

Blackwell, L., Trzesniewski, K., \& Dweck, C. S. (2007). Implicit theories of intelligence predict achievement across an adolescent transition: A longitudinal study and an intervention. Child Development, 78, 246-263.

Borge, A. I., Motti-Stefanidi, F., \& Masten, A. S. (2016). Resilience in developing systems: The promise of integrated approaches for understanding and facilitating positive adaptation to adversity in individuals and their families. European Journal of Developmental Psychology, 13(3), 293-296.

Cadima, J., Enrico, M., Ferreira, T., Verschueren, K., Leal, T., \& Matos, P. M. (2016). Self-regulation in early childhood: The interplay between family risk, temperament and teacher-child interactions. European Journal of Developmental Psychology, 341-361. 
Claro, S., Paunesku, D., \& Dweck, C. S. (2016). Growth mindset tempers the effects of poverty on academic achievement. Proceedings of the National Academy of Sciences of the United States of America, 113, 8664-8668.

Doll, B. (2013). Enhancing resilience in classrooms. In S. Goldstein, \& R. B. Brooks (Eds.), Handbook of resilience in children (pp. 399-411). New York: Springer.

Dweck, C. S. (2006). Mindset. New York, NY: Random House.

Dweck, C. (2008). Can personality be changed? The role of beliefs in personality and change. Current Directions in Psychological Science, 17, 391-394.

Dweck, C. (2012). Mindsets and human nature: Promoting change in the Middle East, the schoolyard, the racial divide, and willpower. American Psychologist, 67, 614-622.

Felner, R. D., \& DeVries, M. (2013). Poverty in childhood and adolescence: A transactional-ecological approach to understand and enhancing resilience in contexts of disadvantage and developmental risk. In S. Goldstein, \& R. B. Brooks (Eds.), Handbook of resilience in children (105-127). New York: Springer.

Good, C., Aronson, J., \& Inzlicht, M. (2003). Improving adolescents' standardized test performance: An intervention to reduce the effects of stereotype threat. Journal of Applied Developmental Psychology, 24, 645- 662.

Hupfeld, K. (2007). Resiliency skills and dropout prevention: A review of the literature. Denver, CO: ScholarCentric.

Grolnick, W. S., Friendly, R. W., \& Bellas, V. M. (2009). Parenting and children's motivation at school. In K. R. Wenzel, \& A. Wigfield, Handbook of motivation in school (pp. 279-300). New York: Routledge.

Jackson, S., \& Martin, E. Y. (1998). Surviving the care system: Education and resilience. Journal of Adolescence, 21, 569-583

Jaffe, R. S. (2013). Family violence and parent psychopathology: Implications for children's socioemotional development and resilience. In S. Goldstein, \& R. B. Brooks (Eds.), Handbook of resilience in children (pp. 127-143). New York: Springer.

Kaplan, H. B. (2013). Reconceptualizing resilience. In S. Goldstein, \& R. B. Brooks (Eds.), Handbook of resilience in children (pp. 39-57). New York: Springer.

Kuperminc, G. P., Wilkins, N. J., Roche, C., \& Alvarez-Jimenez, A. (2009). Risk, resilience, and positive development among Latino youth. In F. A. Villarruel, G. Carlo, J. M. Grau, M. Azmitia, N. J. Cabrera, \& T. J. Chahin 
(Eds.), Handbook of USA Latino psychology: Developmental and community-based perspectives (pp. 213-233). Hoboken: Sage.

Luthar, S. S. (1993). Methodological and conceptual issues in research on childhood resilience. Journal of Child Psychology and Psychiatry, 34(4), 441-453.

Yeager, D. S., \& Dweck, C. S. (2012). Mindsets that promote resilience: When students believe that personal characteristics can be developed. Educational Psychologist, 47, 302-314.

Yeager, D. S., Johnson, R., Spitzer, B., Trzesniewski, K., Powers, J., \& Dweck, C. S. (2014). The far-reaching effects of believing people can change: Implicit theories of personality shape stress, health, and achievement during adolescence. Journal of Personality and Social Psychology, 106, 867-884.

Masten, A. S. (2016). Resilience in developing systems: The promise of integrated approaches. European Journal of Developmental Psychology, 13(3), 279-313.

Masten, A. S. (2011). Resilience in children threatened by extreme adversity: Frameworks for research, practice, and translational synergy. Development and Psychopathology, 23(2), 493-506.

Masten, A. S. (2007). Resilience in developing systems: Progress and promise as the fourth wave rises. Development and Psychopathology, 19(3), 921-930.

Masten, A. S. (1994). Resilience in individual development: Successful adaptation despite risk and adversity. In M. Wang, \& E. Gordon (Eds.), Educational resilience in inner city America: Challenges and prospects. Hillsdale, NJ: Lawrence Erlbaum.

Masten, A. S., Cutuli, J. J., Herbers, J. E., Hinz, E., Obradović, J., \& Wenzel, A. J. (2014). Academic risk and resilience in the context of homelessness. Child Development Perspectives, 8, 201-206.

Masten, A. S., Cutuli, J. J., Herbers, J. E., \& Reed, M. G. (2009). Resilience in development. In S. J. Lopey \& C. R. Snyder (Eds.), The Oxford handbook of positive psychology (pp. 117-133). Oxford: Oxford University Press.

Motti-Stefanidi, F. (2015). Risks and resilience in immigrant youth adaptation: Who succeeds in the Greek school context and why? European Journal of Developmental Psychology, 12(3), 261-274.

O’Rourke, E., Haimovitz, K., Ballwebber, Ch., Dweck, C. S., \& Popović, Z. (2014). Brain points: A growth mindset incentive structure boosts persistence in an educational game. In CHI'14: Proceedings of the SIGCHI Conference on Human Factors in Computing Systems (3339-3348). New York, NY: Association for Computing Machinery. 
Ostaszewski, K. (2012). Resilience: Compensatory, Protective, and Promotive Factors for Early Substance Use. 1st Annual Workshop: Lifespan Development of Substance Abuse, Kiev, Ukraine, November, 14-17.

Paunesku, D., Walton, G. M., Romero, C., Smith, E. N., Yeager, D. S., \& Dweck, C. S. (2015). Mind-set interventions are a scalable treatment for academic underachievement. Psychological Science, 26, 784-793.

Sacher, \& Schoon (2007). Educational resilience in later life: Resources and assets in adolescence and return to education after leaving school at age 16. Social Science Research 36, 873-896.

Sandler, I., Ingram, A., Wolchik, S., Tein, J. Y., \& Winslow, E. (2015). Longterm effects of parenting focused preventive interventions to promote resilience of children and adolescents. Child Development Perspectives, 9(3), 164-171.

Schoon, I., 2006. Risk and resilience. Adaptations in changing times. Cambridge University Press, Cambridge.

Sheridan, S. M., Sjuts, T. M., \& Coutts, M. J. (2013). Understanding and promoting the development of resilience in families. In S. Goldstein, \& R. B. Brooks (Eds.), Handbook of resilience in children (pp. 143-161). New York: Springer.

Turner, M. Y., Thurston, D. A., Gaye, Z., \& Gentry, L. (2008). The relationship of risk, resilience, and dropout: Implications for urban youth living in the south. Conference Proceedings, 646-672. Scarborough: National Association of African American Studies.

Walsh, F. (2016). Family resilience: A developmental systems framework. European Journal of Developmental Psychology, 13(3), 313-325.

Wenzel, K. R. (2009). Students' relationship with teachers as motivational contexts. In K. R. Wenzel, \& A. Wigfield, Handbook of motivation in school (pp. 303-348). New York: Routledge.

Zins, J. E., Weissberg, R. P., Wang, M. C., \& Walberg, H. J. (Eds.). (2004). Building academic success on social and emotional learning: What does the research say? New York: Teachers College Press. 


\subsection{5}

\section{Neuroscientific Findings Concerning Education and what they Imply for Teaching and Learning}

Tina Rutar Leban and Maša Vidmar

\section{Synopsis}

Evidence shows that findings in the area of neuroscience can help teachers develop new ways to improve the learning process. Improving the learning process by adapting it to meet students' neurological characteristics may help them attain higher academic achievements and self-efficiency, factors that counter ESL.

\section{Summary}

The emerging field of neuroeducation, also known as educational neuroscience, explores how children learn and which practices promote and sustain the learning process. Neuroeducation is an interdisciplinary field combining neuroscience, psychology and education to help improve teaching methods and curricula so as make them better support students' individual learning needs (Rich \& Goldberg, 2009). Meeting students' individual learning needs may be seen as a protective factor against ESL.

Recent reviews of neuroeducation highlight the growing body of scientific research that is clearly relevant to education (Ansari, Smedt, \& Grabner, 2012; Goswami, 2006; Twardosz, \& Bell, 2012) and may support teachers' efforts to develop more efficient learning methods. For example, brain imaging enables researchers to map the anatomy of reading and mathematics and correlate individual differences in 
how these skills are acquired with differences in brain structure and function (OECD, 2002; Dehaene, 2009; Nieder \& Dehaene, 2009).

This paper explores selected neuroscientific findings and considers their possible impacts on the learning process. It stresses the importance of such advances in neuroscientific knowledge for teachers' professional development and how this knowledge impacts students, their academic achievements and self-efficiency. These factors are established in the literature (Dumcius, R., Peeters, J., Hayes, N., Van Landeghem, G., Siarova, H., Peciukonyte, L. et al., 2014) as negatively correlating with ESL and thus work as protective factors countering it.

Key words: neuroscience in education, early school leaving, dyslexia, brain changes in adolescence, brain functioning

\section{Introduction}

Neuroscience is a relatively new area of research that brings neurophysiology, neuropharmacology, neurology, psychology and neuro-imaging together (Purpura, 1992; Kandel \& Squire, 2000; Gill, 2005). The development of modern techniques for recording the brain's physiological activity (functional magnetic resonance imaging - fMRI) while children, adolescents and adults perform a certain cognitive activity has allowed scientists to localise neuronal circuits or areas that synchronously activate within the brain (Gazzaniga \& Ivry, 2002; Blakemore \& Frith, 2005; Willingham \& Lloyd, 2007). Neuroscientific studies provide fresh new insights into certain aspects of attention, memory, language, reading and writing, mathematics teaching, sleep and emotion that are useful in the area of education (Berninger \& Corina, 1998; Byrnes \& Fox, 1998; Stanovich, 1998; Brown \& Bjorklund, 1998; Geake \& Cooper, 2003; Geake, 2004). Moreover, neuroscientific methods enable a better understanding of learning, the early diagnosis of learning disabilities and development of alternative methods for children in need of special education (Markram \& Markram, 2010).

Beyond specific neuroscientific domains, general knowledge about how the brain develops might be very beneficial for all teachers. For example, discoveries about structural and functional changes in the adolescent brain (Gogtay et al., 2004) can deepen teachers' understanding of adolescent behaviour. Similarly, knowledge of the prolonged period in which the neural systems implicated in cognitive control and attention develop (Luna et al., 2001) can lead to the appreciation of what constrains learning, 
from learning to play an instrument (Bengtsson et al., 2005) to the development of arithmetic skills (Rivera, Reiss, Eckert \& Menon, 2005), which cannot solely be attributed to immature knowledge or aptitude. Findings indicating that different aspects of memory are activated in various emotional contexts (Erk et al., 2003) support the links between emotion and cognition and give teachers a better understanding of the important role played by emotions in the learning process. The results of cognitive neuroscience research can also provide a better understanding of the roles of sleep (Maquet, 2000) and nutrition (Ivanovic et al., 2004) in brain development and learning, thereby assisting educators when deciding if and how to integrate such variables into their curricula. Further, neuroscientific findings point to structural (Rotzer et al., 2008) and functional particularities (Kaufmann \& Vogel, 2009) in how the brains of children with specific learning difficulties function, for example in mathematics (dyscalculia) or reading (dyslexia). Such research is important for educational work and planning forms of assistance (interventions) for these children and for the early detection of learning difficulties.

This article explores some neuroscientific findings about changes in the brain occurring in adolescence. It presents what happens in the brain during learning and learning difficulties and suggests some strategies and implications for teachers' practice. It focuses on adolescence because this is the period in which changes to the brain have the biggest effect on students' school work and school behaviour. These structural changes in the brain affect adolescents' cognitive and socio-emotional functioning in different ways. Some outcomes of the brain maturing hold implications for the brain's functioning, which may be seen in lower levels of attention, self-discipline, task completion, and emotion regulation. All of these variables influence academic achievement and school engagement which are themselves important preventive factors for ESL (Lan \& Lanthier, 2003). Such structural changes occurring in the brain can exacerbate difficulties with school work, affect school achievement and be especially hard for lower achievers and students at high risk for ESL. Understanding that some of the difficulties they encounter at school may come from development of the brain might make the latter students decide to remain in school and thereby prevent ESL. Further, neuroscientific findings also explain how the brains of students with different learning difficulties function. Given that students' learning difficulties often result in lower levels of achievement, motivation and engagement in school work and that all of these factors 
are well recognised as being ESL risk factors (e.g. Lan \& Lanthier, 2003; European Commission, 2011; PPMI, 2014), monitoring developments in neuroscientific research that touches on learning may indirectly help efforts to prevent ESL.

\section{Methodology}

The article is based on a review of literature entailing a search conducted in the PsycINFO, ERIC, Proquest, Science Direct and Google Scholar, Proquest Dissertation \& Theses Global databases. Key words used in the literature search were: neuroscience in education, neuroeducation, educational neuroscience, early school leaving, dyslexia, brain changes in adolescence, brain functioning etc. For the purposes of this article, we mainly took scientific papers and some online scientific books into consideration.

\section{Changes in adolescents' brain and the implications for teacher practice}

Several MRI-facilitated studies conducted in the past years have investigated the way the structure of the brain develops during childhood and adolescence (e.g. Paus, 2005; Casey, Tottenham, Liston, \& Durston, 2005). Studies carried out on large groups of subjects show there is increased white matter and decreased grey matter density in the frontal and parietal cortices throughout adolescence (e.g. Barnea-Goraly et al., 2005; Giedd et al., 1999; Reiss, Abrams, Singer, Ross, \& Denckla, 1996; Sowell, Thompson, Tessner, \& Toga, 2001; Sowell, Peterson, Thompson, Welcome, Henkenius, \& Toga, 2003). This increase in white matter seems to be linear across all brain areas, with changes in grey matter density appearing first in the brain's sensory and motor regions followed by the rest of the cortex, and finally the temporal cortex (Gogtay et al., 2004). Two brain regions consistently shown to undergo continued development during adolescence are the prefrontal cortex and parietal cortex. The continuing structural changes occurring in these brain regions during adolescence (negatively) affect the cognitive abilities - executive functions - that rely on how such regions function, regions like selective attention, decision-making, voluntary response inhibition and working memory (Jensen \& Nutt, 2014). Each of these executive functions has a role in cognitive control, for example inhibiting impulses, filtering unimportant information, holding in mind a plan to carry out in the future etc. Prospective memory (the ability to hold in mind an intention 
to conduct an action at a future time) is also associated with frontal lobe activity (Burgess, Veitch, Costello, $\&$ Shallice, 2000) and has been shown to develop through childhood as we develop our future-oriented thought and action (Ellis \& Kvavilashvili, 20oo). The ability to multitask is known to be a test of prospective memory because it requires a person to remember to perform several different tasks, mirroring everyday life. In a study of the development of prospective memory from childhood to adulthood (Mackinlay, Charman, \& Karmiloff-Smith, 2003), a significant improvement in both the efficiency and quality of strategies was found between the ages of 6 and 10. However, between the ages of 10 and 14, there was no significant change in performance. The adult group (mean age 25), on the other hand, significantly outperformed the children. The authors argued that prospective memory continues to develop during adolescence and that it is possible that the lack of improvement in performance between the 10- and 14-year-olds is related to their pubertal period that sees structural changes occur in the brain (Mackinlay et al., 2003). Similar results were found in a study (McGivern, Andersen, Byrd, Mutter, \& Reilly, 2002) that investigated the development of working memory and decision-making (functions of the frontal lobe) during childhood through to adolescence and adulthood. The results reveal that at the age of puberty, at 11-12 years, there was a decline in performance compared with the younger group of children. The results suggest there is a dip in performance for such functions in the period of puberty. After puberty, from 13-14 years, performance improved again until it reached the pre-pubescent level at around the age of 16-17. The authors explain this pubertal dip in performance with the proliferation of synapses that results in perturbation of cognitive performance during adolescence. Only later, after puberty ${ }^{1}$, do the excess synapses become refined into specialised, efficient networks, thus a post-pubescent further improvement (McGivern et al., 2002).

It is thus important for teachers to remember that even though teenage brains are learning at their peak efficiency, another considerable part of them is performing inefficiently (in some cases even less so than in childhood), including attention, self-discipline, task completion, and emotions. Accordingly, it is perhaps more reasonable to not overwhelm teenage students with too much instruction at any one time. Although they may look

Puberty is the process of physical changes by which adolescents reach sexual maturity, i.e. become capable of reproduction. Puberty refers to these bodily changes, while adolescence is the period of psychological and social transition between childhood and adulthood (that also includes puberty). 
like they can multitask, their brain is not yet 'wired' enough for this activity and they are not very good at it. Encouraging them to stop and think about what they need to do and when they need to do it will help increase blood flow to those areas of the brain involved in multitasking and slowly strengthen them (Jensen \& Nutt, 2014). Writing instructions and directions down, in addition to giving them orally, and limiting instructions to one or two points can help adolescent students focus more easily. Teachers can also help adolescent students better manage their time and organise their tasks by advising them to use calendars and suggesting they write down their daily schedules.

Apart from executive functions, evidence shows the prefrontal cortex is involved in several other high-level cognitive functions and capacities, including self-awareness (Ochsner, 2004) and theory of mind (Frith \& Frith, 2003), that is, the ability to understand other people by attributing mental states such as beliefs, desires and intentions to them (Frith, 2001). On top of neural development, major hormonal changes are occurring during puberty. While it is impossible to dissect every important influence on adolescents' social and emotional behaviour, both neural development and hormonal changes probably influence their social cognition. In one study (Choudhury, Blakemore, \& Charman, 2006), the development of perspective taking was investigated before, during and after puberty. The results show that the development of social perspective taking undergoes perturbation during puberty parallel to the discontinuous processes of brain maturation. This means that adolescents may find it difficult to understand the perspective of others.

Understanding that these difficulties may also be due to a student's neurological and hormonal background is important for teachers. It is easier to work with possible misbehaviour (deriving from not respecting another person's perspective) when appreciating that such behaviour could be due to neurological and hormonal changes rather than simple egoism and deliberate disrespect. Talking to students openly, explaining the changes occurring in their brains to them helps them to become more aware of these situations and focus more intentionally on other people's perspectives.

\section{What occurs in the brain during learning and learning difficulties and what this implies for teacher practice}

Attention and learning do not occur in isolated brain structures but by way of various layers of neuronal nets that are interconnected via complex 
and unstable links (Edelman, 2006). A further understanding of how information is 'translated' by the sense organs, turned into perception and later stored in long-term memory might assist teachers when preparing instruction strategies to improve students' learning success. Neuro-imaging pinpoints areas of the brain involved in the visual-spatial processing functions that are active during mathematics and science problem-solving. This knowledge suggests that visual-spatial skills should be integrated into mathematics education as a means to develop more efficient methods for teaching mathematics (Dehaene, 1997; Simon, 2006; O'Boyle et al., 2005). This means the teacher can support the learning of maths and science by including activities that encompass visual-spatial skills (such as following directions on a map in space, executing dance moves etc.) in mathematics and science instruction. In addition, future studies in neuro-genetics and neuro-imaging could help understand if the visual and phonological processing occurring in certain areas of the brain are the roots of dyslexia and other learning problems (Fisher \& Francks, 2006; Plomin, Kovas, \& Haworth, 2007).

What is more, neuroscience provides scientific clues about whether some educational approaches might be more effective than others. For example, different teaching strategies are available to help children with dyslexia. Typical public school and special education interventions often stabilise the degree of reading failure rather than remediate (normalise) the reading-skill level (Torgesen, 2006). Using a neuroscientific approach, researchers can identify changes in the brain that may determine the effectiveness of teaching strategies to reduce dyslexia problems. In fact, functional neuroimaging studies show the brain plasticity associated with effective intervention for dyslexia (e.g. Temple et al., 2003; Shaywitz et al., 2004; Aylward et al., 2003; Eden et al., 2004). Studies reveal the most efficient strategy for dyslexia intervention is special intensive (for instance, 100 min. per day for 8 weeks) instruction provided in small groups (1 or 2 students per teacher) and including explicit and systematic instruction in phonological awareness and decoding strategies.

Having said this, there is great potential to harness neuroscience to help design programmes to train neurocognitive functions, such as working memory, that are expected to have effects on overall brain function. Neuroscientific research may be able to enrich our understanding of how academic skills are generally acquired. Further, modern brain-imaging methods hold considerable potential to serve as diagnostic tools as well 
as measures of the effects of educational interventions like those concerning dyslexia (Ansari, De Smedt, \& Grabner, 2012). Moreover, while working with adolescent students who have learning difficulties such as dyslexia, dyscalculia etc. neuroscientific findings may be helpful in explaining to them details of what is going on in their brains and how the educational intervention (special learning strategies, additional work etc.) is designed to alter the way their brain functions so they can understand why they need to do additional work. Showing them brain images can help them to better understand this.

\section{Implications for ESL}

Neuroscientific findings can also be used to help prevent ESL. For example, different neuroscientific studies show that the learning, behavioral and emotional difficulties (such as difficulties with selective attention, decision-making, voluntary response inhibition, working memory etc.) some students encounter during adolescence are to some extent consequences of brain changes in the prefrontal cortex and parietal cortex (e.g. Burgess, Veitch, Costello, \& Shallice, 200o; Ellis \& Kvavilashvili, 2000). These difficulties can produce lower self-efficacy feelings, a lower academic self-image, more negative school-related attitudes, lower achievements and poorer engagement in school (Luna, 2009). All of these factors have been established as important predictors of ESL (e.g. Battin-Pearson, et al., 200o; Lan \& Lanthier, 2003). For example, ESLers and underachievers are identified as having lower self-esteem, a lower academic self-concept and a lower perception of self-efficiency than other students (PPMI, 2014). Other studies show that the self-concept plays a significant role in enhancing students' intrinsic motivation, positive emotion, and performance, all shown in different studies to be important preventive factors for ESL (e.g. Battin-Pearson, et al., 2000; Lan \& Lanthier, 2003).

Helping students at risk for ESL understand the reasons behind some difficulties they are experiencing are also due to natural developmental changes in their brain (which will pass in time) may lessen the impact of these difficulties on their self-image and attitudes to school. Consequently, this strategy may assist in preventing ESL. Moreover, showing students at risk for ESL the use of scientific findings and newly developed technologies (e.g. MRI brain images) in their own life may help them find a reason and motivation to stay at school. This could also be an opportunity for science teachers to go more in depth while addressing the subject of brain 
development and to include the latest neuroscientific findings on adolescent brain development in their lessons (Jensen \& Nutt, 2014).

Although neuro-education is developing very rapidly and we can see its potential in aiding the development of teaching and learning processes, its concrete implications remain limited. Therefore, the strategy presented above is just one of the possibilities revealing how neuroscientific findings can help in improving educational practices and prevent ESL.

\section{Conclusions}

Neuroscientific research of the brain's development during adolescence shows that, while the brain's learning capability is at its peak in adolescence, the continued structural changes in the brain negatively affect teenage cognitive and social-emotional functioning. The results of brain maturation hold implications for functioning of the brain, showing as lower attention, self-discipline, task completion, and lower emotion regulation. Further, neuroscientific research methods, especially brain imaging, provide a deeper understanding of brain functioning in dyslexia, dyscalculia and other learning difficulties.

Education researchers are very optimistic that neuroscience findings can effectively contribute to improving educational practices. But the neuroscientific research itself does not introduce any new educational strategies. This is still the domain of educators. Being familiar with the latest neuroscientific findings on adolescents' brain changes can assist teachers in understanding adolescents' behaviour and adapting their teaching strategies to suit their students' maturing brain functions.

Moreover, teachers can use the neuroscientific knowledge to develop educational interventions for low achieving students, students at risk for ESL and students with dyslexia or other learning difficulties. Becoming familiar with the neuroscientific findings on adolescent brain maturation and functioning might also be very interesting to students, especially those struggling with learning and emotional difficulties. By knowing what is happening in their brains, students might better accept the consequences they experience in everyday life and also be more willing to train their brain with regard to the scope of its accelerated development.

This is even more important for students with learning difficulties and others at greater risk of ESL. Neuroscientific findings on adolescent brain changes can at least to some extent help students at risk for ESL appreciate that some difficulties they are experiencing in their cognitive functioning 
are also due to natural developmental changes occurring in their brain. Knowing that these changes are part of the normal brain development process and that they will pass can at least partially reduce the impact of these difficulties on adolescents' self-image and attitudes to school and thus help students remain at school through to the end, thereby preventing ESL.

\section{References}

Ansari, D., De Smedt, B., \& Grabner, R. H. (2012). Neuroeducation - a critical overview of an emerging field. Neuroethics, 5(2), 105-117.

Aylward, E. H., Richards, T. L., Berninger, V. W., Nagy, W. E., Field, K. M., Grimme, A. C., ... \& Cramer, S. C. (2003). Instructional treatment associated with changes in brain activation in children with dyslexia. Neurology, 61(2), 212-219.

Barnea-Goraly, N., Menon, V., Eckert, M., Tamm, L., Bammer, R., Karchemskiy, A., ... \& Reiss, A. L. (2005). White matter development during childhood and adolescence: A cross-sectional diffusion tensor imaging study. Cerebral Cortex, 15(12), 1848-1854.

Battin-Pearson, S., Newcomb, M. D., Abbott, R. D., Hill, K. G., Catalano, R. F., \& Hawkins, J. D. (2000). Predictors of early high school dropout: A test of five theories. Journal of Educational Psychology, 92(3), 568-582.

Bengtsson, S. L., Nagy, Z., Skare, S., Forsman, L., Forssberg, H., \& Ullén, F. (2005). Extensive piano practicing has regionally specific effects on white matter development. Nature Neuroscience, 8(9), 1148.

Berninger, V. W., \& Corina, D. (1998). Making cognitive neuroscience educationally relevant: Creating bidirectional collaborations between educational psychology and cognitive neuroscience. Educational Psychology Review, 10(3), 343-354.

Blakemore, S. J., \& Frith, U. (2005). The learning brain: Lessons for education. Blackwell Publishing.

Brown, R. D., \& Bjorklund, D. F. (1998). The biologizing of cognition, development, and education: Approach with cautious enthusiasm. Educational Psychology Review, 10(3), 355-373.

Byrnes, J. P., \& Fox, N. A. (1998). The educational relevance of research in cognitive neuroscience. Educational Psychology Review, 10(3), 297-342.

Burgess, P. W., Veitch, E., de Lacy Costello, A., \& Shallice, T. (200o). The cognitive and neuroanatomical correlates of multitasking. Neuropsychologia, $38(6)$, $848-863$. 
Casey, B. J., Tottenham, N., Liston, C., \& Durston, S. (2005). Imaging the developing brain: What have we learned about cognitive development? Trends in Cognitive Sciences, 9(3), 104-110.

Choudhury, S., Blakemore, S. J., \& Charman, T. (2006). Social cognitive development during adolescence. Social Cognitive and Affective Neuroscience, 1(3), 165-174.

Dehaene, S. (1997). The number sense. Oxford: Oxford University Press

Dehaene, S. (2009). Reading in the brain: The new science of how we read. Penguin.

Dumcius, R., Peeters, J., Hayes, N., Van Landeghem, G., Siarova, H., Peciukonyte, L., ... \& Hulpia, H. (2014). Study on the effective use of early childhood education and care in preventing early school leaving. Luxembourg: Publications Office of the European Union.

Edelman, G. M. (2006). Second nature: Brain science and human knowledge. Yale University Press.

Eden, G. F., Jones, K. M., Cappell, K., Gareau, L., Wood, F. B., Zeffiro, T. A., ... \& Flowers, D. L. (2004). Neural changes following remediation in adult developmental dyslexia. Neuron, 44(3), 411-422.

Ellis, J., \& Kvavilashvili, L. (2000). Prospective memory in 2000: Past, present, and future directions. Applied Cognitive Psychology, 14(7).

Erk, S., Kiefer, M., Grothe, J., Wunderlich, A. P., Spitzer, M., \& Walter, H. (2003). Emotional context modulates subsequent memory effect. Neuroimage, 18(2), 439-447.

Fisher, S. E., \& Francks, C. (2006). Genes, cognition and dyslexia: Learning to read the genome. Trends in Cognitive Sciences, 10(6), 250-257.

Frith, U. (2001). Mind blindness and the brain in autism. Neuron, 32(6), 969-979.

Frith, U., \& Frith, C. D. (2003). Development and neurophysiology of mentalizing. Philosophical Transactions of the Royal Society of London B: Biological Sciences, 358(1431), 459-473.

Gazzaniga, M. S., Ivry, R. B., \& Mangun, G. R. (2002). Cognitive neuroscience. New York: W. W.

Geake, J. (2008). Neuromythologies in education. Educational Research, 50(2), 123-133.

Geake, J., \& Cooper, P. (2003). Cognitive neuroscience: Implications for education? Westminster Studies in Education, 26(1), 7-20. 
Giedd, J. N., Blumenthal, J., Jeffries, N. O., Castellanos, F. X., Liu, H., Zijdenbos, A., ... \& Rapoport, J. L. (1999). Brain development during childhood and adolescence: A longitudinal MRI study. Nature Neuroscience, 2(10), 861-863.

Gill, D. J. (2005). Principles and practice of behavioral neurology and neuropsychology. Neurology, 64(4), 769-769.

Gogtay, N., Giedd, J. N., Lusk, L., Hayashi, K. M., Greenstein, D., Vaituzis, A. C., ... \& Rapoport, J. L. (2004). Dynamic mapping of human cortical development during childhood through early adulthood. Proceedings of the National Academy of Sciences of the United States of America, 101(21), 8174-8179.

Goswami, U. (2006). Neuroscience and education: From research to practice? Nature Reviews Neuroscience, 7(5), 406-413.

Ivanovic, D. M., Leiva, B. P., Pérez, H. T., Olivares, M. G., Dı冈az, N. S., Urrutia, M. S. C., ... \& Larrain, C. G. (2004). Head size and intelligence, learning, nutritional status and brain development: Head, IQ, learning, nutrition and brain. Neuropsychologia, 42(8), 1118-1131.

Jensen, F. E. \& Nutt, A. E. (2014). The teenage brain. A neuroscientist's survival guide to raising adolescents and young adults. Harper Collins Publishers.

Kandel, E. R., \& Squire, L. R. (2000). Neuroscience: Breaking down scientific barriers to the study of brain and mind. Science, 29o(5494), 1113-1120.

Kaufmann, L., Vogel, S. E., Starke, M., Kremser, C., Schocke, M., \& Wood, G. (2009). Developmental dyscalculia: Compensatory mechanisms in left intraparietal regions in response to nonsymbolic magnitudes. Behavioral and Brain Functions, 5(1), 35.

Lan, W., \& Lanthier, R. (2003). Changes in students' academic performance and perceptions of school and self before dropping out of schools. Journal of Education for Students Placed at Risk, 8(3), 309-332.

Luna, B., Thulborn, K. R., Munoz, D. P., Merriam, E. P., Garver, K. E., Minshew, N. J., ... \& Sweeney, J. A. (2001). Maturation of widely distributed brain function subserves cognitive development. Neuroimage, 13(5), 786-793.

Luna, B. (2009). Developmental changes in cognitive control through adolescence. Advances in Child Development and Behavior, 37, 233-278.

Mackinlay, R., Charman, T., \& Karmiloff-Smith, A. (2003, April). Remembering to remember: A developmental study of prospective memory in a multitasking paradigm. Poster presented at the Society for Research in Child Development, Biennial Meeting, Tampa, Florida (Vol. 24). 
Maquet, P. (2000). Sleep on it. Nature Neuroscience, 3, 1235-1235.

Markram, K., \& Markram, H. (2010). The intense world theory - a unifying theory of the neurobiology of autism. Frontiers in Human Neuroscience, 4.

McGivern, R. F., Andersen, J., Byrd, D., Mutter, K. L., \& Reilly, J. (2002). Cognitive efficiency on a match to sample task decreases at the onset of puberty in children. Brain and Cognition, 5o(1), 73-89.

Nieder, A., \& Dehaene, S. (2009). Representation of number in the brain. Annual Review of Neuroscience, 32, 185-208.

OECD (2002). OECD Annual Report 2002, OECD Publishing, Paris. DOI: http://dx.doi.org/10.1787/annrep-2002-en

O’Boyle, M. W., Cunnington, R., Silk, T. J., Vaughan, D., Jackson, G., Syngeniotis, A., \& Egan, G. F. (2005). Mathematically gifted male adolescents activate a unique brain network during mental rotation. Cognitive Brain Research, 25(2), 583-587.

Ochsner, K. N. (2004). Current directions in social cognitive neuroscience. Current Opinion in Neurobiology, 14(2), 254-258.

Paus, T. (2005). Mapping brain maturation and cognitive development during adolescence. Trends in Cognitive Sciences, 9(2), 60-68.

Plomin, R., Kovas, Y., \& Haworth, C. (2007). Generalist genes: Genetic links between brain, mind, and education. Mind, Brain, and Education, 1(1), 11-19.

Púrpura, D. P. (1992). A neuroscience curriculum. Commission on Medical Education: The Sciences of Medical Practice. New Jersey: The Robert Wood Johnson Foundation. Princeton.

Reiss, A. L., Abrams, M. T., Singer, H. S., Ross, J. L., \& Denckla, M. B. (1996). Brain development, gender and IQ in children: A volumetric imaging study. Brain, 119(5), 1763-1774.

Rivera, S. M., Reiss, A. L., Eckert, M. A., \& Menon, V. (2005). Developmental changes in mental arithmetic: Evidence for increased functional specialization in the left inferior parietal cortex. Cerebral Cortex, 15(11), 1779-1790.

Rotzer, S., Kucian, K., Martin, E., von Aster, M., Klaver, P., \& Loenneker, T. (2008). Optimized voxel-based morphometry in children with developmental dyscalculia. Neuroimage, 39(1), 417-422.

Shaywitz, B. A., Shaywitz, S. E., Blachman, B. A., Pugh, K. R., Fulbright, R. K., Skudlarski, P., ... \& Fletcher, J. M. (2004). Development of left occipitotemporal systems for skilled reading in children after a phonologically-based intervention. Biological Psychiatry, 55(9), 926-933. 
Simon, M. A. (2006). Key developmental understandings in mathematics: A direction for investigating and establishing learning goals. Mathematical Thinking and Learning, 8(4), 359-371.

Sowell, E. R., Peterson, B. S., Thompson, P. M., Welcome, S. E., Henkenius, A. L., \& Toga, A. W. (2003). Mapping cortical change across the human life span. Nature Neuroscience, 6(3), 309.

Sowell, E. R., Thompson, P. M., Tessner, K. D., \& Toga, A. W. (2001). Mapping continued brain growth and gray matter density reduction in dorsal frontal cortex: Inverse relationships during postadolescent brain maturation. Journal of Neuroscience, 21(22), 8819-8829.

Stanovich, K. E. (1998). Cognitive neuroscience and educational psychology: What season is it? Educational Psychology Review, 1o(4), 419-426.

Temple, E., Deutsch, G. K., Poldrack, R. A., Miller, S. L., Tallal, P., Merzenich, M. M., \& Gabrieli, J. D. (2003). Neural deficits in children with dyslexia ameliorated by behavioral remediation: Evidence from functional MRI. Proceedings of the National Academy of Sciences, 100(5), 2860-2865.

Torgesen, J. K. (2006). Recent discoveries from research on remedial interventions for children with dyslexia. In Snowling, M. \& Hulme, C. (Eds.). The Science of Reading: A Handbook, chap. 27. Blackwell, Malden, MA.

Twardosz, S., \& Bell, M. A. (2012). Introduction to the special issue on neuroscience perspectives on early development and education. Early Education \& Development, 23(1), 1-3.

Willingham, D. T., \& Lloyd, J. W. (2007). How educational theories can use neuroscientific data. Mind, Brain, and Education, 1(3), 140-149. 
2.2 .6

\section{Non-formal Motivational Focuses for Potential Early School Leavers}

Klaudija Šterman Ivančič

\section{Synopsis}

It is possible to foster the learning motivation of potential ESLers already in mainstream education by applying non-formal and informal educational principles to teaching and learning processes. The teacher has two main pathways for enhancing the motivation of at-risk students: by recognising their informally gained knowledge and by organising non-formal learning environments and learning experiences.

\section{Summary}

Motivation for learning is an important predictor of ESL (e.g. Caprara et al., 2008; Fan \& Wolters, 2014; Hardre \& Reeve, 2003). Students at risk of ESL often report low levels of learning motivation or even amotivation. Amotivation is a state in which individuals cannot perceive a relationship between their behaviour and the behaviour's outcome and perceive their behaviour in a school context as outside of their control (Deci \& Ryan, 2002). As such, ESLers perceive low self-competence and self-determination (autonomy) in school settings. Non-formal and informal education addresses this issue as the core of the problem. The primary goal of this article is to discuss principles of non-formal and informal learning that could serve as a good example for teachers to foster the motivation of ESLers already in mainstream education. According to the literature 
review in the article, two main pathways through which teachers can enhance a student's motivation for learning in terms of including non-formal and informal learning principles in their teaching practices are identified: recognising a student's interests and informally gained knowledge (e.g. knowledge and skills related to sports, music, arts, manual crafts, cooking etc.) and organising non-formal learning experiences (field trips, visits and collaboration with different community organisations, museum visits, simulating a laboratory in the classroom etc.). In this way, students have a chance to express themselves, feel accepted and supported in the learning process, gradually build their self-esteem and feeling of autonomy by gaining recognition in areas they are successful in, and have a chance to connect knowledge and skills through experience-based and social learning. Non-formal and informal learning therefore successfully addresses important aspects of ESLers' amotivation for learning and is as such a good example of encouraging motivation for learning and subsequently preventing ESL already in mainstream education (European Commission 2013; Bills et al., 2015; Black et al., 2012; Hill \& Jepsen, 2007; Lagana-Riordan et al., 2011; Polidano et al., 2015).

Key words: ESL, motivation, non-formal education, informal education, prevention, mainstream education

\section{Introduction}

In the last few decades, a significant body of research has emerged that focuses on explaining psychological and contextual factors of educational outcomes such as dropout behaviour, where one of the most important ones is motivation for learning (e.g. Fortier, Vallerand, \& Guay, 1995; Vallerand, Fortier, Daoust, \& Blais, 1995). The theoretical concept of motivation that has proven useful and is the most widely used for explaining ESL behaviour is self-determination theory (Alivernini \& Lucidi, 2011; Deci \& Ryan, 1991; Shih, 2009). According to this theoretical concept (Deci \& Ryan, 1991), there are three forms of motivation which can be ordered along a self-determination (autonomy) continuum: intrinsic motivation, extrinsic motivation and amotivation. Students at risk of ESL often report low levels of learning motivation or even amotivation. Amotivation is a state in which individuals cannot perceive a relationship between their behaviour and the behaviour's outcome and perceive their behaviour in a school context as outside of their control (Deci \& Ryan, 2002). As such, ESLers 
perceive low self-competence and self-determination (autonomy) in school settings. This means they do not have a feeling of control over their learning and decisions connected to it, and engage in learning for external reasons (e.g. to attain positive consequences, avoid negative consequences, to obtain rewards etc.).

A growing body of literature (e.g. Broda, 2007; Evans, Meyer, Pinney, \& Robinson, 2009; Hayes, 2012; McGregora, Mills, Riele, \& Hayes, 2015) in the last few decades addresses different ways for increasing ESLers' motivation for learning. One of the identified areas is to include non-formal and informal educational principles already in mainstream education. Nonformal learning refers to any planned and goal-oriented but highly adaptable programme in institutions, organisations, and situations of personal and social education for young people or adults designed to improve a range of skills and competencies outside the formal educational curriculum (AEGEE, 2007; Babajeva, 2011; Cedefop, 2008; Eshach, 2007). While formal learning environments are characterised by their highly structured nature, non-formal learning environments are semi-structured (non-formal does not imply unstructured). Non-formal learning is intentional from the learner's point of view. Informal learning is defined (AEGEE, 2007; Cedefop, 2000; Eshach, 2007) as learning resulting from an individual's daily life activities related to work, family or leisure. It is even less structured than non-formal learning. It is often referred to as experiential learning and accidental learning and is mostly non-intentional. In this article, we are interested in the connection between non-formal and informal learning principles and a student's motivation for learning.

The article has three main goals. The first is to further discuss studies that examined the amotivation of ESLers and its important aspects, the second is to identify the main principles of non-formal and informal learning, and the third is to identify ways in which teachers can enhance a student's learning motivation by implementing those principles in mainstream educational and learning processes.

\section{Methodology}

In the process of reviewing the available literature in fields of learning motivation of ESLers and aspects of non-formal education that could foster their learning motivation, we first conducted a literature search of the scientific EBSCOhost online research databases (Academic Search Complete, ERIC, PsycARTICLES, PsycBOOKS, PsycINFO, and SocINDEX with full 
text databases). Since our focus was also on investigating project reports of non-formal educational practices, we additionally searched for related results online. The main key words initially used in both cases were: ESLers and motivation for learning, ESLers and engagement in education, motivation for learning in non-formal education, principles of non-formal education, recognition of informal knowledge, and motivation of adult learners. Since we found limited results regarding motivation in non-formal educational settings, we extended the search by stating specific forms of adult education, e.g. motivation for learning in community-based programmes, second-chance programmes, evening schools etc. In addition, we examined references cited in doctoral dissertations, reviewed articles, and project reports. Texts taken into account had to address the motivation of ESLers in general in order to identify good practices that can be applied in mainstream education.

\section{ESLers and their learning motivation}

In the introduction we already defined a theoretical concept of academic motivation that is important for describing the motivation of ESLers. In the following section, we further describe study results that address the link between different aspects of a student's academic motivation, i.e. perceived self-determination and competence, with ESL. Since different studies (e.g. Deci \& Ryan, 1991; Hardre \& Reeve, 2003; Reeve, 2002; Shahar, Henrich, Blatt, Ryan, \& Little, 2003) confirm the importance of considering social support for those aspects when addressing the amotivation of ESLers, and since this aspect is greatly supported in non-formal education settings, we also discuss study results from this field.

The link between a student's motivation for learning and ESL is already well established. Various studies (e.g. Caprara et al., 2008; Fan \& Wolters, 2014; Hardre \& Reeve, 2003) show that academic motivation is an important psychological factor that helps predict whether students are at greater risk of ESL or not. Longitudinal studies (e.g. Caprara et al., 2008; Fan \& Wolters, 2014; Hardre \& Reeve, 2003; Vallerand, Fortier, \& Guay, 1997) reveal there are two aspects of learning motivation that are particularly important when addressing the issue of ESL: a student's perceived self-determination (autonomy) and perceived competence. Students who report lower levels of autonomy and perceive themselves as less competent in school activities have less intention to stay in school and complete their schooling, and vice versa. Such a relationship has also been established in 
different cross-sectional studies (e.g. Alivernini \& Lucidi, 2011; Eccles et al., 1993; Patrick, Skinner, \& Connell, 1993; Peguero \& Shaffer, 2015). Students who were most detached from school had little belief in their academic ability and perceived themselves as non-autonomous in educational settings. On the contrary, students who perceived themselves as more autonomous pursued more ambitious challenges and reported greater commitment to finishing school.

Another important aspect of ESLers' motivation is the broader social context of learning. Different studies (e.g. Deci \& Ryan, 1991; Hardre \& Reeve, 2003; Reeve, 2002; Shahar, Henrich, Blatt, Ryan, \& Little, 2003) show that academic attitudes and behaviours are strongly influenced by key social agents in the student's environment, i.e. teachers, parents and friends. In their longitudinal study, Hardre and Reeves (2003) established there are three dimensions of social support that affect motivation: autonomy support, competence support and interpersonal relatedness. Results revealed that all dimensions of social support are negatively related to amotivation and positively related to intrinsic motivation for learning.

Cross-sectional studies (e.g. Alivernini \& Lucidi, 2011; Reeve et al., 1999; Vallerand et al., 1997) also support these findings. Students who perceived their social support networks (e.g., parents and teachers) as supportive in the sense of their autonomy and competence were also more intrinsically motivated for school work. Authors (e.g. Assor, Kaplan, KanatMaymon, \& Roth, 2005; Reeve, 2002) who studied the effects of the teacher's controlling behaviour on a student's self-determination showed that teachers who exhibit controlling behaviour in the form of rigid directions or orders, supervising and monitoring too closely, and not giving students the opportunity to propose choices and opinions, affect a student's self-determination in a negative way. Moreover, practices such as letting students choose from various alternatives, listening to them, and asking them for their points of view support a student's self-determination. Further, supportive relationships also proved to be an important predictor of ESL (e.g. Alivernini \& Lucidi, 2011). Students who reported to be in a classroom with autonomy-supportive teachers were more likely to stay in school than students in classrooms with controlling teachers.

The amotivation of ESLers is therefore a complex concept that reaches beyond an individual's characteristics and academic achievement and is closely linked to his/her social environment, interpersonal climate in the educational setting and teaching methods; namely, factors that can to some 
extent be systematically supported and encouraged in the process of teaching and learning. Non-formal educational settings are a case of such supportive learning environments. In the following section, we describe the main principles of non-formal and informal learning and consider ways in which they can foster the learning motivation of ESLers and, as such, represent ESL prevention practices.

\section{Principles of non-formal and informal learning}

According to Maier (2011), a central feature of non-formal and informal learning is learning from and through life experience. Both concepts derive from a participant's needs and aspirations and are linked to self-education and personal development. Non-formal education programmes are based on lifelong learning principles and student-centred teaching and learning approaches. It is a humanistic approach to learning where students are considered as individuals possessing their own personal qualities, traits, abilities, values, experiences and worldviews that are important to their learning process.

Falk and Dierking (2000) propose a contextual model (see Figure 31), i.e. principles of non-formal and informal learning. The model is based on theories of cognitive and social constructivism (Piaget, 1971; Vigotsky, 1979) which imply that meaningful learning occurs when a person idiosyncratically restructures knowledge through their own understanding of experience and social interaction, actively basing it on their prior knowledge. The authors (Falk \& Dierking, 200o) suggest there are eight factors influencing learning in non-formal learning environments and they occur within three contextual domains: personal, social and physical context. In terms of the individual's personal context (light-green shapes in Figure 31), i.e. personal and genetic history that an individual carries into the learning situation, non-formal learning is influenced by a learner's motivation and expectations, previous knowledge, interests and beliefs, his/her choice of participation, and a feeling of control over their learning. Since learning is also constructed through social interaction, social factors (dark-green shape in Figure 31) that influence non-formal and informal learning are within-group socio-cultural mediation and facilitated mediations by teachers and other members of a learning group. The last assumption within this model is that, because learning occurs within the physical environment (blue shapes in Figure 31), it is always a dialogue with the environment. Thus, according to the authors in order to be successful it is important for 
the non-formal learning situation to be influenced by environmental factors such as advance organisers and orientation proposed by teachers before entering into the non-formal learning environment, the design of the environment, and reinforced events and experiences outside the environment that enhance the learning experience gained in the non-formal education setting.

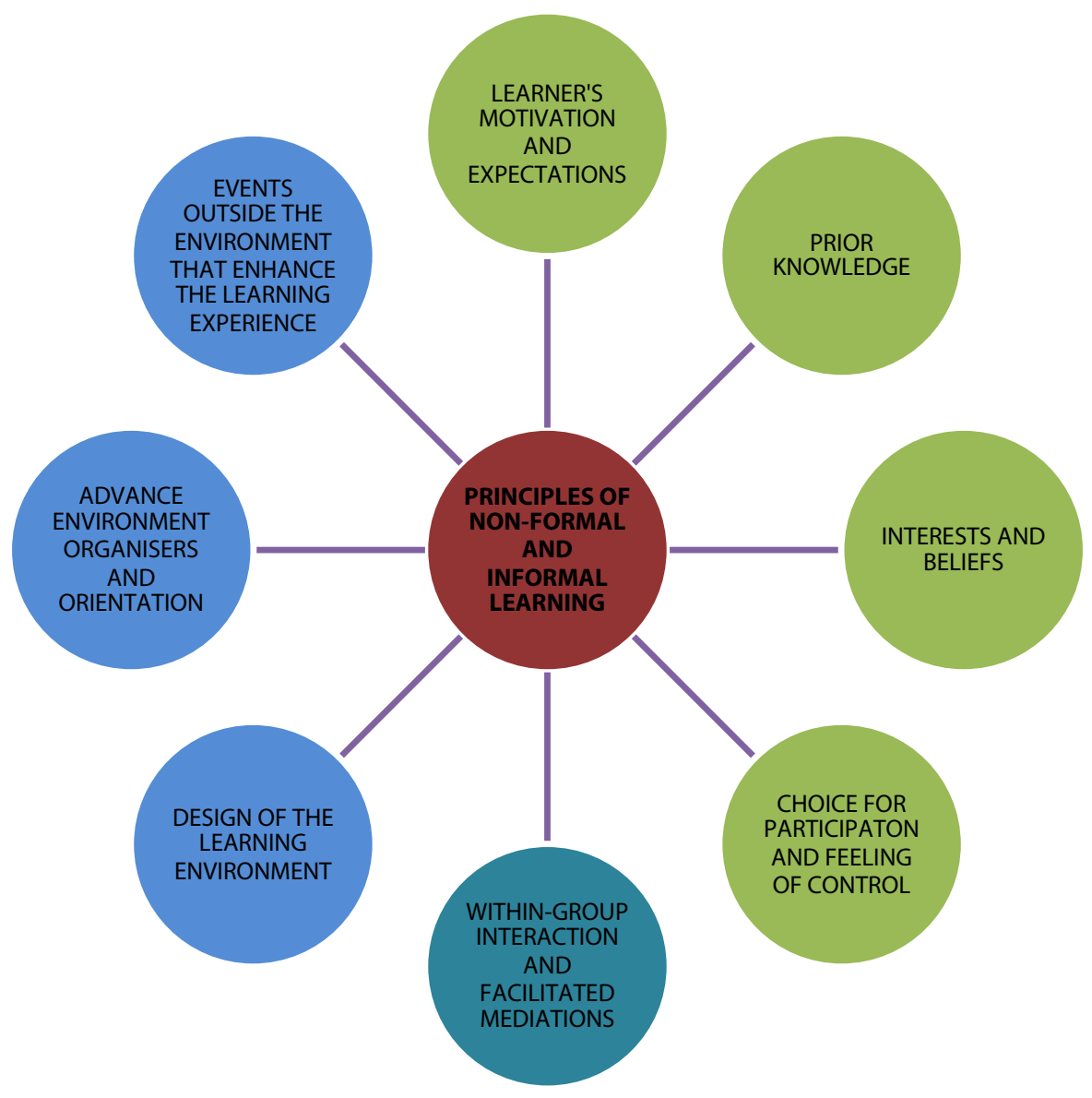

Figure 9. Contextual model of the principles of non-formal and informal learning (Proposed by Falk and Dierking (2000))

Besides understanding knowledge as a construct of the individual's integration of newly gained experience and their prior knowledge, another important aspect of Falk and Dierking's (2000) contextual model 
of non-formal learning is the affective aspect of learning. They state that non-formal learning situations encourage an individual's sense of wonder, interest, enthusiasm, and eagerness to learn (Pedretti, 2002). They provide opportunities for individuals to be active learners in non-evaluative and non-threatening environments and include the enhancement of positive attitudes to learning. In his review of six studies conducted in non-formal settings, Falk (1983) found that such learning experiences generally result in higher learning motivation and enjoyable and long-lasting memories, and that those students also outperform others who did not take part in such learning.

In the following section, we further investigate ways in which teachers can encourage a student's motivation for learning through the implications of non-formal and informal learning principles.

\section{Non-formal motivational focuses}

Different studies and project reports (e.g. Big Picture Education Australia, 2014; Broda, 2007; Evans et al., 2009; Hayes, 2012; McGregora, Mills, Riele, \& Hayes, 2015) confirm that an important point at which teachers can enhance a student's motivation for learning is their recognition of the student's non-formally and informally gained knowledge. The point of such an approach lies in giving students the opportunity to express themselves and experience success that does not rely on traditional reading, maths and science literacy skills. Students thereby gain self-confidence and a feeling of autonomy in learning situations. A student's informally gained knowledge usually derives from different areas of the student's interests, e.g. sports, music, arts, manual work, gardening, cooking etc. A good example of acknowledging a student's interests and increasing their motivation for learning is, for example, Australia's Boronia second-chance school (McGregora et al., 2015) where students were very interested in making music; teachers set up a music studio in which students could write their own lyrics, make music, prepare for live performances etc. Students in this school were given the opportunity to learn, express themselves, collaborate and gain recognition through something they value highly and are good at. They also reported that they felt cared about because the teachers offered them such learning opportunities. The teacher's essential role in such settings is that they recognise the student's potential and afterwards through systematic support (mentoring, setting educational goals, supportive evaluation 
practices) transform the student's gained self-confidence, perceived self-effort and autonomy to other more formal fields of learning.

Another point at which teachers can make use of non-formal learning experiences in order to enhance a student's motivation is by adjusting the environment and conditions in which students learn. Different studies (e.g. AEGEE, 2007; Babajeva, 2011; Broda, 2007; Eshach, 2007; European Commission, 2013) show that enabling a student's real-world opportunities and simulations both provide useful settings for this process to occur. In this way, students are given the opportunity to connect learning to their personal experiences and make personal meaning out of it, which results in higher understanding and thus perceived autonomy and learning motivation. Teachers can thereby lead the student through a semi-structured learning process that connects both: increases the student's motivation and enables the student to acquire specific knowledge and learning goals. Good examples of such learning are different museum visits, school trips, site visits, community learning and simulations of the outside world in the classroom (e.g. market, laboratory, kitchen, workshop).

Eshach (2007) even proposes a model for enhancing a student's motivation for learning by implementing learning in non-formal environments. He describes the following steps in planning such a learning experience:

1) defining the purpose of the non-formal educational setting (the teacher should decide whether his aim is to introduce a learning topic, deepen it, extend it);

2) teachers should visit the location in advance (talk with people in charge about the purpose of the visit, ask for suggestions);

3) share the purpose of the visit with students beforehand (talk about their expectations, prior knowledge, and define the aims of the visit);

4) give students the relevant background knowledge about the topic they wish to address already before the visit so they can connect the skills acquired in the field to this knowledge;

5) provide some (not too many) tasks to be conducted in the field (in this way students notice things they might otherwise ignore, they should also be given freedom to create their own experience); and

6) share the activity with parents and invite them to join, discuss the newly gained knowledge through active teaching methods (group work, project work, role playing etc.). 
The outcome of implementing non-formal and informal educational principles in the educational process therefore increases a student's motivation for learning. Individuals can therefore take an active role in the education process where they are given the possibility to develop their interests, values, skills and competencies. It is a process of learning by doing in a flexible environment, where it is right to make mistakes. It touches upon emotions and attitudes, areas where formal education does not usually reach and as such goes to a deeper level of a student's personality. It also takes into the account the student's personal, social and cultural characteristics when planning the process and tends to integrate disadvantaged youth who were unable to engage in learning in mainstream education for several reasons.

\section{Conclusions}

Low motivation for learning or even amotivation is one of the primary characteristics of students at risk of ESL. Important aspects of their amotivation are perceived low competence and self-determination (level of autonomy) in mainstream educational settings. Those students also report negative ability and effort beliefs, and also place a more negative value on academic tasks (Caprara et al., 2008; Fan \& Wolters, 2014; Hardre \& Reeve, 2003; Vallerand et al., 1997). Two main pathways are identified in the literature concerning how teachers can enhance a student's motivation for learning by considering the principles of non-formal and informal learning. The first is recognising a student's interests and related informally gained knowledge and experience, and the second is organising learning situations in non-formal supportive environments (such approaches often take place in community-based education programmes, evening schools, study circles, second-chance education programmes etc.). In this context, students are perceived as autonomous individuals, with their own interests, aspirations and needs, who are capable of planning and actively participating in the educational process. As such, informal and non-formal education principles address the key motivational shortages of ESLers. It points to the fact that a shift in students' perceptions as competent and capable of self-determination in the mainstream educational process is crucial for supporting their motivation and preventing undesirable learning behaviours such as ESL (European Commission 2013; Bills, Cook, \& Giles, 2015; Black, Polidano, \& Tseng, 2012; Hill \& Jepsen, 2007; Lagana-Riordan et al., 2011; Polidano, Tabasso, \& Tseng, 2015). 


\section{References}

AEGEE (2007). NFE book: The impact of non-formal education on young people and society. Brussels: AEGEE Europe. Retrieved from https://www.aegee. org/wp-content/uploads/publications/NFE_book.pdf

Alivernini, F., \& Lucidi, F. (2011). Relationship between social context, self-efficacy, motivation, academic achievement, and intention to drop out of high school: A longitudinal study. The Journal of Educational Research, 104, 241-252.

Assor, A., Kaplan, H., Kanat-Maymon, Y., \& Roth, G. (2005). Directly controlling teacher behaviors as predictors of poor motivation and engagement in girls and boys: The role of anger and anxiety. Learning and Instruction, 15, 397-413.

Babajeva, L. (2011). Adult's personal development in non-formal education. Paper presented at the ECER Conference. Retrieved from http://www.eera-ecer.de/ecer-programmes/conference/5/contribution/20166/

Big Picture Education Australia. (2014). Retrieved from http://www.bigpicture.org.au/about-us/big-picture-education-australia

Bills, A., Cook, J., \& Giles, D. (2015). Negotiating second chance schooling in neoliberal times: Teacher work for schooling justice. New Zealand Journal of Teacher' Work, 12, 78-95.

Black, D., Polidano, C., \& Tseng, Y. P. (2012). The re-engagement in education of early school leavers. Economic Papers, 31, 202-215.

Broda, H. W. (2007). Schoolyard-Enhanced Learning. Using the Outdoors as an Instructional Tool. Portland: Stenhouse Publishers.

Caprara, G., Fida, R., Vecchione, M., Del Bove, G., Vecchio, G., Barbaranelli, C., \&

Bandura, A. (2008). Longitudinal analysis of the role of perceived self-efficacy for self-regulated learning in academic continuance and achievement. Journal of Educational Psychology 100, 525-534.

Cedefop. (2008). Validation of non-formal and informal learning in Europe. A snapshot 2007. Luxembourg: Office for Official Publications of the European Communities.

Deci, E. L., \& Ryan, R. M. (1991). A motivational approach to the self: Integration in personality. In R. Dienstber (Ed.), Nebraska symposium on motivation: Vol. 38. Perspectives on motivation (pp. 237-288). Lincoln, NE: University of Nebraska Press. 
Deci, E. L. \& Ryan, R. M. (2002). Overview of self-determination theory: An organismic dialectical perspective. In E. L. Deci \& R. M. Ryan (Eds.), Handbook of self-determination research (pp. 3-33). Rochester, NY: University of Rochester Press.

Eccles, J. S., Wigfield, A., Midgley, C., Reuman, D., MacIver, D., \& Feldlaufer, H. (1993). Negative effects of traditional middle schools on students' motivation. The Elementary School Journal, 93, 553-574.

Eshach, H. (2007). Bridging in-school and out-of-school learning: Formal, non-formal, and informal education. Journal of Science, Education and Technology, 16, 171-190.

European Commission. (2013). Preventing early school leaving in Europe Lessons learned from second chance education: Final report. Brussels: European Commission.

Evans, J., Meyer, D., Pinney, A., \& Robinson, B. (2009). Second chances: Reengaging young people in education and training. Essex: Barnardo's.

Falk, J. H. (1983). Field trips: A look at environmental effects on learning. Journal of Biological Education, 17, 137-141.

Falk, J. H., \& Dierking, L. D. (200o). Learning from museums: Visitors experiences and their making of meaning. Walnut Creek, CA: Altamira Press.

Fan, W., \& Wolters, C. A. (2014). School motivation and high school dropout: The mediating role of educational expectation. British Journal of Educational Psychology, 84, 22-39.

Fortier, M. S., Vallerand, R. J., \& Guay, F. (1995). Academic motivation and school performance: Toward a structural model. Contemporary Educational Psychology, 20, 257-274.

Hardre, P. L., \& Reeve, J. (2003). A motivational model of rural students' intensions to persist in, versus drop out, high school. Journal of Educational Psychology, 95, 347-356.

Hayes, D. (2012). Re-engaging marginalised young people in learning: The contribution of informal learning and community-based collaborations. Journal of Education Policy, 27, 641-653.

Hill, L., \& Jepsen, C. (2007). Positive outcomes from poor starts: Predictors of dropping back in. Economics of Education Review, 26, 588-603.

Lagana Riordan, C., Aguilar, J. P., Franklin, C., Streeter, C. L., Kim, J. S., Tripodi, S. J., \& Hopson, L. M. (2011). At-risk students' perceptions of traditional schools and a solution-focused public alternative school. Preventive School Failure, 55, 105-114. 
Maier, M. (2011). Validation of non-formal and informal learning. Journal for Perspectives of Economic, Political, and Social Integration, 17, 1-2.

Patrick, B. C., Skinner, E. A., \& Connell, J. P. (1993). What motivates children's behavior and emotion? Joint effects of perceived control and autonomy in the academic domain. Journal of Personality and Social Psychology, 65, 781-791.

Pedretti, E. (2002). T. Kuhn meets T. Rex: Critical conversations and new directions in science centres and science museums. Studies in Science Education, 37, 1-42.

Piaget, J. (1971). Biology and knowledge. Edinburgh: Edinburgh Press.

Peguero, A. A., \& Shaffer, K. A. (2015). Academic self-efficacy, dropping out, and the significance of inequality. Sociological Spectrum, 35, 46-64.

Polidano, C., Tabasso, D., \& Tseng, Y. P. (2015). A second chance at education for early school leavers. Education Economics, 23, 358-375.

Reeve, J. (2002). Self-determination theory applied to educational settings. In E. L. Deci \& R. M. Ryan (Eds.), Handbook of self-determination research (pp. 183-203). Rochester, NY: University of Rochester Press.

Shahar, G., Henrich, C. C., Blatt, S. J., Ryan, R., \& Little, T. D. (2003). Interpersonal relatedness, self-definition, and their motivational orientation during adolescence: A theoretical and empirical integration. Developmental Psychology, 39, 470-483.

Shih, S. S. (2009). An examination of factors related to Taiwanese adolescents' reports of avoidance strategies. The Journal of Educational Research, 102, 377-388.

Vallerand, R. J., \& Bissonnette, R. (1992). Intrinsic, extrinsic, and amotivational styles as predictors of behavior: A prospective study. Journal of Personality, 60, 599-620.

Vallerand, R. J., Fortier, M. S., \& Guay, F. (1997). Self-determination and persistence in a real-life setting: Toward a motivational model of high school dropout. Journal of Personality and Social Psychology, 72, 1161-1176.

Vallerand, R. J., Fortier, M. S., Daoust, H., \& Blais, M. R. (1995). A motivational analysis of school dropout. University of Montreal: Unpublished manuscript.

Vygotsky, L. (1978). Mind in society: The development of higher psychological processes. Cambridge, MA: Harvard University Press. 



\subsection{7}

\section{Andragogical Knowledge and Skills for Teachers in Mainstream Education as Prevention for ESL ${ }^{\mathrm{I}}$}

Klaudija Šterman Ivančič

\section{Synopsis}

Andragogy is a learner-centred approach to teaching and learning. By incorporating its principles of acknowledging learners as autonomous, self-directed, pragmatically and problem-solving oriented and internally motivated into mainstream education already at early stages, teachers can help prevent ESL.

\section{Summary}

The aim of this article is to present the role andragogical knowledge plays in tackling ESL, especially through its incorporation into mainstream education. Contrary to teacher-centred, andragogy is a learner-centred approach to learning and teaching. In the paper, we focus on its assumptions, transactional processes, practical implications, methods and advantages it can bring to the learning process, and already existing attempts at such practices in mainstream education. Andragogy builds on the assumptions about learners as autonomous, self-directed, internally motivated, problem-solving-oriented and pragmatically-oriented individuals who have a need to be respected and accepted for their knowledge and experience. Therefore, they tend to be actively involved in the learning process in order to become engaged and productive learners. 
This then means the adult education process foresees adults as actively engaged in all stages of planning, performing and evaluating the educational experience. The relationship between the learner and teacher in such a setting is equivalent and interactive teaching methods such as group work, group discussions, applied problem-based sessions, project work, hands-on activities and learner guidance and mentoring are compulsory. Since the main problem of potential ESL students is often feelings of alienation from teachers and schools, disconnectedness, low learning motivation, and a search for the purpose and meaning of life, it is necessary for schools to start responding to their learning needs and the learner-based approach provides one of the ways to address their needs. Teachers in mainstream education thus need to be empowered in andragogical knowledge and approaches to learning, its origins, assumptions, practical implications, methods and advantages in order to successfully address different students' educational needs and help reduce ESL already in mainstream education. It is also important to keep in mind that, if expect teachers to incorporate learner-centred approaches into their work, they themselves need to be taught in the same way we want them to teach.

Key words: andragogy, learner-centred approach, mainstream education, ESL prevention

\section{Introduction}

In the last century, two major philosophies emerged in field of education, i.e. instructivism, and constructivism. In the instructivist approach, which has its roots in behaviourism, the educator sets performance goals and develops a systematic approach to the learning content that is independent of the learner. On the contrary, the constructivist philosophy, which originates from cognitive psychology and humanistic approaches, places the emphasis on the learner and the learner's interpretations of educational processes and outcomes through self-directed explorations (Cartor, 1990; Holton, Swanson, \& Naquin, 2001; Merriam \& Caffarella, 1999). In other words, we are talking about a teacher- and learner-centred educational approach (Taylor \& Kroth, 2009). One of the learner-centred approaches we wish to focus on in this article is andragogy.

Andragogy (Greek: man (adult)-leading) is grounded in humanistic (conceptions of Maslow's and Rogers' self-actualisation of the 
individual) and pragmatic philosophy (the influence of $\mathrm{D}$ ewey a nd Lindeman and their emphasis on knowledge gained from experience rather than formal authority) (Holton et al., 2001; Merriam \& Caffarella, 1999). It first emerged in 1833 when the German educationalist Alexander Kapp coined the term (Chan, 2010; Howard, 1993). It was further developed in 1926 when Lindeman extended the idea, yet it only gained recognition in 1959 when Knowles further explained the basic principles of andragogy. He later characterised it as a model of assumptions about adult learning and a conceptual framework that serves as a basis for an emergent theory (Knowles, 1989). Today, Knowles' andragogical theory is the best known and most acknowledged conception of adult education and learning. Knowles (1980: p. 43) also defined andragogy as an opposing concept in relation to pedagogy where he defined andragogy as a learner-centred approach and pedagogy as a teacher-centred approach. He stated that "andragogy is the art and science of helping adults learn, in contrast to pedagogy as the art and science of teaching children". Although we can find different conceptions of andragogy in the literature (andragogy as a theory, an autonomous science, a discipline of pedagogy) (Klapan, 2002; Zmeyov, 1998), we can say that in general it is an attempt to focus on the learner rather than the teacher. It provides an alternative to the methodology-centred instructional design perspective (Holton, Swanson, \& Naquin, 2001) and has greatly helped in understanding adults as learners. It is also clear that those principles have been emerging in mainstream education over the last few decades (Major \& Palmer, 2006).

The aim of the article is to consider the use of andragogical knowledge and practices in mainstream education in order to prevent ESL. First, we will review the basic concepts and principles of andragogy and present their practical implications in mainstream education. Here we would like to focus on so-called learner-centred education, some of whose aspects have already come to life in some countries, e.g. the United States of America (Harris \& Cullen, 2008; McCombs, 2001). At the end, we draw parallels between the concept of andragogy, learner-centred education in mainstream education, and its role in ESL prevention (see Figure 10). 


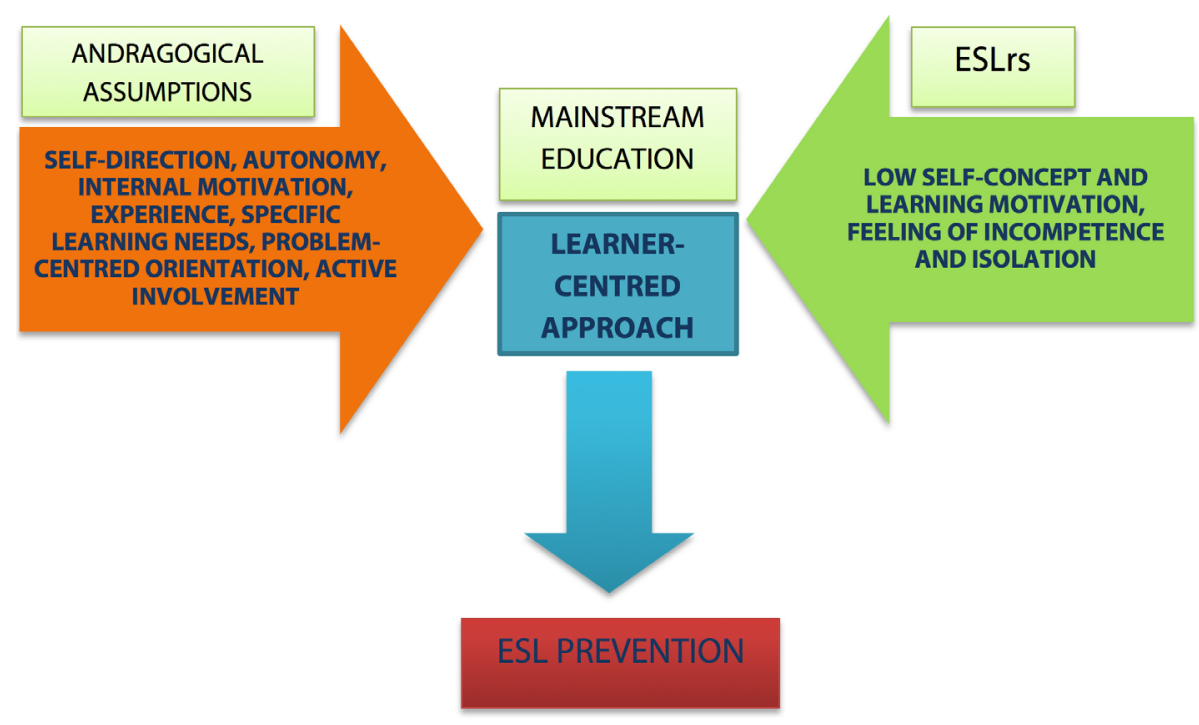

Figure Io. ESL prevention in mainstream education and role of andragogical knowledge

\section{Methodology}

In the process of reviewing the literature in fields of andragogy, andragogical knowledge and its role in mainstream education and fighting ESL, we first conducted a literature search of the scientific EBSCOhost online research databases (Academic Search Complete, ERIC, PsycARTICLES, PsycBOOKS, PsycINFO, and SocINDEX with full text databases). Since our focus was on investigating practical use of andragogical knowledge in mainstream education for ESL prevention, we also searched for related results online. The main key words initially used in both cases were: adult education, andragogy, andragogical knowledge, andragogical principles, principles of adult education, student-centred learning, and andragogical knowledge in mainstream education. Given that we were also interested in comparing the pedagogical and adult education principles, we also searched for results in those areas. In addition, we examined references cited in doctoral dissertations, reviewed articles, curriculum implementations in different countries, and project reports. Texts taken into account had to meet the following criteria: the topic needed to address andragogical principles, use of those principles in mainstream education, or learner-centred practices. 


\section{Concepts and Assumptions of Andragogy}

In this section, we focus on describing the theoretical concepts that underlie andragogy and the andragogical model stated by Knowles (1989) which, as mentioned, is the basis of andragogy.

If we summarise different authors in this field (e.g. Cercone, 2008; Merriam, 2001; Sharan, 2001), there are three such theoretical concepts: concept of experiential learning, concept of self-directed learning, and transformative learning theory. Experiential learning is a concept central to andragogy. It emphasises knowledge of concepts, facts, information and experience, application of this prior knowledge to current, ongoing events and reflection of the newly gained knowledge with a thoughtful analysis of learners' activity that contributes to personal growth. Self-directed learning suggests that the locus of control in learning lies with the adult learner, who can initiate learning with or without assistance from others, while transformative learning theory explains that it is important for an individual learner to understand why he thinks and feels the way he does and shakes off the limiting perspectives that could hinder the learning experience. Learning is therefore a process of critical reflection and is about change in learners. It is learning that occurs when individuals make meaning out of the world through experiences and where the goal is to enable the adult learner to become a more autonomous thinker.

As we can see, these theories emphasise self-direction, flexibility, and the process of learning, rather than the content. They are learner-centred and recognise the importance of a customised approach to learning (Cercone, 2008). As such, they are important pillars of Knowles' andragogical model which consists of two parts: (1) andragogical assumptions that present the core conceptions of adults as learners; and (2) the andragogical process and transaction design where six steps for creating adult learning experience are described. Throughout the description of the andragogical model, we intend to expose the role of the educator in each step. The assumptions of andragogy present the basics for understanding, planning, executing and evaluating an adult education process in practice. In the continuation, we describe these assumptions (see Figure 33) in greater detail.

The need to know. The first assumption underlying andragogy is that adults need to know why they need to learn something before learning it. Educators must therefore make a learning process meaningful and concrete in order to engage adults in learning (ibid.). 


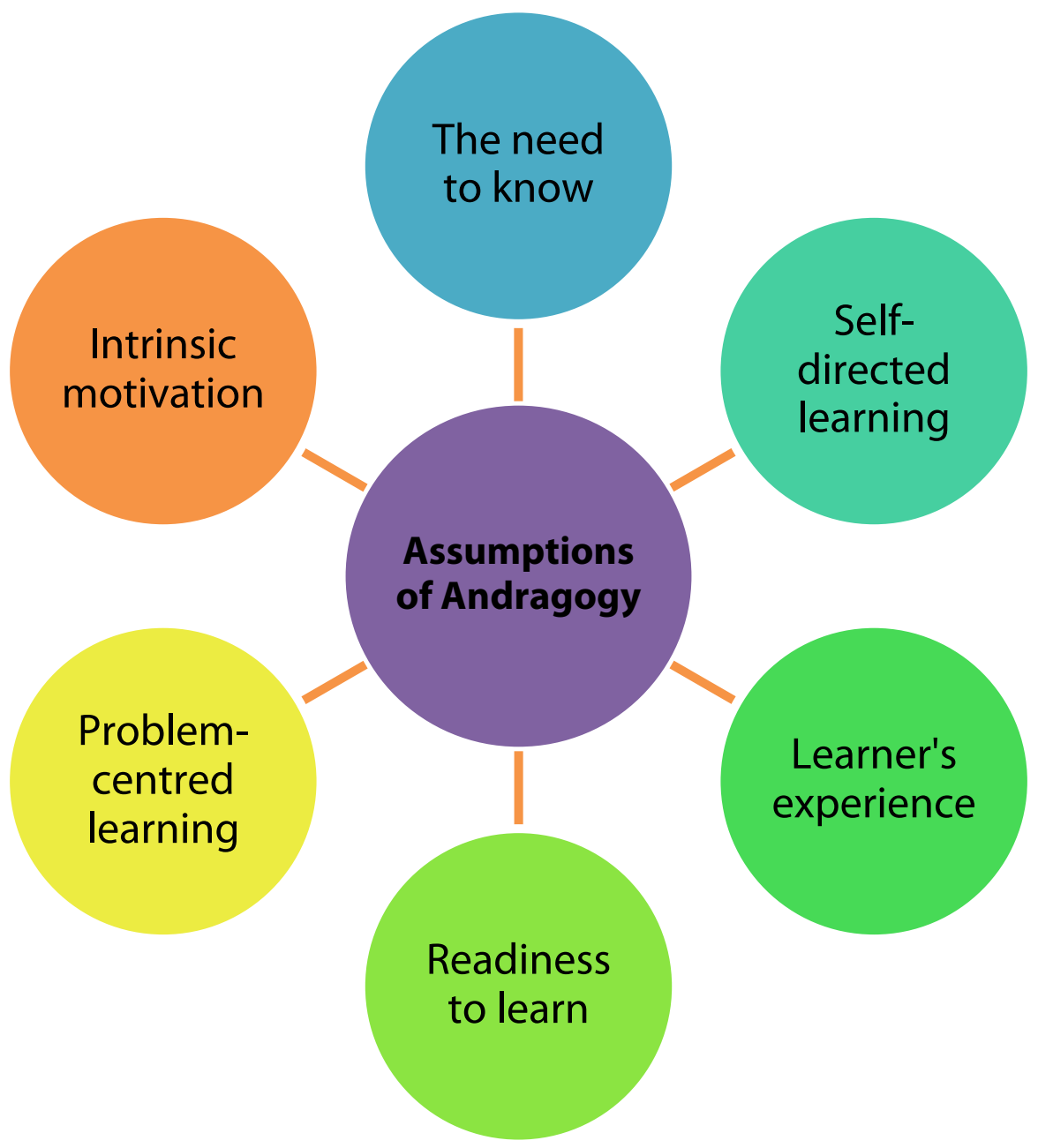

Figure II. Assumptions of andragogy (Proposed by Knowles (1989))

Self-directed learning. The second assumption refers to adult learners' independent self-concept and ability to direct their own learning. Adult learners are perceived as autonomous, independent, self-reliant, and they are self-directed toward goals. The role of educators is thus to encourage them to start taking responsibility for their learning. They should actively involve the participants in the learning process and be facilitators for this process. Other important practical steps that support self-directed learning are the following: organising the appropriate learning climate (e.g. 
informally arranged rooms), diagnosis of the learner's needs (involvement of adult learners in a process of self-diagnosis of their learning needs), involvement of learners in the process of planning their learning, conducting learning experience and treating the learning-teaching transaction as the mutual responsibility of the learner and educator, and appropriate evaluation of learning (the shift from evaluation to self-evaluation) (Cercone, 2008; Holton, Swanson, \& Naquin, 2001).

The learner's experience. The third assumption emphasises the role of adults' life experiences in the educational process. Adults have a large repertoire of experience, which should be treated as a rich resource for learning. This assumption derives from cognitive learning theory where the knowledge construction process involves the individual's need to attach new knowledge to already existing internal knowledge structures. At this stage, it is important for the educator to be aware of the value of the experience and prior knowledge of the participants. Adults want to use what they know and wish to be acknowledged for having that knowledge. To support this, educators should encourage learners to learn how to learn from their experience (recognise and free their minds from preconceptions), encourage experiential learning techniques and give emphasis to the practical application of newly gained knowledge (Merriam \& Caffarella, 1999).

Readiness to learn. The fourth assumption of andragogy refers to the adult's readiness concerning their current developmental tasks and social roles. Merriam (2001) stated that the learning needs of adults are often closely related to their social roles. Adults feel ready to learn when they feel a need to cope with a certain developmental task (e.g. finding a job, raising children etc.). In this way, educators should be aware of considering this aspect when planning the curriculum which must be timed with the developmental tasks of adults and their current social roles. It is also beneficial to combine adults with similar social roles in the educational setting so they can also share their life experience and learn from each other.

Problem-centred learning. The fifth assumption is closely associated to the previous one in that it considers the change in time perspective as people mature from the future application of knowledge to the immediacy of application. This means that adult learning is problem-centred and less subject-centred (Merriam \& Caffarella, 1999). Accordingly, educators should pay attention to this when organising the educational curriculum: it should acknowledge a problem-centred orientation and design learning experience in this manner. 
Intrinsic motivation. The sixth assumption relates to adults' motivation for learning and in a way sums up the previous assumptions. It says that adults can be motivated to learn only by acknowledging their current needs, problems and reasons for learning. Their learning process is therefore generally internally driven (Cercone, 2008).

In line with the assumptions about adults as learners, Knowles (1989) designed the following steps of the educational process that must be acknowledged by an adult educator to successfully create an adult learning experience:

1. involving participants in diagnosing their learning needs;

2. establishing a climate conducive to learning;

3. involving learners in mutual content planning (acknowledging their prior knowledge and experience, designing a flexible curriculum);

4. involving learners in forming their learning objectives and plans;

5. helping learners carry out their learning plans where they take responsibility for their own learning; and

6. involving learners in evaluating their learning outcomes.

All of these steps cannot be performed without use of teaching and learning practices and methods based on the active involvement of the participants and mutual cooperation and non-hierarchical relations between learners and teachers. At this point, we briefly present some of most evident adult education practices and methods that support and acknowledge learners' motivation for learning, self-direction, interests and overall active involvement in the process of learning. These practices are (Cartor, 1990; Gitterman, 2004; Vacarepu, Steiner, \& Kovacs, 2011): interactive teaching methods (e.g. group discussions, applied problem-based sessions, mutual interviews, project work, study circles, discussion about the participant's informal and incidental learning), hands-on activities, students' mentoring (especially for small groups of students), explicit use of students' prior knowledge, sharing experience and reflections of students, responding to the learning needs - target- and goal-oriented, a positive and constructive training environment, applicability of knowledge - personal and professional meaning, and self-directed learning.

The role of an educator is primarily to keep class conversations focused and directed, provide new ideas and perspectives, help students find 
the connections between their experiences and class discussions and assist students create a classroom climate where they feel invested in each other's learning. Students need to be encouraged to help each other to present and develop their ideas while they are in the process of being formed and shaped (Gitterman, 2004).

All the above-mentioned andragogical assumptions, approaches and methods are already widely used in the field of adult education, second-chance programmes, evening schools and also community-based programmes. Parallel to the development of these humanistic and pragmatic approaches to learning and educating in adult education, there have been similar indices of such development in mainstream education in the past two decades in some Western countries. Gehring (2000) states that some developments of new curricula in mainstream education contain certain aspects of andragogy in a way that acknowledges students' concerns and engages them in the process of self-directed discovery. This approach is known as the learner-centred approach and we further describe it in the following section.

\section{Adult education principles (the learner-centred approach) in mainstream education}

The learner-centred approach to teaching and learning is a reflection of andragogical practices already used in adult education. Like andragogy, the learner-centred approach couples a focus on the individual learner (their heredity, experiences, perspectives, backgrounds, talents, interests, capacities and needs) with the process of learning (McCombs, 2001). These principles emphasise the active and reflective nature of learning and learners (APA, 1997). There are 14 learner-centred principles that the APA (1997) categorised into four research-validated domains important for learning: metacognitive and cognitive factors that reflect the andragogical assumptions of the need to know and readiness to learn (e.g. personal relevance of goals, importance of developing higher-order learning strategies and strategic thinking), affective and motivational factors, that reflect the andragogical assumptions of self-directed learning and intrinsic motivation (e.g. the importance of the individual's interests, goals, beliefs, emotions and effort), developmental and social factors, that reflect andragogical assumptions of readiness to learn and problem-centred learning (e.g. learning is most effective when it addresses the individual's developmental stage, social roles and belonging tasks), individual difference factors, that reflect 
the andragogical assumptions of the importance of the learner's experience (e.g. taking into the learner's prior learning experience, knowledge, learning approaches and capabilities the account), and diversity in learning factors (those factors take account of the learner's cultural and social background and as such the learner-centred approach in comparison to andragogical assumptions broadens the acknowledgement of factors that are important for learning processes).

The learner-centred approach is still in its development, especially in practice. Even if there is some evidence of its implementation in some countries, especially the USA (Harris \& Cullen, 2008; McCombs, 2001), the teacher-centred approach continues to prevail in most education systems and the learner-centred approach is more a domain of adult education practices and second-chance programmes. And what is the role of andragogical knowledge and the learner-centred approach in mainstream education in tackling ESL? In the next section, we draw out the connections between the effects of learner-centred approaches to learning in mainstream education and ESL prevention.

\section{The learner-centred approach and ESL prevention}

As mentioned in the introduction, efforts to refocus teaching and learning processes to become more learner-centred have been driven by a new understanding about how humans learn. Different studies (e.g. Harris \& Cullen, 2008; Weimer, 2002) confirm that students are more likely to be receptive to learning if they believe that the information is relevant to their lives and if they feel they are in control of the process. On the other hand, motivation proved to be jeopardised by a lack of the individual's control over the learning process - the more teachers employ control measures, the more students are resistant to learning. By allowing students to share power in making decisions regarding activities, assignments and classroom policies, students tend to take a more active and engaged role in their learning. Studies (e.g. Cornelius-White, 2007; Steckol, 2007; Weimer, 2002; Wells \& Jones, 2005; Wohlfarth et al., 2008) also confirm that using a more collaborative teaching style and formative assessment, working in small groups, encouraging personal portfolios and student-driven classroom experience result in greater learning motivation, grades and self-directed learning. Students also reported that they, like adults, enjoyed being treated as competent individuals who can be trusted with the learning experience. 
Even though the learner-centred approach still needs development and empirical support, based on the available study results we can see that it addresses different obstacles that prevent ESLers from insisting in the learning processes: ESLers' beliefs that school is irrelevant to their lives, low motivation for learning and engagement in the learning processes, feelings of disconnectedness, social isolation, and feelings of personal incompetence and irrelevance in the learning process (Benard, 1991; Frostad, Pijl, \& Mjaavatn, 2014; Schargel \& Smink, 2004). As such, the learner-centred approach could be a powerful tool for preventing ESL when already implemented in mainstream education in early stages.

\section{Conclusion}

Andragogy is a learner-centred approach to learning and teaching where learners are treated as autonomous, self-directed, internally motivated, problem-solving-oriented and pragmatically-oriented individuals who have a need to be respected and accepted for their knowledge and experience. As such, it reflects the theoretical concepts of experiential learning, the concepts of self-directed learning and transformative learning theory. Deriving from those concepts, the learner-centred approach to learning and educating in mainstream education takes into the consideration the individual's needs, inspirations, motives, conditions and abilities. It is inclusive and supports autonomy, competence and relatedness, concepts that are crucial to the individual's motivation for learning and participation (Ryan \& Deci, 2000). Some authors (Brendtro, 1999; McCombs, 2001; Wheatley, 1999) point out that given the rising levels of youth crime, disruptive school behaviour and early drop out, schools no longer have the luxury of ignoring the personal needs of students. At the core of these youth issues lies feelings of alienation, disconnectedness, spiritual crisis, and a search for the purpose and meaning of life. Without corresponding to their learning needs, we are in danger of continuing to ignore students' calls for help when they report they feel disconnected from each other, think school is irrelevant, or drop out mentally or physically from the learning environment. Therefore, what is needed is a learning and teaching approach that reconnects youth, teachers and schools, motivates them for learning, acknowledges their learning needs and actively involves them in the learning process. Studies show that implementing andragogic principles in education results in higher motivation of students, grades, a sense of belonging to school and connectedness (e.g. Steckol, 2007; Weimer, 2002; Wells \& Jones, 
2005; Wohlfarth et al., 2008). This is especially the case with vulnerable groups of students such as potential ESLers. Since the learner-centred approach is both needs- and problem-oriented, it can be one of the ways for achieving that.

One of the first important steps in this process is to empower teachers in andragogical knowledge and learner-centred approaches to learning, its origins, assumptions, practical implications, methods and advantages it can bring to the teacher, learner and community. It is a great shift in perceptions of the whole process of teaching and learning and the role of the teacher in this process. Maybe this is also why the incorporation of these practices in the mainstream education is a slow process. Riley and Roach (2006) also point to an important moment in empowering teachers with this knowledge. They state that if we want teachers to incorporate those principles into their work, we need to teach them in the same way we want them to teach. When they themselves are included in planning the learning process, when their needs and experience are accounted for, when they experience interactive teaching methods themselves and are accepted in a supportive learning environment as respected, self-directed and autonomous individuals, the incorporation of those practices into their work and consequently ESL prevention processes can begin.

\section{References}

American Psychological Association (1997). Learner-centered psychological principles: A framework for school reform. Retrieved from https://www. apa.org/ed/governance/bea/learner-centered.pdf

Benard, B. (1991). Fostering resiliency in kids: Protective factors in the family, school, and community. Oregon: Western Regional Center for Drug-Free Schools and Communities.

Brendtro, L. K. (1999). Tools for reclaiming at-risk youth. Keynote presentation at the 8th Annual Rocky Mountain Regional Conference in Violence Prevention in Schools and Communities. Denver: Colorado.

Cartor, R. A. (1990). A comparison of andragogy and pedagogy: Assessing the relationship between individual personality differences, learning styles, and training types. University of Tennessee: Unpublished dissertation.

Cercone, K. (2008). Characteristics of adult learners with implications for online learning design. AACE Journal, 16(2), 137-159. 
Chan, S. (2010). Applications of andragogy in multi-disciplined teaching and learning. Journal of Adult Education, 39(2), 25-35.

Cornelius-White, J. (2007). Learner-centered teacher-student relationships are effective: A meta-analysis. Review of Educational Research, 77(1), 113-143.

Frostad, P., Pijl, S., \& Mjaavatn, P. (2014). Losing all interest in school: Social participation as a predictor of the intention to leave upper secondary school early. Scandinavian Journal of Education Research (online): http:// dx.doi.org/10.1080/00313831.2014.904420

Gehring, T. (2000). A compendium of material on the pedagogy-andragogy issue. Journal of Correctional Education, 51(1), 151-163.

Gitterman, A. (2004). Interactive andragogy: Principles, methods, and skills. Journal of Teaching in Social Work, 24, 95-112.

Holton, E. F., Swanson, R. A., \& Naquin, S. S. (2001). Andragogy in practice: Clarifying the andragogical model of adult learning. Performance Improvement Quarterly, 14(1), 118-143.

Howard, S. (1993). Accreditation of prior learning: Andragogy in action or a 'cut price' approach to education? Journal of Advanced Nursing, 18(11), $1817-1824$.

Klapan, A. (2002). Andragogy: Between theory and practice. Paper presented at the International Scientific Colloquium "Relationship of Pedagogical Theory and Pedagogical Practice”. Croatia: Crikvenica.

Knowles, M. S. (1980). The modern practice of adult education: From pedagogy to andragogy. Wilton, CT.: Associated Press.

Knowles, M. S. (1989). The making of an adult educator: An autobiographical journey. San Francisco: Jossey-Bass.

Lowry, C. M. (1989). Supporting and facilitating self-directed learning. ERIC Digests, 93, 1-6.

Major, C. H., \& Palmer, B. (2006). Reshaping teaching and learning: The transformation of faculty pedagogical content knowledge. Higher Education, $51,619-647$.

McCombs, B. L. (2001). What do we know about learners and learning? The learner-centered

framework: Bringing the educational system into balance. Educational Horizons, Spring, 182-192.

Merriam, S. B., \& Caffarella, R. S. (1999). Learning in adulthood (2nd ed.). San Francisco: Jossey-Bass. 
Merriam, S. B. (2001). Andragogy and self-directed learning: Pillars of adult learning theory. New Directions for Adult and Continuing Education, 89, 3-14.

Mezirow, J. (1997). Transformative learning. New Directions for Adult and Continuing Education, 74, 5-12.

Riley, D. A., \& Roach, M. A. (2006). Helping teachers grow: Toward theory and practice of an 'emergent curriculum' model of staff development. Early Childhood Education Journal, 33(5), 363-370.

Ryan, R. M., \& Deci, E. L. (200o). Self-determination theory and the facilitation of intrinsic motivation, social development, and well-being. American Psychologist, 55(1), 68-78.

Schargel, F. P., \& Smink, J. (2004). Helping students graduate: A strategic approach to dropout prevention. Larchmont, NY: Eye on Education.

Sharan, B. M. (2001). Andragogy and self-directed learning: Pillars of adult learning theory. New Directions for Adult and Continuing Education, 89, 3-12.

Steckol, K. F. (2007). Learner-centered teaching in higher education: Formative assessment

study turns classroom into research laboratory. The ASHA Leader, 12(5), 14-15.

Taylor, B., \& Kroth, M. (2009). Andragogy's transition into the future: Metaanalysis of andragogy and its search for a measurable instrument. Journal of Adult Education, 38(1), 1-11.

Vacarepu, A. S., Steiner, F., Kovacs, M. (Eds.). (2011). Innovative ways for motivating adults for learning. Cluj-Napoca: Consorpiul Internapional Lectura pi Scrierea pentru Dezvoltarea Gândirii Critice.

Weimer, M. (2002). Learner-centered teaching: Five key changes to practice. San Francisco, CA: Jossey- Bass.

Wells, M. A., \& Jones, B. D. (2005). Conference paper: Commonsense ISD An empirical approach to teaching systems analysis and design. Sydney: Australian Computer Society.

Wheatley, M. J. (1999). Leadership and the new science: Discovering order in a chaotic world ( $2^{\text {nd }}$ Ed.) San Francisco: Berrett-Koehler Publishers.

Wohlfarth, D., Sheras, D., Bennett, J. L., Simon, B., Pimentel, J. H., \& Gabel, L. E. (2008). Student perceptions of learner-centered teaching. Insight: $A$ Journal of Scholarly Teaching, 3, 67-74.

Zmeyov, S. I. (1998). Andragogy: Origins, developments and trends, International Review of Education. 4, 103-108. 
2.3 innovative trainings

for teachers and other

educational staff 



\subsection{I}

\section{Overview of Innovative Online Trainings for Educators}

Tina Vršnik Perše and Maša Vidmar

\section{Synopsis}

The professional development of educators for addressing ESL can be successfully supported by online trainings or other forms based on ICT. Currently, several online training platforms for educators exist across Europe and globally, but evaluation studies are lacking to help highlight best practices in the field.

\section{Summary}

The purpose of this paper is to highlight information on existing approaches and resources based on ICT that could be successful in the field of educators' professional development. This could be addressed by the online teacher training platforms that are implemented as traditional online courses, as video observation of the existing practices or as a set of exercises for gaining knowledge and competencies. Any of these can also be complemented with face-to-face interactions. Online or computer-based environments are flexible and easily accessible opportunities that provide access anytime and anyplace to case materials that can be used for learning new content or methods, for observing real-time situations and for (self)reflection and thus for developing the competencies needed for improving the practice of educators and, by so doing, for reducing the risk factors for students at risk of ESL. 
Existing practices across the world show several approaches to online trainings for educators. Some only target educators (such as Neopass@ction, MyTeachingPartner or SecondChanceEducation.eu), others are used by educators and students (such as Glow Connect) while in some others the educators are only a small group of target participants (like Aula Mentor from Spain). They use different methods such as online classrooms (e.g. Aula Mentor), sharing resources online (e.g. Glow Connect, SecondChanceEducation.eu, OpeningUpSlovenia, Neopass@ction, MyTeachingPartner), examples of best practices (e.g. SecondChanceEducation.eu), discussion groups and forums (e.g. Glow Connect), web-mediated coaching (MyTeachingPartner) etc. The online platforms also differ regarding whether they include a trainer, mentor or tutor. Some include a tutor in an online environment to ensure that objectives are met (e.g. Aula Mentor, Neopass@ction), others include expert consultants (e.g. Glow Connect, MyTeachingPartner) and often rely on the role of a moderator to supervise the contents (e.g. Neopass@ction, MyTeachingPartner, OpeningUpSlovenia, SecondChanceEducation. eu, Glow Connect). Currently, only a few of the above resources offer contents that specifically address early school leaving (ESL); however, such tools are being specifically developed within the TITA project.

Key words: online training platforms, professional development, teacher competences, team cooperation

\section{Introduction}

Educators' work tasks are very complex and have been changing rapidly in the last few decades, thereby offering a great challenge for both educators' performance and job satisfaction. In order to stay in touch with these challenges, educators tend to attend diverse professional development programmes. E-learning or learning with the assistance of ICT (such as online trainings) is one of the approaches that provides effective assistance for professional development because it can ensure rapid communication between colleagues and improves the quality of the work (Chang, 2016), but the choice of a method of e-learning is complex.

Learning based on ICT has several variations and can be carried out as any combination of: purely online (no face-to-face meetings), blended learning (combination of online and face-to-face), tutor-led group, 
self-study, self-study with expert support, web-based (Internet application), computer-based (e.g. DVD), video type, audio type, written-text-based type, synchronous communication (chat, videoconferences,...), asynchronous communication (forum, email,...), webinars, virtual classrooms, exams (online, paper,...), application sharing, resources sharing... Any of the above approaches and its combinations can be used for professional development and can be included in online trainings where educators observe and/or reflect on other educators' (or their own) ideas, practice and examples in a real or virtual environment.

This paper focuses on presenting the role of the existing online training programmes and platforms for educators since several advantages of online trainings for educators have been recognised. The article aims to provide an insight into the pro and cons of online educators' trainings and an overview of the existing online professional development resources for educators, some of which may also tackle issues related to preventing ESL.

\section{Methodology}

We conducted a review of the literature by searching in the ERIC, Proquest, Wiley, Science Direct and Google search engines for information. Search criteria were established concerning e-learning, online training platforms, teachers' professional development, and the cross-references for these search criteria were first examined. The search and analyses of other related papers followed. We included three types of documents: scientific papers for the theoretical background to the contents under scrutiny, web pages representing online training platforms as well as EU documents and reports. Based on these documents, the theoretical background and some already implemented online training programmes were presented in order to offer guidelines for modelling innovative online trainings.

\section{Advantages and limitations of online trainings}

Recently a frequent choice for educators' professional development has been online courses (combined with face-to-face training) since they provide two of the most essential elements of effective professional development: They give participating teachers opportunities to practise what they learn over relatively extended periods of time (as opposed to traditional in-service one-off seminar courses) and they provide an ideal environment for interaction among participants (National Staff Development Council, 
2001). Since existing traditional face-to-face professional development programmes typically do not include all of the educators in a school and the courses are usually held as one-off events, online virtual communities and all complementary alternatives could enable educators to share their experiences and exchange information and reflections and complement them continuously and collaboratively and thus improve as both individuals and a school team.

Many existing teacher professional development programmes are not high in quality, offering only 'fragmented, intellectually superficial' seminars (Borko, 2004) that do not meet the educators' expectations in terms of developing the much needed competencies. Not only are educators often not very satisfied with the traditional professional development training courses but the lack of continuity of and collective approaches to those training courses also needs to be addressed. Therefore, several strong initiatives for implementing new technologies in educators' professional development have emerged since the end of the $2 \mathrm{O}^{\text {th }}$ century.

The use of ICT in education in general was recently found to be most effective when it is used as a teaching supplement, as learning support, as encouragement for reflection and as promotion for cognitive dissonance (Smetana \& Bell, 2012), as an enrichment (Pedro, 2005) and not so much if it is used as the only source for learning. Since teachers are (already) education professionals with limited time and financial resources, ICTsupported possibilities for professional development are among the easily accessible ways to achieve the goal of supporting educators' professional development. It is commonly agreed that we need to build teachers' capacity for development and improvement but we also need to be sure that time, effort and scarce resources are expended only on quality programmes (Dede, Ketelhut, Whitehouse, Breit, \& McCloskey, 2009). Virtual platforms and supporting online networks could make the implementation of educators' competence development more effective in all those aspects: online teacher professional development models can provide high quality learning opportunities; teachers have access to experts in a given field; they are able to collaborate with others; online learning allows time for (self)reflection and for dialogue; it allows for flexibility in scheduling, timing and the development of one's own learning spaces. In other words, it can be empowering as teachers take ownership of their own learning. Online teacher professional development can also serve as a bridge between preservice 
education, new teacher support (induction) and continuing teacher development (Sprague, 2006).

The induction process is often mentioned as an important but organisationally and financially challenging characteristic of a quality education system. Participating in face-to-face situations as an observer (mentor or trainee) is challenging since one cannot be present everywhere at once and cannot pay attention to all students and situations simultaneously. The observations and participation in real-life situations are also very time-consuming. Therefore, the solutions such as computer-supported settings could be implemented because small segments of video clips can be used where teachers observe their own performance or the performance of other teachers and professionally develop through (self)reflection. In addition, a lot of teachers can observe the same situation and learn from it.

As the TALIS survey sums up, in seeking to meet teachers' professional development requirements, policymakers and practitioners need to consider both how to support and encourage participation and how to ensure that opportunities match teachers' perceived needs. This must be balanced with the cost in terms of both finance and teachers' time (OECD, 2009). Moreover, policy measures should be aimed at reviewing and adapting the offer of in-service training opportunities to ensure they respond to teachers' needs for professional development (balancing them with needs at school and at the system level) and have a proven impact on teachers' practice and, consequently, on learner attainment. Providing attractive possibilities for professional development helps teachers address skills deficits and update their competencies throughout their career. This is especially relevant in the current circumstances of limited budgetary possibilities and the barriers to participate in continuing professional development as indicated by TALIS such as 'conflict with schedule' (OECD, 2014). Similarly, policymakers will want to look at the effectiveness of the different forms of continuing professional development on offer and focus on those which combine theory with practice and offer the possibility to collaborate and exchange with peers. In the current budgetary conditions, countries should explore the possibilities offered by Open Educational Resources as they have the potential to address some of the key obstacles identified by teachers, such as high costs and conflict with work schedules (OECD, 2014).

The online trainings and other ICT-supported forms of professional development thus offer many opportunities in terms of providing attractive possibilities for balancing between needs at the individual, school and 
system levels, also considering the limited financial resources and reducing conflicts with the schedule. But, like with other methods, the online forms of professional development must be used with careful consideration.

It is interesting to examine how educators will accept the online or other ICT-based programmes for their professional development. A largescale professional development programme "Intel Teach - Advanced online" in Germany offers a blended-learning course with face-to-face meetings of teachers with a tutor and other teachers and e-learning training phases in which teachers use the online platform for individual and collaborative learning. The evaluation of this programme indicates that teachers have accepted the platform very well and use it as resource for theoretical and practical contents. The teachers' attitudes, with positive attitudes to technology, were also positive regarding the platform. On the other hand, the evaluation showed that a major limitation of implementing the platform was that teachers with low interest and negative attitudes to technology were clearly underrepresented or did not join the platform (Todorova \& Osburg, 2009).

This is a very realistic consideration for all initiatives for implementing ICT involving professional development programmes such as online professional development programmes and a reminder that this might not be the only option and that it should focus on diverse and attractive programmes and methods. Yet, on the other hand, it is very likely that the share of teachers who would join such a platform is larger than those with low interest and negative attitudes to new technologies and that it will grow in the future. TALIS (OECD, 2014) already indicated that teachers are expressing less of a need to learn about ICT than they did in 2008 (OECD, 2009), most probably because more teachers are becoming competent in ICT due to its use in everyday life. Nevertheless, these and other potential limitations of the online or other ICT-based programmes should be considered when planning such solutions in terms of preparing user-friendly solutions that are attractive and in-depth regarding the content. Further, the lack of face-to-face communication could also be considered as a major potential limitation.

Online training courses and traditional professional development courses can address similar issues and, when used as complementary methods, they can offer great potential. Some online programmes are supported with the possibility to watch and/or analyse video resources that can be used as tools for self-confronting one's own activity, for crossed 
self-confrontation crossing with colleagues' activity, confrontation with the recording of others' teaching and also collective confrontation where a group is confronted with a video (of their work or of the work of others) (Flandin \& Lussi Borer, 2016).

Considering the characteristics of modern society like complex working tasks and everyday life it is important to note that the ICT-based solutions for the professional development of teachers should not and cannot completely replace face-to-face programmes and experiences but could offer ongoing support for teachers who are not being provided with the traditional professional development programmes. It could provide a community-based (online community) and collaborative model of professional development.

\section{Examples of existing practice}

Several models for online educators' professional development are available. We present a few based on availability of information about the programme and primarily based on the content of a programme. A comparison of the online resources is found in Table 1.

The presented platforms indicate several similarities and differences.

Table 3. Similarities and differences among online platforms for educators' professional development

\begin{tabular}{|c|c|c|c|c|c|}
\hline Title & $\begin{array}{l}\text { Country } \\
\text { of origin }\end{array}$ & $\begin{array}{l}\text { Target } \\
\text { audience }\end{array}$ & $\begin{array}{c}\text { Methods } \\
\text { (Video, inte- } \\
\text { ractions, foru- } \\
\text { ms...) }\end{array}$ & $\begin{array}{l}\text { Including } \\
\text { trainers, tutors }\end{array}$ & Language \\
\hline Aula Mentor & Spain & $\begin{array}{l}\text { all adults se- } \\
\text { eking profe- } \\
\text { ssional de- } \\
\text { velopment, } \\
\text { computer lite- } \\
\text { racy and per- } \\
\text { sonal deve- } \\
\text { lopment and } \\
\text { unable to } \\
\text { access training } \\
\text { courses }\end{array}$ & $\begin{array}{l}\text { online classro- } \\
\text { oms, also tradi- } \\
\text { tional classro- } \\
\text { oms with } \\
\text { Internet access, } \\
\text { CD Roms, } \\
\text { study guides }\end{array}$ & $\begin{array}{l}\text { tutor or mentor } \\
\text { is included in } \\
\text { all programmes } \\
\text { and they are } \\
\text { responsible } \\
\text { for ensuring } \\
\text { that learning } \\
\text { objectives are } \\
\text { met online }\end{array}$ & Spanish \\
\hline
\end{tabular}




\begin{tabular}{|c|c|c|c|c|c|}
\hline Title & $\begin{array}{l}\text { Country } \\
\text { of origin }\end{array}$ & $\begin{array}{c}\text { Target } \\
\text { audience }\end{array}$ & $\begin{array}{c}\text { Methods } \\
\text { (Video, inte- } \\
\text { ractions, foru- } \\
\text { ms...) }\end{array}$ & $\begin{array}{c}\text { Including } \\
\text { trainers, tutors }\end{array}$ & Language \\
\hline Glow Connect & Scotland & $\begin{array}{l}\text { Glow is used by } \\
\text { staff and lear- } \\
\text { ners in schools } \\
\text { and early years } \\
\text { establishments } \\
\text { in Scotland }\end{array}$ & $\begin{array}{l}\text { tools and reso- } \\
\text { urces for stu- } \\
\text { dents, sharing } \\
\text { resources on- } \\
\text { line, discussi- } \\
\text { on groups and } \\
\text { forums, natio- } \\
\text { nal professional } \\
\text { learning com- } \\
\text { munity }\end{array}$ & $\begin{array}{l}\text { services have } \\
\text { moderators } \\
\text { and some even } \\
\text { consultants } \\
\text { or professio- } \\
\text { nals for expert } \\
\text { support }\end{array}$ & English \\
\hline $\begin{array}{l}\text { Second } \\
\text { ChanceEducati- } \\
\text { on.eu }\end{array}$ & $\mathrm{EU}$ & teachers & $\begin{array}{l}\text { qualitative } \\
\text { benchmarking } \\
\text { of schools, to- } \\
\text { ols for working } \\
\text { with beneficia- } \\
\text { ries (examples } \\
\text { of best practi- } \\
\text { ces such as we- } \\
\text { binars, lear- } \\
\text { ning apps etc. } \\
\text { are available), } \\
\text { validation of } \\
\text { international } \\
\text { placements }\end{array}$ & moderator & English \\
\hline $\begin{array}{l}\text { Opening } \\
\text { Up Slovenia }\end{array}$ & Slovenia & $\begin{array}{l}\text { educators at all } \\
\text { levels of edu- } \\
\text { cation, resear- } \\
\text { chers, industry } \\
\text { and technologi- } \\
\text { cal partners }\end{array}$ & $\begin{array}{l}\text { project initi- } \\
\text { atives, mobi- } \\
\text { le application } \\
\text { presentations } \\
\text { and develo- } \\
\text { pment, MO- } \\
\text { OCs (Massive } \\
\text { Open Onli- } \\
\text { ne Courses) are } \\
\text { online courses } \\
\text { aimed at un- } \\
\text { limited parti- } \\
\text { cipation and } \\
\text { open access } \\
\text { via the web), } \\
\text { events, publica- } \\
\text { tions }\end{array}$ & moderator & $\begin{array}{l}\text { English, } \\
\text { Slovenian }\end{array}$ \\
\hline
\end{tabular}




\begin{tabular}{|c|c|c|c|c|c|}
\hline Title & $\begin{array}{l}\text { Country } \\
\text { of origin }\end{array}$ & $\begin{array}{c}\text { Target } \\
\text { audience }\end{array}$ & $\begin{array}{c}\text { Methods } \\
\text { (Video, inte- } \\
\text { ractions, foru- } \\
\text { ms...) }\end{array}$ & $\begin{array}{c}\text { Including } \\
\text { trainers, tutors }\end{array}$ & Language \\
\hline Neopass@ction & France & educators & $\begin{array}{l}\text { distance self- } \\
\text {-training reso- } \\
\text { urces (written } \\
\text { and video), re- } \\
\text { sources for in- } \\
\text { stitutionali- } \\
\text { sed training } \\
\text { with trainers or } \\
\text { tutors }\end{array}$ & $\begin{array}{l}\text { moderator, tra- } \\
\text { iners, tutors }\end{array}$ & French \\
\hline $\begin{array}{l}\text { MyTeaching } \\
\text { Partner }\end{array}$ & $\begin{array}{l}\text { Virgini- } \\
\text { a,USA }\end{array}$ & teachers & $\begin{array}{l}\text { video clips, tra- } \\
\text { ining course, } \\
\text { web-mediated } \\
\text { individualised } \\
\text { coaching }\end{array}$ & $\begin{array}{l}\text { moderator, } \\
\text { expert consul- } \\
\text { tants }\end{array}$ & English \\
\hline
\end{tabular}

Some of these models are considered formal as they lead to a formal degree or certificate and are developed through multiple partnerships such as Aula Mentor (Spain) and Glow Connect (Scotland).

One of the most complex computer-supported systems designed for continuous professional development is Aula Mentor (Mentor Classroom) from Spain. Today, Aula Mentor offers a range of courses and options and covers 27 different areas, ranging from Introduction to computer technology to Education and several specific professions such as textile and tourism (Aula Mentor, n.d.). Only certain courses specifically target educators and their professional development. Aula Mentor was one of the first web-based designs to focus on the professional development of educators, having been first established in the early 1990 os. It is an open and distance learning system used primarily as a way of communicating through an electronic platform and website and its courses are designed to provide additional training for those seeking professional development. It is aimed at groups unable to access training courses and all successfully completed courses are certified (Aula Mentor, n.d.). Altogether, over 120 courses are offered through the programme (Aula Mentor, n.d.) and they are all intended to last an average of 4 months. In the area of Education, there are 10 different courses of which there are currently no specific courses dealing with early school leaving or cooperation directly, although they are being developed within the TITA project. Given the self-paced nature of all coursework, however, actual study time may either be shorter or longer. In pacing themselves, students (enrolled in courses in Spain) must keep in mind that final exams are 
given five times a year and must be taken in person in order to obtain a certificate (Verdisco, 2002).

Scotland has developed a nationally available digital environment for learning called Glow Connect that also supports programmes that lead to a formal certificate. Glow is the world's first national intranet for education and connects 80o,ooo learners and teachers across Scotland. Glow encompasses over 2,700 schools, 750,000 school students and over 50,000 teaching staff; there is also the capacity to accommodate 700,000 parents within the system. It is funded by the Scottish Government and managed by Learning and Teaching Scotland. A number of contractual stakeholders are identified as users of Glow, among them local authorities, faculties of education and several governing institutions. It provides access to a range of digital tools and services, and an environment in which learners and teachers can create, collaborate and innovate (Glow Connect, n.d.). Therefore, it is designed as a multi-professional system and inter-agency cooperation that supports several different types of experts and stakeholders. Glow is not just a platform but also offers a username and password that gives access to several different web services: Microsoft Office 365 (provides storage space on Microsoft's cloud storage service), WordPress blogs (online blogging system storage), Wikispaces wikis (a social writing platform for education, easy to create an online classroom workspace where teachers and students can communicate and work on writing projects alone or in teams) and Adobe Connect (a web conferencing software service for online meeting experiences for collaboration, virtual classrooms and large-scale webinars) as part of a Broadcasting service (Glow TV and Glow Meet). Glow provides a variety of safe and secure cloud-based services for collaborative, innovative and social learning, co-creation, and easy web publishing. Glow accounts are available to all schools and education establishments across Scotland, including independent schools and teacher education colleges/ universities (Glow Connect, n.d.).

Other models are less formal and involve the use of a variety of tools, including case studies or e-mail discussion boards (such as SecondChanceEducation.eu or Opening-up-Slovenia).

The SecondChanceEducation.eu project is an initiative of the Digital Second Chance Opportunities project and is a learning platform for educators. This project has been funded with support from the European Commission and is carried out by an international consortium. It focusses on the quality improvement of second-chance education, paying particular 
attention to the development of a European online knowledge and quality centre. The training possibilities support teachers, trainers, mentors and other educators working with ESLers to develop and grow. Further education of teachers, qualitative benchmarking of schools, tools for working with beneficiaries and validation of international placements are the project's main goals. More than 30 trainings are available as professional development training programmes for educators and several of them focus on the factors that are common risk factors for early school leaving, such as managing conflict, raising standards through mentoring etc. In addition, more than 30 practices are available that offer best practices in the form of records used by other educators. SecondChanceEducation.eu is also building the largest database of learning methods and good practices in the triangle of learning, living and working. Any educator can join and share their good practice or learning method and therefore receive feedback on their own ideas. It was developed based on previous projects and materials developed in them (such as DISCO - Digital Second Chance Opportunities, that was a project funded by the Erasmus + Programme (EFVET, n.d.), LION Learning, lIving, wOrking for Neet-group, that was a Gruntvig multilateral project, addressing the issues of people who are not in employment, education or training (CESIE, 2013) and EXACT - Excellence academy for trainers, that was funded by the "Lifelong Learning Program" of the EC (SecondChanceEducation, n.d.)).

OpeningUpSlovenia from Slovenia is a full-scale, national-level and unique experimental case study that is attempting to create a unique nationwide research environment in open education. It is planned to support the development and availability of: open digital pedagogies, open educational resources, open ICT-based technologies, open innovative business models, and open digitally-supported learning environments. The initiative is still in its initial phase and development is in progress (OpeningUpSlovenia, n.d.). Its main contribution should be open-access materials for different focus points concerning education and also flexibility for developing areas of interest to educators at any given moment. The test-bed comprises a coalition of all Slovenian universities, compulsory and vocational education institutions with technical, research and industry partners.

Moreover, some course websites are designed for complementing faceto-face professional development programmes (such as Neopass@ction or MyTeachingPartner $\left.{ }^{\mathrm{Tm}}\right)$. 
Neopass@ction is a tool for teacher training from France that seeks to provide examples of actual teacher work at the national level as distance self-training resources or institutionalised training with trainers or tutors. Neopass@ction is mostly based on video resources likely to significantly contribute to the professionalisation of beginning teachers and also for analysing issues for more experienced teachers. The platform is designed to serve at the national level as a resource for either web-based training, which the learner does alone, or for instructor-led training conducted in a classroom setting (Neopass@ction, n.d.).

The training module developed from this platform is therefore not aimed at imparting the practices of expert teachers in a prescriptive manner, but at bringing to bear the real experiences and current practices of beginners in the classroom, in view of gradually transforming those practices in line with personal standards of feasibility and professional effectiveness. One of the design assumptions is that, to facilitate the creation of links between real classroom experiences of platform users and their experiences during the viewing of training videos, the situations viewed must have some features in common with those already encountered by the users (Leblanc \& Ria, 2013).

Similarly, MyTeachingPartner ${ }^{\mathrm{Tn}}$, or MTP, is a system of professional development support from Virginia, USA that was developed for improving teacher-student interactions. It contains three specific resources that may be used either individually or in tandem: a video library of annotated examples of best practice, a college course and web-mediated individualised coaching: The video library contains more than 400 1- to 2-minute video clips of teachers' effective interactions with students for all levels of education and gives teachers an opportunity to observe other teachers' effective interactions as they implement a wide range of instructional activities in various contexts. The MTP coaching programme involves the following five steps in a 2-week cycle: a teacher records a classroom video, a coach reviews and selects the video and writes prompts, the teacher reviews the video and responds to the prompts, the teacher and the coach discuss the prompts and practice, summary and action plan for the next cycle (MyTeachingPartner ${ }^{\mathrm{m}}$, b.d.). One of the research papers concerning the effectiveness of the MyTeachingPartner coaching intervention indicates that a variety of individual and contextual factors relate to teachers' responsiveness to the programme objectives. Psychological factors, specifically anxiety and readiness to change, are related to several indicators of 
responsiveness. Thus, it may be beneficial to focus on participant characteristics prior to an intervention (Roberts et al., 2014).

Based on the evidence and the scarce evaluation studies about certain platforms, the recommendation is to implement a combination of online training and personal contact with the trainer or mentor and/or other participants since that provides an opportunity for implementing the personalised materials and courses regarding the needs of the trainee and also provides an opportunity for personalised improvement and the development of communication competencies. Thus, the motivation for professional development and the interest in further participation in the training are improved.

\section{Conclusions and recommendations}

Online or ICT-supported environments can simply provide easy access to case materials that can be used for learning new content or methods, for observing real-time situations and for (self)reflection and therefore contain a motivation factor in themselves. The analysis of the existing information regarding online or other ICT-based professional development programmes of educators has indicated more advantages than disadvantages of its implementation. As described, the online and other ICT-supported professional development programmes are well established and widely used approaches to the professional development of educators. But although the approaches have shifted a great deal from traditional to modern and are more focused on the construction of knowledge and ICT-supported technologies, the contents of professional development programmes are still mostly oriented to the traditional roles of the educators, mostly involving competencies about certain issues (such as teaching content, didactics, discipline, special needs etc.) and only a few involve contents focused on preventing ESL, such as understanding ESL, educators' self-reflection, social and emotional competencies and other.

The presented programmes are concentrated on several concepts, i.e. the programmes in Aula Mentor (n.d.) are focused on child development, the education of parents and families, sign language and drug use prevention etc., Glow Connect (n.d.) stresses the sharing and developing of resources, chiefly involving teaching content resources, OpeningUpSlovenia focuses on developing innovative approaches, primarily regarding different approaches for how to address the teaching content, Neopass@ction offers resources on how to support students in the transition from education 
to work, how to communicate with students, how to deal with discipline incidents etc., MyTeachingPartner concentrates on teachers' effective interactions with students, while SecondChanceEducation.eu aims to support educators working with ESL by highlighting communication, managing conflicts and connecting the education and work environments. Therefore, the scope and complexity covered by the different online programmes and platforms is very comprehensive and the required educators' competencies are even more so. Accordingly, the choice of a professional development programme for educators is complex.

The support provided by online or other ICT-supported professional development programmes can help trainees improve their understanding of the complex teaching know-how and improve their ability to analyse their own activities. But this link generally remains implicit during their formal training and, for the time being, evaluators must settle for postulating that users will engage in a self-analysis that will be useful to them, if not for acting directly then at least for recognising the corresponding professional situations in the field (Leblanc \& Ria, 2013). An important consideration for the designers of new platforms is thus to establish a system that makes the choice of programme easier by trying to encourage maintaining the use of the newly acquired competencies even after completing the initial course and to provide trainees with an opportunity to return to the platform for learning on another issue they are interested in. Therefore, each platform should be complex and flexible regarding both the contents and methods used but at the same time easy to comprehend and use.

The greatest challenges and points to consider when developing new platforms are: a) to be user-friendly; b) to provide tasks in such a way that participants cooperate/collaborate with each other and with a mentor or coach; c) to incorporate contents that are interesting and attractive to the participants; d) to include face-to-face interaction; e) another issue that could be resolved by including a skilled trainer is how to reach professionals who are not interested in using ICT; and f) establishing a system to maintain use of newly acquired competencies even after completing the initial course and for the return of participants to learn about other topics. When addressing those issues, the developers of online platforms (such as those being developed by the TITA project) should create platforms that will address current issues, such as ESL, but will also have the potential to focus on different issues when the need arises. 


\section{References}

Aula Mentor. (n.d.). Retrieved from http://www.mentor.mec.es/

Borko, H. (2004). Professional development and teaching learning: Mapping the terrain. Educational Researcher, 33(3), 3-15.

CESIE. (2013). LION (Learning, lIving, wOrking for Neet-group) For a holistic approach of work with NEETs. Retrieved from http://cesie.org/en/in-action/ european-cooperation/lion-neet/)

Chang, V., \& Wills, G. (2013). A University of Greenwich case study of cloudcomputing. E-logistics and e-supply chain management: Applications for evolving business, 232-253.

Cole, P. (2012). Linking effective professional learning with effective teaching practice. Melbourne: PTR Consulting and AITSL.

Dede, C., Ketelhut, D. J., Whitehouse, P., Breit, L., \& McCloskey, E. M. (2009). A research agenda for online teacher professional development. Journal of Teacher Education, 6o(1), 8-19.

Guerra, N. G., \& Bradshaw, C. P. (2008). Linking the prevention of problem behaviors and positive youth development: Core competencies for positive youth development and risk prevention. In N. G. Guerra \& C. P. Bradshaw (Eds.), Core competencies to prevent problem behaviors and promote positive youth development. New Directions for Child and Adolescent Development, 122, 1-17.

European Commission. (2012a). Supporting the teaching professions for better learning outcomes. Commission staff working document. Strasbourg: European Commission.

European Commission. (2012b). Assessment of key competences in initial education and training: Policy Guidance. Commission staff working document. Strasbourg: European Commission.

European Commission. (2013). Reducing early school leaving: Key messages and policy support. Final Report of the Thematic Working Group on Early School Leaving. Brussels: European Commission.

European Commission/EACEA/Eurydice/Cedefop. (2014). Tackling early leaving from education and training in Europe: Strategies, policies and measures. Eurydice and Cedefop Report. Luxembourg: Publications Office of the European Union.

EVFET. (n.d.). DISCO - Digital Second chance Opportunities. Retrieved from http://www.efvet.org/index. php?option=com_content $\&$ task=view\&id=59o\&Itemid $=\mathbf{2 2 3}$ 
Flandin, S. \& Lussi Borer, V. (2016). Using video to train teachers: An example in the workplace. Presentation at the European meeting of trainers 'Collaborative work to prevent ESL in Europe what kind of training?', Lyon, 29 January 2016.

Glow Connect. (n.d.). Retrieved from http://connect.glowscotland.org.uk/

Gratton, L., \& Erickson, T. J. (2007). Eight ways to build collaborative teams. Harvard Business Review. Retrieved from https://hbr.org/2007/11/ eight-ways-to-build-collaborative-teams

Koster, B., Brekelmans, M., Korthagen, F., \& Wubbels, T. (2005). Quality requirements for teacher educators. Teaching and Teacher Education, 21, 157-176.

Leblanc, S., \& Ria, L. (2013). Designing the Néopass@ction platform based on modeling of beginning teachers' activity. Design and Technology Education: An International Journal, 19(2), 40-51.

MyTeachingPartner ${ }^{\mathrm{rx}}$. (n.d.). Retrieved from http://curry.virginia.edu/research/ centers/castl/mtp

The National Staff Development Council. (2001). Standards for staff development, revised edition. Oxford: National Staff Development Council.

LION Learning (n.d.). Retrieved from http://www.lionlearning.eu/about

Neopass@ction. (n.d.). Retrieved from http://neo.ens-lyon.fr/neo

OECD. (2009). Teaching and learning international survey. Creating effective teaching and learning environments first results from Talis. Paris: OECD.

OECD. (2014). Talis 2013 results: An international perspective on teaching and learning. OECD Publishing. http://dx.doi.org/10.1787/9789264196261-en

OpeningUpSlovenia. (n.d.). Retrieved from http://ouslovenia.net/

Pantic, N., \& Wubbels, T. (2010). Teacher competencies as a basis for teacher education views of Serbian teachers and teacher educators. Teaching, 26(3), 694-703.

Paulus, T. M. (2005). Collaborative and cooperative approaches to online group work: The impact of task type. Distance Education, 26(1), 111-125.

Pedro, F. (2005). Comparing traditional and ICT-enriched university teaching methods: Evidence from two empirical studies. Higher Education in Europe, 3o(3-4), 399-411.

Roberts, A. M., LoCasale-Crouch, J., DeCoster, J., Hamre, B. K., Downer, J. T., Williford, A. P., \& Pianta, R. C. (2014). Individual and contextual factors associated with pre-kindergarten teachers' responsiveness to the Myteachingpartner coaching intervention. Prevention Science, November 
2014. SpringerLink. Retrieved from http://link.springer.com.ezproxy.lib. ukm.si/article/10.1007/s11121-014-0533-8/fulltext.html

SecondChanceEducation.eu. (n.d.). The European learning platform for teachers. Retrieved from http://www.secondchanceeducation.eu

Smetana, L. K., \& Bell, R. L. (2012). Computer simulations to support science instruction and learning: A critical review of the literature. International Journal of Science Education, 34(9), 1337-1370.

Sprague, D. (2006). Editorial: Research agenda for online teacher professional development. Journal of Technology and Teacher Education, 14(4), 657661. Chesapeake, VA: AACE.

Stoll, L., \& Louis, K. S. (2007). Professional learning communities: Elaborating new approaches. In L. Stoll \& K. S. Louis (Eds.), Professional learning communities: Divergence, depth and dilemmas (pp. 1-13). Berkshire, UK: Open University Press.

Todorova, A. \& Osburg, T. (2009). Intel ${ }^{\circledR}$ Teach - Advanced Online: Teachers' use of and attitudes toward online platform for professional development. Conference ICL2009, Villach, Austria.

Verdisco, A. (2002). Aula Mentor. Making connections and building capacities across continents. TechKnowLogia, Knowledge Enterprise, Inc. Retrieved from www.techknowlogia.org/TKL_Articles/PDF/44o.pdf

Zhu, C., Wang, D., Cai, Y., \& Engels, N. (2013). What core competencies are related to teachers' innovative teaching? Asia-Pacific Journal of Teacher Education, 41(1), 9-27. 



\section{3 .2}

\section{What can we Learn from Second-chance Education Programmes for Adults to Prevent ESL in Younger Generations?}

Klaudija Šterman Ivančič

\section{Synopsis}

A review of second-chance education programmes and practices indicates that mainstream education could help prevent ESL by implementing its main principles: a student-centred approach to learning, encouragement of a supportive school environment and relationships, socio-emotional support, use of interactive teaching methods and connectedness to different community agents.

\section{Summary}

The aim of this article is to present the main practices and principles of second-chance education programmes and discuss their implications for mainstream education in order to prevent ESL. Secondchance education programmes are organised as part of non-formal education in different countries and aim to enrol students who are at risk or have already left education early. They operate on the principles of lifelong learning, adult education and socially just education. This means that, besides offering students academic support and another chance to attain certain knowledge and an educational certificate, second-chance education programmes also address ESLers' educational, personal, social and cultural characteristics. Second-chance education programmes are currently widely present mainly in the USA, Australia and European countries. In our review of different second-chance education practices and project reports 
(Boronia second-chance school from Australia, Eumoschool from Italy, EU national reports from second-chance education in Greece, Austria, Italy and Romania, LION implemented in Italy, PROSA implemented in Austria, USA Big Picture Learning School, USA Opportunity House and Youth Chance High School etc.), we identified the following common principles: all programmes are based on a student-centred approach to teaching and learning, they put an emphasis on supportive relationships and a supportive environment, the socio-emotional development of participants is important, all use interactive teaching methods, and all of them are closely connected to the wider community. The extensive review by the European Commission (2013) supports our findings and concludes that, by including second-chance education programmes and its principles in formal educational content, this would more effectively serve as ESL prevention and compensation (e.g. Bloom, 2010; Ross \& Gray, 2005; Spierings, 2003).

Key words: second-chance education, ESL prevention, mainstream education

\section{Introduction}

In 1995, the European Commission issued the White Paper on Education and Training (Teaching and Learning: Towards the Learning Society), with the aim to fight social exclusion in Europe (Efstathiou, 2009). Another important part of this strategy was the implementation of second-chance education programmes into educational schemata in order to address the issue of ESLers as a group of socially excluded individuals. When the second-chance school scheme began in the EU context, second-chance education programmes were reflecting the belief of many experts and policy-makers that ESLers should not be brought back to 'the place of failure' and that one should think more in terms of job creation, vocational training and social care when attempting to help this target group.

Second-chance education programmes were, as a strategic approach involving schools, wider community agents and employers, further elaborated in 2006 and 2007 through the European Parliament's Lifelong Learning Action Programme and the European Commission's Action Plan on Adult Learning. These programmes provided the statutory and fiscal support to institutions participating in fighting against ESLers' segregation by offering them the opportunity to re-engage in education (European 
Commission, 2001; European Council, 2003; European Parliament, 2006; University of Florence, 2010).

Second-chance education is based on the idea that, through an accessible, non-selective, effective and organised educational structure, an individual can actualise an educational opportunity they missed or failed when enrolled in mainstream education for the first time (European Commission, 2001; Inbar \& Sever, 1989; Shavit, Ayalon, \& Kurleander, 2001).

Second-chance education programmes are today widespread in different countries around the world, but are most systematically researched and reported in Europe, the USA and Australia. They are referred to in various ways (e.g. flexible learning centres, second-chance schools, alternative schools, second-chance community, youth coaching programmes, evening schools, transfer schools etc.) and enrol different target groups. They can enrol students who are still involved in mainstream education but are at risk of not attaining any qualifications ${ }^{1}$ from the secondary education level (lower or upper), young people above the age of 15 not currently in education, employment or training, as well as individuals regardless of age, those already employed and who require special educational support in order to achieve a certain education level. As such, second-chance education programmes can entail ESL prevention and compensation for educational qualifications, from basic education to higher secondary education, up to continuing tertiary education (opening up cross-over points between the secondary and tertiary sectors). However, all of them aim to include individuals who are disadvantaged from an educational point of view, in labour market terms, socially and also culturally, and promote education as a means to keep or reintegrate individuals into the education and training system (Bills, Cook, \& Giles, 2015; Bloom, 2010; Efstathiou, 2009; LaganaRiordan et al., 2011; McGregora, Mills, Riele, \& Hayes, 2015; ROBIN project, 2016).

In its report on implementation of the Second Chance Education Pilot Project, the European Commission (2001) concluded that 94\% of investigated ESLers from 11 European countries could be rescued in a second-chance education scheme. This means that ESLers are not necessarily lost to the

1 In this type of second-chance education programmes, students are simultaneously involved in mainstream education and second-chance education. Second-chance education can be offered within or outside mainstream school facilities and provides more flexible ways of delivering mainstream courses. As such, second-chance education programmes are part, not only of an ESL compensation, but also an ESL prevention strategy. 
education system in the first place. Accordingly, another important question emerges: could the approach to education used in second-chance education prevent ESL already during the 'first chance' (European Commission, 2001)?

In the following article, we examine different second-chance education practices and project reports in order to: define the main principles of second-chance education programmes and, most importantly, present aspects of second-chance education programmes that could benefit mainstream education in order to prevent ESL already in the early years.

\section{Methodology}

Since the literature on second-chance education programmes in connection to ESL is wide and versatile, in addressing the topic we first conducted a search for policy frameworks and definitions, followed by a review of project reports carried out on the international (e.g. reports of the European Commission and European Council) and national levels. For a better review, we classified the projects according to region (European and non-European projects), target group and aims. Since the project reports are usually widely accessible, we first searched for the results online, followed by a search of the scientific EBSCOhost online research databases (Academic Search Complete, ERIC, PsycARTICLES, PsycBOOKS, PsycINFO, and SocINDEX with full-text databases). The main key words initially used in both cases were: second-chance education, second-chance education projects, second-chance education approach to ESL, second-chance education principles and second-chance programmes and ESL prevention/compensation. We also examined references cited in the project reports and the described implemental practices in different countries, and reviewed articles. Texts taken into account had to address second-chance education implementation, lessons learned from implementations, second-chance practices, principles, the use of those principles in mainstream education, and the use of second-chance approaches in preventing ESL.

\section{Principles of second-chance education programmes}

Cartier and associates (Cartier, Langevin, \& Robert, 2011) found that about $71 \%$ of American students who drop out of school admit they wish to return. Research also indicates that many students who drop out of high school are academically capable of finishing high school if given the right 
type of educational choices (Franklin \& Streeter, 1992, 1995; Franklin et al., 2007). Second-chance education programmes are designed in a way to offer such a choice.

As mentioned in the introduction, second-chance education programmes can enrol different age groups of individuals and can vary according to the content. Their main purpose is to offer a second chance to attain educational qualifications to educationally, socially and culturally disadvantaged individuals who are at risk or have already left mainstream education for various reasons. In this section, we present the main principles of second-chance education programmes we identified in our review of second-chance education project reports, summaries, meta-analyses and case studies (e.g. Black, Polidano, \& Tseng, 2012; Efstathiou, 2009; European Commission, 2001, 2013; McFadden, 1996; McGregora et al., 2015; ROBIN project, 2016; Ross \& Gray, 2005): the student-centred approach to learning, the socio-emotional development of participants, supportive teacher-student relationships, a supportive learning environment, interactive teaching methods, and cooperation with the local environment. As evident from main descriptions in the next section, at some points it is hard to describe a given principle as completely separate from other principles. Since they together form a process, i.e. a specific approach to teaching and learning, and since they are mutually and tightly connected, at times their descriptions overlap.

\section{Student-centred approach to learning}

The main aspect that distinguishes most second-chance education programmes from mainstream education is their approach to teaching and learning that is based on student-centred adult education approaches. This means that, when designing the curriculum, programmes are sensitive to social and cultural issues, individuals' interests, aspirations and differences, and they recognise the capacity of students to engage in decisions about their own learning and the capacity to be internally motivated for learning. As such, the student-centred approach enables students to mediate previous negative educational experiences and in this way they construct a positive self-image as a learner. An example from Australia's Boronia second-chance school (McGregora et al., 2015) shows that for teachers the biggest challenge of the student-centred approach is maintaining ESLers' motivation for learning. There are days when students are amotivated for learning and on such days support from teachers is of great importance. But 
it pays off in the end since they gain quality knowledge when they themselves decide to learn and work on things. Teachers also report that good practices for ESLers' motivation within the student-centred approach are: making the content authentic, organising activities based on students' interests, and drawing on real-life situations.

\section{Socio-emotional development of participants}

During the last decade, second-chance education programmes have also clearly defined social and emotional skill development as an important prerequisite for the cognitive and professional development of the learners. This means that ESLers are expected to develop beyond academic performance and achievements, i.e. they are expected to develop personally and socially (e.g. development of determination, adaptability, helpfulness, affective maturity, self-confidence, self-knowledge, inventiveness, resourcefulness, creativity, imagination, sociability and openness). As such, second-chance education programmes address the needs of students that are not met to such an extent in regular schools (European Commission, 2007; European Council, 2003; European Parliament, 2006; Franklin et al., 2007). Some good practices and projects based on fighting ESL through emotional learning (e.g. the Youth + programme in Europe and Australia, Eumoschool - Emotional education for early school leaving prevention in Italy) (Eumoschool, 2016; European Commission, 2013) show that in this way students develop into active citizens who are aware of the importance of their active participation in society and are able to understand themselves and their surroundings. To achieve that, teachers in those programmes report that they themselves need to take students' views seriously and also negotiate their own views with them on a daily basis in order to find a compromise and support them in developing more adaptable world-views.

\section{Supportive role of teachers}

Teachers that have a relevant qualification (e.g. teachers' subject knowledge, knowledge of conflict mediation, self-evaluation and the implementation of different teaching methodologies), teaching experience and possess a deeper, personal commitment to the success of students, empathy and compassion, are the key to the success of second-chance education programmes. In such a setting, teachers offer students an adult treatment and build on closer and more supportive student-teacher relationships. Teachers from second-chance education programmes in the USA. and Italy (e.g. 
alternative schools in the USA, Second-chance schools in Italy) (European Commission, 2013; USA State University, 2016) reported the prime advantage of such programmes lies in the flexibility of their own time, which enables them to form close relationships with ESLers and their families. This is especially important at the beginning of the educational process when they set the learning goals and plans together. In this way, this process can be personalised and forms the basis of an individualised learning plan. Teachers also support their students in setting reasonable and adaptive rules and regulations that consider a student's availability and other obligations. Riele (2000) concludes that such an approach enables alienated and disadvantaged students to be educated in more constructive ways.

\section{A supportive learning environment}

One of the important aims of many second-chance education programmes (e.g. USA Big Picture Learning School, USA alternative schools) is to create a suitable and flexible learning environment where, instead of discipline or correction, the environment is caring and emphasises learners' strengths (McGregora et al., 2015; Mills \& McGregor 2014). Different studies (e.g. Franklin et al., 2007; Saunders, Jones, Bowman, Loveder, \& Brooks 2003; Wang, Haertel, \& Walberg, 1997; Wyn, Stokes, \& Tyler, 2004) confirm that in such learning environments there are fewer incidents of violence, higher attendance levels, lower dropout rates, increased participation in extracurricular activities, meaningful relationships with peers and staff, and students' greater sense of belonging. Students from the Big Picture Learning second-chance school in the USA reported that when behavior problems occur the teachers negotiate with them honestly and also firmly. If students are not ready to participate, they are not penalised but are asked to take time off and come back when they feel ready to start afresh. Students reported that in this way they feel the teachers never give up on them. ESLers who attend second-chance education often come from socially disadvantaged environments. Teachers from the USA alternative schools report that when entering second-chance education ESLers often need to be taken care of (e.g. warm drink, some food, understanding interaction etc.) before making an educational plan. They thereby feel like persons in the process, which motivates them for future participation (Big Picture Learning, 2016; USA State University, 2016). 


\section{Interactive teaching methods}

Given that the aim of second-chance education programmes is the participants' active involvement and engagement in the educational process, the use of interactive teaching methods is inevitable. Teachers in second-chance education programmes from different EU countries (Greece, Austria and Italy) (European Commission, 2016; Frame, 2002; Hansen, 2006; Harrison, Price, Gavin, \& Florey, 2002; Koutrouba \& Karageorgou, 2013; Wurdinger \& Enloe, 2011) reported that the methods used depend on the competencies the programme aims to develop. In those countries, second-chance education aims to build general competencies as well as media skills, conflict resolution, self-research study confidence, and support for self-evaluation. They report that the most efficient teaching methods that are often used are: the creation of individual portfolios, project learning, learning in groups, partner work, individual self-learning phases, practice-oriented learning formats and exemplary learning. Another approach to teaching and learning that has proved to be effective when working with ESLers in second-chance education is the MGS (Movement, Games and Sport for psychosocial development) approach. Teachers in second-chance education programmes from Romania (European Commission, 2013) reported that the training, which is very practical and based on the experiential learning method of games as a psychosocial tool, simultaneously develops the mind, body and soul, promotes teamwork, builds self-confidence, encourages the expression of emotions, and stimulates creativity. Competition and exclusion is excluded from the methodology, and promotes cooperation and inclusion through sports, games and creative activities. It is also important to note that teachers from Greece, Austria, Italy and Romania stated that, in order to effectively implement interactive teaching methods, it is essential for them to be regularly trained in professional skills such as teamwork, supervision, reflection, feedback and self-evaluation.

\section{Cooperation with the local environment}

In our review, another important aspect of second-chance education programmes proved to be their local partnership with a large variety of partners, including mainstream schools. Practices from the USA alternative schools (e.g. Opportunity House, 2010; Youth Chance High School, 2016) show it is very important for ESLers' motivation and social integration to give them the opportunity to go to mainstream schools and take a class they prefer. If that works for them, they can stay and, if not, they return and 
take the class in an alternative setting. Recently, there have been several European Commission projects (e.g. PROSA in Austria, LION 28 in Italy) (ROBIN project, 2016) that specifically aimed to connect second-chance education programmes with social work institutions, community work, housing corporations, municipalities, educational institutions and businesses and welfare institutions. Project reports (Opportunity House, 2010; ROBIN project, 2016; Youth Chance High School, 2016) confirm that effective practices supported different opportunities for young people (e.g. deliberately-focused placements at potential employers, cultural activities, targeted learning support, remedial education groups, individual tuition, student-student guidance etc.) and also teachers (mobility experiences for trainers, tools and training for teachers etc.). Such cooperation of second-chance education programmes with the environment is vital because students who are enrolled in second-chance education programmes often need support and advice from different experts (European Commission, 2001).

In the case of fighting ESL, the role of employers is also pivotal since they show young people that a job requires skills, including basic skills. By offering work experience, employers assist youth in acquiring qualifications in demand on the labour market and also enable youngsters to set clear expectations and goals for the future (Kollas \& Halkia, 2014; Lange \& Sletten, 1995).

\section{Implications for mainstream education}

Different authors (e.g. Black et al., 2012; Hill \& Jepsen, 2007) state that, despite many good studies of practices, little systematic research and evidence examines the engagement of ESLers in second-chance education programmes on the national level. In their studies, they confirmed that the time of an individual's re-engagement with study is an important point when considering ESL. For youth, the rates of re-engagement were strongly falling during the period since they left school, with the highest rates of re-engagement being in the first year out, after which they dropped dramatically up until year 4 . Such findings point to the importance of the early re-engagement of ESLers in education and therefore the availability of second-chance education programmes that enable and encourage such inclusion. Further, it is important to encourage the integration of second-chance education principles already in mainstream education in order to prevent ESL. 
In our review of the practices of second-chance education programmes and projects (e.g. Boronia second-chance school from Australia, Eumoschool from Italy, EU national reports form second-chance education in Greece, Austria, Italy and Romania, LION 28 from Italy, PROSA from Austria, USA Big Picture Learning School, USA Opportunity House and Youth Chance High School etc.), we identified that the common main approaches to teaching and learning which distinguish them from mainstream education derive from their student-centred approach to learning, socio-emotional support of students during the process, the creating of supportive teacher-student relationships and a supportive learning environment, the use of interactive teaching methods and connection to wider community experts and organisations. Our findings are in line with one of the most systematic and extensive reviews of second-chance education in European countries (European Commission, 2013) whose aim was to shape second-chance education-based directions for teachers in mainstream education so as to help prevent ESL already in the early stages. Their practical implications for preventing ESL in mainstream schools are specific (see Figure 34) and encompass a multiprofessional approach to at-risk students (e.g. early career guidance and work experience, health and emotional support, involvement of social care institutions and cultural organisations), an inclusive school climate (e.g. student involvement in making decisions, small class sizes, development of positive relationships with their peers, teachers and staff), flexible curricula (e.g. focusing on learners' strengths, empowering to take ownership of personal learning, providing opportunities for work experience, introducing arts and sports), stimulating learning environments (e.g. a safe and stimulating environment, opportunities to socialise, flexibility in organising the day), personalised learning (e.g. individual attention, availability of a counsellors), social and emotional support (e.g. acknowledgement of the complex personal situations of at-risk students), and adaptable assessment and progression (e.g. different objectives - recognition of achievements related to personal development, motivation, engagement, and integration into employment). The European Commission (2013) concludes that, as such, second-chance education programmes provide a good example of how to build confidence and motivation in mainstream education for learners at the highest end of the ESL 'risk' spectrum and therefore serve as effective ESL prevention. 


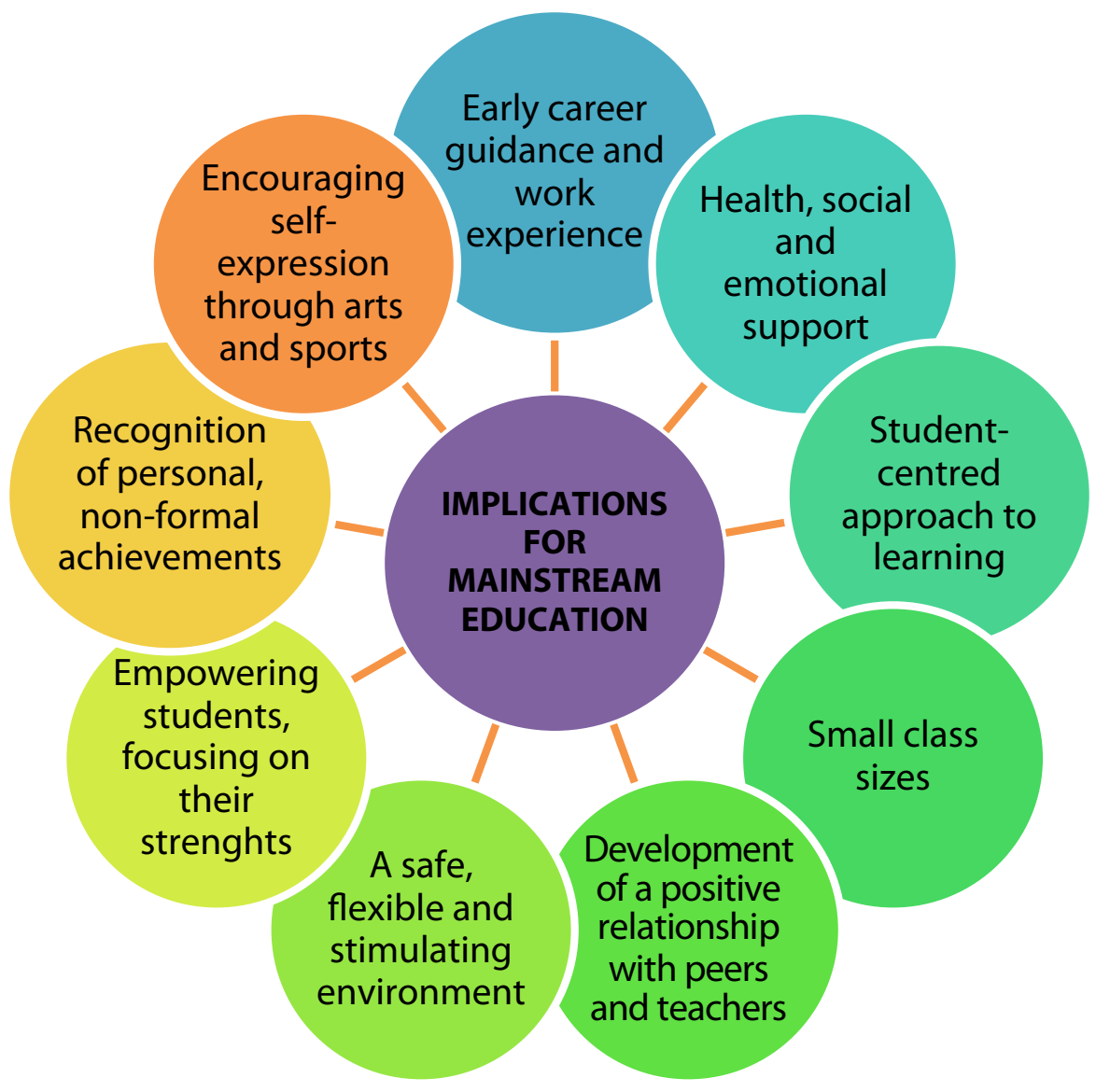

Figure I2. Implications for mainstream education in order to prevent ESL in early stages

\section{Conclusions}

According to our review of second-chance education practices, we may conclude that there are two primary forms of second-chance education programme implementation: Their principles can be implemented within mainstream education and thus serve at-risk students or can be implemented as part of a flexible, non-linear education system and address students who have already left mainstream education. Although there is much space for further systematic research, especially in the area of implementing second-chance education practices in mainstream education, so far the existing research results (e.g. Bills et al., 2015; Black et al., 2012; Efstathiou, 2009; 
European Commission, 2001, 2013; Hill \& Jepsen, 2007; Lagana-Riordan et al., 2011; Polidano et al., 2015) show that it is a practice worth developing, particularly when it comes to implementing preventive strategies for reducing ESL rates and strategies for the re-engagement of ESL students.

Different authors (e.g. Bloom, 2010; Riele, 2000; Ross \& Gray, 2005; Smyth \& Hattam 2004, Spierings, 2003; Wyn et al., 2004) also point to the fact that, in order for second-chance programmes and the implementation of their principles in mainstream education to become successful and efficient, fiscal- and system-level changes are needed. They state that educational systems should allow students to leave education and return at a later stage. Linear educational models and EU educational benchmarks suggest that young people should at least complete secondary education. However, for a substantial minority of students who are alienated from school this is counterproductive. Retention may therefore be increased by providing flexible structures that allow young people to leave education and come back at a later stage. The traditional, uni-dimensional models based on age or the school-to-work transition are inadequate because they fail to capture the complexities of youth transitions in the post-modern era. It is therefore necessary to develop multiple educational pathways for youth. Some ESLers have the interest and capacity to move into postsecondary programmes, others would do better in occupationally oriented programmes and would benefit from early working experience and contact with employers, and still others need special approaches tailored to young people with very low levels of basic skills. Such a flexible approach would also decrease the funding problems of second-chance education programmes, another problematic area of second education programmes identified by the European Commission (2001, 2013). By integrating the principles of second-chance education into mainstream education and thereby lowering ESL levels, second-chance education would not be required to such an extent and national education systems would then benefit from lower extra costs. Integration of the second-chance education principle into mainstream education could therefore yield many positive effects not only for potential ESLers (academic development and personal growth), and teachers (professional growth), but also schools and the community as a whole (better social cohesion and lower costs). 


\section{References}

Bills, A., Cook, J., \& Giles, D. (2015). Negotiating second chance schooling in neoliberal times: Teacher work for schooling justice. New Zealand Journal of Teacher' Work, 12, 78-95.

Black, D., Polidano, C., \& Tseng, Y. P. (2012). The re-engagement in education of early school leavers. Economic Papers, 31, 202-215.

Bloom, D. (2010). Programs and policies to assist high school dropouts in the transition to adulthood. The Future of Children, 20, 90-108.

Cartier, S. C., Langevine, L., \& Robert, J. (2011). Learning strategies of students attending a second chance school. Alberta Journal of Educational Research, 57, 171-184.

Eumoschool. (2016). Eumoschool - emotional learning for early school leavers. Retrieved from http://eumoschool.eu/it/

European Commission. (2001). Second chance schools: The results of a European pilot project. Brussels: European Commission.

European Commission. (2007). Communication from the Commission to the Council, the European Parliament, the European Economic and Social Committee and the Committee of the Regions. Action Plan on Adult Learning: It is always a good time to learn. Brussels: European Commission.

European Commission. (2013). Preventing early school leaving in Europe Lessons learned from second chance education: Final report. Brussels: European Commission.

European Council. (2003). Council conclusions on reference levels of European average performance in education and training (Benchmarks). Brussels: European Commission.

European Parliament. (2006). Decision of the European Parliament and of the Council of 15 November 2006 establishing an action programme in the field of lifelong learning. Brussels: Official Journal of the European Union.

Efstathiou, I. (2009). Enhancing students' critical awareness in a second chance school in Greece: Reality or wishful thinking? Journal for Critical Education Policy Studies, 7, 382-405.

Frame, J. D. (2002). The new project management: Tools for an age of rapid change, complexity and other business realities (2nd ed.). San Francisco, CA: Jossey-Bass.

Franklin, C., \& Streeter, C. L. (1992). Differential characteristics of high-achieving/high-income and low-achieving/low-income dropout youths: 
Considerations for treatment programs. Social Work in Education, 14, $42-55$.

Franklin, C., \& Streeter, C. L. (1995). Assessment of middle class youth at-risk to dropout: School, psychological, and family correlates. Children and Youth Services Review, 11, 433-448.

Franklin, C., Streeter, C. L., Kim, J. S., \& Tripodi, J. (2007). The effectiveness of a solution-focused public alternative school for dropout prevention and retrieval. Children and Schools, 29, 133-144.

Goldman, J., \& Bradley, G. (1997). The educational experiences of Australian high school dropouts who return to school. International Journal of Lifelong Education, 16(1), 18-38.

Hansen, R. S. (2006). Benefits and problems with student teams: Suggestions for improving team projects. Journal of Education for Business, 82, 11-19.

Harrison, D. A., Price, K. H., Gavin, J. H., \& Florey, A. T. (2002). Time, teams, and task performance: Changing effect of surface- and deep-level diversity on group functioning. Academy of Management Journal, 45, 1029-1045.

Hill, L. \& Jepsen, C. (2007). Positive outcomes from poor starts: Predictors of dropping back in. Economics of Education Review, 26, 588-603.

Inbar, D. \& R. Sever. (1989). The importance of making promises: An analysis of second-chance policies. Comparative Education Review, 33, 232-242.

Kollas, S. \& Halkia, K. (2014). Second chance schools in Greece: Science teachers' views and practices on designing scientific literacy curricula. Scientific Literacy and Socio-Scientific Issues, 2, 289-305.

Koutrouba, K. \& Karageorgou, E. (2013). Cognitive and socio-affective outcomes of project-based learning: Perceptions of Greek second chance school students. Improving Schools, 16, 244-26o.

Lagana Riordan, C., Aguilar, J. P., Franklin, C., Streeter, C. L., Kim, J. S., Tripodi, S. J., \& Hopson, L. M. (2011). At-risk students' perceptions of traditional schools and a solution-focused public alternative school. Preventive School Failure, 55, 105-114.

Lange, C. M., \& Sletten, J. (1995). Characteristics of alternative schools and programs serving at-risk students: Research report No. 16. Minnesota: University of Minnesota.

McFadden, M. G. (1996). Second chance education: Accessing opportunity or recycling disadvantage? International Studies in Sociology of Education, $6,87-111$. 
McGregor, G., Mills, M., Riele, K., \& Hayes, D. (2014). Excluded from school: Getting a second chance at a meaningful education. International Journal of Inclusive Education, 19, 1-18.

Munns, G., \& M. McFadden (2000) First chance, second chance or last chance? Resistance and response to education. British Journal of Sociology of Education, 21, 59-76.

Opportunity House. (2010). Alternative high school in Oregon. Retrieved from http://www.oregon.gov/ode/Pages/default.aspx

Polidano, C., Tabasso, D., \& Tseng, Y. P. (2015). A second chance at education for early school leavers. Education Economics, 23, 358-375.

Riele, K. (2000). The best thing I have ever done: Second chance education for early school leavers: Project report. Deakin: Australian Association for Research in Education.

ROBIN project (2016). Research study on the current methodologies used within second chance programmes: Project report. Brussels: European Commission.

Ross, S., \& Gray, J. (2005). Transitions and re-engagement through second chance education. The Australian Educational Researcher, 32, 103-140.

Shavit, Y., H. Ayalon, \& M. Kurleander (2001). Second-chance education and inequalities in Israel. Retrieved from http://www.mzes.unimannheim.de/ rc28/papers/shavit_etal_f.doc

Smyth, J., \& R. Hattam (2004). Dropping out, drifting off, being excluded: Becoming somebody without school. New York: Peter Lang Publishing Inc.

Spierings, J. (2003). Learning alternatives: A last chance or a real choice? Dusseldorf

Skills Forum. Retrieved from http://www.dsf.org.au/papers/113/LAlt_JSp_ SEPo3_o.pdf

The Big Picture School. (2016). Big picture learning. Retrieved from http:// www.bigpicture.org/

University of Florence. (2010). Enabling the low skilled to take their qualifications one step up: Implementation of action plan on adult learning. Final report: Case study reports. Florence: University of Florence. Retrieved from http://www.ec.europa.eu/education/more-information.pdf.

USA State University. (2016). Alternative school models. Retrieved from http:// education.stateuniversity.com/pages/1746/Alternative-Schooling.html 
Wang, M. C., Haertel, G. D., \& Walberg, H. J. (1997). Fostering educational resilience in inner-city schools. Philadelphia: National Research Center on Education in the Inner Cities.

Wurdinger, S., \& Enloe, W. (2011). Cultivating life skills at a project-based charter school. Improving Schools, 14(1), 84-96.

Wyn, J., Stokes, H., \& Tyler, D. (2004). Stepping stones: TAFE and ACE program development for early school leavers. Retrieved from http://www. ncver.edu.au/research/proj/nroo15.pdf.

Youth Chance High School. (2016). YAMCA of San Francisco. Retrieved from https://www.ymcasf.org/youth-chance-high-school 


\section{Index}

A

academic achievement 32, 33, 34, 6o, 72, 99, 100, 101, 102, 103, 104, 105, $106,107,108,115,116,123,126,134$, 140, 150, 154, 159, 175, 181

academic self-concept 129, 130, 131, $132,133,134,135,136,137,138,139$, 164

aggression 58, 106

andragogy $185,186,187,188,189,190$, 191, 193, 195, 196, 197, 198

anxiety 49, 57, 61, 109, 142, 181, 212 autonomy $88,114,117,121,122,171$, $172,173,174,175,178,179,180,183$, 195

B

brain changes 158, 160, 164, 165 brain changes in adolescence 158 , 160
C

career guidance 228 community-based education 180 community learning 179 competence $28,30,34,35,36,37,38$, $41,42,44,59,73,75,88,89,101,107$, $112,114,115,117,121,122,126,132$, $134,139,140,153,171,173,174,175$, $180,195,204$

D

depression 79, 115 detection 159 dyslexia 140, 141, 158, 159, 160, 163 , $164,165,166,167,170$

E

educational outcomes 59, 64, 172 education system 29, 63, 67, 71, 73, $123,194,205,222,229,230$ emotional competencies $27,28,29$, $30,35,37,46,47,51,57,64,73,88$, 
98, 99, 101, 102, 103, 111, 112, 113, 114,

$115,116,123,126,213$

emotional development 40, 112, 113 ,

$127,220,223,224$

emotional intelligence $30,44,47,58$,

$59,66,111,112,113,115,116,124,125$, 126,127

engagement $28,31,32,34,40,43,50$, 6o, 61, 89, 90, 99, 100, 107, 108, 111, $112,113,133,134,141,142,153,159$,

$164,174,181,195,226,227,228,230$, 231, 233

ESL prevention 77, 79, 100, 122, 145, $147,176,186,187,188,194,196,220$, 221, 222, 228

extracurricular activities 225

F

family background 125

France 209, 212

\section{$\mathrm{H}$}

health care 148

I

individual factors 146

L

learner-centred approach 185,186 , $187,193,194,195,196$

learning difficulties $143,147,159,162$, 164, 165

learning disabilities 158

local community 33

Luxembourg 75, 167, 181, 215

M

mainstream education $171,172,173$, $174,180,185,186,187,188,193,194$,
$195,196,219,220,221,222,223,227$, 228, 229, 230

model of circular emotional reaction 46, 51, 114

models of self-reflection 77,90

motivation $32,39,55,61,63,67,68$, 69, 71, 72, 85, 89, 92, 108, 122, 130, $131,133,134,135,139,140,141,142$, $152,154,156,159,164,171,172,173$, $174,175,176,178,179,180,181,182$, $186,192,193,194,195,198,213,223$, 224, 226, 228

motivation for school work 130, 131 multi-professional teams 25,46

N

neuroscience in education 158,160 non-formal education 172, 173, 174, $177,180,181,219$

0

online training platforms 201, 202, 203

P

personality $44,59,61,124,126,127$, 139, 142, 155, 183

PISA 31, 43

policy measures 205

positive youth development 74, 106, 124, 215

problem behaviour 109 professional development 28, 38, 51, $63,64,65,66,67,68,69,70,71,72$, $73,74,75,76,77,78,79,80,81,83$, $84,85,87,88,89,90,91,92,104,105$, 158, 201, 202, 203, 204, 205, 206, 207, 209, 211,212, 213,214, 215, 217, 224 
protective factor $41,143,144,146$, $150,152,153,157$

$\mathrm{R}$

relatedness 175, 183, 195

relational competence $28,30,36,37$, $38,42,44,73,89$

resilience $108,143,144,145,146,147$, 149, 151, 152, 153, 154, 155, 156, 234

S

school achievement 159

school climate $87,103,143,144,228$

school engagement 40, 43, 60, 100,

108, 111, 113, 133, 153, 159

school factors 41, 93

school structure 33, 133

second-chance education 180,210 ,

219, 220, 221, 222, 223, 224, 225,

$226,227,228,229,230$

self-concept 98, 129, 130, 131, 132, 133,

$134,135,136,137,138,139,140,141$,

$142,153,164,190$

self-determination theory 183,198

self-reflection $46,47,63,64,70,73$,

$77,78,79,80,81,82,83,84,85,86$,

$88,89,90,93,213$

social and emotional competence

28, 30, 41, 59, 153

social and Emotional Learning 39,

$43,97,104$

social background 194

social behaviour 112, 123

social care 220,228

social competence $101,114,115,117$,

$122,126,132$

system level 205
$\mathrm{T}$

teacher competences 202

teachers' competencies 64

teacher-student relationship 31, 34, 46, 49, 57, 130, 135

teachers' unpleasant emotions 46, 47

teaching style 194

team effectiveness 47,57

transitions $68,102,230$

W

whole school approach 105 



\section{List of Authorities}

A

Alivernini, F. 172, 175, 181

B

Bandura, A. 101, 106, 131, 134, 139, 181

Battin-Pearson, S. 33, 38, 49, 58, 130, $134,135,138,139,164,166$

Black, D. 181, 231

Blum, R. W. 75, 106

Bridgeland, J. M. 38, 39

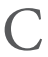

Caprara, G. 101, 102, 106, 131, 134, 139, 171, 174, 180, 181

Cercone, K. 189, 191, 192, 196

$\mathrm{D}$

Deci, E. L. $171,172,174,175,181,182$, 183, 195, 198

Durlak, J. A. 28, 29, 40, 43, 73, 74, 75, 99, 102, 103, 107
E

Eccles, J. S. 28, 42, 43, 130, 133, 140, 182

Edwards, P. 106

Efstathiou, I. 220, 221, 223, 229, 231

F

Frenzel, A. C. $46,58,60$

G

Goswami, U. 157, 168

Gray, B. 47, 220, 223, 230, 233

Guerra, N. G. 215

Guskey, T. R. 66, 75

$\mathrm{H}$

Habe, K. 92

Hardre, P. L. 171, 174, 175, 180, 182

Hargreaves, D. 31, 40, 67, 68, 69, 73, 75

Harter, S. 134, 140

Hawkins, J. D. 38, 97, 103, 106, 107, 111, 124, 139, 166 
I

Izard, C. E. 112, 123, 126

J

Jennings, P. A. 31, 40, 41, 42, 59

Jensen, H. 28, 29, 36, 37, 38, 41, 168

Jimerson, S. 41

Juul, J. 28, 35, 36, 37, 38, 41

K

Knowles, M. S. 187, 197

Korthagen, F. A. J. 75, 77, 78, 85, 86, $87,88,90,91,92,216$

Košir, K. 92

L

Licardo, M. 92

Luna, B. 164, 168

$\mathrm{M}$

Martin, N. 111, 113, 115, 147, 149, 151, $153,154,169$

Masten, A. S. 99, 102, 105, 108, 144, $145,147,148,153,155$

Mathieu, J. E. 100

McGregor, G. 225, 233

Merriam, S. B. $168,189,197,198$

Milivojević, Z. 46, 47, 51, 52, 60, 112, $114,116,117,118,120,123,126,130$, $135,138,139,141$

$\mathrm{O}$

Osipova, A. V. 93

P

Parker, J. D. 100, 108, 114, 115, 125, 126, 127

Peklaj, C. 73,76

Polidano, C. 180, 181, 183, 223, 231, 233
$\mathrm{R}$

Rogers, L. 81, 84, 93

Rumberger, R. W. 141

Ryan, R. M. 103, 106, 111, 124, 171, $172,174,175,181,182,183,198$

S

Schoon, I. 143, 145, 146, 147, 150, 151, 156

Sellars, M. 93

Simon, V. 163, 170, 198

Skaalvik, E. M. 129, 131, 132, 134, 140, 142

Smetana, L. K. 217

Smink, J. 195, 198

Sowell, E. R. 160, 170

T

Tement, S. 92

Traag, T. 93

Turner, M. Y. 144, 145, 156

V

Vidmar, M. 5, 13, 27, 36, 44, 45, 63, 77, 101, 111, 157, 201

Vitaro, F. 125

W

Wilson, D. B. 46, 49, 61, 97, 100, 109

Wood, J. D. 114, 126, 167, 168 

Early School Leaving: Training Perspectives

Scientific monograph

Editors: Urška Štremfel and Maša Vidmar

Series: Digitalna knjižnica/Digital Library

Editorial Board: Igor Ž. Žagar (Educational Research Institute \& University of Primorska), Jonatan Vinkler (University of Primorska), Janja Žmavc (Educational Research Institute), Alenka Gril (Educational Research Institute)

Subseries: Dissertationes (znanstvene monografije/Scientific Monographs), 34

Editor in chief: Igor Ž. Žagar

Reviewers: Katja Košir, Marta Licardo

Proofreading: Murray Bales

Graphic Design, Typesetting and Digitalization: Jonatan Vinkler

Publisher: Pedagoški inštitut/Educational Research Institute

For the Publisher: Igor Ž. Žagar

Ljubljana 2018

ISBN 978-961-270-283-o (pdf)

http://www.pei.si/ISBN/978-961-270-283-o.pdf

ISBN 978-961-270-284-7 (html)

http://www.pei.si/ISBN/978-961-270-284-7/index.html

DOI: https://www.doi.org/10.32320/978-961-270-283-0

(C) 2018 Pedagoški inštitut/Educational Research Institute

The publication was produced as part of the project »TITA (Team cooperation to fight early school leaving: Training, Innovative Tools and Actions)«. The project was co-financed by the European Commission. This publication has been produced with the assistance of the European Union. The contents of this publication are the sole responsibility of the authors and can in no way be taken to reflect the views of the European Commission.

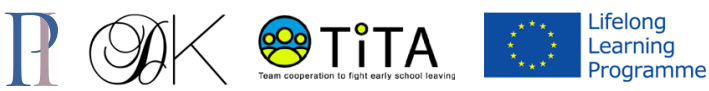





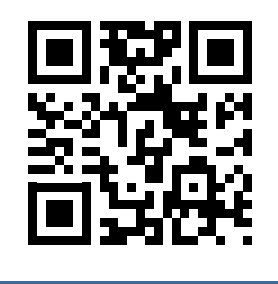

